\title{
Final Master Work Plan: Environmental Investigations at Former CCC/USDA Facilities in Kansas, 2002 Revision
}
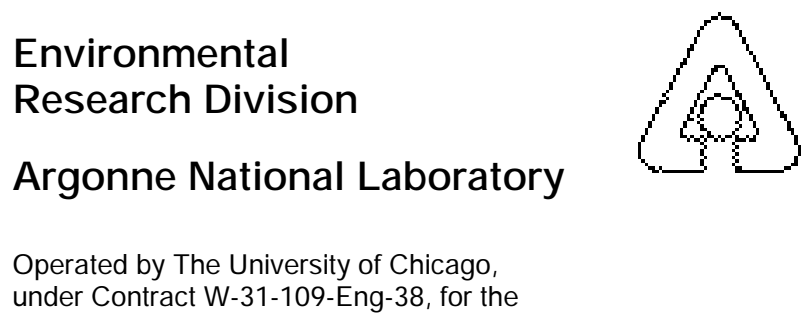

under Contract W-31-109-Eng-38, for the

United States Department of Energy 


\begin{abstract}
About Argonne National Laboratory
Argonne is managed by The University of Chicago for the U.S. Department of Energy under contract W-31-109-Eng-38. The Laboratory's main facility is outside Chicago, at 9700 South Cass Avenue, Argonne, Illinois 60439. For information about Argonne and its pioneering science and technology programs, see www.anl.gov.
\end{abstract}

\title{
Availability of This Report
}

This report is available, at no cost, at http://www.osti.gov/bridge. It is also available on paper to U.S. Department of Energy and its contractors, for a processing fee, from:

U.S. Department of Energy

Office of Scientific and Technical Information

P.O. Box 62

Oak Ridge, TN 37831-0062

phone (865) 576-8401

fax (865) 576-5728

reports@adonis.osti.gov

\section{Disclaimer}

This report was prepared as an account of work sponsored by an agency of the United States Government. Reference herein to any specific commercial product, process, or service by trade name, trademark, manufacturer, or otherwise, does not necessarily constitute or imply its endorsement, recommendation, or favoring by the United States Government or any agency thereof.

The views and opinions of document authors expressed herein do not necessarily state or reflect those of the United States Government or any agency thereof, Argonne National Laboratory, or The University of Chicago. 


\section{Final Master Work Plan: Environmental Investigations at Former CCC/USDA Facilities in Kansas, 2002 Revision}

Applied Geosciences and Environmental Management Section,

Environmental R esearch Division,

Argonne National Laboratory, 9700 South Cass Avenue, Argonne, Illinois 60439

December 2002

Work sponsored by Commodity Credit Corporation, United States Department of Agriculture 


\section{Contents}

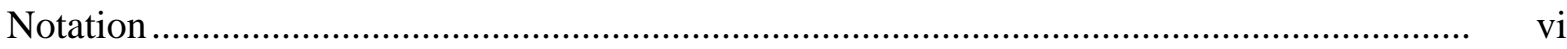

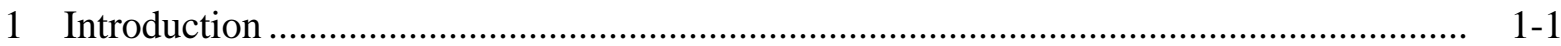

2 Environmental Protection Controls and Performance Standards ................................... 2-1

2.1 Procedure for Identifying Controls and Standards ........................................... 2-2

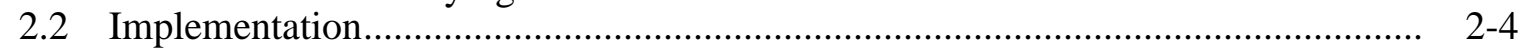

3 Health and Safety Plan .................................................................................

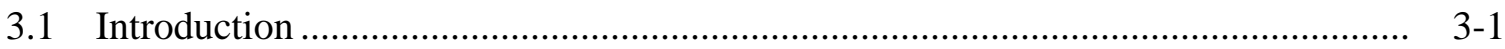

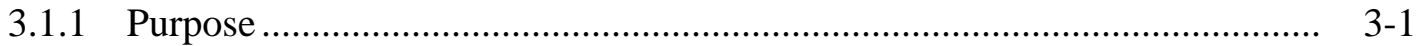

3.1.2 Site Location and Background …….................................................... 3-2

3.2 Organization, Regulations, and Responsibilities........................................ 3-2

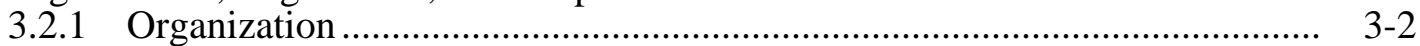

3.2.2 Rules and Regulations ..................................................................... 3-2

3.2.3 Responsibilities of the Health and Safety Coordinator .............................. 3-2

3.2.4 Responsibilities of the Field Team .............................................................. $3-4$

3.2.5 Responsibilities of Subcontractors ......................................................... 3-4

3.3 General Health and Safety Practices ............................................................. 3-4

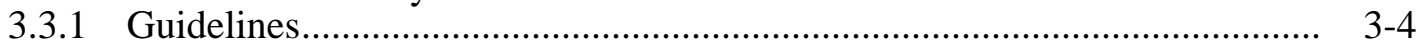

3.3.2 Emergency Plan........................................................................... 3-4

3.3.3 Hazard Assessment......................................................................... 3-5

3.3.4 Physical Hazards ............................................................................... $3-5$

3.3.5 Chemical Hazards......................................................................... 3-8

3.3.6 Electrical Hazards............................................................................... 3-9

3.3.7 Confined Space Entry Procedures ......................................................... 3-10

3.3.8 Site Monitoring............................................................................ 3-10

3.3.9 Personal Protective Equipment ............................................................... 3-11

3.3.10 Provision of Services and Equipment ............................................... 3-14

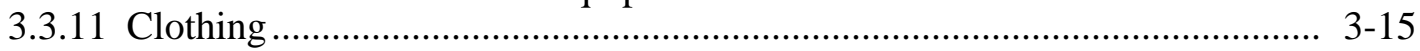

3.3.12 Food and Beverages ......................................................................... 3-15

3.3.13 Transportation of Hazardous Materials ................................................. 3-16

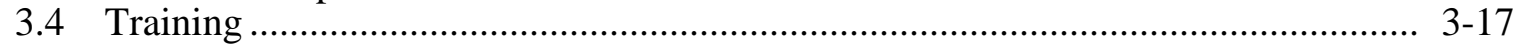

3.5 Work Area Designations/Site Control........................................................... 3-18

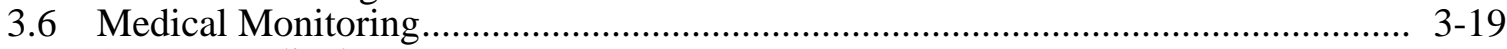

3.6.1 Medical Program ................................................................................ 3-19

3.6.2 Heat Stress ......................................................................... 3-19

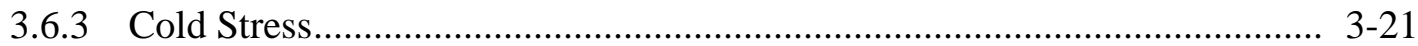

3.7 Accident Investigation and Record Keeping ................................................... 3-22

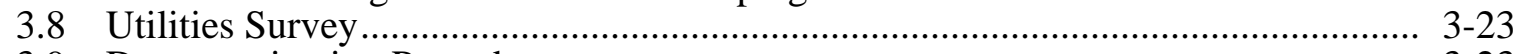

3.9 Decontamination Procedures...................................................................... 3-23

3.9.1 Decontamination of Sampling Equipment …...................................... 3-23

3.9.2 Decontamination Equipment Checklist..................................................... 3-24

3.10 Health and Safety Guidance Resources........................................................... 3-25

4 Quality Assurance/Quality Control Plan ................................................................... 4-1

4.1 Overarching Quality Assurance/Quality Control Provisions ................................. 4-1

4.1.1 Data Quality Objectives …........................................................................ 4-2 


\section{Contents (Cont.)}

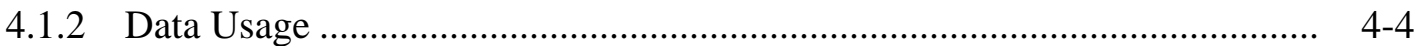

4.1.3 Project Organization and Responsibility ............................................. 4-5

4.2 Quality Assurance/Quality Control for Sampling and Analysis ............................ 4-5

4.2.1 Field Quality Assurance/Quality Control................................................. 4-6

4.2.2 Laboratory Quality Assurance/Quality Control ...................................... 4 4-8

4.2.3 Quality Assurance Records ................................................................... 4-9

4.2.4 Analytical Data Reduction, Validation, and Reporting ............................ 4-10

4.3 Quality Assurance/Quality Control for Other Field Activities ................................ 4-12

4.3.1 Quality Assurance/Quality Control for the Geology Investigation............... 4-12

4.3.2 Quality Assurance for the Hydrogeology Investigation............................. 4-14

4.3.3 Quality Assurance for the Geophysics Investigation .............................. 4-17

4.3.4 Quality Assurance of Spatial Control Procedures ...................................... 4-19

4.3.5 Quality Assurance for Computer Records............................................. 4-21

5 Community Relations Plan...................................................................................... 5-1

5.1 Model Community Relations Plan …................................................................ $5-1$

5.1.1 Site Description ............................................................................ 5-1

5.1.2 Community Background ….................................................................. 5

5.1.3 Community Relations Objectives........................................................ $5-2$

5.1.4 Timing of Community Relations Activities .............................................. 5-2

5.1.5 Contact List of Key Officials ............................................................. 5- 5

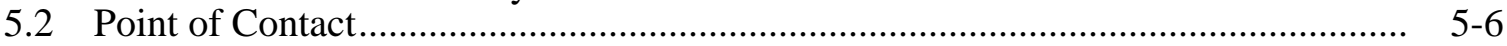

6 General Technical Program.......................................................................................... 6-1

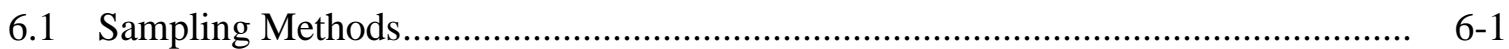

6.1.1 Soil Sampling for Chemical or Geotechnical Analysis.............................. 6-1

6.1.2 Groundwater Sampling for Chemical Analysis........................................... 6-2

6.1.3 Surface Water Sampling for Chemical Analysis........................................ 6-4

6.1.4 Vegetation Sampling for Chemical Analysis ......................................... 6-4

6.1.5 Disposal of Contaminated Materials ...................................................... $6-5$

6.2 Sample Preservation and Handling ................................................................ 6 6-6

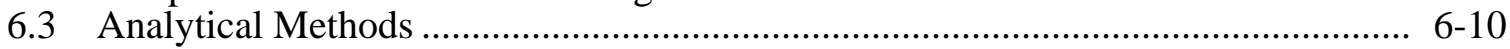

6.3.1 Analysis of Soil Samples........................................................................ 6-10

6.3.2 Analysis of Water Samples ................................................................ 6-12

6.3.3 Analysis of Vegetation Samples............................................................ 6-14

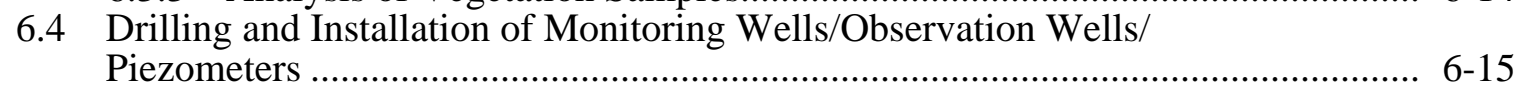

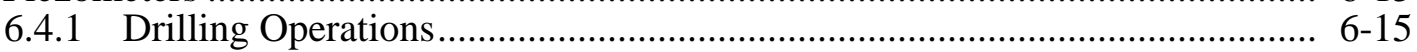

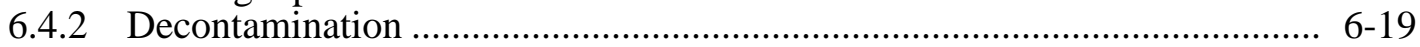

6.4.3 Monitoring Well Installation ................................................................ 6-20

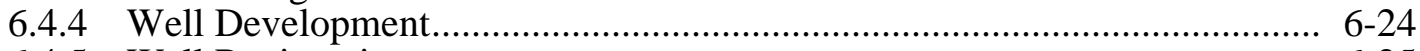

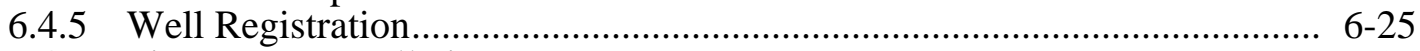

6.4.6 Piezometer Installation ......................................................................... 6-25

6.4.7 Abandonment of Soil Borings, Boreholes, and Piezometers ......................... 6-28

6.5 Electronic Cone Penetrometer and Geoprobe .................................................. 6-29

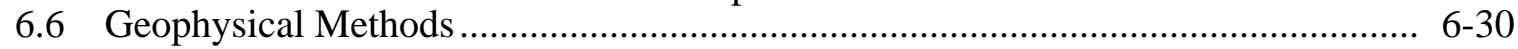

6.6.1 Seismic Reflection Surveys ................................................................ 6-30

6.6.2 Seismic Refraction Surveys......................................................... $6-35$

6.6.3 Seismic Check Shot Surveys ........................................................... 6-37

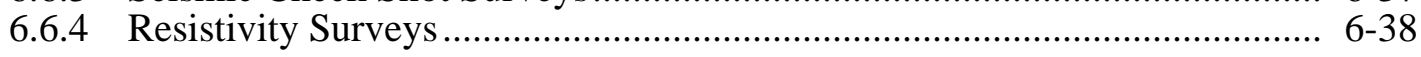




\section{Contents (Cont.)}

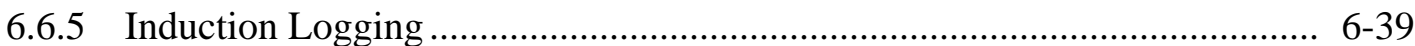

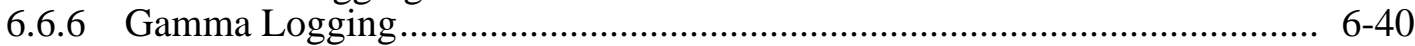

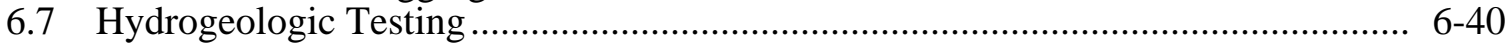

6.7.1 Aquifer Pump Testing ........................................................................... 6-41

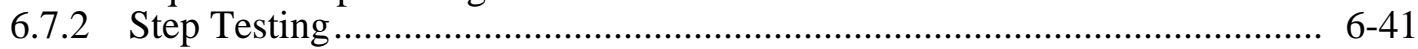

6.7.3 Well Response Testing ................................................................... 6-41

6.7.4 Analysis of Aquifer and Well Test Data .............................................. 6-42

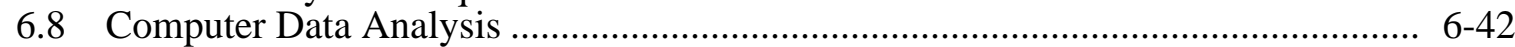

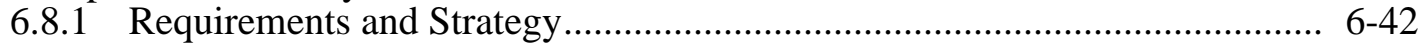

6.8.2 Staff and Equipment ...................................................................... 6-43

6.8.3 Computer Software for Field Operations ................................................ 6-44

6.8.4 Computer Software for Laboratory Operations........................................ 6-46

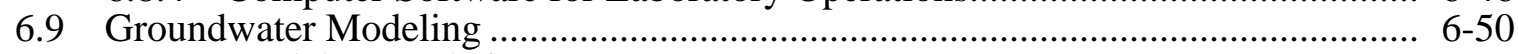

6.9.1 Model Formulation......................................................................... 6-51

6.9.2 Calibration and Testing ................................................................... 6-53

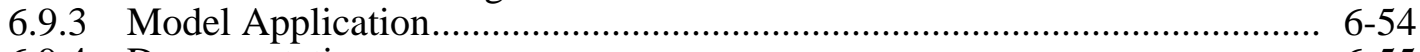

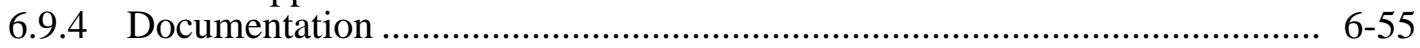

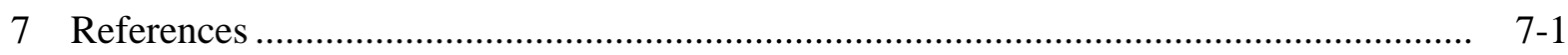

Appendix A: Site Safety Review Form.......................................................................... A-1

Appendix B: Tailgate Safety Meeting Form.............................................................. B-1

Appendix C: Material Safety Data Sheets …............................................................. C-1

Appendix D: Sample and Document Management Procedures ....................................... D-1

Appendix E: Standard Operating Procedures ............................................................... E-1

Appendix F: Forms and Diagrams for Drilling Operations in Kansas ............................. F-1

Tables

2.1 Potential applicable or relevant and appropriate requirements for former CCC/USDA facilities in Kansas........................................................... 2-6

4.1 Analytical levels appropriate to data uses ........................................................... $4-3$

6.1 Container type, sample size per aliquot, and preservation parameters for soil samples . 6-6

6.2 Container type, sample size per aliquot, and preservation parameters for water samples.

6.3 Maximum concentrations of hazardous materials used as preservatives in water samples that are exempt from DOT hazardous materials regulations.......

6.4 Sample matrix, target compounds, and laboratory analytical methods for the CCC/USDA investigations. 
Master Work Plan for Former CCC/USDA Facilities in Kansas Version 01, 12/20/02

\section{Figure}

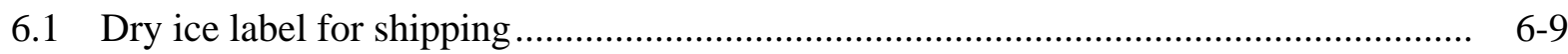




\section{Notation}

\begin{tabular}{|c|c|}
\hline A & ampere(s) \\
\hline AGEM & Applied Geosciences and Environmental Management \\
\hline ARAR & applicable or relevant and appropriate requirement \\
\hline ASTM & American Society for Testing and Materials \\
\hline AWQCs & ambient water quality criteria \\
\hline BFB & 4-benzofluorobenzene \\
\hline BTEX & benzene, toluene, ethylbenzene, xylene \\
\hline${ }^{\circ} \mathrm{C}$ & degree(s) Celsius \\
\hline $\mathrm{CCC}$ & Commodity Credit Corporation \\
\hline CERCLA & Comprehensive Environmental Response, Compensation, and Liability Act \\
\hline CFR & Code of Federal Regulations \\
\hline CLP & Contract Laboratory Program \\
\hline $\mathrm{cm}$ & centimeter(s) \\
\hline CMP & common midpoint \\
\hline CWA & Clean Water Act \\
\hline $\mathrm{dB}$ & decibel(s) \\
\hline DCEs & dichloroethenes \\
\hline DEM & Digital Elevation Model \\
\hline DOE & U.S. Department of Energy \\
\hline DOT & U.S. Department of Transportation \\
\hline ECD & electron capture detection \\
\hline ECPT & electronic cone penetrometer \\
\hline EDD & electronic data deliverable \\
\hline EPA & U.S. Environmental Protection Agency \\
\hline EQO & $\begin{array}{l}\text { Office of Environment, Safety, and Health/Quality Assurance Oversight } \\
\text { (Argonne) }\end{array}$ \\
\hline ER & Environmental Research Division (Argonne) \\
\hline ESC & Expedited Site Characterization \\
\hline $\mathrm{eV}$ & electron volt(s) \\
\hline${ }^{\circ} \mathrm{F}$ & degree(s) Fahrenheit \\
\hline FR & Federal Register \\
\hline FS & feasibility study \\
\hline $\mathrm{ft}$ & foot (feet) \\
\hline g & $\operatorname{gram}(\mathrm{s})$ \\
\hline gal & gallon(s) \\
\hline
\end{tabular}


GC

GMS

GPS

HAP

$\mathrm{HNu}$

$\mathrm{hr}$

HSA

HSC

HSL

$\mathrm{Hz}$

I.D.

in.

KAR

KDHE

KSA

L

lb

$\mu \mathrm{g} / \mathrm{kg}$

$\mu \mathrm{g} / \mathrm{L}$

$\mathrm{m}$

MCL

MCLG

$\mathrm{mg}$

$\min$

$\mathrm{mL}$

$\mathrm{ms}$

MS

MSDS

NCP

NEIC

ng

NPDES

NSDWRs

O.D.

OSHA

OVM

PCE gas chromatograph

Groundwater Modeling System

global positioning system

hazardous air pollutant

photoionization detector for vapors

hour(s)

hollow-stem auger

health and safety coordinator

Hazardous Substance List

hertz

inner diameter

inch(es)

Kansas Administrative Regulations

Kansas Department of Health and Environment

Kansas Statutes Annotated

liter(s)

pound(s)

microgram(s) per kilogram

microgram(s) per liter

meter(s)

maximum contaminant level

maximum contaminant level goal

milligram(s)

minute(s)

milliliter(s)

millisecond(s)

mass spectrometer

material safety data sheet

National Oil and Hazardous Substances Pollution Contingency Plan

National Enforcement Investigations Center

nanogram(s)

National Pollutant Discharge Elimination System

National Secondary Drinking Water Regulations

outer diameter

Occupational Safety and Health Administration

organic vapor meter

tetrachloroethene 


$\begin{array}{ll}\text { pg } & \text { picogram(s) } \\ \text { PM } & \text { particulate matter } \\ \text { POTW } & \text { publicly owned treatment works } \\ \text { ppb } & \text { part(s) per billion } \\ \text { ppm } & \text { part(s) per million } \\ \text { ppt } & \text { part(s) per trillion } \\ \text { PVC } & \text { polyvinyl chloride } \\ \text { QA } & \text { quality assurance } \\ \text { QC } & \text { quality control } \\ \text { RCRA } & \text { Resource Conservation and Recovery Act } \\ \text { RI } & \text { remedial investigation } \\ \text { RSD } & \text { relative standard deviation } \\ \text { s } & \text { second(s) } \\ \text { SDWA } & \text { Safe Drinking Water Act } \\ \text { SMCL } & \text { secondary maximum contaminant level } \\ \text { SNR } & \text { signal-to-noise ratio } \\ \text { TU } & \text { tritium unit(s) } \\ \text { USC } & \text { United States Code } \\ \text { USDA } & \text { U.S. Department of Agriculture } \\ \text { V } & \text { volt(s) } \\ \text { VOC } & \text { volatile organic compound } \\ \text { yr } & \text { year(s) } \\ & \end{array}$




\section{Final Master Work Plan: Environmental Investigations at Former CCC/USDA Facilities in Kansas, 2002 Revision}

\section{Introduction}

The Commodity Credit Corporation (CCC) of the U.S. Department of Agriculture (USDA) has entered into an interagency agreement with the U.S. Department of Energy (DOE) under which Argonne National Laboratory provides technical assistance for hazardous waste site characterization and remediation for the CCC/USDA. Carbon tetrachloride is the contaminant of primary concern at sites in Kansas where former CCC/USDA grain storage facilities were located. Argonne applies its QuickSite ${ }^{\circledR}$ Expedited Site Characterization (ESC) approach to these former facilities. The QuickSite ${ }^{\circledR}$ environmental site characterization methodology is Argonne's proprietary implementation of the ESC process (ASTM 1998). Argonne has used this approach at several former CCC/USDA facilities in Kansas, including Agenda, Agra, Everest, and Frankfort.

The Argonne ESC approach revolves around a multidisciplinary, team-oriented approach to problem solving. The basic features and steps of the QuickSite ${ }^{\circledR}$ methodology are as follows:

- A team of scientists with diverse expertise and strong field experience is required to make the process work. The Argonne team is composed of geologists, geochemists, geophysicists, hydrogeologists, chemists, biologists, engineers, computer scientists, health and safety personnel, and regulatory staff, as well as technical support staff. Most of the staff scientists are at the Ph.D. level; each has on average, more than 15 years of experience. The technical team works together throughout the process. In other words, the team that plans the program also implements the program in the field and writes the reports. More experienced scientists do not remain in the office while individuals with lesser degrees or experience carry out the field work.

- The technical team reviews, evaluates, and interprets existing data for the site and the contaminants there to determine which data sets are technically valid and can be used in initially designing the field program. A basic mistake sometimes made in the site characterization process is failure to use 
technically sound available data to form working hypotheses on hydrogeology, contaminant distribution, etc. for initial testing.

- After assembling and interpreting existing data for the site, the entire technical team visits the site to identify as a group the site characteristics that might prohibit or enhance any particular technological approach. Logistic and community constraints are also identified at this point.

- After the field visit, the team selects a suite of technologies appropriate to the problem and completes the design of the field program. No one technique works well at all sites, and a suite of techniques is necessary to delineate site features fully. In addition, multiple technologies are employed to increase confidence in conclusions about site features. Noninvasive and minimally invasive technologies are emphasized to minimize risk to the environment, the community, and the staff. In no case is the traditional approach of installing a massive number of monitoring wells followed.

A dynamic work plan that outlines the program is produced for the sponsoring and regulatory agencies. The word "dynamic" is emphasized because the work plan is viewed as a guide, subject to modification, for the site characterization activity, rather than a document that is absolute and unchangeable. Therefore, the health and safety plan and the quality assurance/quality control plan must be broad and encompass all possible alterations to the plan. The cooperation of the regulating agency is essential in successful implementation of this process. The sponsoring and regulatory agencies are notified if significant changes to the site-specific work plan are necessary.

- The entire team participates in the technical field program. Several technical activities are undertaken simultaneously. These may range from different surface geophysics investigations to vegetation sampling. Data from the various activities are reduced and interpreted each day by the technical staff. Various computer programs are used to visualize and integrate the data. However, people do the data interpretation and integration, not the computers, which are just one more tool at the site. 
At the end of the day, the staff members meet, review results, and modify the next day's program as necessary to optimize activities that are generating overlapping or confirming site details. Data are not arbitrarily discarded each finding must be explained and understood. Anomalous readings may be due to equipment malfunctions, laboratory error, or the inability of a technique to work in a given setting. The suite of selected technologies is adjusted in the field if necessary.

- The end result of this process is the optimization of the field activity to produce a high-quality technical product that is cost and time effective.

The QuickSite ${ }^{\circledR}$ process has been proven to be both cost and time effective in generating a high-quality site characterization program exceeding in technical scope the traditional remedial investigation. The program is abbreviated only in time and cost, not in technical content or adherence to the regulatory framework.

This Master Work Plan describes the general QuickSite ${ }^{\circledR}$ investigative program to be followed at all former Kansas CCC/USDA facilities. This plan contains all material common to the programs for the sites. Section 2 details the regulatory guidelines and statutes governing the investigation. The health and safety plan is presented in Section 3. Quality assurance/quality control guidelines are given in Section 4 , and the general outline of site community relations activities is presented in Section 5. Section 6 delineates general aspects of the QuickSite ${ }^{\circledR}$ technical program (e.g., sampling and analysis) that are common to all sites. In addition to this Master Work Plan, Argonne prepares site-specific work plans that contain only site-specific material (site description, site history, geologic/hydrogeologic setting, specific health and safety plans, specific community relations details, and the specific technical site program). For each site, therefore, the technical work plan will comprise the integrated combination of this Master Work Plan and site-specific work plans and reports.

The QuickSite ${ }^{\circledR}$ investigative program for any site is typically divided into two phases. Therefore, the series of documents for any site will include a Phase I work plan, Phase I results and Phase II work plan (one document), and a Phase II report. Material is not repeated in detail from one report to the next in order to streamline the process. All site reports plus the Master Work Plan must be consulted for the complete details of the QuickSite ${ }^{\circledR}$ program at any specific site. 
When Phase I and Phase II QuickSite ${ }^{\circledR}$ investigations have been completed at a site, the CCC/USDA will determine whether an analysis of corrective actions is necessary. If the CCC/USDA determines that such an analysis is needed and adequate funding is available, Argonne will perform this analysis and will report the results as a Phase III document for the site. 


\section{Environmental Protection Controls and Performance Standards}

Section 121(d) of the Comprehensive Environmental Response, Compensation, and Liability Act of 1980 (CERCLA) requires on-site remedial actions to attain upon completion of the remedial action, or receive waivers for, federal environmental applicable or relevant and appropriate requirements (ARARs), more stringent state environmental ARARs, and state facility-siting laws. Compliance with ARARs of other environmental laws is a pillar of CERCLA. ARARs are a prerequisite for determining whether a remedy is protective of human health and the environment; that is, ARARs provide cleanup goals and guide remedy implementation. The site-specific characteristics of CERCLA sites preclude the development of prescribed ARARs. This means that ARARs are identified on a site-specific basis. Factors including the chemicals present, the location, the physical features, and the actions under consideration as remedies at a given site will determine the standards that must be met. The 1990 National Oil and Hazardous Substances Pollution Contingency Plan (NCP), published in the Federal Register on March 8, 1990 (55 FR 8666) and codified in Part 300 of Title 40 of the Code of Federal Regulations (40 CFR 300), also requires compliance with ARARs during remedial actions and during removal actions to the extent practicable, considering the urgency of the situation at a site.

The NCP does not explicitly require the development and application of ARARs until the remedial investigation/feasibility study phase is reached (40 CFR 300.430(d)). As a matter of policy, however, the U.S. Environmental Protection Agency (EPA) has stated that treatment or disposal of investigation-derived wastes produced during response activities must ensure protection of human health and the environment and must, to the extent possible, comply with (or waive) federal and state ARARs (EPA 1988, 1991, 1992). Consequently, this section provides a brief discussion of the environmental protection controls and performance standards that, when applied to site characterization activities, will ensure that the activities do not adversely affect public health or the environment. In addition, this section discusses the mechanisms by which site-specific controls are to be established at each location undergoing characterization to ensure that the desired levels of environmental protection are attained. This section addresses only environmental protection controls and standards, not the numerous controls and standards for protecting the health and safety of site workers and the general public and for assuring the quality and accuracy of data gathered. Those standards and controls are discussed in Sections 3 and 4, respectively, of this Master Work Plan. 


\subsection{Procedure for Identifying Controls and Standards}

Guidance for the determination of ARARs has been published by the EPA in numerous sources (e.g., EPA 1987, 1988, 1989a, 1998a).

Environmental protection controls and performance standards for site characterization activities are determined after the ARARs are identified as described in these guidance documents. Specifically, federal statutes, executive orders, federal regulations, state laws, state regulations, and local ordinances were all reviewed as potential sources of necessary, reasonable, and prudent controls and standards. State laws and regulations and local ordinances were considered only when they were (1) promulgated so that they are legally enforceable and generally applicable (i.e., consistently enforced) and (2) more stringent in their controls than the corresponding federal requirements. In addition to statutes and regulations directed specifically at protection of the environment, state laws and regulations pertaining to the siting of certain facilities were also reviewed.

In general, applicable requirements are those that, as a matter of basic statutory or regulatory jurisdiction, would apply to an activity, whether or not that activity was conducted under the authority of CERCLA. The EPA guidance defines applicable requirements as "those cleanup standards, standards of control, and other substantive environmental protection requirements, criteria, or limitations promulgated under Federal or State law that specifically address a hazardous substance, pollutant, contaminant, remedial action, location, or other circumstance present at a CERCLA site." Relevant and appropriate requirements are defined as "those cleanup standards, standards of control, and other substantive environmental protection requirements, criteria, or limitations promulgated under Federal or State law that, while not 'applicable' to a hazardous substance, pollutant, contaminant, remedial action, location, or other circumstance at a CERCLA site, address problems or situations sufficiently similar to those encountered at the CERCLA site that their use is well suited to the particular site." These same definitions were used to identify environmental controls and standards for QuickSite ${ }^{\circledR}$ investigations.

As in the case of ARARs, additional standards and controls for site characterizations can be derived from nonpromulgated guidance or advisories issued by federal or state agencies. Although they are not legally binding, such guidance and directives, defined as "to be considered" requirements in the formal ARAR process, have been reviewed for their usefulness in developing operating procedures or best management practices that assure compliance with 
federal and state regulations and protection of public health and the environment during the site characterization process.

Environmental protection controls and standards are classified as chemical specific; performance, design, or action specific; or location specific. Chemical-specific (or ambient) controls and standards are health-based or risk-based standards issued for specific chemicals (or chemical families).

Performance-, design-, or action-specific requirements are applicable to the generation, management, and disposal of wastes associated with planned site characterization activities. Because it is generally nonintrusive, the QuickSite ${ }^{\circledR}$ investigation produces minimal amounts of wastes. Nevertheless, some waste streams that are expected to result from the planned site characterization activities include (1) cuttings from soil borings and well installations, (2) well development fluids, (3) purge water recovered from sampling wells, (4) residuals and quality control duplicates from sample analyses performed both in the field and in off-site laboratories, (5) equipment decontamination rinsates, (6) soiled and potentially contaminated personal protective equipment, and (7) other miscellaneous wastes associated with well installation and sampling of various environmental media. Planned sited characterization activities might also result in minimal air emissions of particulate matter or other emissions from drilling equipment. Therefore, air pollution laws and regulations can also be ARARs.

The anticipated chemical-specific requirements applicable to the generation, management, and ultimate disposal of site characterization wastes for the locations addressed in this Master Work Plan would be carbon tetrachloride and, at some locations, nitrates. (Even though the nitrate contamination that might be encountered is not attributable to CCC/USDA activities, the presence of such contamination in site characterization wastes will establish the applicability of nitrate-specific controls in the management and disposal of those wastes.)

Finally, location-specific requirements are restrictions placed on concentrations of hazardous substances, or the conduct of activities involving those substances, solely because of the special or sensitive nature of the location within which the substances or activities are found. It is beyond the scope of this Master Work Plan to develop a comprehensive list of locationspecific requirements. However, this Master Work Plan directs that a reconnaissance survey of each location to be characterized be made before characterization activities begin. This survey is to identify the presence of environmentally sensitive areas that could be affected by the investigation. Such sensitive areas include but are not limited to faults displaced in Holocene 
time; 100-yr floodplains; salt dome formations; historic properties; critical habitats upon which endangered or threatened species depend; wetlands; wilderness areas; wildlife refuges; areas immediately adjacent to streams or rivers; areas affecting national, wild, scenic, or recreational rivers; wellhead protection areas; and other sensitive areas as defined by the EPA or state authorities. In addition, the survey is to identify all requirements imposed by federal or state siting statutes and regulations.

The principal agency implementing environmental protection programs in the state of Kansas is the Kansas Department of Health and Environment (KDHE). Kansas environmental protection programs have been authorized by the EPA to operate in lieu of their federal counterparts, and therefore the state regulations are analogous to federal standards or represent the state's exercise of authorities granted it under various federal statutes (e.g., establishment of stream classifications and use of federal water quality criteria to establish levels of protection and effluent limits for surface waters of the state).

An analysis of the federal and state environmental protection controls and performance standards that are applicable or relevant and appropriate to planned sited characterization activities is in Table 2.1 (at the end of this section).

\subsection{Implementation}

The QuickSite ${ }^{\circledR}$ methodology relies on the professional judgment of the site investigators in selecting among various intrusive and nonintrusive investigative techniques to accomplish the characterization objectives. The application of the standards and requirements identified in Table 2.1 is dependent on the chosen techniques, the specific location where activities will be conducted, and the chemical constituency of the resulting investigative waste at each site. Consequently, the controls ultimately applied will be determined during the site characterization activity at each location.

In all instances, investigation-derived wastes are to be managed in a manner consistent with the applicable EPA Office of Solid Waste and Emergency Response directive (EPA 1989d, 1991, 1992). In addition, field investigators are to seek site-specific guidance and directives from the appropriate regulatory authorities, including federal, state, and local environmental or public health authorities. In Kansas, the relevant guidance is in KDHE policy BER-RS-003. The most 
important elements of the approach to management of investigation-derived wastes are as follows (EPA 1991):

- Leave a site in a condition no worse than before the investigation.

- Remove wastes that pose an immediate threat to human health or the environment.

- Leave on-site wastes that do not require off-site disposal or extended aboveground containerization.

- Comply with federal ARARs, to the extent practicable.

- Comply with state ARARs, as practicable.

- Exercise careful planning and coordination for management of investigationderived wastes.

- Minimize the quantity of wastes generated. 
TABLE 2.1 Potential applicable or relevant and appropriate requirements (ARARs) for former CCC/ USDA facilities in Kansas. ${ }^{a}$

Title Citation ${ }^{b}$ Description

Maximum Contaminant Level Goals (MCLGs)

Standards for Owners and Operators of Public Water Supply Systems

\section{Underground Injection Control} Regulations

Sole-Source Aquifers
42 USC $300(f)$ et seq.

40 CFR Part 141, Subparts B Establishes maximum contaminant levels (MCLs), and $G$

40 CFR Part 143

40 CFR Part 141, Subpart F goals at levels of no known or anticipated adverse health effects, with an adequate margin of safety. The MCLG for carbon tetrachloride is zero.

40 CFR Part 141

Provides treatment requirements for public water supply systems (i.e., systems that serve at least 25 people or have at least 15 connections).

Provides for protection of underground sources of drinking water.

Prohibits activities, including drilling, in an area designated a sole-source aquifer without special permission of the EPA.
MCLs for organic constituents are applicable to groundwater contamination in a sole-source aquifer.

NSDWRs are applicable if groundwater is a source of drinking water and if the NSDWRs have been adapted as enforceable standards by the state.

MCLGs for organic constituents may be relevant and appropriate if a more stringent standard is required to protect human health and the environment.

MCLs would be relevant and appropriate in the establishment of cleanup goals for groundwater contamination.

Applicable if a remedial alternative involved underground injection.

Applicable if the aquifer in the area were a sole-source aquifer. 
TABLE 2.1 (Cont.)

\begin{tabular}{ccc}
\hline Title & Citation & Description \\
\hline
\end{tabular}

National Pollutant Discharge Elimination System (NPDES)
33 USC 1251 et seq.

40 CFR Part 131

40 CFR Parts 122, 124 and 125

40 CFR Part 403
Section 304(a) of the Clean Water Act (CWA) requires the EPA to publish and periodically update ambient water quality criteria (AWQCs). These criteria are to ". . . accurately reflect the latest scientific knowledge... . on the kind and extent of all identifiable effects on health and welfare including, but not limited to, plankton, fish, shellfish, wildlife, plant life ... which may be expected from the presence of pollutants in any body of water. ..." Water quality criteria developed under Section 304(a) are based solely on data and scientific judgments on the relationship between pollutant concentrations and environmental and human health effects. These recommended criteria provide guidance for states and tribes in adopting water quality standards under Section 303(c) of the CWA.

Establishes NPDES permit procedures, criteria, and standards governing the discharge of pollutant from any point source into waters of the United States (Sections 318, 402, and 405 of the CWA).

Provides general pretreatment standards and regulations for existing and new sources of pollution; establishes standards to control pollutants that pass through or interfere with treatment processes in

publicly owned treatment works or that may contaminate sewage sludge.
AWQCs have been developed for some organic constituents in groundwater and may be relevant and appropriate.
Discharge limits will be established if effluent is discharged to a surface water body.

No permit is required for on-site response actions under CERCLA, but the substantive requirements would apply if a remedial alternative involved discharge into a creek or other

surface water on-site. A permit would be required if the discharge were to a creek or other surface water off-site.

Applicable if a remedial alternative involved discharge to publicly owned treatment works. 
TABLE 2.1 (Cont.)

\begin{tabular}{ccc}
\hline Title & Citation & Description \\
\hline
\end{tabular}

\section{Clean Water Act (Cont.)}

Dredge or Fill Requirements

40 CFR Parts 230-233

(40 CFR Part 6.302(a))

Executive Order on Protection of Wetlands

Rivers and Harbors Act of 1899

Section 10 Permit

Executive Order on Floodplain Management

\section{Clean Air Act}

National Primary and Secondary

Ambient Air Quality Standards

National Emissions Standards for Hazardous Air Pollutants

33 USC 401 et seq.

33 CFR Parts 320-330

\section{CFR Part 50}

Executive Order 11,900

(40 CFR Part 6.302(a))

Executive Order No. 11,988 affecting navigable waters.

Requires federal agencies to evaluate the potential effects of actions in a floodplain to avoid, to the extent possible, the adverse impacts associated with direct and indirect development of a floodplain.

42 USC 7401 et seq

Establishes national primary and secondary ambient air quality standards under Section 109 of the Clean Air Act to protect public health and welfare.

Provides emissions standards for hazardous air pollutants for which no ambient air quality standard exists. Carbon tetrachloride and chloroform are substances for which a Federal Register notice has

been published that included consideration of the serious health effects, including cancer, from ambient exposure to the substance.
Applicable if a remedial alternative required discharge of dredged or fill material into navigable waters.

Applicable if a remedial alternative had a negative effect on a wetland.

Applicable if a remedial alternative affected a navigable waterway.

Applicable if activities were located in a 100-yr floodplain.

Applicable if contaminants were discharged to the air during treatment.

Relevant or appropriate if on-site treatment units with emissions were part of remedial actions. 
TABLE 2.1 (Cont.)

\begin{tabular}{ccc}
\hline Title & Citation & Description \\
\hline
\end{tabular}

Identification and Listing of Hazardous Wastes

Standards Applicable to Generators of Hazardous Waste

Standards Applicable to

Transporters of Hazardous Waste
40 USC 6901 et seq

amended by the Resource

Conservation and Recovery Act

(RCRA), as amended

Criteria for Classification of Solid

Waste Disposal Facilities and

40 CFR Part 257

Practices

0 CFR Part 261

40 CFR Part 262

40 CFR Part 263
Establishes criteria for use in determining which solid waste disposal facilities and practices pose a reasonable probability of adverse effects on health [Sections 1008(a)(3) and 4004(a) of RCRA] and thereby constitute open dumps prohibited under Section 4005 of RCRA.

Provides for protection of surface water and groundwater at solid waste disposal facilities (40 CFR 257.3-3 and -4).

Identifies solid wastes that are subject to regulations as hazardous wastes under 40 CFR Parts 124 $262-265,268,270$, and 271

Establishes standards for generators of hazardous waste.

Establishes standards that apply to transporters of hazardous waste within the United States if the transportation requires a manifest under $40 \mathrm{C} \mathrm{F} \mathrm{R}$ Part 262.
Applicable if a remedial alternative involved land disposal of solid waste.

Applicable if a remedial action included provisions for an on-site landfill.

Applicable if a material at the site were defined as a solid and hazardous waste; would require handling as a hazardous waste.

Applicable if hazardous wastes are generated as a result of on-site activities.

Applicable if a remedial alternative involved off-site transportation of hazardous wastes. 
TABLE 2.1 (Cont.)

\begin{tabular}{ccc}
\hline Title & Citation & Description \\
\hline
\end{tabular}

Standards for Management of

Specific Types of Hazardous

Waste Management Facilities

Land Disposal Restrictions

Hazardous Waste Permit Program

40 CFR Part 270

Technical Standards and Corrective Action Requirements

for Owners and Operators of

Underground Storage Tanks

Occupational Safety and Health Act (OSHA)

Occupational Safety and Health Standards

40 CFR Part 280

29 CFR Part 1910
Establishes minimum national standards that define the acceptable management of hazardous wastes for owners and operators of facilities that treat, store, or dispose of hazardous waste.

Provides for groundwater protection standards, general monitoring requirements, corrective action requirements, and technical requirements.

Establishes requirements that apply to recyclable materials.

Identifies hazardous wastes that are restricted from land disposal; defines limited circumstances under

which an otherwise prohibited waste may continue to be land disposed.

Establishes provisions covering basic EPA permitting requirements.

Establishes regulations related to underground storage tanks.

29 USC 651 et seq.

Establishes safety and health standards for workers.
Applicable or relevant and appropriate if hazardous waste were disposed of on-site.

RCRA standards could be relevant and appropriate for groundwater at the site if an on-site landfill were constructed.

No substances are expected to be present at CCC/ USDA sites in quantities to warrant recycling.

Applicable or relevant and appropriate if hazardous waste were disposed of on-site.

No permit is required for on-site CERCLA response actions. Substantive requirements are addressed in 40 CFR Part 264.

Applicable if a remedial alternative involved use of underground storage tanks.

Under 40 CFR Section 300.150, response actions under the NCP will comply with the OSHA requirements for the safety and health of response action workers. 
TABLE 2.1 (Cont.)

\begin{tabular}{ccc}
\hline Title & Citation & Description \\
\hline
\end{tabular}

Noise Control Act of 1972

42 USC Sect. 4901 et seq.

49 USC 5101 et seq

Hazardous Materials Transportation Act

\section{Hazardous Materials}

Transportation Regulations

\section{National Historic Preservation Act}

Protection of Historic Properties

\section{USC 470 et seq.}

36 CFR Parts 800

(40 CFR 6.301(b))

Executive Order on Protection and Executive Order 11,593

Enhancement of Cultural

Environments

Archaeological and Historic

Preservation
16 USC 469 et seq

(40 CFR 6.301(c))
Prohibits federal activities resulting in noise that would jeopardize the health or welfare of public.

Applicable for activities such as drilling near a public access point.

Applicable if an alternative involved

Protects against the risks to life and property

inherent in the transportation of hazardous material by listing the materials deemed hazardous and describing required labeling, placarding, and training.

Requires federal agencies to consider the effects of any federally assisted undertaking (including those carried out with federal financial assistance and those requiring a federal permit, license, or approval) on any district, site, building, structure, or object that is listed in the National Register of Historic Places or eligible for such listing; requires federal agencies to give the Advisory Council on Historic Preservation a reasonable opportunity to comment on those undertakings.

Requires federal agencies to preserve, restore, and maintain the nation's historic and cultural environment in their activities.

Establishes procedures for preservation of historical and archaeological data that might be destroyed through alteration of terrain as a result of a federal construction project or a federally licensed activity or program.
Applicable if a district site, building, structure, or object listed on or eligible for the National Register is on or adjacent to the site.

transportation of hazardous materials. Does not apply to remediation on-site.

Applicable if historical or archeological data are on or adjacent to the site. 
TABLE 2.1 (Cont.)

\begin{tabular}{ccc}
\hline Title & Citation & Description \\
\hline
\end{tabular}

Protection of Archeological Resources

43 CFR Part 7,

36 CFR Part 296

(40 CFR 6.301(b))

Historic Sites Buildings, Objects, and 16 USC 461 et seq. Antiquities Act (40 CFR 6.301(a)) Act
American Indian Religious Freedom

\section{CFR 3}

(40 CFR Sect. 6.301(b)

Executive Order 11,593

\section{USC 470 aa et seq.}

Arch
Act

42 USC 1996 et seq.
Protects all historic and prehistoric sites on federal

lands and prohibits excavation or destruction of such antiquities without the permission (Antiquities Permit) of the secretary of the department that has the jurisdiction over those lands; authorizes the president to declare areas of public lands as national monuments and to reserve or accept private lands for that purpose.

Supplements the provisions of the Antiquities Act of 1906; prohibits excavation or removal from public or Indian lands any archeological resources without a permit from the land manager; authorizes issuance of permits only to educational or scientific institutions and only if the resulting activities will increase knowledge about archeological resources.

Establishes the uniform definitions, standards, and procedures to be followed by all federal land managers in providing protection for archaeological resources located on public lands and Indian lands of the United States.

Requires federal agencies to consider the existence and location of landmarks on the National Registry of Natural Landmarks to avoid undesirable impacts to such landmarks.

Affirms the right of Native Americans to have access to their sacred places; directs federal agencies to consult with Indian religious practitioners if a place of religious importance to American Indians may be affected by an undertaking.
Applicable if site operations affect antiquities on federal lands.

Applicable if site operations affect archeological resources on public or Indian lands.

Applicable if an entity on the National Register of National Landmarks is on or adjacent to the site.

Applicable if site operations affect access to sacred Indian sites. 
TABLE 2.1 (Cont.)

\begin{tabular}{ccc}
\hline Title & Citation & Description \\
\hline
\end{tabular}

Native American Graves Protection 43 CFR Part 10 and Repatriation Regulations

Native American Grave Protection and Repatriation Act

25 USC 3001 et seq

Endangered Species Act

Interagency Cooperation

16 USC 1531 et seq.

50 CFR Part 402
Executive Order 13,007

Requires federal land managing agencies to

accommodate access to and ceremonial use of Indian sacred sites by Indian religious practitioners and to avoid adversely affecting the physical integrity of such sacred sites; also requires agencies to develop procedures for reasonable notification of proposed actions or land.

Establishes the priority for ownership or control of Native American cultural items excavated or discovered on federal or tribal land after 1990 and the procedures for repatriation of items in federal possession; allows the intentional removal or excavation of Native American cultural items from federal or tribal lands only with a permit or upon consultation with the appropriate tribe.

Defines items included under the Native American Grave Protection and Repatriation Act; describes the consultation procedure applicable to intentional excavation or inadvertent discovery of remains or objects covered. Defines items included under the Native American Grave Protection and Repatriation Act. (40 CFR 6.302(h)

Requires action to conserve threatened and endangered species within critical habits upon which
Applicable if site operations affect access to sacred Indian sites.

Applicable if site operations involve excavation or discovery of Native American cultural items on federal or tribal lands.

\section{Applicable if threatened or} endangered species depend, including consultation and conferencing with the Department of the Interior (U.S. Fisheries and Wildlife Service/ U.S. National Marine Fisheries Service) 位al habitats were identified at the site. 
TABLE 2.1 (Cont.)

\begin{tabular}{ccc}
\hline Title & Citation & Description \\
\hline
\end{tabular}

\section{Migratory Bird Treaty Act}

Migratory Bird Permits

Executive Order on Responsibilities of Federal Agencies to Protect

Migratory Birds

U.S. Fisheries and Wildlife Director's Order on the

Applicability of the Migratory Bird

Treaty Act to Federal Agencies

and the Requirements for Permits

\section{Bald and Golden Eagle Protection} Act

Eagle Permits

50 CFR Part 22

Fish and Wildlife Coordination Act

16 USC 661 et seq. (40 CFR 6.302(g))

Wilderness Act

Wilderness Preservation and Management

16 USC 703 et seq.

50 CFR Part 21

50 CFR Part 35

43 CFR Part 8560
Executive Order 13,186

Director's Order No. 131

Prohibits federal actions that would jeopardize the

Applicable if a remedial alternative habitat of birds with migratory pathways through the would affect a migratory pathway. area.

Directs federal agencies taking actions having or likely to have a negative effect on migratory bird populations to work with the U.S. Fisheries and

Wildlife Service to develop an agreement to conserve those birds.

Requires a permit from the U.S. Fisheries and Wildlife Service to move nests because of construction or operation of project facilities.

Requires consultation with the U.S. Fish and Wildlife Service/ U.S. National Marine Fisheries Service, when a federal department or agency proposes or authorizes any modification of any stream or other water body, as well as adequate provision for protection of fish and wildlife resources.

16 USC 1311 et seq.
Applicable if project activities affect bald and golden eagle populations, including construction or operation of facilities that call for the moving of nests.

Applicable if a remedial alternative wildlife by modifying a stream or body of water. would cause damage to or loss of 
TABLE 2.1 (Cont.)

\begin{tabular}{ccc}
\hline Title & Citation & Description \\
\hline
\end{tabular}

National Wildlife Refuge System

Administration Act

Executive Order on the

Management and General Public

Use of the National Wildlife Refuge

System

Wild and Scenic Rivers Act

16 USC 1271 et seq.

Wild and Scenic Rivers

(40 CFR 6.302(e))

36 CFR Part 297

Kansas State Laws

Kansas Air Quality Control Act;

KSA, Chapter 65, Article 30 Kansas Air Pollution Emission Control KAR, Title 28, Article 19 Regulations
Restricts activities within a national wildlife refuge; directs preservation of a national network of lands and waters for the conservation and management of

fish, wildlife, and plant resources of the United States for the benefit of present and future generations.

Selects certain rivers of the nation possessing remarkable scenic, recreational, geologic, fish an wildlife, historic, cultural, or other similar values;

preserves these rivers in a free-flowing condition and protects their local environments.

Establishes a notification process for federally assisted water resource projects in any portion of a designated river

Requires permitting and preconstruction notice for ai contaminant sources; provides for reporting and inspections; establishes state emission standards for listed hazardous air pollutants and state air quality standards to protect the public health.

Provides emission standards for hazardous air pollutants (HAPs) (KAR 28-19-200 et seq.). HAPs include carbon tetrachloride and chloroform

(KAR 28-19-201(a)). Emission above a certain threshold requires an annual emissions fee

(e.g., 10 tons/yr of a single HAP and 25 tons/ yr of any combination of HAPs) (KAR 28-19-202).
Applicable if a wildlife refuge area existed on-site or adjacent to the site.

Applicable if a scenic river were in the area of the site.

Applicable if any listed pollutants were discharged to the air during

investigation or remediation through air stripping, thermal destruction, handling of contaminated soil,

gaseous waste treatment, aeration, or municipal solid waste landfill disposal. 
TABLE 2.1 (Cont.)

\begin{tabular}{ccc}
\hline Title & Citation & Description \\
\hline
\end{tabular}

Kansas Air Quality Control Act;

Kansas Air Pollution Emission Control

Regulations (Cont.)

Kansas Drinking Water Regulations

KSA, Chapter 65, Article 33; KAR, Title 28, Article 15

Kansas Water Pollution Control Regulations

KSA, Chapter 65, Article 33; KAR, Title 28, Article 16
Emissions above certain threshold amounts require a construction permit (e.g., 25 tons/yr of particulate matter [PM], 15 tons/yr of PM 10, 100 tons/yr of carbon monoxide, 40 tons/yr of volatile organic compounds [VOCs]) or a preconstruction approval (e.g., $5 \mathrm{lb} / \mathrm{hr}$ of PM, $2 \mathrm{lb} / \mathrm{hr}$ of PM 10, $50 \mathrm{lb}$ per 24-hr period of carbon monoxide, $50 \mathrm{lb}$ per 24-h period of VOCs (either $15 \mathrm{lb}$ per 24-hr period or

$3 \mathrm{lb} / \mathrm{hr}$ in a nonattainment area) (KAR 28-19-300).

Establishes new source performance standards for municipal solid waste landfills, including reporting, calculating nonmethane organic compound emissions, installing collection and control systems (28-19-720 et seq.).

Establishes emission standards for major source HAPs (28-19-750 et seq.).

Establishes MCLs pertaining to public water supplies. The MCLs for carbon tetrachloride, total

trihalomethanes (including chloroform), and total nitrate are $0.005 \mathrm{mg} / \mathrm{L}, 0.1 \mathrm{mg} / \mathrm{L}$, and $10 \mathrm{mg} / \mathrm{L}$, respectively (KAR 28-15-13).
Provides for the maintenance and protection of public health and welfare and the use of surface water for aquatic life; for agricultural, domestic, an industrial water supply; and for recreation. Controls surface water use designation. Establishes surface water quality standards (KAR 28-16-28 et seq.). Federal MCLs adopted by reference (KAR 28-16$28 b(d d))$
Applicable if waste derived from investigation or remediation entered public water systems. Not applicable to investigative wells, as such, that are not used for drinking water supply; however, relevant and appropriate for establishing sampling and analysis parameters during investigation.

Applicable if contaminated investigative or remediation effluent were discharged into surface water; also might be applicable to alluvial aquifers demonstrated to be hydraulically connected to surface water bodies. 
TABLE 2.1 (Cont.)

\begin{tabular}{lll}
\hline Title & Citation & Description \\
\hline
\end{tabular}

Kansas Water Pollution Control Regulations (Cont.)
Surface water must be free from the harmful effects of substances that produce any public health hazard; hazardous substances must not occur in surface

water at concentrations that jeopardize public health and other protected life (KAR 28-16-28e)

Provides numeric criteria by use category for different parameters (KAR 28-16-28e(d)). For chloroform the values are $28,900 \mu \mathrm{g} / \mathrm{L}$ for aquatic life-acute, 1,240 $\mu \mathrm{g} / \mathrm{L}$ for aquatic life-chronic, and $15.7 \mu \mathrm{g} / \mathrm{L}$ for public health-food procurement. (For public health-domestic water supply the EPA has promulgated criteria for Kansas under 40 C F R

$\S 136.36$. No values are specified for agriculturelivestock and agriculture-irrigation.) For carbon tetrachloride the value is $35,200 \mu \mathrm{g} / \mathrm{L}$ for aquatic life-acute. (For public health-food procurement and public health-domestic water supply the EPA has promulgated criteria for Kansas under 40 C F R $\S 136.36$. No values are specified for aquatic lifechronic, agriculture-livestock, and agricultureirrigation.)

Establishes procedures relating to the discharge of wastewaters complying with the NPDES (KAR 28-1657 et seq.)

Requires water management planning for water quality management areas deemed critical by state authorities (KAR 28-16-69 et seq.)

Establishes limitations on the types of wastes that can be discharged to a publicly owned treatment works (POTW) and governs pollutants from nondomestic sources that are subject to one or more pretreatment standards and that are indirectly discharged, or otherwise introduced by any means, into any POTW (KAR 28-16-83 et seq.).
Regulations state that, when numeric values are not listed for specific

substances, criterion development is

to be guided by water quality criteria published by the EPA. When the

$\mathrm{KDHE}$ finds that the criteria listed are underprotective or overprotective for a given surface water segment, the KDHE may, in accordance with

KAR 28-16-28f(f), make appropriate site-specific determinations.

National effluent standards are adopted by reference.

Applicable if contaminants resulting from investigation or remediation are discharged into a water quality management area.

Applicable if investigation or remedial alternatives involved discharge of contaminated groundwater to a

POTW. 
TABLE 2.1 (Cont.)

\begin{tabular}{ccc}
\hline Title & Citation & Description \\
\hline
\end{tabular}

Kansas Solid and Hazardous Waste Act; Kansas Solid Waste

Management Regulations
KSA, Chapter 65, Article 34; KAR, Title 28, Article 29

Establishes requirements for location, licensing, construction, operation, and closure of solid waste management facilities (KAR 28-29-21 et seq.).

Establishes location restrictions, design standards, operating standards, groundwater monitoring,

corrective action, and financial assurance for closure and postclosure, for new municipal solid waste landfill units (KAR 28-29-102 et seq.). Liner standards for new municipal solid waste landfills must be designed

in accordance with KAR 28-19-104(e)(1)(A)or(B). Alternative designs must demonstrate that a carbon tetrachloride concentration of $0.005 \mathrm{mg} / \mathrm{L}$ will not be exceeded (KAR 28-29-104(e)(1)(B)). Small units may request exemption (KAR 28-19-103). Requires detection and assessment monitoring for carbon tetrachloride and chloroform (KAR 28-29113).

KSA, Chapter 65, Article 34; KAR, Title 28, Article 31
Establishes standards for hazardous waste generators and transporters and for storage, treatment, and disposal facilities (KAR 28-31-4 et seq.).

Solid waste generators must make a hazardous waste determination. For a waste that is not excluded from hazardous waste regulations and not listed as a hazardous waste, the determination is generally made through testing by a laboratory certified for such analyses by the KDHE (KAR 28-31. 4(b))

Storage by certain hazardous waste generators for more than 90 days requires a permit (KAR 28-31$4(\mathrm{~g})$ ). Federal land disposal restrictions are adopted by reference (KAR 28-31-14).
Applicable if nonhazardous materials were discarded as a result of the investigation or remediation and were landfilled on-site.

Applicable if investigation samples o remediation-generated wastes were determined to be hazardous.

Applicable if hazardous wastes were managed on-site through treatment storage, and disposal or were transported. Transportation requirements do not include manifesting requirement for samples sent for characterization. 
TABLE 2.1 (Cont.)

$\begin{array}{ccc}\text { Title } & \text { Citation } & \text { Description }\end{array}$

Kansas Storage Tanks Act

KSA Chapter 65, Article 34

Governs underground storage tanks.

Kansas Water Well Contractor's License Regulations; Water Well

Construction and Abandonment Regulations

Kansas Underground Injection

Control Regulations

Kansas Nongame and Endangered Species Conservation Act; Kansas

Nongame and Endangered Species

Conservation Regulations

Kansas Levee Law
KAR, Title 28, Article 30

KAR, Title 28 , Article 46 KAR, Title 115, Article 15

KSA, Chapter 24, Article 1 KAR, Title 5, Article 45
Establishes requirements for licensing of well drillers and standards for construction, operation, and plugging of wells (KAR 28-30-3 et seq.).

Governs discharges into underground injection wells (KAR 28-46-1 et seq.)

Requires consultation with the Kansas Department of Wildlife and Parks pertaining to actions that might affect threatened or endangered species and their critical habitats. Projects that receive public funds through Kansas water permit procedures and affect these species or their habitats require review and permitting (KSA 32-957 through -963; KAR 115-15$1,-2,-3$, and -4$)$.

Requires prior approval of chief engineer before construction of floodplain fills and levees (KSA 24-126).

"Floodplain fill" means material, usually soil, rock, or rubble, placed in a floodplain to an average height of more than $1 \mathrm{ft}$ above the existing ground, which has the effect of diverting, restricting, or raising the level of floodwaters on a stream (KAR 5-45-1).
Applicable if a remedial alternative involved use of underground storage tanks.

Applicable if investigation or remediation involved drilling monitoring wells and other wells.

Applicable if investigative or remedial wastes were introduced into wells for discharge or disposal. In general national SDWA regulations are adopted by reference.

Applicable if threatened or endangered species were identified at or near the site.

Applicable if site activities involved construction of floodplain fills. 
TABLE 2.1 (Cont.)

\begin{tabular}{|c|c|c|c|}
\hline Title & Citation ${ }^{b}$ & Description & Comment \\
\hline Kansas Historic Preservation Act & $\begin{array}{l}\text { KSA, Chapter } 75 \text {, Article } 27 \\
\text { KAR, Title } 118 \text {, Article } 3\end{array}$ & $\begin{array}{l}\text { Provides for protection and preservation of sites and } \\
\text { buildings listed on state or federal historic registries } \\
\text { (KSA 75-2701 et seq.). }\end{array}$ & $\begin{array}{l}\text { Applicable if the investigation or } \\
\text { remediation site is a listed state or } \\
\text { federal historic site or is adjacent to } \\
\text { such a site and if activities requiring } \\
\text { permitting are initiated at the site. }\end{array}$ \\
\hline $\begin{array}{l}\text { Kansas Unmarked Burial Sites } \\
\text { Preservation Act }\end{array}$ & $\begin{array}{l}\text { KSA, Chapter } 75 \text {, Article } 27 \\
\text { KAR Title } 118 \text {, Article } 2\end{array}$ & $\begin{array}{l}\text { Establishes Burial Sites Preservation Board; prohibits } \\
\text { unauthorized disturbance; and requires permits for } \\
\text { excavation (KSA 75-2741 et seq.). }\end{array}$ & $\begin{array}{l}\text { Applicable if investigation or } \\
\text { remediation activities encounter a } \\
\text { burial site. }\end{array}$ \\
\hline
\end{tabular}

a In addition to the ARARs listed here, the following advisory levels are to be considered:

- EPA health advisories for exposure to drinking water

\begin{tabular}{lcc} 
& \multicolumn{2}{c}{ Concentration $(\mu \mathrm{g} / \mathrm{L})$} \\
\cline { 2 - 3 } Exposure & $\begin{array}{c}\text { Carbon } \\
\text { Tetrachloride }\end{array}$ & Chloroform \\
One day (10-kg child) & 4,000 & 4,000 \\
Ten days (10-kg child) & 200 & 4,000 \\
Long term (10-kg child) & 70 & 100 \\
Long term (70-kg adult) & 300 & 400 \\
Lifetime (70-kg adult) & Not available & Not available
\end{tabular}

- EPA Region III risk-based criteria for tap water
Carbon tetrachloride
$0.16 \mu \mathrm{g} / \mathrm{L}$
Chloroform
$0.15 \mu \mathrm{g} / \mathrm{L}$

b Abbreviations for citations:

CFR, Code of Federal Regulations

USC, United States Code

Sect., Section

KSA, Kansas Statutes Annotated

KAR, Kansas Administrative Regulations 


\section{Health and Safety Plan}

\subsection{Introduction}

\subsubsection{Purpose}

This health and safety plan contains the information required to protect personnel at former CCC/USDA facilities during (1) periodic groundwater and soil sampling; (2) the installation, construction, development, and sampling of groundwater monitoring wells; (3) soil boring around potentially contaminated areas with conventional drilling methods; (4) soil and water sampling with electronic cone penetrometer methods; and (5) the collection of geophysical data. This section provides only general information relative to all former CCC/USDA facilities to be investigated. The site-specific information needed to support this section is provided in site-specific work plans.

The principal purpose of this health and safety plan is to provide the Argonne field team members with the information, procedures, regulations, and guidelines needed to conduct their work with minimal hazard to their own health and safety and the health and safety of the surrounding public and the environment. The primary intent of the plan is to document the responsibility of all workers to conduct their operations safely and to provide them with the means to do so, in keeping with the policy of the CCC/USDA and Argonne that health and safety are foremost considerations in conducting the field investigation.

Secondary purposes are (1) to demonstrate to the CCC/USDA, the Occupational Safety and Health Administration (OSHA), the EPA, and state and local regulatory agencies that health and safety have been given adequate consideration in the planning and execution of the work; (2) to show that applicable regulatory requirements are being met; and (3) to show that relevant policy and procedural requirements of Argonne and its Environmental Research Division are being satisfied. 


\subsubsection{Site Location and Background}

Information provided for each former CCC/USDA facility in a site-specific work plan includes a brief history of the site and the details of previous investigations. The results of the previous investigations are the primary basis for identifying the appropriate health and safety concerns for each site.

\subsection{Organization, Regulations, and Responsibilities}

\subsubsection{Organization}

Before field work begins, the site-specific health and safety plan is submitted for review by the Safety, Health, and Environmental Protection Committee of Argonne's Environmental Research Division. The project health and safety coordinator (HSC) is responsible for executing the health and safety plan during field sampling and data collection activities. The HSC is to have received appropriate health and safety training.

\subsubsection{Rules and Regulations}

The general health and safety rules in effect at Argonne are used at sampling sites. Thus, the Argonne Environment, Safety and Health Manual (ESH Manual) and other documents listed in Section 3.10 all apply. The regulations and guidelines of DOE, OSHA, the EPA, and state and local regulatory agencies also apply. Although Argonne's ESH Manual; the Environmental Research Division's Safety, Health, and Environmental Protection Policy and Procedures Manual; DOE orders; and OSHA regulations are not considered to be mutually exclusive, OSHA regulations will prevail in all instances of inconsistency.

\subsubsection{Responsibilities of the Health and Safety Coordinator}

The HSC is responsible for preparing the health and safety plan, determining that the field team members are adequately trained, and arranging for additional training where necessary. Names and telephone numbers of field team members and subcontractors are provided in each site-specific work plan. 
The HSC provides the required health and safety information to team members and subcontractors, is available on the site at all times when sampling and associated work are conducted, and ensures that team members follow the health and safety plan. The responsibilities of the HSC include the following:

- Ensuring that all personnel are aware of the potential hazards at the site and of the proper procedures for handling those hazards, including the health and safety provisions in this plan.

- Assuring that required personal protection equipment is available and is used properly by all site personnel, in accordance with provisions of this plan.

- Implementing this health and safety plan. This responsibility includes monitoring the safety performance of personnel to ensure that mandatory health and safety procedures are adequate and correcting any aspects that do not comply with this plan.

- Conducting monitoring as required to ensure that the existing hazards are characterized adequately and that the level of personal protective equipment is appropriate.

- Monitoring personnel for signs of temperature stress or exposure to hazards.

- Ensuring that field crews observe the appropriate work practices and decontamination procedures.

The HSC, in carrying out his/her responsibilities, is to stop or modify any work considered unsafe or out of compliance with this plan. If an activity has been stopped because of unacceptable health and safety practices, a conference is to be convened by the HSC, to include the field team leader, the affected team members, and other appropriate representatives. Experts in the specific activity may be used as consultants. This conference committee will deliberate on safe practices to implement, but the HSC has overall decision-making authority if agreement cannot be reached. Upon resolution of the issue, work may resume in conformance with the agreement reached. 


\subsubsection{Responsibilities of the Field Team}

The project manager is responsible for instructing field team members that all work will be performed with the maximum consideration for health and safety.

All field team members are responsible to conduct work safely and not to endanger themselves or their colleagues. Team members must obtain appropriate health and safety information when they are uncertain about these aspects of their work and must follow the prescribed health and safety procedures.

\subsubsection{Responsibilities of Subcontractors}

Subcontractors used by the field team are subject to the same health and safety rules and regulations as the field team itself, including the authority of the HSC. In addition, subcontractors are directly and solely responsible for ensuring that their own employees have been provided with appropriate personal protective devices, have been adequately instructed with respect to the requirements of this plan, and conduct themselves in full conformance with the provisions of this plan at all times.

\subsection{General Health and Safety Practices}

\subsubsection{Guidelines}

General health and safety precautions to be observed during sampling activities are described here. Requirements for health and safety practices and exposure limits are given in the documents listed in Section 3.10.

\subsubsection{Emergency Plan}

If an emergency situation such as injury, illness, or fire arises, the appropriate immediate response must be taken by the first person to recognize the situation. A list of emergency contacts and the route to the nearest hospital is provided in each site-specific work plan. A copy 
of the emergency telephone numbers and the route to the hospital is to be posted clearly on the site.

\subsubsection{Hazard Assessment}

Each day before work begins, the HSC assesses the hazard of each activity to be conducted on that day. A tailgate safety meeting is to be held to review the personal protection measures needed to ensure the safety of the workers.

\subsubsection{New Activity}

The HSC is to provide or obtain the needed information for any unusual or new activity whose health and safety potential has not been evaluated. Such an activity is to undergo a safety review by a committee consisting of the HSC, the project manager, and affected team members as necessary. A written report of the review will be prepared by the HSC. A copy of the form to be used for this report is in Appendix A.

\subsubsection{Site Safety Meetings}

Daily, and before a sampling activity begins, the project manager, the HSC, and all personnel working on the project meet to discuss site safety. Items for review include potential physical and chemical hazards, site-specific procedures, required personal protective equipment, emergency procedures, and staff responsibilities. Forms for conducting the on-site safety meeting are in Appendix B.

\subsubsection{Physical Hazards}

\subsubsection{Mechanical Hazards}

Common mechanical hazards exist around heavy equipment (such as drill rigs, electronic cone penetrometer vehicles, and earth moving equipment), in or around excavations, and in places where heavy objects might cause injury by falling on the worker. Drilling rig hazards 
include pinch points, rotating parts, tall derricks (because of potential contact with overhead power lines), and heavy support equipment. Electronic cone penetrometer hazards include pinch points and the potential for contact with overhead power lines when push rods extend through the roof of the vehicle. The following requirements pertain to working around mechanical hazards:

- All personnel must remain a safe distance from the drilling equipment and the electronic cone penetrometer rig, as indicated by the project manager, when they are not involved in operating the drill rig or in monitoring activities.

- Workers must remain aware of their own and others' positions with regard to rotating equipment and $\mathrm{U}$-joints and be extremely careful when assembling, lifting, and carrying auger flights or pipe to avoid pinch point injuries and collisions.

- Workers must not, under any circumstances, enter or ride in or on any backhoe bucket, material hoist, or similar device not specifically designed for carrying human passengers.

- Personal protective equipment minimally includes a hard hat and safety shoes. Eye protection is required where eye hazards exist and is to be worn during all sample collection.

\subsubsection{Noise}

Drilling operations generate high noise levels near the rig. Hearing protection is required when personal noise exposure levels are in excess of $85 \mathrm{dBA}$ as a time-weighted average over an 8-hr shift. Guidelines for determining the allowable duration of continuous noise exposure are as follows:

Hours per Day

Sound Level (dBA)

$\begin{array}{cr}8 & 85 \\ 4 & 88 \\ 2 & 91 \\ 1 & 94 \\ 1 / 2 & 97 \\ 1 / 4 & 100 \\ 1 / 8 & 115\end{array}$


Hearing protection must have a manufacturer noise reduction rating sufficient to reduce noise exposure levels to $85 \mathrm{dBA}$ or less. Hearing protection is to be worn in the proper manner to assure that the noise reduction rating is effective. As a general rule, hearing protection is required if workers must shout at a distance of $3 \mathrm{ft}$ in continuous noise or when load impact noise is expected. All work areas are to be monitored at the initial startup time by using a sound level meter. A warning is to be issued when noise levels are of concern.

\subsubsection{Lighting}

All field activities are expected to be performed during daylight hours. All operations on the site will cease at sunset unless the work area is adequately illuminated (to at least 5 foot candles) with artificial lighting.

\subsubsection{Fire}

A multipurpose (A:B:C) dry-chemical fire extinguisher must be available at every drill site. Workers must avoid driving over dry grass that is higher than the ground clearance of a vehicle. Catalytic converters on the undercarriages of vehicles are sufficiently hot to ignite dry grass. A vehicle with a warm undercarriage must never be allowed to sit in a stationary location over dry grass or other combustible materials. Several multipurpose (A:B:C) dry-chemical fire extinguishers are to be available on the site. One will be on the inside wall of each electronic cone penetrometer vehicle, and the rest will be distributed among support vehicles.

\subsubsection{Dry Ice}

Dry ice is routinely used for holding and shipping soil samples. Dry ice is solid carbon dioxide at a temperature of $-78.5^{\circ} \mathrm{C}\left(-109.3^{\circ} \mathrm{F}\right)$. Contact with skin causes cryogenic burns (severe frostbite). Dry ice handlers must protect their skin and eyes as appropriate for their level of exposure to the solid.

Dry ice sublimates (changes directly from a solid to a vapor) at temperatures above $-78.5^{\circ} \mathrm{C}$. In a closed space, the carbon dioxide vapor generated can cause asphyxia by displacing oxygen. Concentrations of carbon dioxide in excess of $1.5 \%$ in air can cause death. To protect against this hazard, ventilate storage areas and transport vehicles. 
In a tightly closed space, gas pressure resulting from sublimation of dry ice can cause explosion. Provide for relief of pressure when preparing dry ice storage containers and packaging samples. Know and obey the current dry ice shipping regulations. Carriers and shipping services impose dry ice weight limits. Safety precautions for dry ice are in Appendix C.

\subsubsection{Chemical Hazards}

The likely contaminants at former CCC/USDA facilities are carbon tetrachloride and chloroform. Investigations at these facilities have shown that contamination is typically well below a level that would present a health hazard to field investigators. Nevertheless, exposure of field personnel to site contaminants could result from contact with contaminated soil, water, or vapors. Use personal protective equipment (Section 3.3.9) and adhere to safe work practices to limit exposure to volatile organics that might be present. Appendix $\mathrm{C}$ contains material safety data sheets (MSDSs) and OSHA guidelines for carbon tetrachloride and chloroform. Appendix C also contains MSDSs for sulfuric acid and hydrochloric acid, which are routinely used in very small quantities by field investigators.

If additional chemical hazards are identified at any of the former CCC/USDA facilities to be investigated, appropriate information about these chemicals will be provided in the sitespecific technical work plan.

\subsubsection{Carbon Tetrachloride}

Carbon tetrachloride is a noncombustible, colorless liquid with a sweet, aromatic, etherlike odor. Prolonged exposure to high concentrations can cause loss of consciousness and death due to respiratory failure. Exposure to low concentrations can cause severe gastrointestinal upset progressing to serious kidney and liver damage. Carbon tetrachloride as a vapor or liquid is also an eye irritant, causing burning and tearing. The EPA considers carbon tetrachloride to be a probable human carcinogen. The best estimate of the odor threshold for carbon tetrachloride in air is $250 \mathrm{ppm}$.

The OSHA maximum concentration limit for carbon tetrachloride in workplace breathing-zone air is $10 \mathrm{ppm}$ for an 8-hr workday (time-weighted average) over a 40-hr work week. A ceiling concentration of $25 \mathrm{ppm}$ may not be exceeded during an 8 -hr workday except 
for a 5 -min period every $4 \mathrm{hr}$. The acceptable maximum peak during the 5 -min period is 200 ppm.

\subsubsection{Chloroform}

Chloroform is a noncombustible, colorless liquid with a pleasant, sweet odor. This compound is classified as moderately toxic when exposure occurs orally. Potential health effects resulting from acute exposure include dizziness, mental dullness, nausea, headache, and fatigue. Chloroform is a well-known anesthetic. Inhalation can initially induce a warm feeling on the face and body that is followed by irritation of the mucous membranes and skin. Prolonged inhalation can cause paralysis accompanied by respiratory failure and eventually death. The EPA recognizes chloroform as a probable human carcinogen. OSHA cites odor threshold concentrations in air of 85-307 ppm. OSHA has set a permissible exposure limit of $50 \mathrm{ppm}$ as a non-exceedable ceiling value in workplace breathing-zone air.

\subsubsection{Electrical Hazards}

All electrical equipment to be used during field activities must be properly grounded. Before any $120-\mathrm{V}$, single-phase, 15- or 20-A receptacle outlet is used, a ground fault circuit interrupter approved by Underwriters Laboratories must be installed in the outlet. Only qualified persons may work on electrical equipment, and all equipment must be maintained in safe condition. Underground electrical utilities must be located before drilling or excavation begins (Section 3.8).

The drilling rig derrick must be kept at least $10 \mathrm{ft}$ from electrical power lines unless such lines have been de-energized. Documentation of the date, time, and location of plans to de-energize lines is to be obtained. De-energizing of power lines may not be conducted by Argonne or subcontracting personnel.

If work close to buried or overhead power lines cannot be avoided, the Argonne project manager must verify that the power has been turned off, with the circuit breaker appropriately locked out and tagged by appropriate facility or utility company personnel, before the work begins. 


\subsubsection{Confined Space Entry Procedures}

For the purpose of this health and safety plan, a confined space is defined as any area having limited space for entry and exit and the potential for the presence of a toxic, explosive, or oxygen-deficient atmosphere. This definition includes manholes, certain trenches (particularly those through waste disposal areas), and all test pits more than $4 \mathrm{ft}$ deep in potentially contaminated soil.

The following procedures and requirements apply to the entry of any confined space:

- No employee may enter any test pit or trench more than $4 \mathrm{ft}$ deep unless the sides are shored or laid back to a stable slope.

- When an employee must enter a pit or trench $4 \mathrm{ft}$ deep or more, an adequate means of entry and exit, such as a slope of at least $2: 1$ to the bottom of the pit or a secure ladder or steps, must be provided.

- Before a worker enters any confined space, including any test pit or any trench that might have the potential for the accumulation of toxic gases or vapors, the atmosphere must be tested. Any employee entering a confined space must be equipped with an appropriate level of respiratory protection. However, no employee may enter a confined space if that confined space requires the use of Level B or Level A protection (Section 3.3.9).

- A Confined Space Entry Permit, Argonne form ANL-614, must be completed before any confined space entry. This permit specifies additional entry requirements.

\subsubsection{Site Monitoring}

All necessary monitoring equipment and supplies are to be available before site work begins. The HSC ensures that ambient air monitoring is conducted for hazardous materials 
whenever appropriate. The following types of equipment are to be available for monitoring exposures:

- A field photoionization detector, such as $\mathrm{HNu}$ P1-101, OVM 580, or Mini Rae P10. Lamp selections will include 11.7-eV types. (Carbon tetrachloride has $90 \%$ sensitivity, and chloroform has $60 \%$ sensitivity.)

- Carbon dioxide monitor.

- Oxygen meter.

- Combustible gas indicator.

- Draeger pump and detector tubes for carbon tetrachloride (\#8101021) and chloroform (\#6728861).

The HSC is to ensure that monitoring is conducted for hazardous materials and noise whenever appropriate. Calibration and air monitoring results must be documented.

\subsubsection{Personal Protective Equipment}

Personal protective equipment is selected according to the site characterization, job tasks, site hazards, and potential employee exposures. Experience and specific-site information gathered for other former CCC/USDA facilities indicate that the personal protective equipment to be used during sampling activities will be Level D or Level D modified to include chemicalresistant coveralls and gloves when potentially contaminated soils are handled. The decision to upgrade to Level $\mathrm{C}$ is to be based on work conditions and concentrations of airborne organic vapors. Because of low levels of contaminants expected, such upgrades are not anticipated.

No sampling activity that requires Level A or Level B protection may be conducted by the Argonne team. The appropriate protection requirements are outlined below. Specific brands and models are not listed because these may change with time. 


\subsubsection{Level C Protection}

Select Level C protection when the type of hazardous airborne substance is known, its concentration has been measured, criteria for using air-purifying respirators are met, and skin or eye exposure is unlikely. Monitor the air to comply with OSHA regulations and to ensure respirator effectiveness. Level $\mathrm{C}$ protection includes the following:

- Air-purifying respirator (as directed by the Mine Safety and Health Act and approved by the National Institute for Occupational Safety and Health) equipped with an organic vapor cartridge. Cartridges must be changed daily.

- Chemical-resistant (polyethylene coating recommended for protection against liquid) clothing (one-piece coverall; hooded, two-piece chemical splash suit; chemical-resistant hood and apron; disposable chemical-resistant coveralls).

- Chemical-resistant inner and outer gloves. (Viton or polyvinyl alcohol is recommended for handling liquids.)

- Boots, steel toe and shank, chemical resistant.

- Disposable chemical-resistant outer boots, optional.

- Two-way radio communications, optional (intrinsically safe).

- Hard hat, near mechanical hazards.

- $\quad$ Escape mask, optional (respirator).

\subsubsection{Level D Protection}

Level D is primarily work clothing. It should be used only in areas where respiratory or skin hazards do not exist and where work clothing will not become contaminated with transferable hazardous materials. Level D protection includes the following:

- Coveralls or work clothing 
- Safety shoes with steel toe (leather or chemical resistant)

- Gloves

- Safety glasses or goggles

- Hard hat, near mechanical hazards

\subsubsection{Modified Level D Protection}

Modified Level D protection is designed for areas where skin and respiratory hazards might exist because of low levels of contaminants. This level of protection includes all of the protective equipment listed above, plus the following:

- Chemical-resistant coveralls (polyethylene coated)

- Chemical-resistant gloves during sampling activities (nitrile, Viton, or polyvinyl alcohol)

\subsubsection{Noise Protection}

Hearing protection equipment is required as indicated in Section 3.3.4.2.

\subsubsection{Guidelines for the Use of Personal Protective Equipment}

Guidelines for use of personal protective equipment are as follows:

- Avoid direct contact with contaminated materials unless contact is necessary for sample collection or observation. Wear personal protective equipment at all times. 
- Do not handle contaminated soil, waste samples, or any other potentially contaminated items without appropriate chemical-resistant, impermeable gloves.

- Always use the appropriate level of personal protection indicated in the sitespecific procedures. Inadequate levels of protection can allow otherwise preventable exposure; excessive levels of protection can impair efficiency and increase the potential for accidents.

- Establish prearranged hand signals or other means of emergency communication for personnel wearing respiratory equipment, because this equipment can seriously impair oral communication.

- Nonparticipating visitors to the site, such as nearby property owners and community residents, are escorted when they are near site investigation activities. Visitors to the site are evaluated with regard to (1) the reason for the visit, (2) the length of the visit, and (3) the level of participation in site activities. Appropriate health and safety actions taken on this basis include participation in daily safety review meetings and the use of safety goggles, hearing protection, and other personal protective equipment.

\subsubsection{Provision of Services and Equipment}

The following services, personal protective equipment, and safety supplies are to be provided as shown below for the Argonne field team. Argonne-EQO/IH indicates Argonne's Office of Environment, Safety, and Health/Quality Assurance Oversight, Industrial Hygiene organization; Argonne-ER indicates the Environmental Research Division. 


\section{Service/Equipment}

Medical evaluation

Respiratory protective equipment, training, and fit testing

Monitoring equipment and supplies for evaluation of chemical and noise exposures

Protective clothing, eye and face protection, and hearing protection

Safety shoes, glasses, work clothing

First aid kit

(approved by Argonne Medical

Department)
Provider

Argonne Medical Department

Argonne-EQO/IH

Argonne-EQO/IH and ArgonneER

Argonne-ER

Team members

Argonne-ER

Subcontractors are responsible for providing appropriate safety and health-related equipment and devices for their employees.

\subsubsection{Clothing}

Discard clothing that is suspected of being contaminated as arranged by the HSC.

\subsubsection{Food and Beverages}

Eating, drinking, and smoking are prohibited at the work site during sampling activities. All employees are to wash their hands (and faces if necessary) thoroughly before they eat, drink, smoke, or chew gum, in order to avoid hand-to-mouth contamination. 


\subsubsection{Transportation of Hazardous Materials}

Argonne personnel involved in shipping hazardous materials are to follow all applicable U.S. Department of Transportation regulations. Hazardous materials include the following:

- Dry ice

- Explosives

- Flammable compressed, nonflammable compressed, or poisonous gases

- Flammable, combustible, or spontaneously combustible liquids

- Flammable solids

- Dangerous-when-wet, poisonous, or corrosive materials

- Oxidizers and organic peroxides

- $\quad$-Butyl phthalate

- Infectious substances

- Materials whose form, quantity, or packaging presents a limited hazard during transportation

- Materials having anesthetic, noxious, or similar properties that could cause extreme annoyance or discomfort to personnel

Direct questions about the shipment of hazardous materials to the Argonne Transportation Safety Officer at 630-252-5712. 


\subsection{Training}

All members of the field sampling team must be trained according to requirements of the OSHA regulation Hazardous Waste Operations and Emergency Response Standard, 29 CFR (Code of Federal Regulations), Regulation 1910.120.

To maintain maximum flexibility in assigning appropriately trained field teams and to maximize employee protection in an unpredictable environment, the following specific requirements apply:

1. All employees directly involved with general on-site field activities must complete a 40-hr course for workers at hazardous waste sites that includes both classroom instruction and field exercises (Argonne course 106 or the OSHA equivalent). Topics covered are to include standard operating procedures, hazardous physical and chemical exposures, hazard-monitoring equipment, and emergency response. This requirement extends to both Argonne employees and subcontractor employees. In addition to the 40-hr course, three days of on-the-job training are required. Exceptions are addressed under point 2 .

2. Observers at the site or minor participants whose work consists of only occasional and limited tasks, during which

- Chemical or noise exposures will not exceed permissible limits,

- Respirators and hearing protection will not be necessary, and

- An emergency involving hazardous chemical exposure is not expected to develop,

must have $24 \mathrm{hr}$ of training for work at a hazardous waste site plus $8 \mathrm{hr}$ of onthe-job training. On-site security measures must guarantee that these employees do not enter work areas entailing greater hazard and therefore additional training requirements. If these employees become general site workers or are expected to be required to wear or be prepared to wear 
respiratory protection (routinely or for emergency response), they are to be given the additional $16 \mathrm{hr}$ of training required for workers described under point 1.

3. All Argonne employees in supervisory or management capacities must complete an additional $8 \mathrm{hr}$ of hazardous waste management training that includes site-specific information. Coupled with the 40-hr course required under point 1 , this training will prepare team members to function as HSCs.

4. All Argonne employees and subcontractors' employees who continue to participate in on-site activities at hazardous waste sites must obtain $8 \mathrm{hr}$ of retraining annually.

Completion of training is considered when subcontractors are hired. Documentation of course attendance or its equivalent is required. All requests for exceptions to the immediate application of these training requirements (such as equivalent training or experience substitutes) must be submitted by the project manager for consideration by the HSC and by other ArgonneEQO personnel as appropriate.

\subsection{Work Area Designations/Site Control}

Conduct sampling activities in a way that minimizes the transfer of hazardous substances from sampling locations to "clean" areas.

Control access to sampling locations to reduce the possibility of (1) exposure to any contaminants present and (2) contaminant transport off the site by personnel or equipment. Reduce or eliminate the possibility of exposure or translocation of substances by (1) setting up security and physical barriers to exclude unnecessary personnel from the general area, (2) establishing work zones within the site, (3) conducting operations in a way that reduces the exposure of personnel and equipment and eliminates the potential for airborne or waterborne contaminant dispersion, and (4) minimizing the personnel and equipment at the site while maintaining effective operations.

The exclusion zone is the contaminated area where sampling activities take place. Mark this area clearly with lines, signs, or hazard tape, or enclose it with physical barriers such as 
chains, fences, or ropes. The contamination reduction zone is the transition area between the exclusion zone (the contaminated area) and the support zone (the clean area), where decontamination takes place. Protective equipment is removed and stored or discarded in this area. Situate this area upwind of any field activities. The support zone is the uncontaminated area where personnel are not exposed to hazardous conditions. This zone is clean and contains the equipment that might be needed in the exclusion zone.

\subsection{Medical Monitoring}

\subsubsection{Medical Program}

The medical program for site sampling personnel includes periodic physical examinations, the components of which are at the discretion of the Argonne Medical Department. At a minimum these should include annual blood tests, blood pressure and pulse readings, and heart and lung testing (electrocardiogram and chest X-ray). Because exposure to chlorinated hydrocarbons is likely, medical monitoring should include liver and kidney function tests. If any examinations or tests are specifically applicable to planned field work, such as stress testing or monitoring of the blood for elevated levels of heavy metals, these are to be scheduled between team members and the Argonne Medical Department before field activities begin.

Subcontractors' employees are to receive medical services at least equivalent to those described above from their company physicians.

\subsubsection{Heat Stress}

In the field, a worker's heat tolerance is reduced when impermeable clothing is worn, and his/her physical condition should be observed closely. The following is a summary of the basic symptoms and treatments field team workers should be able to recognize for heat-stress-related illnesses. 
Category

Heat stroke

Heat exhaustion

Heat cramps

Sunburn

\section{Symptom}

Hot, dry skin; temperature high and rising; mental confusion, loss of consciousness, coma

Fatigue, nausea, headache, giddiness; clammy, moist skin; faint, rapid pulse

Painful spasms of muscles used during work

Redness and possible blistering of the exposed skin
Treatment

Immediately and rapidly cool by immersing in cool water; wrap in wet sheets and fan with cool, dry air.

Remove to cooler environment; administer electrolyte replacement fluids; allow to rest.

Administer electrolyte replacement fluids; allow to rest.

Remove victim from the sun; apply sun block lotions and lip balm often to prevent burning.

If heat stress occurs, the employee is to leave the work area, rest in a shaded or air-conditioned area, cool off, and drink plenty of cool water. The employee is to notify the HSC, and medical assistance will be obtained if necessary. Personnel wearing protective clothing are to be observed for signs and symptoms of heat-stress-related illnesses when the ambient temperature is $70^{\circ} \mathrm{F}$ or above. The frequency of observation and assessment are to increase as the ambient temperature increases and as the use of protective clothing increases. To protect workers from heat stress, the following evaluation and control measures are to be used when appropriate:

\section{- Environmental Monitoring}

The air temperature or adjusted dry-bulb temperature will be used as an index for expressing environmental heat load.

- Work-Rest Regimen

An appropriate work-rest regimen will be developed on the basis of environmental heat load, work load, and level of personal protective equipment.

- Physiological Response Monitoring

Physiological response to heat load (e.g., increase in heart rate, body temperature, skin temperature, and sweat production) will be evaluated as appropriate. 
- Providing Adequate Water and Electrolyte Supplements

An adequate supply of cool water is to be maintained at the work site, and electrolyte supplements are to be available as needed. Salt tablets are NOT recommended.

\subsubsection{Cold Stress}

Sustained field exposure to low temperatures, especially accompanied by wind or wet clothing, can cause various degrees of cold stress. The following is a summary of the basic symptoms field team workers should be able to recognize for cold-stress-related illnesses, with appropriate treatments.

\begin{tabular}{|c|c|c|}
\hline Category & Symptom & Treatment \\
\hline Hypothermia & $\begin{array}{l}\text { Initial signs: exhaustion, } \\
\text { reluctance to move, trembling } \\
\text { and shivering, false feeling of } \\
\text { well-being, clumsiness, and } \\
\text { loss of judgment }\end{array}$ & $\begin{array}{l}\text { Stop and immediately get to } \\
\text { shelter; attempt to slowly rewarm } \\
\text { the victim (add layers of clothes } \\
\text { or blankets); attempt to get hot, } \\
\text { sweet food or drink into the } \\
\text { victim; seek medical attention. }\end{array}$ \\
\hline Frostbite & $\begin{array}{l}\text { Sudden blanching of the skin; } \\
\text { tingling, stinging, or dull ache in } \\
\text { affected area, followed by } \\
\text { numbness }\end{array}$ & $\begin{array}{l}\text { Place frozen area in warm place } \\
\text { immediately. Do not rub } \\
\text { frostbitten area. Seek medical } \\
\text { attention. }\end{array}$ \\
\hline
\end{tabular}

If cold stress occurs, contact the HSC. Obtain medical assistance if necessary.

To protect workers from cold stress, appropriate insulating clothing is to be worn, and the following evaluation and control measures are to be taken:

\section{- Environmental Monitoring}

When the temperature falls below $32^{\circ} \mathrm{F}$, the dry-bulb temperature and wind speed will be evaluated every $4 \mathrm{hr}$ and used as an index for expressing environmental cold stress. Personnel will be checked routinely for signs of frostbite. 
- Work-Rest Regimen

An appropriate work-rest regimen will be developed on the basis of environmental monitoring, work load, and protective clothing.

- Providing Adequate Fluid Replacement

Dehydration can occur insidiously in the cold environment. Therefore, fluids will be available during breaks.

\subsection{Accident Investigation and Record Keeping}

Field sampling team members are required to promptly notify the HSC and project manager of all accidents and known or suspected safety-related occurrences that

- Have a real or potential effect on the safety and well-being of sampling operations or personnel;

- Have a real or potential impact on the safety and well-being of the surrounding public;

- Relate to violations of prescribed safety standards;

- Involve "near-miss" occurrences, indicating the need for additional precautions or corrective action on equipment, systems, or procedures; or

- Could cause adverse public reaction.

If any occupational injury or illness occurs, report the injury or illness to Monte Brandner (630-252-2885) or David Peterson (630-252-3924) in Argonne's Environmental Research Division, as soon as immediate health and safety needs have been met.

All accidents or injuries requiring first aid or medical treatment are to be investigated by the HSC and, if they involve Argonne personnel, reported to the Argonne Medical Department. Incidents involving non-Argonne personnel are to be reported to the injured person's employer. 


\subsection{Utilities Survey}

Before any subsurface work begins, borehole and well locations are to be surveyed to determine whether any underground utilities are present. In Kansas, call 800-344-7233 (800-DIG-SAFE); in Nebraska, call 800-331-5666. If overhead power lines are present near a drilling location, all wires are to be considered live and dangerous. Before the rig mast is raised, the clearance must be checked to ensure that a safe distance of operation $(10 \mathrm{ft})$ exists between the mast and overhead lines. The mast is to be lowered when equipment is moved between locations.

\subsection{Decontamination Procedures}

Decontamination is a method of minimizing the transfer of hazardous substance(s) from the survey area to unaffected areas. Decontamination procedures are arranged by the HSC before field work and sampling begin. The location(s) of decontamination station(s) and the procedures for decontamination are to be mutually agreed upon by the facility authorities, the HSC, and the project manager.

\subsubsection{Decontamination of Sampling Equipment}

Decontaminate all drilling and electronic cone penetrometer equipment (including, as applicable, auger sections, drill rods, bits, and center plugs) before each monitoring well is drilled and at the end of each working day. First scrape the equipment and wipe it clean of all mud, grease, and oil (if present). Thoroughly clean the equipment by using a high-pressure hot water washer (or a steam cleaner), and rinse the equipment with distilled water.

Decontaminate sampling equipment such as split spoons and stainless steel spoons according to the following procedure:

1. Scrape and wipe equipment clean of all mud, grease, and oil (if present).

2. Wash and scrub equipment thoroughly with nonionic detergent and water.

3. Rinse with tap water. 
4. Rinse with distilled water.

5. Repeat steps 2-4, if necessary.

6. Air dry.

7. Wrap dried equipment in aluminum foil for storage.

8. Dispose of contaminated materials as indicated in Section 6.1.5

\subsubsection{Decontamination Equipment Checklist}

The following decontamination equipment is needed:

- Large containers for drill cuttings and decontamination water

- Five-gallon container(s) of potable water (for decontamination only)

- Soft- and stiff-bristled brushes with long handles

- Detergent (solid or liquid)

- Spray bottles for rinsing

- Paper towels or other disposable cleaning cloths

- Plastic garbage bags (for disposal of solid/hazardous wastes)

- Hand pump sprayer

- Plastic drop cloth 


\subsection{Health and Safety Guidance Resources}

1. Argonne National Laboratory, Environment, Safety and Health Manual, Argonne National Laboratory-East (www.aim.anl.gov/manuals/eshman/).

2. Environmental Research Division, Safety, Health, and Environmental Protection Policy and Procedures Manuals, Argonne National Laboratory (www.anl.gov/ER/manuals.html).

3. U.S. DOE Order 5480.4, Environmental Protection, Safety, and Health Protection Standards (www.directives.doe.gov).

4. Occupational Safety and Health Guidance Manual for Hazardous Waste Site Activities, 1985, prepared by National Institute for Occupational Safety and Health (NIOSH), Occupational Safety and Health Administration, U.S. Coast Guard, and U.S. Environmental Protection Agency, U.S. Department of Health and Human Services (NIOSH) Publication No. 85-115 (www.cdc.gov/niosh/85-115.html).

5. American Conference of Governmental Industrial Hygienists, Threshold Limit Values for Chemical Substances in the Work Environment and Biological Exposure Indices, revised annually (available at www.acgih.org/store/).

6. Lewis, R.J., 1993, Sax's Dangerous Properties of Industrial Materials: 1993 Update, 8th ed., Van Nostrand Reinhold, New York. 


\section{Quality Assurance/Quality Control Plan}

The quality assurance/quality control (QA/QC) guidelines presented here constitute a statement of the philosophy and approach to QA/QC to be taken by all Argonne personnel and subcontractors participating in QuickSite ${ }^{\circledR}$ field investigations. All field activities that could affect the quality of the results were considered during the development of this plan. One of the major goals of the field program is to generate qualitative and quantitative (where appropriate) data that reliably identify and characterize environmental problems at each site. It is therefore vital that all data generated be of known quality, to support decisions concerning environmental actions. Such an approach ensures that all of the field work activities produce scientifically accurate, defensible data.

This QA/QC plan is divided into three major parts. Section 4.1 deals with the overarching data quality requirements inherent in the QuickSite ${ }^{\circledR}$ process, including data quality objectives, data usage, and project organization and personnel requirements. Section 4.2, developed on the basis of guidance from the EPA, describes QA/QC for specific sampling and analytical aspects of field work: sample collection, sample analysis, and documentation. Section 4.3 addresses all other specific areas of field work for which well-defined QA/QC procedures are not generally developed, including QA/QC procedures for geologic logging, hydrogeology investigations, geophysical investigations, surveying of sampling locations, and management and storage of computer files. These procedures are considered by Argonne to be minimum requirements to assure that all data generated during the entire program are of the highest possible quality.

\subsection{Overarching Quality Assurance/Quality Control Provisions}

The QuickSite ${ }^{\circledR}$ process relies on the interaction of a number of different disciplines to characterize a contaminated site completely and accurately. Hence, all of the geologic, hydrogeologic, geochemical, and geophysical data available in the field are acquired, interpreted, and integrated on the site. Discrepancies between geophysical results, well logs, pump tests, analytical results, or electronic cone penetrometer (ECPT) soundings must be resolved in the field to ensure maximum confidence in the final results. All investigation team members must communicate in a constructive and mutually reinforcing manner to arrive at the most scientifically defensible interpretation. Final interpretation of all results is made by the project manager. 


\subsubsection{Data Quality Objectives}

The QuickSite ${ }^{\circledR}$ process was developed at Argonne to decrease the cost and time of the remedial investigation/feasibility study (RI/FS) while producing a high-quality technical investigation. The process is designed to characterize a contaminant plume's configuration and movement. Doing so requires an understanding of the geologic and hydrogeologic controls on groundwater movement, as well as of the nature and extent of any remaining source of carbon tetrachloride or chloroform in soils. The QuickSite ${ }^{\circledR}$ program uses a multidisciplinary technical approach that incorporates geology, geochemistry, hydrogeology, and geophysics. The field activities include sampling, analysis, and borehole and surface geophysical surveys. This work is typically separated into two phases. Phase II activities are dependent on the results of Phase I. Therefore, a careful review is required before Phase II begins to evaluate the project's QA/QC needs. Because a QuickSite ${ }^{\circledR}$ investigation is designed to meet all the requirements of an RI/FS, the data quality objectives must meet all requirements set forth in guidance from the EPA.

The results from the QuickSite ${ }^{\circledR}$ investigation may be used for risk assessment, to evaluate alternatives for remediation, or to provide data for the development of an engineering design. To meet these objectives, all of the data provided must be of a quality capable of supporting scientifically accurate and legally defensible decisions.

Chemical analytical data are generated at several different EPA-defined levels (Table 4.1). Groundwater samples are screened for parameters such as $\mathrm{pH}$, conductivity, and temperature by using field instruments (EPA Level I). Both soil and water samples are shipped to the Applied Geosciences and Environmental Management (AGEM) Laboratory at Argonne for rapidturnaround analysis for volatile organic compounds (VOCs) of interest, including carbon tetrachloride and chloroform, with a gas chromatograph-mass spectrometer (GC-MS) and modifications of EPA procedures (EPA Level V; Section 6.3). Chemical data generated at these two levels are used to develop and guide sample collection throughout the entire program. In addition, a minimum of $10 \%$ of the total number of soil and water samples collected are sent to a second analytical laboratory for verification analysis under the EPA's Contract Laboratory Program (CLP; EPA Level IV).

The EPA has assigned no data quality levels for the geophysical, geologic, and hydrogeologic investigations performed during the QuickSite ${ }^{\circledR}$ program. However, the quality of data generated by these activities is as important to the entire program as is the quality of the 
TABLE 4.1 Analytical levels appropriate to data uses. (Source: CDM 1987.)

\begin{tabular}{|c|c|c|c|c|}
\hline $\begin{array}{c}\text { Analytical } \\
\text { Level }\end{array}$ & Data Uses & Type of Analysis & Limitations & Data Quality \\
\hline 1 & $\begin{array}{l}\text { Site characterization } \\
\text { Monitoring during } \\
\text { implementation }\end{array}$ & $\begin{array}{l}\text { Total organic/ inorganic } \\
\text { vapor detection using } \\
\text { portable instruments } \\
\text { Field test kits }\end{array}$ & $\begin{array}{l}\text { Instruments respond } \\
\text { to naturally } \\
\text { occurring compounds }\end{array}$ & $\begin{array}{l}\text { With instruments } \\
\text { calibrated and } \\
\text { data interpreted } \\
\text { correctly, can } \\
\text { provide indication } \\
\text { of contamination }\end{array}$ \\
\hline II & $\begin{array}{l}\text { Site characterization } \\
\text { Evaluation of } \\
\text { alternatives } \\
\text { Engineering design } \\
\text { Monitoring during } \\
\text { implementation }\end{array}$ & $\begin{array}{l}\text { Variety of organics by } \\
\text { gas chromatography; } \\
\text { inorganics by atomic } \\
\text { absorption; x-ray } \\
\text { fluorescence } \\
\text { Tentative identification; } \\
\text { analyte-specific } \\
\text { Detection limits vary } \\
\text { from low parts per } \\
\text { million to low parts } \\
\text { per billion }\end{array}$ & $\begin{array}{l}\text { Tentative } \\
\text { identification } \\
\text { Techniques and } \\
\text { instruments limited } \\
\text { mostly to volatiles } \\
\text { and metals }\end{array}$ & $\begin{array}{l}\text { Depends on QA/QC } \\
\text { steps used } \\
\text { Data typically } \\
\text { reported in } \\
\text { concentration } \\
\text { ranges }\end{array}$ \\
\hline III & $\begin{array}{l}\text { Risk assessment } \\
\text { Determination of } \\
\text { potentially } \\
\text { responsible parties } \\
\text { Site characterization } \\
\text { Evaluation of } \\
\text { alternatives } \\
\text { Engineering design } \\
\text { Monitoring during } \\
\text { implementation }\end{array}$ & $\begin{array}{l}\text { Organics and inorganics } \\
\text { with EPA procedures } \\
\text { other than CLP can be } \\
\text { analyte specific } \\
\text { RCRA characteristic } \\
\text { tests }\end{array}$ & $\begin{array}{l}\text { Tentative } \\
\text { identification in } \\
\text { some cases }\end{array}$ & $\begin{array}{l}\text { Detection limits } \\
\text { similar to CLP } \\
\text { Less rigorous } \\
\text { QA/ QC than CLP } \\
\text { Can provide data of } \\
\text { same quality as } \\
\text { Level IV }\end{array}$ \\
\hline IV & $\begin{array}{l}\text { Risk assessment } \\
\text { Determination of } \\
\text { potentially } \\
\text { responsible parties } \\
\text { Evaluation of } \\
\text { alternatives } \\
\text { Engineering design }\end{array}$ & $\begin{array}{l}\text { HSL (Hazardous Substance } \\
\text { List) organics and } \\
\text { inorganics by gas } \\
\text { chromatography-mass } \\
\text { spectrometry; atomic } \\
\text { absorption; inductively } \\
\text { coupled plasma } \\
\text { Detection limits in low } \\
\text { parts per billion }\end{array}$ & $\begin{array}{l}\text { Tentative } \\
\text { identification of non- } \\
\text { HSL parameters } \\
\text { Sometimes required } \\
\text { for validation of } \\
\text { packages }\end{array}$ & $\begin{array}{l}\text { Goal is data of } \\
\text { known quality } \\
\text { Rigorous QA/QC }\end{array}$ \\
\hline V & $\begin{array}{l}\text { Risk assessment } \\
\text { Determination of } \\
\text { potentially } \\
\text { responsible parties } \\
\text { Engineering design }\end{array}$ & $\begin{array}{l}\text { Nonconventional } \\
\text { parameters } \\
\text { Method-specific detection } \\
\text { limits } \\
\text { Modifications of existing } \\
\text { methods } \\
\text { Appendix B (CDM 1987) } \\
\text { parameters }\end{array}$ & $\begin{array}{l}\text { Might require method } \\
\text { development or } \\
\text { modification } \\
\text { Mechanism to obtain } \\
\text { services requires } \\
\text { special lead time }\end{array}$ & Method-specific ${ }^{a}$ \\
\hline
\end{tabular}

a As a performance-based quality standard, the AGEM Laboratory demonstrates that its modifications of Level III and Level IV methods meet or exceed the quality standards of the unmodified methods. 
chemical data. Only with a complete, accurate understanding of existing conditions at a site can effective remedial alternatives be evaluated or designed and risk assessments developed. Therefore, the third portion of this $\mathrm{QA} / \mathrm{QC}$ plan describes quality controls and checks imposed on the geophysical, geologic, and hydrogeologic activities to ensure that all data generated during the QuickSite ${ }^{\circledR}$ process meet the data quality objectives.

\subsubsection{Data Usage}

All of the data generated during the field activities are carefully integrated to provide a complete and accurate picture of the conditions at a site. These data are ultimately used to support decisions about potential remedial actions. The chemical analytical data obtained from the sampling events are used to define the general water quality underlying the site and to establish the extent of contamination by VOCs in both soil and groundwater.

Information about the underlying geologic conditions at the site is gathered throughout the entire program. Existing information from well logs and previous geologic investigations shapes the initial hypotheses on major geologic features to be investigated. During the investigation, data for evaluating the local geologic and hydrogeologic conditions are collected through a geologic investigation using both drilling techniques and the ECPT.

Geophysical investigations provide additional and confirmatory details about local geologic and hydrogeologic conditions. Such data aid in formulation of an integrated geologichydrogeologic picture of the site that supports decisions about sample collection and well placement.

The coordinates of each sample location are surveyed to provide the most accurate picture of subsurface geologic controls and contaminant distribution. Surveying the locations of geophysical investigations and existing wells is necessary to verify and support geologic interpretations. Data such as the elevations and locations of pumping wells provide additional information about the local hydrogeologic conditions.

Integration of all of these data provides necessary information about the nature, location, and extent of the contaminant plume and subsurface conditions controlling contaminant migration. Only when the results of all the field activities are properly evaluated and integrated are recommendations made for remediation of contamination. 


\subsubsection{Project Organization and Responsibility}

The following responsibilities are identified in QuickSite ${ }^{\circledR}$ investigations:

- Project Manager

An Argonne senior staff member serves as the principal contractor and manager for all on-site activities. This person must have extensive training and experience in geology, geophysics, sampling, and analytical procedures and protocols. This person is responsible for ensuring that QA/QC requirements are met for all disciplines.

- $\quad$ Project $Q A / Q C$ Coordinator

An Argonne staff member serves as the principal QA/QC coordinator for on-site activities. This person is also responsible for analytical data reduction and assists team members in interpretation of analytical results reported in data packages.

- Project Health and Safety Coordinator

The field work planned for any given CCC/USDA site may involve multiple and diverse technical teams (e.g., geophysics, sample collection, geology, surveying). An Argonne staff member with the proper OSHA and industrial hygiene training serves as the principal project HSC for on-site activities.

\subsection{Quality Assurance/Quality Control for Sampling and Analysis}

Quality in sampling and analysis is assured through documentation of activities, performance audits, system audits, and periodic evaluations of QC procedures. The project QA/QC requirements can be satisfied through periodic and final reviews covering all aspects of sampling, field measurements, chemical analyses, data collection, data reporting, periodic instrument calibrations, routine maintenance of analytical equipment, calibration of analytical instruments, and standardization procedures in analyses. In addition, technical review of the results ensures that the stated objectives of the project are met. 
The identification, cause, and corrective action for conditions significantly adverse to quality are to be documented and reported to the project manager and QA/QC coordinator. Examples of conditions that are adverse to the intent of faithful implementation of QA/QC procedures are deficiencies in the use of procedures or instructions, failure to implement corrective actions in response to a nonconformance report, and unexpected loss of or damage to documentation. Corrective action is to be implemented in a timely manner. Actions taken to correct problems or deficiencies in the field (during sampling) and in laboratory analyses are to be documented and described in the QA portion of the sampling and analysis report.

\subsubsection{Field Quality Assurance/Quality Control}

\subsubsection{Sample Collection}

Two criteria that must be met in sampling are (1) that the samples must be a genuine representation of the conditions prevalent at the site and (2) that adequate numbers of samples must be available for a meaningful characterization of the site, in the judgment of the project manager. In some cases, it might not be possible to collect samples from an intended location because of constraints in obtaining access. In such cases, alternate or additional samples may be collected, as appropriate, from more easily accessible areas without compromising the original objectives of the work. To contain costs, some samples collected in the sampling activity might not be analyzed. However, no fewer than $90 \%$ of the samples submitted for analysis are to be analyzed. If original samples submitted for analysis are accidentally lost, backup samples (if available) may serve as substitutes.

\subsubsection{Field Instrument Calibration Procedures}

The project manager, in conjunction with team members, ensures that instruments used for field measurements are properly calibrated, reliable, and in proper working order. The typical field measurements are temperature, $\mathrm{pH}$, and electrical conductivity determinations of water samples. Calibration information documented in the sample logbook for each instrument includes the instrument's name and model or serial number, the date of calibration and calibration method, and the signature of the person performing the calibration. The logbook is to contain dated, signed entries for all field measurements. 


\subsubsection{Field Blanks, Field Rinsates, Field Replicates, and Trip Blanks}

Quality control samples collected as part of the field sampling activity include field blanks, field rinsates, field replicates, and trip blanks. The first two types are samples of waters used for decontamination of field equipment. Field replicates provide a measure of consistency in both sampling and analytical methodologies. Trip blanks are included in shipments of samples for VOC analysis to demonstrate that contamination of samples has not occurred during shipment. The nature and frequency of these types of samples are as follows:

\section{- Field Blanks}

A field blank is collected as a sample of the water used in the field for the decontamination procedure described in Section 3.9.2. This water is obtained from an uncontaminated source in the field or is transported to the field expressly for decontamination and other sampling activities. Blanks of other materials that might affect sample integrity are also collected as necessary. Field blanks are analyzed for VOCs.

\section{- Rinsates}

Some equipment (e.g., sampling bailers) is used repeatedly in sampling activities. It is essential to decontaminate this equipment after each use to assure that repeated use does not result in cross-contamination of samples. A rinsate sample consists of water rinsed over a piece of sampling equipment after it has been cleaned and decontaminated. Rinsate samples are collected with a frequency of one sample per 20 pieces of equipment cleaned, with a minimum of one sample per cleaning session. All rinsate samples are analyzed for VOCs.

\section{- Trip Blanks}

Trip blanks are prepared at the AGEM Laboratory or in another suitable uncontaminated area. The blank sample is shipped to the laboratory along with the field samples for VOC analysis. The recommended frequency for trip blanks is one per ice chest shipped. Trip blanks are analyzed only for VOCs.

\section{- Field Replicates/Split Samples}

Field replicates of soil, water, and vegetation samples are used to verify consistency in the sampling methodology and the reproducibility of the 
analytical results. The frequency is one for every 10 samples collected. All field replicates collected are analyzed.

\subsubsection{Laboratory Quality Assurance/Quality Control}

\subsubsection{Laboratory Duplicates}

Section 4.2.1.3 describes the collection of field replicate samples during sampling activities. The field replicates serve, in part, to verify the reproducibility of the analytical results. As a further verification of analytical reproducibility, the analytical laboratory selects some samples for duplicate analysis.

\subsubsection{Volatile Organic Analysis}

Samples collected for VOC analyses are shipped to the AGEM Laboratory for immediate analysis with a GC-MS and modified EPA procedures (described in detail in Section 6.3). Analysis of the samples is prioritized in consultation with the project manager, so that the results can be used to optimize decision making in the field. Water samples are analyzed by using modifications of EPA Methods 5030B and 8260B (purge-and-trap method by GC-MS). Soil samples are analyzed by using a modification of EPA Method 8260B (Level V). Vegetation samples are analyzed with a modification of EPA Method 5021 (headspace analysis by GC with electron capture detection [GC-ECD]).

In reviewing the analytical results, QA/QC procedures are verified in these laboratoryrelated areas: chain-of-custody records for samples, storage of samples, storage of sample extracts, holding times before analyses, calibration and maintenance of analytical instruments, performance standards of the instruments (reproducibility, standards, spike recoveries, etc.), and logbooks. The verification involves thorough evaluation of laboratory practices and procedures, audits of logbooks, and review of data packages (both original and reduced forms of data) by the project QA/QC coordinator. The results of this evaluation, in keeping with EPA guidelines (EPA 1994), are presented in the QA portion of the sampling and analysis report.

A minimum of $10 \%$ of all water and soil samples collected at a site are to be shipped to an EPA-certified laboratory for a second analysis to verify the results obtained by the AGEM 
Laboratory. Samples are selected for verification analysis on the basis of the AGEM Laboratory's results. The selected samples are to have a wide range of carbon tetrachloride values (from below the detection limit to high concentrations) to allow comparison of the analytical methods over the range of concentrations found. In addition, groundwater samples that support the final delineation of the plume are to be submitted for verification analysis by the second laboratory. Water samples are analyzed by the second laboratory according to the EPA CLP SOW 2/88 (EPA 1989b). Soil samples are analyzed by using EPA Method 8260B, Revision 4, January 1998, as referenced in the EPA's SW 846 (EPA 1998b). Each sample subjected to verification analysis by the second laboratory is to be accompanied by complete CLP documentation.

\subsubsection{Other Analyses}

Selected samples might be subjected to other analyses (unrelated to site contamination) to aid in development of the site hydrogeologic model. Groundwater samples might be selected for inorganic or tritium analysis to aid in characterization of groundwater geochemistry. Soil samples might be selected for analysis of physical parameters such as particle size, bulk density, or percent moisture. These analyses are conducted by certified laboratories with accepted procedures. The analytical methodologies used and results of a review of QC procedures for these analyses are presented in the sampling and analysis report as necessary.

\subsubsection{Quality Assurance Records}

Records that document quality must be assembled and maintained. Records are to be legible, identifiable, and retrievable and must be protected against damage, deterioration, or loss. Such QA records pertain to all activities related to the sampling and analysis work at the CCC/USDA sites. The QA records include soil boring logs, well completion logs, daily logbook entries, sample logbooks, sample labels, and chain-of-custody records.

\subsubsection{Field Notes}

All field notes relating to the collection of samples are to be recorded in permanent ink in a bound, numbered notebook. Notes provide information on the sampling conditions and sample handling and collection methods. The sample identification number, the date and time of sampling, the place of collection (with a simple hand-drawn location map), the weather conditions at the time 
of sampling, and any measurements made by field monitoring equipment are the minimal data recorded. Each entry is to be signed by the sampler. See Appendix D, Section D.1.3, for more information.

\subsubsection{Labels}

A sample label is affixed to each sample container to identify the sample. Sample labels are discussed in Appendix D, Section D.1.4.

\subsubsection{Chain-of-Custody Records}

A chain-of-custody record is maintained to track the possession of the samples from the time of collection to the time of delivery to the analytical laboratory. The chain-of-custody record is discussed in Appendix D, Section D.1.5.

\subsubsection{Analytical Data Reduction, Validation, and Reporting}

\subsubsection{Data Reduction}

All notebooks, logbooks, and related records (for both sample collection and sample analysis) completed during the conduct of the individual tasks are submitted to the QA/QC coordinator for storage with the project files. The analytical results, with all pertinent information about sample locations and sampling conditions, are entered into a computer file for integration with other activities and presentation in the final report.

\subsubsection{Data Validation}

If QC limits are exceeded by the analytical laboratory, all data from the associated batch of samples must be thoroughly scrutinized. If no analytical problems are found, the data and out-ofcontrol point are discussed in the QC section of the site-specific report. If problems with the analytical data are found, the samples associated with the batch are to be reanalyzed, and the data from the reanalysis are reported. If holding times defined in the procedure for the reanalysis are exceeded, both sets of data are to be reported. 
In the final report, all sample data are presented along with detection limits and concentrations found.

\subsubsection{Data Reporting}

For all analyses, the laboratory report is to show, at a minimum, traceability to the sample analyzed. The report is to contain the following information:

- Project identification

- Field sample number

- Laboratory sample number

- Sample matrix description

- Date of sample collection

- Date of sample receipt at the laboratory

- Analytical method description

- Individual parameter results

- Date of analysis (extraction, first runs, and subsequent runs)

- Quantitation limits achieved

- Dilution of concentration factors

- Corresponding QC report (to include method blanks, blanks/spikes, and continuing calibrations)

- Raw chromatogram data 
- Chain-of-custody form

- Case narrative (where appropriate)

\subsection{Quality Assurance/Quality Control for Other Field Activities}

\subsubsection{Quality Assurance/Quality Control for the Geology Investigation}

The approach to maintaining quality in defining the local geologic and hydrogeologic conditions at a site is described here. The discussion includes the review of existing data, on-site drilling, and ECPT investigation. Primary responsibility for QA/QC in the geology investigation rests with the project manager.

\subsubsection{Review of Existing Data}

Available geologic logs for all wells, borings, and test holes within the immediate area of the CCC/USDA site (within at least a one-mile radius) are studied. These geologic logs normally include detailed state geological survey data and less detailed drillers' descriptions of formations. From these data, marker stratigraphic units are identified and geologic cross sections drawn. From the geologic logs and cross sections, an initial stratigraphic and hydrostratigraphic understanding of the area is interpreted by trained, experienced geologists.

\subsubsection{Drilling and Electronic Cone Penetrometer Investigations}

The initial (Phase I) field investigation focuses on confirming or modifying hypotheses about the stratigraphic sequence, as well as identifying the water-bearing units. The information is gathered by drilling a continuous core hole at or near the former CCC/USDA grain storage facility. The core is initially logged in detail by at least two Argonne geologists. The log records include all the information identified in Section 4.3.1.3. The geologic logs are recorded daily and then turned over to the senior geologist for confirmation and evaluation against the existing data. The core is retained for the duration of the field activity. If the core needs to be retained longer, it is placed in core boxes for further examination and testing and is properly catalogued. 
Aside from the drilling program, the ECPT is used to collect additional data and information. Maintenance and calibration of all ECPT equipment is to be in conformance with the standard operating procedure for the specific equipment used. Calibration of the ECPT is to be performed when field work begins for each site. In addition, recalibration of the system is required if any extremes in temperature occur, as well as at the end of the field program. The ECPT cone is calibrated by using National Institute of Standards and Technology standards, and a log is kept of each calibration. The geologic log and drill hole serve as the control for interpreting both geophysical logs and ECPT physical measurements and probe sensor data through comparison of the results with the known geologic stratigraphy. The geologic log is the initial control for geophysical and ECPT logs, which might provide more detail on individual stratigraphic horizons than do the logs of visible geology. The additional data in geophysical and ECPT logs are particularly important with respect to variations in clay, silt, and sand contents within a stratigraphic unit. Incorporation of all logging results into the known geologic control establishes the geologic and hydrostratigraphic sequence for subsequent investigations at a site.

During the subsurface sampling activity of each investigation, additional core drilling might be carried out where subsurface confirmation of the stratigraphic sequence is required. Downhole geophysical logging of the drill hole is also performed when possible. At some drill hole sites, an ECPT boring is completed to compare downhole ECPT responses with the core and geophysical logging data. Variations in the details of the sequence are highlighted, and new geologic cross sections are drawn showing any lateral or vertical changes. On average, five or six core holes are drilled to collect soil and groundwater samples at depths beyond the capabilities of other subsurface sampling equipment. Electronic logging is typically performed adjacent to these core holes. An ECPT boring is to be completed at a minimum of two of the core hole sites. The data generated during the ECPT work are sent to a data acquisition system on the ECPT truck for processing and storage. Hard copies and computer backups of the data for each location are provided to the site geologist.

In the areas between core holes, surface geophysical measurements, if technically appropriate, are made to demonstrate the continuities and discontinuities of the major stratigraphic boundaries or units. In addition, where the ECPT is used to collect subsurface samples, both physical and geophysical probe sensors may be used to refine the descriptions of geologic units. At all of the sample sites, however, total thrust pressures are recorded and used in an attempt to identify major stratigraphic boundaries and units. 


\subsubsection{Soil Boring Logs}

Soil and rock materials encountered during drilling activities are recorded at the time of drilling by a qualified geologist. Soils are classified by using the modified Wentworth-Udden grain size scale and Burmeister's descriptive terms for soil, combined with regular sampling of sandy materials for grain-size analysis. All necessary information is recorded on the boring $\operatorname{logs}$. Standard borehole log forms are used. Details are in Section 6.4.1.5.

\subsubsection{Quality Assurance for the Hydrogeology Investigation}

This section addresses all hydrogeologic operations involved in a QuickSite ${ }^{\circledR}$ investigation, including construction of monitoring or aquifer pumping wells, water level monitoring, and in situ aquifer testing. The quality objective of the hydrogeology program is to design and conduct effective and appropriate hydrogeologic measurements. Primary responsibility for QA in the hydrogeology investigation rests with the project manager.

\subsubsection{Selection of Subcontractors and Instrumentation}

Before field operations begin, the project manager defines the nature and extent of hydrogeologic data required to satisfy the site characterization objectives.

To participate in the hydrogeology investigation, the project manager identifies subcontractors having verifiable records demonstrating reliability and appropriate expertise in their disciplines.

All drilling subcontractors must be licensed by the relevant state to drill and install monitoring and drinking water wells. The project manager verifies that all necessary drilling permits and licenses are obtained before field work begins.

The project manager identifies the equipment needed to meet the objectives of the sitespecific work plan and is responsible for proper preparations before the field operations begin, including details about the equipment, the prescribed calibration procedures to be followed in the field, and procedures for contacting the equipment manufacturer in case problems arise in the field. 


\subsubsection{Data Acquisition}

During the field operations, the quality of the data acquired is assured by rigorous monitoring of the selection of locations to be surveyed, the calibration of instruments and equipment, and the recording of data.

\section{Selection of Locations}

The project manager, in conjunction with the site hydrogeologist and the site geologist, selects locations for investigation that will provide information useful for the overall program. The project manager ensures that these locations are correctly identified and flagged for coordinates surveying, that the surveyors are made aware of all hydrogeologic investigation locations to be surveyed, that these locations are recorded, and that the data are transmitted to the appropriate computer personnel.

\section{Calibration of Instruments and Equipment}

The site hydrogeologist ensures that each instrument is maintained within the calibration limits specified by the manufacturer. The water level measuring, pressure sensing, and data recording devices employed for QuickSite ${ }^{\circledR}$ investigations cannot be calibrated in the field; special equipment available only to the instrument manufacturer is required. The project manager, in conjunction with the site hydrogeologist, therefore must ensure that instrument checks, as outlined in Appendix E, Section E.1, are performed in the field to verify that all instruments are in proper working order at the time of use. The hydrogeologist is to record the date, time, and results of the instrument checks.

\section{Recording of Data}

The project manager, in coordination with the site hydrogeologist, ensures that data are collected according to the standard operating procedures described in this Master Work Plan. The hydrogeologist records the date and time at which field data are acquired, the model number and serial number of the equipment used to collect the data, and the personnel operating the equipment. The hydrogeologist further certifies that the standard operating procedure for the particular method 
used was followed. Variances from the standard operating procedure are to be noted and explained.

Water level records are accompanied by all necessary supporting data. The supporting data include the following:

- Project identification

- Monitoring point identification

- Time of measurement

- Date of measurement

- Type of measurement or test

- Description of reference datum

- Recorder's name

- Weather conditions at the site

\subsubsection{Well Construction}

The project manager ensures that well construction is completed in accordance with state and federal requirements, as described in detail in Section 6.4.

\subsubsection{In Situ Aquifer Testing}

The project manager, in conjunction with the site hydrogeologist, identifies the most appropriate aquifer tests for achieving the investigation's objectives and on this basis determines equipment and logistic requirements. Information on hydrogeologic testing is in Section 6.7. 


\subsubsection{Quality Assurance for the Geophysics Investigation}

This section addresses all geophysics operations involved in the QuickSite ${ }^{\circledR}$ investigation, including seismic, electromagnetic, and borehole geophysical surveys. The quality objective of the geophysics program is to acquire, process, and interpret geophysical data that are scientifically valid and are meaningful to the interpretation of the geologic and hydrogeologic features of the site. The primary responsibility for QA in geophysics operations rests with the project manager. The site geologist is responsible for reviewing the interpreted geophysics results in a timely manner and reporting inconsistencies between the geophysical data and geologic/hydrogeologic data derived from other sources, such as well logs and ECPT readings.

\subsubsection{Selection of Methods and Equipment}

Before field operations begin, the project manager, in conjunction with the site geophysicist, determines which geophysical methods are most appropriate for the site. The site geophysicist is responsible for mapping physical properties that will produce information germane to the overall goals of the investigation, as defined by the project manager. When appropriate techniques have been selected, the project manager and the geophysicist develop a plan for field activities to be integrated with other operations.

The project manager, in conjunction with the site geophysicist, identifies the equipment needed to meet the objectives of the site-specific work plan and ensures that the necessary equipment is tested for proper operation before field work begins. The geophysicist records the model number and serial number of each piece of equipment, the prescribed calibration procedures to be followed in the field, and procedures for contacting the equipment manufacturer in case problems arise in the field.

\subsubsection{Data Acquisition}

During field operations, the quality of the data acquired is assured by rigorous monitoring of the selection of locations to be surveyed, the calibration of instruments and equipment, and the recording of data. 


\section{Selection of Locations}

The project manager, in conjunction with the site geophysicist and the site geologist, selects locations for geophysical surveys that will provide information useful for the overall investigation. The project manager ensures that these locations are correctly identified and flagged for coordinates surveying, that the surveyors are made aware of all geophysical investigation locations to be surveyed, that these locations recorded, and that the survey information is transmitted to the appropriate computer personnel.

\section{Calibration of Instruments and Equipment}

The site geophysicist ensures that all instruments are maintained within field calibration, according to the specifications provided by the equipment manufacturer, on the schedule given in the standard operating procedure for that instrument (see Section 6.6). The geophysicist records the date and time at which each instrument is calibrated, the instrument's model number and serial number, and the calibration method. Any variance from the standard operating procedure, either in the scheduling or method of calibration, is also recorded.

\section{Recording of Data}

The project manager, in conjunction with the site geophysicist, ensures that data are collected according to the standard operating procedure established for each survey method. The geophysicist records the date and time at which field data are acquired, the model number and serial number of the equipment used to collect the data, and the personnel operating the equipment and certifies that the standard operating procedure for the particular method used was followed. Variances from the standard operating procedure are noted and explained. 


\subsubsection{Data Processing}

\section{Validation of Processing Software}

The site geophysicist ensures, through the use of standard benchmarks, that the software to be used for processing geophysical data is operating properly and certifies the validation of the processing software before data processing begins.

\section{Selection of Processing Steps}

The site geophysicist is responsible for selecting the steps to be used in processing geophysical data. Any variances from the standard operating procedure for a given geophysical method are to be recorded and justified. The site geophysicist is also responsible for ensuring that geophysical data are processed according to the specified procedures.

\subsubsection{Data Interpretation}

The geophysical data are interpreted by the site geophysicist, in consultation with the project manager and other team members. The project manager, in conjunction with the site, is responsible for ensuring the scientific validity of the final results and for quantifying the error associated with the geophysical data. The geophysicist records the initial interpretations of geophysical data, any reprocessing performed to refine the interpretations further, and the final interpretations.

\subsubsection{Quality Assurance of Spatial Control Procedures}

Spatial control is maintained by integrating in-house resources and professional coordinates survey data. The horizontal and vertical surface locations of data collection and other significant points are determined through a survey by a registered surveyor. The horizontal survey is tied to recognized reference points in the state plane or to another coordinate system appropriate to the study region. Elevations are derived from recognized benchmarks and reported in feet above mean sea level. 
Argonne cartographers use feature coordinates to tie base maps created for field use into the formal grid system. These maps, based on U.S. Geological Survey 1:24,000 quadrangle maps, aerial photographs, and other available resources, are computer drawn by using equipment described in Section 6.8. Computerized field maps showing activity locations and analytical and interpretive data are updated throughout the field event. Target locations are marked in the field and temporarily referenced to landmarks by direct measure.

When characterization efforts are complete, the surveyor formally surveys locations targeted by Argonne personnel. Argonne personnel normally visit each location with a representative of the survey crew. The locations are otherwise to be described in sufficient detail for the surveyors to identify the positions easily. The surveyor is to deliver a list of target location coordinates identified by using the project's field notation system. The following items are also made available to provide a means of detecting gross errors in the coordinates list (such as misnaming of a location) through comparison with investigation maps, measures, and other field records:

- A scaled plot of surveyed points

- A base map marked with field-sketched approximate locations of all surveyed points

- A description of the approximate locations of surveyed points, consisting, where appropriate, of horizontal ties of sampling points to features on the base map

After the field effort, the coordinates of data collection points provided by the surveyor are reviewed and entered into a computer mapping system. The coordinates are layered by location type and used to create the desired plots.

The global positioning system (GPS) may be used as an alternative or adjunct to the conventional survey. If GPS is used, the project manager assigns responsibility for assuring that the equipment is maintained and operated properly to team members with a thorough understanding of the principles underlying GPS, who are familiar with the procedures used to determine positions in an appropriate coordinate system and have been trained and are experienced in the use of the instrumentation and equipment. The GPS surveys are to be calibrated to and compared with known points. The team members are to ensure that appropriate supporting software (e.g., baseline 
solution and datum transformation software) is used. Written logs detailing GPS activities are to be maintained and archived along with other field logs.

\subsubsection{Quality Assurance for Computer Records}

Computer records are computer files that contain either data acquired in the course of site characterization or the results of processing and interpreting these data. The primary quality objective with regard to computer records is to maintain the security and integrity of characterization data, from initial acquisition through final archival, while providing characterization team members with ready access to information contained in the computer records.

The project manager designates a site computer specialist who is responsible for verifying that computer records of field data are assembled and maintained according to the QA standards defined in this section. Each team member who is involved in acquiring computer-recorded field data is responsible for recording original computer records according to the procedures defined in Section 4.3.5.1 and for making these records available to the site computer specialist in the prescribed formats.

After field data have been verified by the site computer specialist, the members of the computer group are responsible for notifying that individual immediately of any problems that could compromise the quality of computer records.

\subsubsection{Field Data}

The following are requirements for field records that are generated, stored, or transferred in the form of computer files. This includes both data recorded directly by means of computer systems - such as geophysical well logs, seismic recordings, and electromagnetic soundings and data transferred to computer systems for analysis and/or storage — such as survey information, geologic well logs, processed geophysical data, and transcribed chemical analysis data. 


\section{Original Records}

The primary QA concern with regard to original field data is that accurate, secure copies of all data are preserved and that no data are lost or altered because of mishandling or computer system failure.

Any original records that are entered directly onto a computer hard disk or memory are to be backed up onto a removable storage medium, such as floppy or cartridge discs, tapes, or compact disks, and these copies are to be handled as original or master data files. If the original recording is made on a removable medium, these originals are to be considered to be master files, and all further processing of the data is to be done with working copies made from these master files.

\section{Transcribed Data}

Field data that are transcribed from written form into computer files, such as survey coordinates, analytical results, or geologic logs, are to be checked and verified for accuracy at the time of transcription by the site computer specialist. Following verification, a copy of the computer file is to be saved on a removable medium as a master file, together with copies of paper records from which the master files were transcribed. These master files are then handled in the same manner as original master data files.

\section{Master Data Files}

Master data files, defined as either original data recorded on transportable media or transcriptions of original data onto transportable media, are to be stored in a secure work or storage location that is separate from working copies of these files. Copies of original supporting paperwork, such as field notes, laboratory reports, observer reports, and paper logs, are to be maintained with the master data files, either in the form of duplicate paper copies or as digital images. Master data files are to be labeled in a manner that includes the site location.

If corrections are made to original paperwork that has been used to generate a master file, the team member initiating the change is responsible for informing the site computer specialist, who then verifies the correction of the original master file. 


\subsubsection{Data Processing}

To ensure that master data files are not altered or damaged, all processing of field data is performed by using duplicate copies of master files for input, not the master data files. Quality assurance of processed data consists of ensuring (1) that processing is conducted with approved methods for preserving data integrity throughout the processing sequence and (2) that processed data are quickly made available to technical team members for review and verification. The QA procedures are discussed below.

\section{Testing of Hardware and Software}

All hardware, software, and processing sequences to be used in processing field data are to be tested before field operations begin. Testing of any new system, program, or sequence of programs involves processing benchmark data sets and verifying that the new results are consistent with results obtained through established methods. If no comparable results have been produced previously, the new processing results are to be verified through review by the appropriate technical team members.

\section{Data Processing Standards}

Data are to be processed by technical or computer group personnel using benchmark-tested software and systems. Documentation of software used in processing is to be maintained and available for reference. The site computer specialist is responsible for keeping track of software and upgrades that meet quality standards and for providing documentation of software.

Field data are initially preprocessed into a common format that can be imported to processing, display, and database programs. This normally is a spreadsheet format, except in the case of certain surface geophysical data, for which industry-standard formats are specified. Data from these files are imported to analysis and display programs such as LogPlot and MapInfo to produce graphic displays of results in the field. Results are submitted to technical team members for validation. 
During all stages of data processing, records are to be backed up daily on a storage medium that is independent of the computer on which the processing takes place. This medium may be an external hard disk, a removable disk, a floppy disk or cartridge, or a tape.

\section{Review and Correction of Errors}

To minimize errors in processed field data, processing results are circulated for review by team members. Where possible, results are presented in graphic format to facilitate review and detection of errors. Maps are distributed showing the locations of field activities, such as soil borings, cone penetrometer sites, and water samples. Analytical results are normally in the form of listings, but values are also shown on maps and cross sections where possible. Subsurface geologic and hydrologic data are displayed in the form of well logs and cross sections. Surface geophysical data are displayed in map and/or cross-section form, as appropriate. These displays may be made from interim or temporary processing results, provided that all displays indicate the version and/or date of the processing file from which the display was generated.

Team members are responsible for notifying the site computer specialist immediately of any erroneous or inconsistent results in graphic displays. Corrections to master data files are to be documented and approved by the site computer specialist, according to the procedures in Section 4.3.5.1.

\subsubsection{Final Data Processing Results}

Whenever final results of data processing are reported in a form other than listings of raw field data, the computer files that generated these results are to be saved with appropriate labeling to indicate a final result. This includes files that generate graphic displays, database files, spreadsheet listings, and AutoCAD or MapInfo maps, for example.

\subsubsection{Quality Control Tracking}

At various stages in the acquisition, processing, and reporting sequence, data files are to be processed into database formats for compilation and display. Processing of data is to be coordinated by the site computer specialist to ensure that only accurate data are included. 


\subsubsection{Data Archival}

All master data files, files of final results, files of significant intermediate or auxiliary results, and copies of databases are to be archived in permanent storage, together with supporting paperwork and documents. Archival material is to be on a removable medium that is stored in addition to data saved on standard backup systems. 


\section{Community Relations Plan}

Argonne has developed this model community relations plan to provide overall guidance for facilities where a QuickSite ${ }^{\circledR}$ investigation is performed. The actual site-specific community relations plan for each community varies somewhat to accommodate issues or characteristics that are unique to that community.

\subsection{Model Community Relations Plan}

The community relations plan for each specific site consists of the following sections:

1. Site description

2. Community background

3. Community relations objectives

4. Timing of community relations activities

5. Contact list of key officials

\subsubsection{Site Description}

The site description section discusses the location of the community (with reference to a map) and the history of site use and ownership and provides a brief summary of events relating to the groundwater contamination and actions taken to date.

\subsubsection{Community Background}

The community background section includes a community profile, a history of community involvement, and key community concerns. 


\subsubsection{Community Relations Objectives}

The community relations objectives section of the community relations plan has six major objectives:

1. Explain the QuickSite ${ }^{\circledR}$ investigation plans of the CCC/USDA and provide general information about the program in order to gain community acceptance.

2. Inform the local community of the investigation's findings and developments.

3. Respond to citizen inquiries about site activities and the presence of health and/or environmental hazards.

4. Ensure that the public has appropriate opportunities for involvement in siterelated decisions.

5. Identify, on the basis of community interviews, appropriate activities that will ensure such public involvement.

6. Provide appropriate opportunities for the community to learn about the site.

\subsubsection{Timing of Community Relations Activities}

The section about timing of community relations activities identifies the numerous activities needed to meet the objectives of the community relations plan. Many of these activities need to take place before field work begins. The QuickSite ${ }^{\circledR}$ investigation milestones and planned community relations activities are discussed below. 


\subsubsection{Activities before Field Work Begins}

The CCC/USDA and Argonne provide for the conduct of the following community relations activities, to the extent practicable, before field work begins:

- A point of contact is designated for Argonne. The individual is Argonne's liaison with the community regarding implementation of the community relations plan.

- Upon obtaining approval from the CCC/USDA to do so, Argonne makes initial contact with leaders of the community government to explain proposed QuickSite ${ }^{\circledR}$ activities and schedules.

- Argonne, in coordination with community leaders, makes arrangements to conduct discussions (by telephone and in person) with local officials, residents, public interest groups, or other interested or affected parties, as appropriate, to determine their concerns and information needs and to learn how and when citizens would like to be involved in the QuickSite ${ }^{\circledR}$ process. This activity can accomplish the following specific tasks:

- Develop a list of names, addresses, and telephone numbers of local officials, interested citizens, and any local news media.

- Identify an information repository, as agreed by community leaders.

- Identify wells near the site that could be used for sampling.

- Discuss access issues.

- Learn of any physical or legal constraints or barriers to investigation plans.

- Upon completion and approval of the formal, site-specific work plan, Argonne requests the assistance of local community leaders in arranging a meeting or meetings between appropriate CCC/USDA, Argonne, and community officials; interested citizens; and any local news media. State and EPA officials should 
also be invited. The purpose of the meeting(s) is for the CCC/USDA and Argonne to accomplish the following:

- Describe the site location and problem.

- Explain why action is required (legal, health, other issues).

- Explain what the CCC/USDA and Argonne hope to accomplish through the investigation.

- Describe the site-specific work plan and its schedule in detail, including staff, contractors, and equipment to be on the site.

- Introduce key staff people, including points of contact (telephone numbers and addresses).

- Present the CCC/USDA-Argonne communications plan to be followed during all phases of the investigation.

- Seek input and answer questions from the community regarding the investigation and the communications plan.

- Discuss any access issues/problems that might need to be addressed.

- Announce the location of the information repository.

- Update the list of names, telephone numbers, and addresses of public officials, interested citizens, and any local news media. This list can be used to distribute information at various phases of the QuickSite ${ }^{\circledR}$ investigation.

- Argonne makes every effort to ensure that individuals living just outside community boundaries are provided with information about the investigation. 
- Argonne establishes an information repository and an administrative record file. The repository is to be available for public inspection and copying and includes the following:

- The contact list of key officials (names, telephone numbers, and addresses of the CCC/USDA and Argonne officials), other federal officials, state and local leaders, and interested groups and citizens.

- Copies of the community relations plan, all applicable correspondence, fact sheets, the site-specific work plan, investigation results, guidance documents, and any other relevant information.

\subsubsection{Activities during the Field Work}

The CCC/USDA and Argonne provide for the conduct of the following community relations activities, to the extent practicable, during field work:

- Arrange for meetings with public officials and interested citizens when needed.

- Continue to update the information repository and the contact list.

- Prepare and distribute fact sheets or letters to inform the community of the investigation's progress, significant milestones, and changes in plans.

- Maintain telephone contact with state and local officials, as well as any interested residents. 


\subsubsection{Activities upon Completion of the Investigation}

The CCC/USDA and Argonne provide for the conduct of the following community relations activities, to the extent practicable, upon completion of the investigation:

- Arrange for meetings with public officials and interested citizens to discuss the investigation's findings, results, and recommendations, along with any future activities at the site.

- $\quad$ Prepare and distribute information outlining QuickSite ${ }^{\circledR}$ results and any future activities at the site.

- Conduct information sessions with citizens and/or key community leaders.

\subsubsection{Contact List of Key Officials}

The contact list of key officials includes federal, state, and local officials; interest groups; media representatives; interested citizens; individuals living or working near the site; and principals of nearby schools.

\subsection{Point of Contact}

Argonne designates a point of contact to coordinate community relations activities. The point of contact performs only tasks that are approved in advance by the CCC/USDA and the Argonne project manager. The point of contact is responsible for ensuring that the community relations plan is carried out and for answering questions from the public about QuickSite ${ }^{\circledR}$ activities. When appropriate, the point of contact refers questions to the CCC/USDA.

The point of contact does the following:

- Takes responsibility for accomplishing community relations objectives and coordinating community relations activities as outlined in this document. 
- Initiates, before field work begins, introductory communications by telephone and in person with key community officials, involved community groups, and affected residents.

- Documents, during all phases of the investigation, all communications involved in the community relations program, including meetings, telephone calls, and correspondence.

- Takes responsibility for establishing an information repository and for informing the public of its existence and location. The administrative record file is also to be located with the information repository.

- Coordinates the preparation of fact sheets and other community relations materials to be presented to the public.

- Ensures that all Argonne employees and contractors are aware of the procedures outlined in the community relations plan. 


\section{General Technical Program}

This section describes the procedures used in the QuickSite ${ }^{\circledR}$ technical program, specifically sample collection (Section 6.1), sample preservation and handling (Section 6.2), and analytical methods (Section 6.3) for soil, water, and vegetation samples; drilling operations and monitoring well installation (Section 6.4); electronic cone penetrometer operations (Section 6.5); geophysical methods (Section 6.6); computer data analysis (Section 6.7); and hydrologic testing (Section 6.8).

\subsection{Sampling Methods}

Site-specific work plans contain details about sampling media, modes, intervals, and frequencies for specific sampling events. Section 6.1 describes the techniques generally used to acquire soil, water, and vegetation samples. Regardless of the recovery method used or the matrix sampled, the labeling, documentation, and QC procedures in Appendix D and Section 4.2.1 apply. Use the container types and preservation methods specified in Section 6.2. After sample collection, wipe containers clean or dry, seal them in plastic bags, and hold and ship them as described in Section 6.2. Prevent cross-contamination by using sampling gloves and clean equipment. Procedures for decontamination of sampling equipment are in Section 3.9. Dispose of waste material generated during sampling as indicated in Section 6.1.5.

\subsubsection{Soil Sampling for Chemical or Geotechnical Analysis}

Various methods are used to recover soil samples for geotechnical and chemical analyses. The principal drilling configuration consists of a hollow-stem auger used to reach depth and a solid-core barrel or split-spoon sampler to acquire core. The principal push configuration consists of a Geoprobe Macro-Core soil sampler that is pushed hydraulically with a cone penetrometer rig (Section 6.5) or a Geoprobe or similar hydraulic sampling unit. Push cores are normally sleeved in plastic. To recover near-surface soil, use hydraulic-push technology, a hand-driven coring device such as an $\mathrm{ESP}^{\mathrm{TM}}$ sampler, a hand-pushed coring device, or hand tools such as a shovel, as appropriate. Backfill or refill shallow holes with appropriate clean material. Abandon drill holes as described in Section 6.4.7. 


\subsubsection{Soil Sampling for Chemical Analysis}

Regardless of recovery method, immediately place soil samples collected for chemical analyses in jars, and place the jars on dry ice in an ice chest. If the core is loose in the sleeve, slide the target portion of the core directly into the jar. If the core is stuck to the sleeve, access the target material by cross-cutting or by slitting the plastic sleeve lengthwise. If necessary, place the core in a clean pan for immediate subsampling. If near-surface soil is accessed with a shovel or by similar means, scoop or spoon freshly exposed material directly into a jar. In all cases, the goal is to cryogenically lock volatiles into the sample as quickly as possible. Maintain cryogenic conditions until the samples are removed for analysis in the laboratory.

\subsubsection{Soil Sampling for Geotechnical Analysis}

Collect soil samples for geotechnical analysis by using a split barrel or a thin-walled tube sampler fitted with a Shelby tube, according to procedures in ASTM D1587-00 (available from the ASTM at the Internet location http://www.astm.org). Insert the tubes by push or drive methods, controlled to prevent compaction, and twist the tubes to shear the core before pulling up. If the analytical parameters include moisture, seal the ends of the sample in the tube with a nonpenetrating, nonshrinking wax. Fill the remaining void space with nonabsorbent material, and cap and label the tube. Physical samples for some geotechnical analyses (such as grain size) may be collected in labeled bags or jars.

\subsubsection{Groundwater Sampling for Chemical Analysis}

Collect groundwater samples from existing private or public wells, temporarily screened wells, monitoring wells, or pushed or bored holes by using existing pumps, introduced pumps, or bailers, as discussed below. Regardless of the way groundwater is recovered, follow the guidelines in Section 6.2 for placing the samples in containers and for preserving, holding, and shipping them. Samples for tritium analysis may be held and shipped at ambient temperatures above freezing. Hold all other groundwater samples at $4{ }^{\circ} \mathrm{C}$, and ship them at $4^{\circ} \mathrm{C}$ as soon as is feasible. Monitor conductivity, $\mathrm{pH}$, and temperature by using field meters. 


\subsubsection{Groundwater Sampling from an Existing Borehole}

In general, use a bailer to recover groundwater samples from an open or temporarily screened existing borehole. Use other means of recovery as the situation requires.

\subsubsection{Groundwater Sampling with a Drilling Rig}

A HydroPunch sampler can be used in conjunction with a hollow-stem auger to collect groundwater. In this method, drill a hole with an auger to within $1 \mathrm{ft}$ of the target depth, and drive the HydroPunch $1 \mathrm{ft}$ past the target depth. Pull up on the sampler to release the tip, exposing $1 \mathrm{ft}$ of screen. Allow the sampler to fill for about $1 \mathrm{hr}$. Remove the sampler from the hole and collect the sample.

\subsubsection{Groundwater Sampling with the Cone Penetrometer}

Use the ECPT (Section 6.5) to sample groundwater by pushing a tip-and-screen system to $3 \mathrm{ft}$ below the desired sampling depth. Pull back to release the tip and expose the screen. Monitor the water level until it becomes stable. Then proceed with sampling by using a clean string and bailer.

\subsubsection{Groundwater Sampling from Existing Wells}

\section{Non-Production Wells}

Before sampling, purge monitoring wells and other non-production wells of stagnant water. Use a Redi-Flow pump or a bailer to purge and sample. Ensure recovery of a representative sample by monitoring the purge volume and field parameters. Sample only after field parameters are stable (for $\mathrm{pH}, \pm 0.2$ units; for electrical conductivity, $\pm 5 \%$ ). The minimum purge volume is three well volumes. When purging is complete, decrease the pumping rate, and collect samples through a Teflon-lined sampling hose. Alternatively, recover sample from the purged well with a bailer. For wells of a size or condition not suited to a normal purging-sampling routine, discuss alternative procedures, as appropriate to data needs, with the project manager. 


\section{Active Private and Public Supply Wells}

Sample active private supply wells through the existing pump and plumbing system. Domestic wells are not constructed or plumbed for chemical sampling, and because in-use wells often cannot be accessed, well and water depths are often unknown. Analytical results for samples from such wells will not have the same meaning as those from monitoring wells or temporarily screened holes.

Sample domestic wells from a tap as near as possible to the wellhead and upstream from water treatment installations. Open the sampling point tap, and run the water at capacity for at least 5 min to activate the pump and flush the system between the pump and the sampling point. Monitor $\mathrm{pH}$ and conductivity during this time. Factors that affect purge times include owner concerns, distance between sampling point and well, amount of water in the pressure tank, specific knowledge about the well itself, and the stability of $\mathrm{pH}$ and conductivity values.

A similar approach is used in sampling active public wells. Use a spigot near the wellhead to collect a sample while the well the pump is in production mode, with water routed into the normal system. Special scheduling arrangements might be required.

\subsubsection{Surface Water Sampling for Chemical Analysis}

When practical, collect surface water by filling the sample vial directly from the source. Otherwise, transfer the sample into the vial with a scoop. Take care in either case to minimize aeration of samples for VOC analysis.

\subsubsection{Vegetation Sampling for Chemical Analysis}

Because trace carbon tetrachloride concentrations move through plants in transpiration water, vegetation sampling can help locate subsurface contaminants and can guide the selection of subsurface sampling locations. Various plant species and tissue types may be sampled when viable vegetation is available. Preferably, collect aerial portions of available grasses (often brome or foxtail). Pull or dig the grass up by the roots, knock the dirt off, remove dead material, and snip off the roots with pruning shears. Insert the cut aerial ends as a loose bunch into a prelabeled VOC analysis vial or jar; trim the vegetation to fit. Because of the very low contaminant concentrations 
within plants, cross-contamination is not a problem, and decontamination of the shears is unnecessary. Place the container immediately on dry ice in an ice chest. Maintain cryogenic conditions until the samples are removed for analysis in the laboratory.

\subsubsection{Disposal of Contaminated Materials}

Site investigations result in the generation of waste materials that potentially pose a risk to human health or the environment. These investigation-derived wastes can include drilling muds, soil cuttings, purge water, decontamination fluids, disposable sampling equipment, and personal protective equipment.

Collect all drilling spoils, trash, etc., and seal the material in 55-gal drums or in roll-offs at the drill site. Identify each container with the well or hole number. Consider the material hazardous until analyses are complete. Determine the appropriate disposal method on the basis of analytical results for investigative soil samples collected during drilling, analytical results for representative samples of containerized material, or both.

The water produced during well development and sampling is expected to total less than 1,000 gal. Management of aqueous investigation-derived wastes is to be protective of human health and the environment. The appropriate disposal option depends on site conditions and the volume of the waste and the level of contaminant present. Management options include the following:

- Discharge at the site of origin

- Place in containers for evaporation of low-concentration VOCs

- Place in containers for on-site treatment or disposal

- Place in containers for transport to a nearby publicly owned treatment facility 


\subsection{Sample Preservation and Handling}

Tables 6.1 and 6.2 present information about sample containers and preservatives for soil and water samples, respectively. Document control procedures are discussed in detail in Appendix D.

Use sampling containers that have been cleaned to EPA specifications. Hold and ship all water samples collected for chemical analysis at $4{ }^{\circ} \mathrm{C}$, except for tritium samples (for which there is no temperature requirement except that the sample should not freeze). Preserve water samples for total nitrate-nitrite analysis with sulfuric acid, $\mathrm{pH}<2$. Because calcareous solids react with acid, remove solids from the sample before acidification by placing the sample in a settling container. Wait for the water to become clear. Decant the clarified water into a sample bottle, and adjust the $\mathrm{pH}$. Attempts to adjust the $\mathrm{pH}$ of turbid water can result in the use of excessive acid (enough to affect results via dilution), foaming, container pressurization with consequent leakage, and a sample $\mathrm{pH}$ outside the preservation range.

Review the MSDSs (Appendix D) for sulfuric acid and dry ice before using these materials.

Prepare samples for shipment as follows:

1. Place the containers constituting each individual sample in a plastic bag. Place the samples in a sturdy ice chest lined with a plastic trash bag.

TABLE 6.1 Container type, sample size per aliquot, and preservation parameters for soil samples.

\begin{tabular}{|c|c|c|c|}
\hline $\begin{array}{l}\text { Analytical } \\
\text { Parameter }\end{array}$ & Container Type & $\begin{array}{l}\text { Sample Size } \\
\text { per Aliquot } \\
\text { (g) }\end{array}$ & Preservation \\
\hline $\begin{array}{l}\text { Volatiles } \\
\text { (soils) }\end{array}$ & $\begin{array}{l}\text { Glass } \\
125 \mathrm{~mL} \\
\text { I-CHEM No. 341-0120 }\end{array}$ & 50 & Dry ice $\left(-78.5^{\circ} \mathrm{C}\right)$ \\
\hline $\begin{array}{l}\text { Volatiles } \\
\text { (vegetation) }\end{array}$ & $\begin{array}{l}\text { Glass } \\
60-\mathrm{mL} \text { jar or } 40-\mathrm{mL} \text { vial } \\
\text { I-CHEM No. } 341-0120\end{array}$ & $\begin{array}{l}\text { Fill container } \\
\text { loosely }\end{array}$ & Dry ice $\left(-78.5^{\circ} \mathrm{C}\right)$ \\
\hline
\end{tabular}


TABLE 6.2 Container type, sample size per aliquot, and preservation parameters for water samples.

\begin{tabular}{|c|c|c|c|c|}
\hline $\begin{array}{l}\text { Analytical } \\
\text { Parameter }\end{array}$ & Container Type & $\begin{array}{l}\text { Sample Size } \\
\text { per Aliquot } \\
(\mathrm{mL})\end{array}$ & Preservation & $\begin{array}{l}\text { Maximum } \\
\text { Holding Time } \\
\text { (days) }\end{array}$ \\
\hline Volatile organics & $\begin{array}{l}\text { Borosilicate } \\
20 \mathrm{~mL}, 40 \mathrm{~mL} \\
\text { I-CHEM No. S 336-0040 }\end{array}$ & 80 & $4^{\circ} \mathrm{C}$, no headspace & 10 \\
\hline $\begin{array}{l}\text { Metals (inorganic } \\
\text { cations) }\end{array}$ & $\begin{array}{l}\text { High-density polyethylene } \\
250 \mathrm{~mL} \\
\text { I-CHEM No. 319-0500 }\end{array}$ & 250 & $\begin{array}{l}4^{\circ} \mathrm{C}\left(\mathrm{HNO}_{3} \text { to } \mathrm{pH}\right. \\
<2 \text { after filtering } \\
\text { in the laboratory) }\end{array}$ & 180 \\
\hline $\begin{array}{l}\text { Inorganic anions } \\
\text { (other than } \\
\text { nitrates) and } \\
\text { alkalinity }\end{array}$ & $\begin{array}{l}\text { High-density polyethylene } \\
250 \mathrm{~mL} \\
\text { I-CHEM No. 319-0500 }\end{array}$ & 250 & $\begin{array}{l}4^{\circ} \mathrm{C}\left(\mathrm{HNO}_{3} \text { to } \mathrm{pH}\right. \\
<2 \text { after filtering } \\
\text { in the laboratory) }\end{array}$ & 28 \\
\hline Nitrates $\left(\mathrm{NO}_{3}{ }^{-}\right)$ & $\begin{array}{l}\text { High-density polyethylene } \\
250 \mathrm{~mL}, 500 \mathrm{~mL}\end{array}$ & 500 & None & $\begin{array}{c}2 \\
(48 \mathrm{hr})\end{array}$ \\
\hline $\begin{array}{l}\text { Total nitrates- } \\
\text { nitrites } \\
\left(\mathrm{NO}_{3}^{-}+\mathrm{NO}_{2}^{-}\right)\end{array}$ & $\begin{array}{l}\text { High-density polyethylene } \\
100 \mathrm{~mL}\end{array}$ & 100 & $\mathrm{H}_{2} \mathrm{SO}_{4}$ to $\mathrm{pH}<2$ & 28 \\
\hline Tritium isotopes & $\begin{array}{l}40 \mathrm{~mL} \\
\text { I-CHEM No. S 336-0040 }\end{array}$ & 80 & None & $\begin{array}{l}\text { No } \\
\text { requirement }\end{array}$ \\
\hline Carbon isotopes & $\begin{array}{l}40 \mathrm{~mL} \\
\text { I-CHEM No. S 336-0040 }\end{array}$ & 80 & $4^{\circ} \mathrm{C}$ & 14 \\
\hline
\end{tabular}

2. Pack analytical samples with specified holding temperatures as follows:

- Soil Samples for VOC Analysis. Pack the sample containers with chunks of dry ice inside the trash bag. Include a soil trip blank. Close the trash bag, and then cut ventilation slits in its top to prevent a buildup of gas pressure.

- Vegetation Samples for VOC Analysis. Pack the sample containers with chunks of dry ice inside the trash bag. No trip blank is used. Close the trash bag, and then cut ventilation slits in its top to prevent a buildup of gas pressure. 
- Water Samples for VOC Analysis. Layer the samples with crushed conventional (water) ice inside the trash bag. Include a water trip blank. Close and seal the outer trash bag. Place absorbent material between the ice chest and the trash bag.

- Water Samples in Unbreakable Containers, with Holding Temperature of $4^{\circ} \mathrm{C}$. Ship the samples with crushed conventional (water) ice and/or "blue ice" inside the sealed trash bag. Include a water trip blank. Place absorbent material between the ice chest and the trash bag.

3. Complete a chain-of-custody record (Appendix D) inventorying the contents of the ice chest. Place the record inside a clearly marked plastic bag or pouch, and affix the bag or pouch to the inside lid of the ice chest.

4. Tape the ice chest securely with fiber filament (or equivalent strength) tape.

5. Affix at least one custody seal (Appendix D), signed and dated by the shipping coordinator, to the outside of the ice chest so that the chest cannot be opened without breaking the seal.

6. Place package orientation labels on the sides of the ice chest.

7. Complete a standard Federal Express airbill (or equivalent carrier waybill). Retain a copy of the airbill until receipt of the shipment is verified.

8. If the package contains dry ice, indicate that in the "Special Handling" section of the Federal Express airbill. For air shipment, the package must comply with the International Air Transport Association's Dangerous Goods Regulations. Attach the required Class 9 shipping label (Figure 6.1).

Samples of substances listed in the U.S. Department of Transportation's (DOT's) hazardous materials table (49 CFR, Regulation 172.101) must be identified, packaged, marked, labeled, documented, and shipped according to the regulations listed for that substance. A letter of understanding between the EPA and DOT states that preservatives in water samples are exempt if the reagents do not exceed the concentrations specified in Table 6.3. 


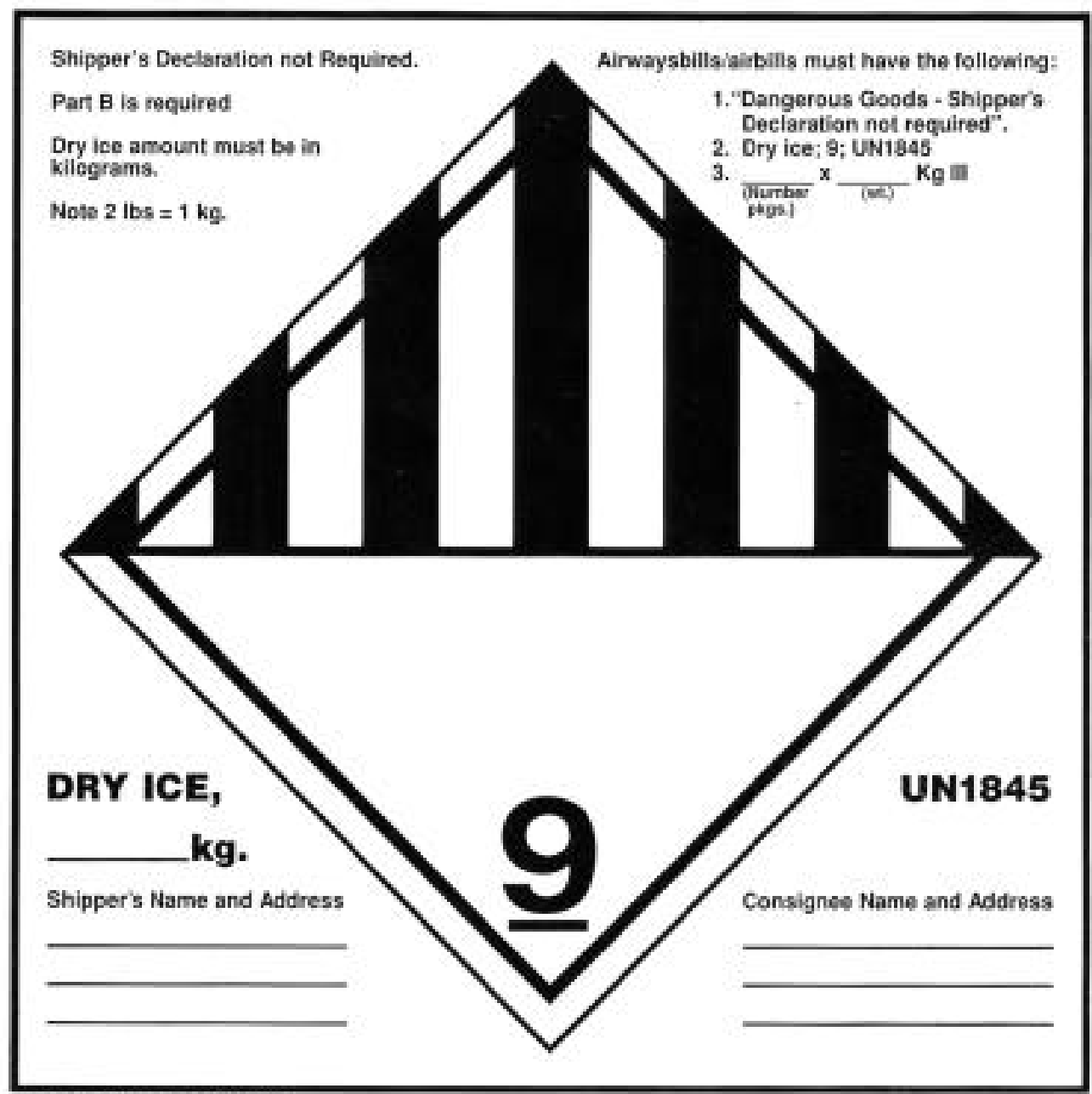

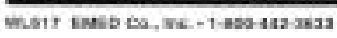

FIGURE 6.1 Dry ice label for shipping.

TABLE 6.3 Maximum concentrations of hazardous materials used as preservatives in water samples that are exempt from DOT hazardous materials regulations.

Preservative Concentration

$\mathrm{HCl}$

$0.4 \%$ by weight

$\mathrm{HgCl}_{2}$

$0.004 \%$ by weight

$\mathrm{HNO}_{3}$

$0.15 \%$ by weight

$\mathrm{H}_{2} \mathrm{SO}_{4}$

$0.35 \%$ by weight

$\mathrm{NaOH}$

$0.08 \%$ by weight

$\mathrm{H}_{3} \mathrm{PO}_{4}$

$\mathrm{pH}$ between 4 and 2 
Ship samples directly from the field to the analytical laboratory, where they are to be received by a sample custodian, logged in, and stored until analysis. The sample receiving procedures will be in accord with CLP protocols.

\subsection{Analytical Methods}

Fundamental to the QuickSite ${ }^{\circledR}$ process is the immediate analysis of sufficient soil and water samples, while the investigation team is in the field, to guide decision making about the location and extent of contamination. Samples collected for VOC analyses are shipped overnight to the AGEM Laboratory. On the basis of its analytical results, the AGEM Laboratory selects at least $10 \%$ of the samples for verification analysis at a second laboratory with CLP procedures (EPA CLP SOW 2/88; EPA 1989b), as described in Section 4.2.2.

Laboratory analytical methods to be used for all samples collected at former CCC/USDA facilities are listed in Table 6.4 by the number assigned them in the EPA's SW-846 manual of analytical procedures (EPA 1998b or most recent version). Modifications of these methods under EPA data quality Level V (Section 4.1.1) are permitted when the QA/QC requirements of the EPA methods are met. The modifications used by the AGEM Laboratory are described in Appendix E, Section E.3. Physical and chemical analyses conducted by sampling personnel during collection of water samples are identified in Table 6.4 by the manufacturer of the commercial kit. The methods are described briefly below.

\subsubsection{Analysis of Soil Samples}

\subsubsection{Analysis for Volatile Organic Compounds}

Soil samples are shipped overnight to the AGEM Laboratory for gas chromatographic analysis for the VOCs of interest (including carbon tetrachloride and chloroform). The AGEM Laboratory uses the following methods (or modifications of these methods, with all QA/QC requirements being met at EPA data quality Level V), as referenced in the EPA's SW-846 (EPA 1998b):

- Gas chromatograph-mass spectrometer (GC-MS) method: EPA Method 8260B, Revision 2, December 1996. 
TABLE 6.4 Sample matrix, target compounds, and laboratory analytical methods for the CCC/ USDA investigations.

\begin{tabular}{|c|c|c|c|c|c|}
\hline \multirow[b]{2}{*}{$\begin{array}{l}\text { Sample } \\
\text { Matrix }\end{array}$} & \multirow[b]{2}{*}{$\begin{array}{l}\text { Target } \\
\text { Analytes }\end{array}$} & \multirow[b]{2}{*}{$\begin{array}{l}\text { Extraction } \\
\text { Procedure }\end{array}$} & \multicolumn{3}{|c|}{ Analytical Method } \\
\hline & & & $\begin{array}{l}\text { Preparation } \\
\text { Procedure }\end{array}$ & EPA No. ${ }^{a}$ & $\begin{array}{l}\text { Analysis } \\
\text { Procedure }\end{array}$ \\
\hline \multirow[t]{10}{*}{ Water } & VOC & None & Purge and trap & EPA CLP 2/ 88 & GC-MS \\
\hline & $\mathrm{pH}$, conductance & $N A^{C}$ & NA & $4500 \mathrm{H}, 2510$ & Electrometric \\
\hline & Dissolved oxygen & NA & NA & NA & Titrimetric \\
\hline & Alkalinity & NA & NA & 310.1 & Titrimetric \\
\hline & Anions & None & NA & 300.0 & IC \\
\hline & Metals & None & Digestion & $\begin{array}{l}300.1 / 6010 B \\
6020\end{array}$ & $\begin{array}{l}\text { ICP-AES } \\
\text { ICP-MS }\end{array}$ \\
\hline & Isotopes & & & & \\
\hline & Tritium & None & NA & NA & Scintillation \\
\hline & Stable oxygen & $\mathrm{CO}_{2}$ exchange & NA & NA & MS \\
\hline & Stable hydrogen & Zinc reduction & NA & NA & MS \\
\hline$V_{e}{ }^{d}$ & VOC & Water & Purge and trap & NA & GC-ECD-MS \\
\hline Soil & VOC & Methanol & Purge and trap & EPA CLP 2/ 88 & GC-MS \\
\hline
\end{tabular}

a EPA standard methods are described in EPA 1989b, EPA 1989c, EPA 1998b, and Greenberg et al. 1992.

b Abbreviations: GC = gas chromatograph, MS = mass spectrometer, ICP-AES = inductively coupled plasma-atomic emission spectrometry, IC = ion chromatography, ECD, electron capture detection.

c NA, not applicable.

d Veg, vegetation (roots, stem, trunk, and leaves). 
- Purge-and-trap method: EPA Method 5030B, Revision 2, December 1996.

- Headspace method: EPA Method 5021-1, Revision 0, December 1996.

When the soil samples arrive at the AGEM Laboratory, each sample is split. One portion of each sample $(0.5-1 \mathrm{~g})$ is placed in a sealed headspace vial for immediate analysis with a modification of EPA Method 5021-1 (with all QA/QC requirements being met), followed by separation and analysis with a gas chromatograph and electron capture detection (GC-ECD). Quantitation is based on calibration curves for laboratory-prepared external standards.

To the second portion (approximately $10 \mathrm{~g}$ ) of each sample, methanol is added to an approximate sample/methanol ratio of 1:1. Analysis occurs after a minimum waiting period of $24 \mathrm{hr}$. A portion of the methanol extract is analyzed by using modifications of the purge-and-trap method (EPA Method 5030B) and the GC-MS method (EPA Method 8260B), with all QA/QC requirements being met. The instrument detection limit is $0.05 \mu \mathrm{g} / \mathrm{kg}$, and the method detection limit is $10 \mu \mathrm{g} / \mathrm{kg}$. A third aliquot of each sample is used for determination of moisture content.

The AGEM Laboratory selects at least $10 \%$ of the soil samples for shipment to a second laboratory for CLP analysis for VOCs of interest, including carbon tetrachloride and chloroform. This second analysis is according to the EPA CLP SOW 2/88 method (EPA 1989b), which uses a capillary column GC-MS. The current detection limit for this method, identified for medium-level soils, can be as high as $60 \mu \mathrm{g} / \mathrm{kg}$.

\subsubsection{Grain Size Analysis}

Grain size analysis of soil samples is in accordance with ASTM Method D422-63(1998) (available from the ASTM at the Internet location http://www.astm.org).

\subsubsection{Analysis of Water Samples}

Water samples are analyzed for VOCs including carbon tetrachloride and chloroform, the contaminants of primary concern. In addition, several physical and chemical parameters of groundwater samples are measured to characterize the hydrogeologic conditions. Parameters used for hydrologic characterization include (1) the field-measured parameters of temperature, $\mathrm{pH}$, and 
conductivity; (2) concentrations of dissolved cations and anions determined in the laboratory; and (3) ratios of stable oxygen and hydrogen isotopes. Results of chemical isotope analyses of groundwater samples can be used to distinguish waters from different aquifers or stratigraphic intervals, as well as to trace apparent flow paths in the subsurface. Isotope ratios can be particularly useful for distinguishing waters from predominantly shale or predominantly limestone aquifers. Selected groundwater samples are also analyzed for their tritium isotope compositions. Tritium, a radioactive isotope of hydrogen, has a half-life of $12.43 \mathrm{yr}$ and decays into the stable helium isotope, ${ }^{3} \mathrm{He}$. Tritium analyses are useful in identifying relatively young $(<60 \mathrm{yr})$ components of groundwater. Measurement of tritium and ${ }^{3} \mathrm{He}$ together in water allows calculation of the time elapsed since the water was in contact with the atmosphere. The tritium-helium dating method can provide groundwater dates that are accurate to within $1 \mathrm{yr}$. The analytical methods are described briefly below.

\subsubsection{Analysis for Volatile Organic Compounds}

Analyses of water samples for VOCs at the AGEM Laboratory are performed at EPA data quality Level V by using a purge-and-trap procedure (Method 5030B, Revision 2, December 1996) and a GC-MS procedure (Method 8260B, Revision 2, December 1996). All QA/QC requirements described in the methods are met. The sample is placed in an autosampler, and helium is used as the carrier gas. Collection of VOCs on an adsorbent is followed by desorption and GCMS analysis. The instrument detection limit is $0.05 \mu \mathrm{g} / \mathrm{L}$, and the method detection limit is $1 \mu \mathrm{g} / \mathrm{L}$.

Water samples shipped to a second laboratory for verification analysis are analyzed for all VOCs of interest, including carbon tetrachloride and chloroform, by following rigorous analytical methods such as EPA CLP SOW 2/88, which has a method detection limit of $5 \mu \mathrm{g} / \mathrm{L}$.

\subsubsection{Analysis for Water Quality Parameters}

Temperature, $\mathrm{pH}$, and conductivity are measured in the field by using a Checkmate Field Meter system after calibration with the appropriate standard solutions. In the laboratory, alkalinity is measured by EPA Method 310, and dissolved oxygen is determined by a titrimetric method. 


\subsubsection{Analysis for Anions}

Laboratory inorganic analyses include the determination of dissolved anion concentrations. Anion concentrations (chloride, sulfate, nitrate, and phosphate) are determined by following EPA Method 300.0, using ion chromatography. Total nitrogen in nitrates and nitrites is determined by EPA Method 353.2.

\subsubsection{Analysis for Metals}

Groundwater samples can be analyzed for metals (including aluminum, calcium, iron, magnesium, manganese, potassium, sodium, silicon, and zinc) by inductively coupled plasmaatomic emission spectrometry (EPA Methods 300.1 and 6010) or by inductively coupled plasmamass spectrometry (EPA Method 6020; EPA 1998b).

\subsubsection{Analysis for Isotopes}

Tritium isotope concentrations are determined by liquid scintillation counting of an aliquot (approximately 2-20 mL) of the unfiltered, unpreserved sample. The detection limit of the direct counting technique is $5 \mathrm{TU}$ (tritium units). Oxygen isotope ratios are measured by allowing water samples to equilibrate with carbon dioxide gas and then analyzing the carbon dioxide gas with a dual-inlet mass spectrometer. Hydrogen isotope ratios are measured in the hydrogen gas produced from water samples by reduction with zinc metal at approximately $650^{\circ} \mathrm{C}$.

\subsubsection{Analysis of Vegetation Samples}

All vegetation samples are shipped overnight to the AGEM Laboratory for analysis. The plant tissues are prepared by cutting or grinding to increase the surface area of the material. The analytical method used is a modification of EPA Method 5021-1 (Revision 0, December 1996), with analysis by GC-ECD. Approximately $0.5-1.0 \mathrm{~g}$ of vegetation is placed in a tare-weighted 20-mL headspace vial with a high-temperature Teflon-faced septum seal. Sample weights are determined to an accuracy of $\pm 0.01 \mathrm{~g}$, and the vials are placed in an autosampler. The analytical protocol is modified by raising the equilibration temperature to $90^{\circ} \mathrm{C}$ for $120 \mathrm{~min}$ to ensure reliable volatilization of the carbon tetrachloride and chloroform in the sample. Standards are prepared by using known quantities of carbon tetrachloride, chloroform, and tetrachloroethene. The GC system 
is calibrated on the basis of the mass of the spike components detected in the standard. Quantitation is based on calibration curves for laboratory-prepared external VOC standards with concentrations ranging from 0.125 to $2.5 \mathrm{ng}$.

\subsection{Drilling and Installation of Monitoring Wells/Observation Wells/Piezometers}

Drilling for the QuickSite ${ }^{\circledR}$ program is conducted primarily to collect soil, rock, and groundwater samples, and secondly, if required, to install monitoring wells/observation wells/piezometers. All drilling is to be conducted under the direct supervision of Argonne personnel by a driller licensed by the relevant state to drill and install monitoring and drinking water wells. All necessary drilling permits and licenses are to be obtained before field work begins.

Drilling methods used are typically hollow-stem auger, mud rotary, sonic drilling, and dual- or triple-wall percussion. Other methods are considered case by case. A site geologist who is to be present during all drilling and well installation activities is to document in a logbook the tasks performed in support of these activities. The site geologist is to have on-site a copy of this Master Work Plan, the site-specific work plan, and the project health and safety plan.

Before the drill is set up, a bermed ground cover of plastic sheeting is placed under the drill rig to contain any fluid discharged from the rig.

\subsubsection{Drilling Operations}

Required equipment for all drilling operations includes an appropriately sized and adequately equipped drill rig, a drill support truck, a steam cleaner, steel drums, plastic sheeting, and sorbent pads. When drilling occurs in a surficial aquifer, drilling must be terminated before the basal aquitard is totally penetrated. The depth drilled into the aquitard is determined by the sitespecific geology. Penetrations of aquifers below the water-table aquifer are limited to avoid crosscontamination. If drilling must proceed into a lower aquifer(s), casing is set to ensure that crosscontamination does not occur. 


\subsubsection{Hollow-Stem Auger Drilling}

Drilling of unconsolidated materials can be accomplished with a hollow-stem auger (HSA), as follows:

1. Advance the HSA in increments of $5 \mathrm{ft}$ or less. If a continuous core is required, fit the auger with a Central Mine Equipment continuous coring device. Place all cuttings in 55-gal steel drums or roll-off containers.

2. If a coring device is used, retract the device at each 5-ft interval, and place the core in a polyvinyl chloride (PVC) trough for logging by the site geologist.

3. If a continuous core is not required, advance the auger to the desired sampling depth, and lower a split-spoon sampler or HydroPunch through the HSA to obtain the soil or water sample.

4. When use of the auger is complete in a hole where a well will not be installed, remove the auger from the hole, and abandon the hole as described in Section 6.4.7.

\subsubsection{Mud Rotary Drilling}

Drilling of consolidated materials can be accomplished with mud rotary drilling methods, as follows:

1. Drill with the HSA to the top of consolidated, firm bedrock, as described in Section 6.4.1.1.

2. After the auger is withdrawn, install the casing as follows:

- Advance an appropriately sized flush-joint steel casing approximately 6 in. into bedrock to ensure that a good seal has been achieved. 
- Tremie a bentonite slurry at least $3 \mathrm{ft}$ deep into the annular space around the outside of the casing to provide extra assurance that no leakage of circulation fluids will occur. Allow the seal to set at least overnight before drilling water is introduced. Fill the remainder of the annular space with auger cuttings to stabilize the casing, if needed.

- Before coring begins, use fresh water to wash out any material that falls into the casing.

3. After the casing is set, advance the hole by using the wireline diamond coring method. For circulation fluid, use only water from an approved source. Analyze water to be used for coring for VOCs and inorganic constituents. Introduce no other fluids, air, or muds into the drill hole. Place cuttings from the recirculation tank in 55-gal steel drums or roll-off containers. Minimize core losses by using only bottom-discharge bits; keeping drilling fluid circulation to the minimum required to remove the drill cuttings; and closely monitoring drill rod vibration, rotation, and rate of advancement. A minimum core recovery of $90 \%$ is required. Limit drilling runs to $5 \mathrm{ft}$ to help ensure good recovery. Place the core in wooden core boxes or heavy, waxed cardboard boxes for immediate logging by the site geologist.

\subsubsection{Sonic Drilling}

Drilling in locations like glacial terrains, which are typically difficult to penetrate, can be accomplished by using the sonic drilling method, in which a dual line of drill pipe is oscillated through the soil. An outer pipe prevents collapse of the borehole and is used in construction of monitoring wells and piezometers. An inner pipe contains a core bit and functions as a core barrel sampler. Recover core with a standard split spoon, Shelby tube, or other conventional sampling device, or as follows:

- Advance the inner drill pipe and core bit approximately 6-9 ft into the subsurface.

- Advance the outer drill pipe down over the inner pipe to hold the boring open. 
- Use the drill head to lift the inner pipe to the surface for recovery of the core.

- Vibrate the core out of the inner drill pipe into a plastic sheath or stainless steel tray.

- Advance the inner barrel to the next sampling interval.

\subsubsection{Percussion Casing Hammer Drilling}

Drilling of unconsolidated materials can be accomplished by using the dual- or triple-wall percussion casing hammer drilling method, as follows:

1. Advance the percussion casing in increments of $10 \mathrm{ft}$ or less. If a continuous core is required, fit the percussion hammer with a power swivel and a 94-mm core system. Place all ancillary cuttings in 55-gal steel drums or roll-off containers.

2. If a coring device is used, retract the device at each 5-ft interval. Place the core in a PVC trough for logging by the site geologist.

3. If a continuous core is not required, advance the percussion casing to the desired sample depth, and lower a split-spoon sampler or HydroPunch through the casing to obtain the soil or water sample.

4. When use of the percussion casing hammer is complete in a hole where a well will not be installed, remove the casing from the hole and abandon the hole as described in Section 6.4.7.

\subsubsection{Geologic Logging}

All borings are to be logged by a geologist. The site geologist is responsible, at only one operating drill rig, for monitoring the drilling operations, preparing the boring logs and well diagrams, and recording the well installation procedures. Logs are recorded in a field notebook, on 
a boring $\log$ (Figure F.1 in Appendix F), or both. Field logs will include the following, at a minimum:

- Boring number and location (GPS coordinates in decimal degrees)

- Drilling method and borehole diameter

- Lithologic descriptions

- Core and split-spoon recoveries

- Evidence of contamination

- Weather conditions

- Groundwater levels (depth encountered and static)

- Notations on materials placed by humans

- Sample depths and identification numbers

\subsubsection{Decontamination}

Steam clean all drilling equipment - including rigs, water tanks (inside and out), augers, drill casings, rods, samplers, tools, and recirculation tanks - with approved water when the equipment arrives at the site and between borings/wells. Before they arrive on the site, all casings, augers, recirculation and water tanks, etc. must be devoid - both inside and out - of any asphaltic, bituminous, or other encrusting or coating material, grease, grout, soil, etc. To the extent possible, perform all cleaning in an area that is remote from any location to be sampled. 


\subsubsection{Monitoring Well Installation}

\subsubsection{Monitoring Well Installation Procedures}

Monitoring well installation is to follow guidelines in the Handbook of Suggested Practices for the Design and Installation of Ground Water Monitoring Wells (National Ground Water Association 1989). See the construction diagrams in Appendix F, Figures F.2 and F.3. General well installation procedures are as follows:

1. When drilling is complete, measure the bottom of the borehole with a tape to verify its depth.

2. If the interval selected for screening is not at the bottom of the hole, backfill the hole with bentonite to within approximately $1 \mathrm{ft}$ of the bottom of the selected interval. Allow the bentonite to hydrate for at least $1 \mathrm{hr}$. Then place a 1-ft layer of filter sand over the bentonite, and insert the well assembly.

3. Assemble the monitoring well screen, end plug, casing, top cap, and centralizers (if required). Lower the well assembly until it rests on the layer of filter sand.

4. Withdraw the auger in increments of $2.5 \mathrm{ft}$ while filter pack sand is added. Take repeated depth soundings of the bottom of the hole to monitor the level of the sand and to detect any bridging of sand.

5. Allow sufficient time for the filter pack to settle through the water column within the augers before withdrawal of the auger continues.

6. Extend the filter pack sand to approximately 2-3 ft above the top of the well screen.

7. Place a seal of bentonite at least $3 \mathrm{ft}$ thick above the filter pack. Tremie the bentonite slurry or pellets (in wells more than $30 \mathrm{ft}$ deep), or pour the slurry or pellets into the annular space. Allow the slurry or pellets to set for approximately $60 \mathrm{~min}$ before grouting begins. 
8. While the augers are being removed, tremie cement/bentonite grout into the annulus above the bentonite seal. Top off the grout level periodically during auger removal.

9. Before the grout sets, center the protective steel casing on the PVC well casing, and insert it into the grouted annulus.

10. After $24 \mathrm{hr}$, install the concrete pad and protective well cap.

\subsubsection{Monitoring Well Construction Details and Materials}

\section{Well Casing}

Well casings typically consist of threaded, flush-joint, 2- or 4-in.-I.D., schedule 40 or schedule 80 PVC pipe. Use only casings cleaned and prepackaged by the manufacturer. Extend the casing from the top of the well screen to approximately $3 \mathrm{ft}$ above ground level, and attach a sanitary seal with casing vent. Do not use solvents, cements, or adhesive tapes to join sections of casing.

\section{Well Screens}

Well screen lengths are not to exceed $10 \mathrm{ft}$ unless special conditions warrant a longer screen. Use only well screens cleaned and prepackaged by the manufacturer. The screens are to be flush-joint, 2- or 4-in.-I.D., schedule 40 or schedule 80 PVC pipe with factory-machined continuous slots of appropriate slot size as determined by a sieve analysis (see Filter Pack section below). Well screens are to have PVC bottom plugs. Do not use solvents, cements, or adhesive tapes to join the screen to the casing.

\section{Centralizers}

Use stainless steel centralizers on wells built with "open" holes to center the well in the borehole and maintain its alignment during grouting. Locate centralizers at the top and bottom of 
the screen and at 20-ft intervals on the casing. Do not use cements or adhesive tapes to affix the centralizers.

\section{Filter Pack}

Fill the annular space between the well screen and the borehole wall with clean filter pack. Extend the filter pack from approximately $1 \mathrm{ft}$ below the well screen to approximately 2-3 ft above the top of the well screen. Unless otherwise stipulated, the filter pack grain size is to be based on formation grain size analysis. Use the value of the D30 (70\% retained) sieve size, multiplied by a factor not less than 3 or greater than 6 , to determine the appropriate grain size.

\section{Bentonite/Expanding Cement Seal}

Install a 2-ft bentonite pellet seal above the filter pack if the sealed interval is below the water table. If the sealed interval is above the water table, use expanding cement instead of bentonite.

\section{Cement/Bentonite Grout}

Tremie grout the annular space between the well casing and the borehole wall from the top of the bentonite seal to the ground surface. Make the grout mixture with Portland cement, bentonite powder, and potable water in the proportions of $94 \mathrm{lb}$ (one bag) of Portland Type II cement to 3-5 lb of bentonite powder. Prepare the grout by first thoroughly mixing the bentonite and water and then mixing in the Portland cement. Lower the tremie line to within $5 \mathrm{ft}$ of the bottom of the zone to be grouted. Withdraw the tremie line as the annulus fills with grout, taking care to ensure that the discharge end of the tremie line remains submerged by a minimum of $5 \mathrm{ft}$ in the grout during cement placement. 


\section{Protective Steel Guard}

Install a protective steel guard with a hinged and lockable steel cap over the well casing. Embed the protective cap in the cement/bentonite grout before it has set. Drive steel pickets (three or four) evenly around the well at a distance of $4 \mathrm{ft}$.

\subsubsection{Monitoring Well Completions}

\section{Flush-Mount Completions}

Certain sites require a flush-mount surface completion for a well (Appendix F, Figure F.4). All installations are to conform to individual state requirements. Dig a hole large enough to contain the steel flush-mount housing around the casing, so that the cover plate is at or slightly above the surrounding surface. Set the attached steel or PVC skirt or shroud in cement to preclude migration of water into or around the well. Upon installation of the housing, terminate the well casing as high in the flush-mount as possible. Unless otherwise stipulated, install a concrete ring 8 in. thick and 8 in. beyond the edge of the flush-mount ring. Finally, install a water-proof cover plate (Appendix F, Figure F.3).

\section{Stick-Up Completions}

Under certain conditions, a stick-up surface completion is appropriate. The subsurface well construction is the same as for the flush-mount completion, except that the PVC casing extends approximately $3 \mathrm{ft}$ above the ground surface (Appendix F, Figure F.2) and is enclosed in an 8- to 12-in. protective PVC shroud with a lockable cap.

\section{Concrete Pad}

At the ground surface and around the protective steel casing, install a concrete pad (Sakrete, Quikrete, or equivalent) at least 8 in. thick and 8 in. beyond the edge of the flush-mount or stickup installation, with a 12:1 or 12:2 slope to prevent pooling of surface water. 


\subsubsection{Well Construction Diagram}

Record the construction of each well on a well construction diagram (Appendix F, Figure F.5) in the field, and attach the diagram to the boring log (Appendix F, Figure F.1). Graphically denote at least the following information:

- Total depth of hole

- Screen location and length

- Filter pack interval

- Bentonite seal interval

- Grout interval

- Centralizer locations

- Height of riser

- $\quad$ Casing/screen size(s) and slot size

- $\quad$ Protective casing detail

\subsubsection{Well Development}

After well construction is complete, develop the well until a consistent yield of clean water is produced. Use a surge block and bailer or a surge block and submersible pump for development. Decontaminate any equipment entering a well on the site before it is inserted.

Employ two well development techniques, overpumping and surging, in tandem. Initially pump the well at a rate higher than recharge. Then surge the well by using a plunger to force water back and forth through the well screen, filter pack, and formation. Any water introduced to facilitate development must be approved by an Argonne representative before it is introduced. 
Containerize or discard water produced from well development as determined by local environmental regulators. Record the following information before and during development:

- Date and method of development

- Static water level before and after development

- Development water volumes (in gallons)

- Volume and source of water added (if any)

- Final water clarity

\subsubsection{Well Registration}

At the completion of drilling, installation, and development of a well, complete the appropriate well registration form (Appendix F, Figure F.6), and give the completed form to the licensed contractor for state filing as required.

\subsubsection{Piezometer Installation}

Install piezometers or well points to permit collection of long-term water level data by using the ECPT (Section 6.5). In Kansas, conduct the installation in accordance with Kansas regulations, including Article 12, Groundwater Exploration and Protection Act, and Article 30, Water Well Contractor's License/Water Well Construction and Abandonment. In Nebraska, conduct the installation in accordance with Nebraska regulations, including Article 12 of the Water Well Standards and Contractors' Licensing Act (Nebraska Administrative Code, Title 178, Chapters 10-12). 


\subsubsection{Flush-Mount Piezometer Installation}

To install a flush-mount piezometer, well point, or sand point well, use the following procedure:

- Use the ECPT unit to push a non-instrumented cone to depth, as specified in Appendix F, Figure F.7.

- Pull the cone back to the surface.

- Attach a 3.25-in.-diameter expendable tip to a 0.5-in.- to 1-in.-diameter PVC screen prepacked with sand in a stainless steel mesh. Place this screen inside a 3.25-in. Geoprobe push rod. Attach the rod to the expendable tip, and push to the desired depth. The maximum screen length for sampling a discrete interval is $5 \mathrm{ft}$.

- Use $15-\mathrm{cm}^{2}$ (with 0.5 -in. screen) or 2.25-in. (with 1-in. screen) push rods to advance the assembly to the base of the desired sampling interval. Withdraw the rods enough to expose the 5 -ft screen.

- Withdraw a water sample if desired.

- To install a piezometer, sand point, or well point, lower 0.5- to 1-in.-diameter schedule 40 PVC riser pipe into the hole through the rods. Attach the pipe to the top of the screen, and withdraw the ECPT rods.

- Tremie silica sand or gravel into the hole to a level 2-3 $\mathrm{ft}$ above the top of the screen. Unless otherwise stipulated, base the filter pack grain size on a formation grain size analysis. Use the value of the D30 (70\% retained) sieve size, multiplied by a factor not less than 3 or greater than 6 , to determine the appropriate grain size. Use a water level meter or other measuring device to determine the location of the top of the sand and ensure that sufficient sand is in place. 
- Pour bentonite pellets into the hole (to a thickness of 2-3 ft) with some water. Allow the pellets to hydrate for at least $20 \mathrm{~min}$ to form an effective seal between the screened interval and the section above.

- Mix grout and tremie it into the hole from the top of the bentonite seal to a depth of $3 \mathrm{ft}$ below ground level. Mix bentonite grout to a minimum density of $9.4 \mathrm{lb} / \mathrm{gal}$ and neat cement to a minimum density of $15.2 \mathrm{lb} / \mathrm{gal}$.

- For the surface installation, dig out an area 18 in. in diameter and 36 in. deep around the borehole and riser pipe. Place a 6-in.-deep layer of bentonite pellets on top of the grout.

- Set a 12-in. O.D. by 24-in. flush mount. See Appendix F, Figure F.7, for construction details.

- Fill the surface hole outside the flush mount with grout, and finish to a smooth surface with a 12:1 or 12:2 slope. The concrete pad must be a minimum of 8 in. thick and must extend at least 8 in. beyond the flush mount $(28 \mathrm{in}$. minimum).

- Cut the riser pipe to the appropriate height. For wellhead protection, install a 12-in. Morrison Brothers Co. (Dubuque, Iowa) Model 418XA Flush Mount Cover (Appendix F, Figure F.3). Fit the top of the casing with a Morrison Brothers Co. "J" Plug Model 678XA (Appendix F, Figure F.8) and a screened vent with a locking pipe plug and padlock.

- Complete a piezometer installation form (Appendix F, Figure F.5), and give the completed form to the licensed water well contractor so that the installation can be registered with the state regulatory agencies.

\subsubsection{Stick-Up Piezometer Installation}

If a stick-up piezometer installation is more appropriate than a flush-mount installation, follow the procedure above (Flush-Mount Piezometer Installation) for all aspects of the subsurface installation. However, refer to Appendix F, Figure F.9, for the surface completion details. 
Complete a piezometer installation form (Appendix F, Figure F.5), and give the completed form to the licensed water well contractor so that the installation can be registered with the state regulatory agencies.

\subsubsection{Measurement of Water Levels in Piezometer Installations}

In many instances, an electronic pressure transducer device is installed down the casing in the piezometer or sand well to record water level fluctuations through time. Refer to Appendix E, Section E.1, for detailed installation, test setup, and data retrieval procedures.

\subsubsection{Abandonment of Soil Borings, Boreholes, and Piezometers}

Abandonment procedures must conform to applicable state requirements for drill hole abandonment. For Kansas, Water Well Contractor's License/Water Well Construction and Abandonment regulations apply (KAR, Title 28, Article 30). For Nebraska, regulations governing well abandonment (Title 178, Chapter 12 of the Nebraska Administrative Code) apply. The following general guidelines also apply:

- Fill open holes with a bentonite slurry or neat cement. If the hole is deeper than $10 \mathrm{ft}$, emplace the bentonite or cement grout with a tremie pipe from the bottom of the hole up until the grout/bentonite displaces all water in the hole and flows onto the ground surface. Shallow holes less than $3 \mathrm{ft}$ deep may be backfilled with native soil or grouted to the surface.

- Abandon wells by removing as much of the casing as possible. Then proceed as for open holes.

- Abandon piezometers by first grouting with a tremie pipe. Then remove the top $3 \mathrm{ft}$ or more of casing. Install a 1-ft-thick cement plug, and backfill to the surface with native soil or grout.

- Complete the appropriate state abandonment/plugging form (Figure F.10, Appendix F), and submit the form to the licensed contractor for state filing as required. 


\subsection{Electronic Cone Penetrometer and Geoprobe}

Push technologies used include the Geoprobe and the ECPT. Both involve hydraulically driven probes or samplers that are pushed into the ground, rather than drilled, to obtain subsurface information, samples, and/or data. The advantages of the push technologies over drilling are that (1) the former are usually less costly; (2) they are less invasive, with little to no cuttings or fluids needing disposal; and (3) they are generally more rapid. The disadvantages of push technologies are primarily that (1) they cannot penetrate as deeply — usually less than $120 \mathrm{ft}$ below ground surface - and (2) they are not effective in well-consolidated or cemented lithology.

The ECPT is a truck-mounted device that offers a cost-effective alternative or supplement to conventional drilling methods. The ECPT enables rapid, high-quality subsurface exploration and sampling with significantly reduced site disturbance and waste generation. Argonne operates two cone penetrometer vehicles: (1) a 40-ton truck unit and (2) a 22-ton van den Berg, Inc., alltrack crawler unit. In addition, other direct-push devices, such as the Geoprobe, are used to collect subsurface samples.

With the ECPT, an instrumented cone 10 or $15 \mathrm{~cm}^{2}$ in diameter is hydraulically pushed into the ground, while several physical, geophysical, and chemical measurements are made. Soil, soil moisture, soil gas, and groundwater samples can also be retrieved.

The data from the ECPT are recorded and stored in real time by computers on the truck. The data and analytical results can be transferred to other storage media.

The application of the ECPT to environmental site investigation and remediation monitoring is evolving rapidly. Additional sensors and probe attachments measuring a broad range of subsurface parameters will enhance the use of ECPT in subsurface environmental investigations.

The Geoprobe can be used to core and to collect soil and water samples by direct pushing or vibration. The Geoprobe can use electronic sensors when it is in the direct-push mode. Currently available sensor technology adapted for use with the Geoprobe system includes conductivity, pore pressure, tip, local friction (sleeve), and inclination. 


\subsection{Geophysical Methods}

The primary role of geophysics in the QuickSite ${ }^{\circledR}$ program is to help define the geologic controls on the configuration and movement of contaminants at investigation sites.

The same basic methods of investigation (seismic, electrical, and borehole) are considered at all sites. However, the suite of geophysical surveys selected for each site varies somewhat, depending on the geologic framework and the data needs. The geophysics team reviews all available data pertaining to each site to identify the most appropriate geophysical techniques.

The available geophysical data for any site are generally sparse or nonexistent. A preliminary field investigation before the main field program begins can quantify the more crucial geophysical parameters.

Well logs are acquired with different downhole geophysical sensors in the early field investigation to correlate important lithologic units with geophysical parameters and select the most promising geophysics methods. Downhole well data are also used to model the responses of various surface techniques and identify the methods that are most sensitive to the desired geophysical targets.

Methods that might be selected for any given site include the following:

1. Seismic P- and S-wave refraction/reflection profiling

2. Resistivity sounding

3. Additional borehole geophysical logging as required

The following sections describe specific surveys that can be used at any given site.

\subsubsection{Seismic Reflection Surveys}

Two-dimensional seismic reflection surveys can map the continuity and thicknesses of lithologic units when suitable impedance contrasts are present in the geologic section. 


\subsubsection{Survey Parameters and Equipment Requirements}

For seismic reflection surveys, use the following general guidelines for acquisition geometry and equipment:

- Use the common midpoint (CMP) method whenever possible. The common offset method may be used if fewer recording channels are available and if velocity control and the signal-to-noise ratio (SNR) are sufficient to produce an acceptable section.

- Use an instantaneous floating point, digital instantaneous floating point, or 24-bit delta-sigma exploration seismograph. The seismograph must have a dynamic resolution of at least $78 \mathrm{~dB}$ and a system dynamic range of at least $124 \mathrm{~dB}$. The seismograph should be able to record at least 24 channels, although most surveys will prove much more cost effective if 48 channels or more are used. (This is especially true if a multicomponent survey is planned.) A sample interval of $0.5 \mathrm{~ms}$ or less is required, along with the appropriate antialias and other signal-conditioning filters. The seismograph must have a 32-bit stacker and should be able to record at least 20,000 samples per channel.

- Use geophones with a resonant frequency of 25-50 Hz. Horizontal-component geophones should have the same frequency characteristics as verticalcomponent geophones.

- Survey constraints determine source and geophone spacing. Geophone spacing is likely to be $2-20 \mathrm{ft}$, while the source spacing is determined by the fold requirements. A CMP fold of at least 6 is required.

- Maximum source-receiver offset must be at least as great as the depth to the primary target. Minimum offset is to be no greater than twice the geophone spacing.

- A symmetric split-spread cable configuration is preferred. An off-end or an asymmetric split-spread configuration may be used if fewer recording channels are available. 
- CMP-type cables are preferred, although refraction cables are acceptable if the ratio of total takeouts to active channels is at least 2:1. Space takeouts $5-20 \mathrm{ft}$ apart.

- Position source points halfway between geophone locations if the cable configuration is split spread. If the cable configuration is off-end, the source points may occupy the same locations as the geophones.

- Use a CMP roll box, a cable switch box, or a software-controllable channel selection facility to facilitate CMP data acquisition.

\subsubsection{Data Acquisition}

\section{Geophone Placement}

Critical to high-quality seismic reflection data is the placement of geophones, which determines coupling. Much of the attenuation of the seismic signals occurs in the first several feet of topsoil. Even if it is impractical to bury the geophones a few feet, scrape off the first few inches of loose topsoil and vegetation and then push the geophones firmly into the ground. When each geophone is planted, apply slight pressure by hand to detect any tendency to wobble. Replant the geophone if any motion is detected.

\section{Seismic Source Selection}

Make the final selection of seismic sources in the field, during walkaway tests. Test energy sources through a series of recordings at a single location, by varying the type of source and the number of source impulses recorded. All of the methods will probably use the signal enhancement capabilities of the seismograph to average a series of surface impulses, increasing the SNR by averaging out random noise. Potential sources include the following:

1. Hammer blows on metal plates, preferably delivered with a sledge hammer because of its high frequency, repeatability, and portability 
2. Blank shotgun shells fired from a buffalo gun (Betsy Seisgun; see operating procedure in Appendix E, Section E.4) into the ground

3. Electrically fired shotgun-size charge (300 grain or 500 grain) buried $2-10 \mathrm{ft}$ deep; optimal charge depth and size (the number of individual charges per hole) to be determined by testing

4. Accelerated weight drop (e.g., Elastic Wave Generator from Bison)

5. Minivibrator

\section{Walkaway Test}

Choose the most favorable array geometry, geophone placement, and seismic sources for each site on the basis of a walkaway test. Select the following parameters:

- Geophone and shot spacing; maximum and minimum offset

- The seismic source (hammer blows, weight drops, mechanical weight, vibrator)

- Geophone placement and coupling (spikes, plates, buried geophones)

- Field filter parameters

In a walkaway test, a single spread of geophones is spaced very closely (typically at intervals of 1-2 ft), to prevent any aliasing of surface noise or reflection signal. The first source point is one geophone spacing from the end of the spread. Move subsequent source points away from the spread one spread length at a time, until the maximum required offset is achieved. Splice the individual shot records together to simulate a single, very finely sampled shot record. Then identify the optimal offset and geophone spacing on the walkaway record. Perform source testing at the optimal offset from the spread. 


\subsubsection{Data Processing}

The general processing flow for high-resolution CMP reflection data is as follows:

1. Input array geometry (to edit headers)

2. Component rotation/differencing (for S-wave surveys)

3. Bad trace edit

4. Elevation statics

5. First-arrival mute(s)

6. CMP sort

7. Velocity analysis

8. Surface-consistent statics

9. Filter

10. Automatic gain control scaling

11. CMP stack

Perform tests to determine whether additional steps, such as deconvolution, F-K filtering, or migration, are needed. Two very important steps in this sequence are velocity analysis and surface-consistent statics. Velocity analysis is generally performed at regular intervals along the line. However, where rapid variations in the overburden velocity are noted or bedrock topography varies greatly, velocity analysis might be required at more CMPs. Because of the interaction needed, the processing time increases with the number of velocity analyses performed. Surfaceconsistent statics can be crucial when variable water table elevations occur near the surface. Refraction analysis on the data might be needed to determine the depth to the water table for use in static corrections. 


\subsubsection{Calibration}

Conduct comprehensive tests on the instruments before the field program begins to ensure that filters, amplifiers, and analog-to-digital conversion circuits are within specification. Perform daily checks to calibrate the polarity and timing of each data channel. Document geophone-cable polarity by recording tap tests at each recording station. Monitor background noise by recording periodic wind strips (recordings made without a seismic source). Monitor overall operation of the system continuously by inspecting field records and noting the polarity and amplitude of first arrivals and visible reflectors. Generate read-after-write paper records for each shot record to verify the digital recording of data. Calibrate velocity measurements against the air wave velocity, known to be $1,087 \mathrm{ft} / \mathrm{s}$ (if the air wave is visible on the shot records), and also against the check shot survey.

\subsubsection{Seismic Refraction Surveys}

Seismic refraction surveys are used primarily to identify the interface between bedrock and unconsolidated deposits when the bedrock geometry seems to influence aquifer flow patterns. Given sufficient velocity contrast, seismic refraction can also be used to identify the water table.

\subsubsection{Survey Parameters and Equipment Requirements}

For seismic refraction surveys, use the following general guidelines for acquisition geometry and equipment:

- If both reflection and refraction data are to be acquired, the seismograph must meet the requirements for a reflection survey (see Section 6.6.1). If only refraction data are to be acquired, the seismograph may have as few as 12 channels, and the requirements for dynamic resolution can be relaxed. A sample interval of $0.5 \mathrm{~ms}$ or less is still required, along with the appropriate anti-alias and other signal-conditioning filters. The seismograph must have a 32-bit stacker and should be able to record at least 2,000 samples per channel.

- Geophones must have a resonant frequency of 25-50 Hz. 
- Survey constraints determine source and geophone spacing. Geophone spacing will likely be 10-50 ft. Both reverse and forward profiles must be acquired to remove any dip ambiguity.

- The maximum source-receiver offset must be large enough to allow at least four geophones to pick up refraction arrivals from the deepest refractor of interest.

- Refraction cables are to have takeouts spaced 10-50 ft apart.

\subsubsection{Data Acquisition}

\section{Geophone Placement}

Good geophone coupling is important for identifying first breaks accurately. Scrape off the first few inches of loose topsoil and vegetation, and then push the geophones firmly into the ground. Once each geophone is planted, apply slight pressure by hand to detect any tendency to wobble. Replant the geophone if any motion is detected.

\section{Seismic Source Selection}

Several seismic sources are available for refraction surveying. For each site, choose the source chosen that gives adequate signal strength, ease of use, and reasonable cost in the local surface and soil conditions. The Betsy Seisgun, the tool of choice in many surveys, employs an industrial shotgun firing shells with powder only. This source gives adequate signal with reasonable frequency content in most cases. The standard operating procedure for safe operation of the Betsy Seisgun is in Appendix E, Section E.4. Other sources that can be used are sledgehammer blows on a metal plate, an accelerated weight drop such as the Bison Elastic Wave Generator, a vibrator, or small buried charges.

\subsubsection{Data Processing}

Shortly after acquisition, process data on a portable computer in the field. Continually monitor the SNR, frequency content, and overall signal quality. Interactively identify first breaks 
as soon as possible after recording, and make adjustments in spread offsets as needed. Process refraction data by using the GREMIX software package from Interpex, Ltd., or equivalent. This software is based on the general reciprocal method; it produces a complex multilayer model in which velocities may vary laterally.

\subsubsection{Calibration}

Conduct comprehensive tests before the instruments arrive on the site to ensure that filters, amplifiers, and analog-to-digital conversion circuits are within specifications. Perform daily checks to calibrate the polarity and timing of each data channel. Generate read-after-write paper records for each shot record to verify digital recording of data. Calibrate velocity measurements against the air wave velocity, known to be $1,087 \mathrm{ft} / \mathrm{s}$.

\subsubsection{Seismic Check Shot Surveys}

Surface seismic reflection surveys record the time required for a pulse of energy created at the surface to travel into the ground, be reflected from an acoustic impedance contrast, and travel back to the surface. Converting time to depth requires an accurate knowledge of the subsurface velocity profile. Some velocity information can be obtained from the observed behavior of reflection arrival times as a function of offset, but a check shot survey is much more reliable in providing detailed information about velocities. The subsurface velocity profile also helps in interpreting seismic refraction surveys. Such a profile is generated by making measurements of the time required for a burst of energy created at the surface to travel to known depths in the subsurface. These measurements can be made either by placing a geophone in an existing borehole or by using the seismic capability of the ECPT vehicle (Section 6.5).

The check shot survey consists of a series of shot records, in which the output of a surface energy source is recorded with a downhole geophone or ECPT cone positioned at various depths. The first arrival of energy at each geophone provides a direct measurement of the travel time required for the energy to reach a known depth; interval velocities are determined by noting differences in the arrival times at different depths.

The seismograph used in the surface geophysical surveys is also used for the downhole check shot survey. See Sections 6.6.1.1 and 6.6.2.1 for seismograph specifications. The downhole geophone assembly must have some mechanism, either hydraulic, pneumatic, or 
mechanical, for pressing the geophone against the side of the borehole for good coupling. The geophone may have only one component (vertical) for P-wave check shot surveys, but it must have three components (vertical plus two orthogonal horizontal components) for S-wave check shot surveys. An orientation sensor is desirable for S-wave check shot surveys.

The source and receiver systems in the ECPT have capabilities and specifications similar to those of the regular seismic systems, except that obtaining data is much easier with the ECPT, and data points can be taken at much smaller depth intervals with little impact on survey time. P-wave energy is generated for ECPT check shot surveys with either a hammer and plate placed beside the truck or with an onboard hydraulic source. S-wave energy is generated in opposing horizontal directions with an onboard hydraulic source.

\subsubsection{Resistivity Surveys}

Resistivity surveys with appropriate array configurations are useful where major resistivity changes occur at relatively shallow depths. Such surveys can map the water table, as well as interfaces between major types of lithologies (e.g., clay to limestone or clay to sand).

\subsubsection{Survey Parameters and Equipment Requirements}

Resistivity measurements require two electric dipoles, with a smaller receiver dipole centered at the same location as the transmitter dipole. A constant direct-current voltage is supplied to the transmitter dipole, and the resulting voltage drop is measured across the receiver dipole. Larger dipoles permit greater depths of penetration. Moving the electrodes farther apart allows measurement of the apparent resistivity of deeper sections of the subsurface and generates a vertical electrical sounding. The data allow interpretation of subsurface layers with different resistivity characters. Determine the optimal array configuration and electrode spacing by field testing.

Equipment to make resistivity measurements is mature and available from a number of sources including ABEM, Inc., and Bison Instruments. These systems include a receiver, transmitter, electrodes, and wire. Any commonly used system is appropriate for measurements at former CCC/USDA facilities. 


\subsubsection{Data Processing}

No conditioning of resistivity data is required. Interpret each vertical electrical sounding by developing a multilayered resistivity model of the subsurface. Software to develop and compute the models, such as the RESIX program from Interpex, Ltd., is commonly available.

\subsubsection{Calibration}

Calibrate instruments with an ohmmeter. To ensure that the measured current is entering the ground, enhance the electrode coupling by soaking the area around the electrodes with water. Calibration of the interpreted geoelectric section depends on correlation with complementary information related to ground resistivity from sources including borehole resistivity or induction logging and published results of electrical or electromagnetic surveys in the area. Calibrate interpreted results by correlation with subsurface geologic and geohydrologic conditions found directly through drilling and sampling or indirectly through other geophysical methods.

\subsubsection{Induction Logging}

Induction logs run in preexisting wells and in wells drilled during the field program aid in correlation of subsurface geology and generate conductivity parameters as input for surface electromagnetic surveys. The induction logging tool is the Geonics EM-39, with the Mount Sopris logging unit. The EM-39 operates through the use of a continuous-wave, 39.2-kHz signal. The transmitted primary-field signal induces a secondary current in conductive subsurface formations. The secondary currents create magnetic fields that are detected by a receiver coil placed $50 \mathrm{~cm}$ from the transmitter coil. A third coil placed midway between the transmitting and receiving coils is used as a focusing or compensating coil to reduce sensitivity to borehole fluid and to improve vertical resolution. The EM-39 has proved to be a valuable tool for accurate conductivity measurements. Induction logging can be performed only in holes cased with PVC or some other nonconductive material.

Calibrate the EM-39 against a known standard before it is shipped to the field. Set the tool to zero before each run. To do this, a staff member holds the device above his/her head, as far away as possible from the ground and any metal structures. 


\subsubsection{Gamma Logging}

In gamma logging, a sodium iodide gamma particle detector measures the passage of gamma particles into the logging tool's receptor in counts per second. Gamma particles are produced by the radioactive decay of naturally occurring uranium, potassium, and thorium in soil and rock. Gamma logs run in preexisting wells and in new wells drilled during the field program can be used to differentiate lithologies and aid in geologic correlation.

Calibrate the gamma logging tool against known standards before it is shipped to the field. Because the accuracy of gamma logging is crucially dependent on logging speed, ensure that the rate of descent or ascent of the tool is slow enough to allow for proper accumulation of statistics.

\subsection{Hydrogeologic Testing}

The hydraulic parameters of an aquifer, aquifer system, or well installation are determined by using conventional well pumping (pump test or step test) or well response (slug test) techniques. These tests are used primarily to estimate aquifer transmissivity and storativity; however, under certain conditions, aquifer tests also provide information on the confined, unconfined, or semiconfined nature of the aquifer; vertical and horizontal isotropy within the aquifer; aquifer boundary conditions; and the vertical hydraulic conductivity of confining beds. The procedures used to select and conduct aquifer tests are similar to those described in the ASTM standards D4043 and D4044 (available from the ASTM at the Internet location http://www.astm.org) and discussed in standard texts such as Freeze and Cherry (1979) and Kruseman and deRidder (1991).

Determine the form, location, and number of aquifer test(s) to be employed at any site on the basis of the unique hydrogeologic characteristics of the site and the specific technical objectives of the site investigation. Design the aquifer testing program after development of the conceptual understanding of the site geology and hydrogeology, including information on the thickness, lithology, stratification, depth, continuity, and boundary conditions of the aquifer system and the characteristics of groundwater flow.

Detailed procedures for measuring water levels in wells are in Appendix E, Section E.1. 


\subsubsection{Aquifer Pump Testing}

A pump test or constant-discharge test is typically carried out by using a centrally located pumping well and at least one nearby observation well. Record the decline of the groundwater level in the developing cone of depression around the pumping well to the nearest $0.01 \mathrm{ft}$ by using automatic data recorders and pressure sensors. Monitor static water levels in the pumping and observation wells for several days before the aquifer test, and record local variations in barometric pressure and precipitation both before and during the test to permit correction of the test data for possible background trends in water level variations, aquifer barometric efficiency, or both. The duration of the pumping depends on the hydrogeologic characteristics of the site, but it typically ranges from $12 \mathrm{hr}$ to $72 \mathrm{hr}$. Water level recovery is monitored for a similar period after termination of pumping.

\subsubsection{Step Testing}

A step test or variable-discharge test is carried out by monitoring the water level response, usually in a single well, as it is pumped at successively higher rates in a series of three to four stages or steps. The duration of each step is variable, but it typically ranges from 1 to $3 \mathrm{hr}$. Record water level data to the nearest $0.01 \mathrm{ft}$ by using either an automatic data recorder and pressure sensor or a manually operated water level probe, depending on the specific conditions of the well installation. Step test drawdown data are used to estimate the pumping efficiency or degree of development of the pumping well installation. Water level recovery data recorded upon termination of pumping can also give an estimate of aquifer transmissivity (Kawecki 1993).

\subsubsection{Well Response Testing}

Well response tests or slug tests are performed in a single well by causing a rapid change (either rise or fall) in water level within the well casing, then recording the subsequent recovery of the water column to its predisturbance level. Slug tests are performed by using a modification of the methods described by Prosser (1981) and Kelly (1991), in which gas (air or inert gas) pressure, supplied from a mechanical compressor or storage tank via a suitable wellhead manifold, is used to depress and stabilize the water level within the well casing. To initiate the test, release the pressure, creating a condition equivalent to an instantaneous drop in head. Monitor water level recovery by using a pressure transducer and automatic logger capable of a high data acquisition rate. Repeat the slug test procedure at least three times for each well tested. 


\subsubsection{Analysis of Aquifer and Well Test Data}

Interpret aquifer and well test data by using documented procedures that are appropriate to the specific conditions of each test. Analytical methods for test evaluation are described in ASTM standards D4104, D4105, and D4106 (available from the ASTM at the Internet location http://www.astm.org), as well as in standard texts and publications (e.g., Freeze and Cherry 1979; Kruseman and deRidder 1991; Kawecki 1993). Commercially available well test analysis packages, such as AQTESOLV (Geraghty and Miller Software, Reston, Virginia) and AquiferTest (Waterloo Hydrogeologic, Inc., Waterloo, Ontario, Canada) incorporate many of these procedures and are also used.

\subsection{Computer Data Analysis}

Computer operations in the field and in the laboratory reflect Argonne's multidisciplinary QuickSite ${ }^{\circledR}$ approach to problem solving. The diverse suite of computer applications used was chosen by scientists in different fields. Where necessary, the computer staff extracts data from the master database in a common format for processing in the various programs. The computer programs used are described below.

\subsubsection{Requirements and Strategy}

The ESC process has two basic requirements for computer data analysis. The first requirement is for real-time retrieval, analysis, and display of data as it is collected. This interactive function, performed in the field, provides field crews with the daily information needed to make decisions regarding drilling, sampling, and data acquisition. The second requirement is for organization of data sets into databases, integration of various data types, and display of final results of data analysis. This function, which requires more sophisticated equipment and analytical procedures, is performed at Argonne.

The strategy for meeting these two distinct requirements employs two levels of computer equipment and software. In the field, data analysis is performed with portable computer equipment, with software that is especially suited to the rapid analysis of the specific data sets to be acquired in a given field operation. In the laboratory, sophisticated analytical software operating on more powerful desktop computers is used for final integration and graphic representation of data. 
Communication between the field system and the laboratory system is maintained during field operation by daily electronic transfer of data. Use of a common input data format for field and laboratory programs ensures compatibility of the two systems.

\subsubsection{Staff and Equipment}

The in-field computer procedures and software applications integrate the field data to help the scientists visualize site conditions quickly and make optimal decisions. Constant communication between the computer staff and the management staff allows for quick turnaround and thoroughness. Rapid site characterization demands that the direction of field activities be changed on the basis of new information. Therefore, the computer staff monitor the coordination of site activities to ensure that all data are incorporated into the computerized site database and distributed as rapidly as possible. Upon return from the field, more comprehensive analytical data are available, and more extensive processing and modeling are performed. The interpretations may be refined later, but in the field scientists across the technical areas need immediate access to a graphic representation of the developing conceptual model of the site.

The scientists conducting the field investigations are occupied with monitoring instruments and crews. To ensure that data input is immediate, the computer staff circulate regularly among the field activities to retrieve the latest test results. An on-site photocopier allows for quick duplication of logbooks without delaying the field crews. The data are updated throughout the day, not only at the completion of field work each day. These procedures require the computer staff, not the field scientists, to assume responsibility for collecting test results for data entry.

The computer staff includes (1) field personnel who retrieve, compile, and display data for immediate use by the field crew and (2) home base operators who integrate all data into a permanent database and generate final report displays. A field computing center is set up near the work site, preferably in the recreational vehicle that offers on-site indoor work space. Some or all the equipment might be in the living quarters of the team if no other space is available. Equipment available in the field includes portable laptop computers, desktop computers, printers, and copiers. Specific equipment to be taken to the field depends on the size and duration of the field project.

Equipment maintained in the laboratory includes a Sun SPARCstation, Macintosh and Intel-based personal computers, and dedicated printers and plotters. Laboratory computers are used for data analysis and visualization functions that include spatial and relational database 
development, geophysical data processing, groundwater modeling, log plotting, and cross section refinement. A variety of software packages is used to create final data displays for incorporation into project reports.

\subsubsection{Computer Software for Field Operations}

In the field, data are entered or imported to the extent possible into data tables via spreadsheets. The tables are designed for compatibility with and eventual importing into the master relational database. Data extracted or derived from the master files are used by the computer staff and other scientists in a number of software packages. Those listed below are currently being used. Most are representative of a number of commercial packages that perform similar functions. The programs can be operated on portable computer systems that can be used on-site during field work. Their function is to immediately compile and integrate data for use in evaluating the progress of field activities.

\subsubsection{Excel}

Microsoft Excel, from Microsoft Corporation, Redmond, Washington, is run on personal computers to create and manipulate data files in a format that is accessible to both field and laboratory computer programs. Handwritten information (such as geologic logs and location coordinates) and ASCII files produced by various data loggers are entered or imported into preformatted Excel spreadsheets and exported to analytical software packages. The data can also be plotted easily by the charting functions in the Excel spreadsheet.

\subsubsection{Access}

Microsoft Access from Microsoft Corporation, Redmond, Washington, is used in conjunction with Excel, MapInfo, and the EarthSoft EQuIS database programs for database management. Access has file format compatibility with these programs, and its report generation and query facilities expedite data reporting and manipulation. 


\subsubsection{LogPlot 2001}

Geologic descriptions of boreholes, geophysical logs, ECPT logs, and chemical sampling results are compiled and displayed with LogPlot 2001 from RockWare, Inc., Golden, Colorado. This program allows integration and comparison of various data types from a single location.

\subsubsection{Software for Geologic Sections}

Argonne has developed custom software for geologic sections.

\subsubsection{Maplnfo}

Accurate base maps of a project area are constructed before field work begins, and MapInfo, a product of MapInfo Corporation, Troy, New York, is used in the field to generate updated maps showing planned and completed field operations and sampling results. MapInfo provides scaling, georeferencing, digitizing, and direct linking of data stored in Excel and Access files.

\subsubsection{RockWorks}

RockWorks from RockWare, Inc., Golden, Colorado, is an integrated collection of earth science software that runs on a personal computer. RockWorks includes standard geology utilities for functions such as gridding and contouring, as well as tools for producing geologic diagrams and for surveying and mapping. RockWorks also includes sophisticated modules for producing and manipulating borehole logs, cross sections, models, and surfaces. Data sets from the master database are imported and combined for two- and three-dimensional views of the developing site model. RockWorks can export data in multiple formats.

\subsubsection{Surfer}

Surfer, from Golden Software in Golden, Colorado, is a contour and three-dimensional surface-mapping package. Surfer is used to generate contour maps and related interpretive displays from geologic, geophysical, and chemical data that are associated with geographic coordinates. 
AutoCAD maps and spreadsheet or text data files can be imported for plotting. Surfer creates contour plots with regular or irregular contour intervals, automatic or user-defined color zones, and color or pattern fill between contour lines. The maps can be displayed, printed, or exported to other software packages.

\subsubsection{AQTESOLV and AquiferTest}

AQTESOLV (Geraghty and Miller Software, Reston, Virginia) and AquiferTest (Waterloo Hydrogeologic, Inc., Waterloo, Ontario, Canada) are menu-driven applications for IBMcompatible personal computers that determine hydraulic properties of aquifers from pumping test and slug test data. Both packages allow on-screen visual matching of type curves to test data and automatic curve matching through nonlinear least-squares parameter estimation.

\subsubsection{GORILLA!}

GORILLA! ${ }^{\circledR}$ from A.P. van den Berg Machinefabriek B.V., Heerenveen, The Netherlands, is the data acquisition and display software used with the ECPT rigs. This software provides a graphic presentation of ECPT data for review by field scientists. Its layout editor allows creation of custom graphic displays and simultaneous printing of multiple ECPT tests.

\subsubsection{Computer Software for Laboratory Operations}

Diverse software programs are used in the laboratory in functional areas including (1) map creation, (2) spatial and relational database management, (3) data analysis and visualization, (4) geophysical data processing, and (5) groundwater modeling. Many of the applications used in the laboratory are also used in the field. The software used for laboratory functions is described below.

\subsubsection{Map Creation}

The base map for a site is digitized before field work begins, often with the use of AutoCAD from AutoDesk, Inc., Sausalito, California. The base map represents the surveyed X and $\mathrm{Y}$ locations for the site and surrounding areas. Large-format copies of the base map, produced 
before field mobilization, are distributed to project personnel and posted at the field computing center. AutoCAD sometimes is used to create original base maps in the field. Once the base map has been produced, it is imported into MapInfo (MapInfo Corporation, Troy, New York), from the spatial database carried to the field.

Original mapping sources vary, but most are derived from U.S. Geological Survey 1:24,000 topographic maps. Many of these, along with Digital Elevation Models (DEMs), are now available digitally, allowing the maps to be imported directly into MapInfo without AutoCAD digitizing. Other map sources include state, county, and municipal records and reports. Paper formats require either digitizing or scanning and registration before electronic use. MapInfo projection and translation routines allow all these maps to be viewed in a common reference grid.

Aerial photos provide records of previous structures and land use. Software programs might be required to "warp" a photo to a vector map. Software that has been used to integrate raster images and vector files includes DIMPLE, remote sensing image analysis software from Process Software, University of Wollongong, New South Wales, Australia; ENVI, hyperspectral image processing software from Eastman Kodak, Rochester, New York; and MapInfo.

\subsubsection{Spatial and Relational Database Management}

Two relational database management systems from EarthSoft, Inc., of Pensacola, Florida, are used to organize and archive site data. EQuIS Geology, used for geologic logs, ECPT electronics files, water level measurements, borehole coordinates, and other subsurface parameters, includes links to GMS (Section 6.8.4.3) and LogPlot. Because the database files are in Microsoft Access format, reporting and exporting can be done from Access as well as from EQuIS. SQL Server and Oracle versions are also available.

EQuIS Chemistry is used to store and manage analytical data. It includes templates for data input from Excel and can also accommodate various electronic data deliverable (EDD) formats. Like EQuIS Geology, it has links to GMS, LogPlot, and other popular geoscience programs, and it stores data in Microsoft Access format.

Relational data from EQuIS Geology and Chemistry are displayed in MapInfo, so that the contaminant extent can be viewed on any of the maps incorporated into the MapInfo spatial 
database for a site. Because each EQuIS data record is linked to a specific geographic location (usually a well or soil boring location), all data can all be visualized in MapInfo.

MapInfo is augmented by its optional programming language, MapBasic, also from MapInfo Corporation, Troy, New York. This language allows customization and automation of graphic data displays, such as posting of analytical values by depth on borehole maps.

\subsubsection{Data Analysis and Visualization}

Data visualization is a term that encompasses the integration of all data sources into a graphic, spatial display that helps scientists interpret results and communicate the findings of a site characterization. A number of the software programs already discussed contribute to visualization of site data. The representation builds from two-dimensional plots and maps, logs, and cross sections developed in the RockWare software, plus groundwater modeling outputs, to threedimensional views produced in Surfer, Visual MODFLOW, RockWorks, and Slicer Dicer from PIXOTEC, LLC, of Renton, Washington. The final displays for project reports are often produced as a graphic combination of output from many of these packages in a computer graphics program such as Adobe Illustrator from Adobe Systems, Mountain View, California.

Several software packages are used to analyze data for significant features. Slicer Dicer (available separately or bundled with RockWorks) enables many different two- and threedimensional representations of large data sets. PV-WAVE from Visual Numerics, Boulder, Colorado, provides integrated graphics, image processing, statistics, signal processing, and mathematical capabilities. It allows users to interactively access, analyze, manipulate, and visualize multidimensional data to understand trends, draw conclusions, and produce results.

Two groundwater modeling software packages also include tools for site visualization. Groundwater Modeling System (GMS), developed under the direction of the U.S. Army Corps of Engineers and with support from the Department of Defense, DOE, and the EPA, provides a complete groundwater modeling environment, integrating models (e.g., MODFLOW, MODPATH, MT3D) with tools for site characterization and model conceptualization. Visual MODFLOW, from Waterloo Hydrogeologic, Inc., of Waterloo, Ontario, Canada, also provides a graphic modeling environment in three-dimensional space. These programs are used as tools to integrate site characterization findings and reveal the implications. 


\subsubsection{Geophysical Data Processing}

Processing of geophysical data is discussed in Section 6.6.

\subsubsection{Geochemical Interpretation}

Software used for geochemical interpretation of groundwater analyses for QuickSite ${ }^{\circledR}$ investigations includes geochemical plotting programs, geochemical modeling programs, and combined modeling and plotting programs. Appropriate software is selected to fit the scope of each geochemical investigation.

Microsoft Excel is a spreadsheet used as a geochemical plotting program to convert chemical concentrations to milliequivalents per liter, compute the charge balance, and plot Piper diagrams. This simple plotting program enables evaluation, classification, and grouping of sample points.

Visual MINTEQ is a geochemical modeling program (a Windows version of MINTEQA2 version 4.0) from Kungl Teknisks Högskolan (Royal Institute of Technology), Stockholm, Sweden. MINTEQA2 is an equilibrium speciation model that calculates the equilibrium compositions of dilute aqueous solutions in the laboratory or in natural aqueous systems. Specifically, the model calculates the equilibrium mass distribution among dissolved species, adsorbed species, and multiple solid phases under a variety of conditions including a gas phase with constant partial pressures. The comprehensive database included is adequate for solving a broad range of problems without additional user-supplied equilibrium constants. PHREEQC is a similar program from the U.S. Geological Survey that performs a variety of geochemical calculations for low-temperature aqueous systems. Results from these programs are produced in tabular form. Graphic displays of the results, such as Piper, Stiff, or Schoeller diagrams, can be generated separately. Online software sources are as follows:

- Visual MINTEQ: http://www.lwr.kth.se/english/OurSoftWare/vminteq/index.htm

- PHREEQC: http://wwwbrr.cr.usgs.gov/projects/GWC_coupled/phreeqc/index.html 
The third geochemical interpretation software category links basic geochemical calculations, modeling software, and graphic displays in a single package. In this category, Argonne uses AquaChem software (from Waterloo Hydrogeologic, Inc., Waterloo, Ontario, Canada), as the primary geochemical processing software for QuickSite ${ }^{\circledR}$ investigations. AquaChem, which combines processing and plotting software with the PHREEQC geochemical modeling program, can generate Piper, Stiff or Schoeller diagrams to display geochemical data.

\subsubsection{Groundwater Modeling}

Software used in the laboratory for groundwater modeling includes MODFLOW, MODPATH, GWPATH, ODAST, BIOSCREEN, AT123, MT3D, Surfer for Windows, Processing Modflow, Visual MODFLOW, and SESOIL. See Section 6.9 for details about groundwater modeling.

\subsection{Groundwater Modeling}

Groundwater modeling as discussed here consists of the mathematical simulation or prediction of groundwater movement, or of coupled groundwater flow and contaminant transport, in the subsurface on the basis of fundamental mass and momentum balance equations that describe these processes. (See, for example, Anderson and Woesner 1992.) In the context of the QuickSite ${ }^{\circledR}$ process, groundwater modeling can play a number of roles. In earlier stages of an investigation, mathematical modeling is a tool in interpreting and integrating available field data and in refining the site conceptual hydrogeologic model. In later phases, mathematical simulations can predict the expected performance of alternative groundwater remediation scenarios and provide input for the estimation of health and environmental risks. Throughout the site investigation, models provide a means of (1) evaluating possible groundwater flow and contaminant transport mechanisms and (2) illustrating flow and transport patterns in complex hydrogeologic systems.

To use groundwater modeling effectively in such varied ways, the detailed aspects of model formulation, calibration and testing, application, and subsequent documentation must be individually tailored to the specific hydrogeologic setting and technical program objectives identified for each site. The general guidelines below are applicable to all modeling programs in QuickSite ${ }^{\circledR}$ investigations. 


\subsubsection{Model Formulation}

Site-specific groundwater flow and transport models are developed by using published or commercially available modeling packages (typically computer program codes) that (1) have been extensively tested, (2) are fully documented, and (3) have an established track record of acceptance by environmental regulatory and other agencies involved in the investigation of groundwater issues. Modeling packages and supporting software currently available for use in QuickSite ${ }^{\circledR}$ investigations are briefly summarized below. All of the programs listed are available for use on either desktop or portable, Intel 80 X86 (X = 3 or greater) or Pentium-based computers. The programs are as follows:

- $M O D F L O W$

MODFLOW is a modular, three-dimensional, finite-difference code originally developed by the U.S. Geological Survey (McDonald and Harbaugh 1988). The code has subsequently been updated and enhanced many times (e.g., Harbaugh and McDonald 1996; Harbaugh et al. 2000) for the simulation of groundwater flow in complex, heterogeneous aquifer systems. Capable of representing a wide variety of groundwater source, sink, and boundary conditions under both steady-state and transient flow conditions, MODFLOW interfaces directly with both the MODPATH and MT3D packages.

- $M O D P A T H$

MODPATH is a semianalytical code developed by the U.S. Geological Survey (Pollock 1989) to calculate three-dimensional particle tracking (advective transport) path lines on the basis of output from steady-state simulations obtained with MODFLOW. MODPATH supports all steady-state groundwater source, sink, and boundary condition options available in MODFLOW.

- $\quad$ GWPATH

GWPATH is a numerical particle tracking code (Shafer 1992) for the estimation of advective transport path lines in two dimensions. It will accept output from any steady-state, numerical or analytical, saturated groundwater flow model.

\section{- ODAST}

ODAST is an analytical code (Javandel et al. 1987) for the simulation of onedimensional solute transport in a uniform flow field. ODAST incorporates the effects of solute dispersion, decay, and adsorption. 
- BIOSCREEN

BIOSCREEN is a spreadsheet-based analytical model (Newell et al. 1996) for the simulation of two-dimensional solute transport. BIOSCREEN incorporates dispersion, adsorption, and biodegradation.

- $\quad A T 123$

AT123 is an analytical code (Yeh 1981; current version available from International Groundwater Modeling Center, Colorado School of Mines, Golden, Colorado) for the estimation of transient one-, two-, or threedimensional solute transport in a homogeneous, isotropic aquifer with uniform groundwater flow. AT123 includes the effects of dispersion, adsorption, and solute decay.

\section{- $\quad$ MT3D and MT3D 99}

MT3D is a modular numerical code (Zheng 1992,1996) for the simulation of three-dimensional solute transport in complex hydrogeologic settings under both steady-state and transient conditions. MT3D interfaces directly with MODFLOW and other block-centered finite-difference flow programs. Capable of representing solute dispersion, adsorption, decay, and chemical reactions, plus a range of solute sources and sinks, it supports all groundwater source, sink, and boundary conditions available in MODFLOW. MT3D 99 (Zheng 1999) is an enhanced version of the original MT3D code that incorporates improved numerical solution techniques for the governing solute transport equations, as well as provisions for simulating multispecies transport.

- $\quad$ Surfer for Windows

Surfer for Windows is a menu-driven, graphics-based application (Golden Software 1995) for the production, editing, display, and printing of contour and three-dimensional surface maps in a range of formats from input $\mathrm{X}-\mathrm{Y}-\mathrm{Z}$ data sets. Surfer enables the manipulation of input data sets and the gridding of irregularly spaced data by using multiple interpolation schemes.

- $\quad$ Processing Modflow and Visual MODFLOW

Processing Modflow (Chiang and Kinzelbach 1998) and Visual MODFLOW (Waterloo 1999) are menu-driven, graphics-based interface programs that can be used to assemble and edit input data files required for use with MODFLOW, 
MT3D, AND MODPATH, as well as to display and analyze the results of simulations generated by these programs.

- SESOIL

SESOIL is a seasonal soil compartment model (Bonazountas and Wagner 1984) for the simulation of groundwater movement and contaminant migration in the vadose zone. SESOIL integrates the output of three submodels that address, respectively, runoff from the soil surface, moisture movement within the subsurface, and pollutant fate and transport (the last by incorporating chemical partitioning, retardation, and degradation).

The appropriate modeling packages for any given investigation are selected case by case; however, MODFLOW and MT3D are considered the primary groundwater flow and solute transport packages, respectively, for most QuickSite ${ }^{\circledR}$ investigations. Other modeling packages in addition to those listed may be employed as necessary, if they meet the basic acceptability criteria outlined above.

The physical scale (areal extent and depth) of the hydrogeologic domain to be modeled and the level of complexity (one, two, or three dimensions; analytical versus numerical solution; scale of spatial discretization; etc.) to be represented in mathematical models must be tailored to the specific characteristics of each site. Whenever possible, however, the modeled domain should be sized to take optimal advantage of any natural physical boundaries or stable hydraulic boundaries that might affect groundwater flow or solute transport processes near the site. Several models at different scales might be required, with telescopic mesh refinement (Anderson and Woessner 1992) being used to establish suitable boundary conditions for the site. To the extent possible, sitespecific data (including aquifer characteristics; boundary conditions; water levels; source and sink locations and flow rates; local rainfall and recharge; surface drainage characteristics; contaminant properties, concentrations, and distribution) that are relevant to the physical domain and process(es) being simulated should be used in construction of the models. Where specific data are lacking, the use of parameter values obtained from previous Argonne investigations at hydrogeologically similar locations, or from valid published analogs, might be necessary.

\subsubsection{Calibration and Testing}

Model calibration is routinely carried out by using an iterative trial-and-adjust procedure. Detailed notes are to kept of each calibration step, so that the chain of adjustments leading to the 
final calibrated model can be evaluated or recreated if necessary. Numerical inverse-modeling algorithms like the U.S. Geological Survey package MODFLOWP (Hill 1992), may be used when they are applicable to the conditions of specific investigations.

Evaluation of the model calibration is based on both quantitative and qualitative assessment of the overall hydrogeologic reasonableness of the model results. Example parameters and approaches that may be used to develop the calibration include matching of simulated and measured hydraulic heads under both steady-state and transient flow conditions; comparison of estimated recharge rates with measured recharge and rainfall data; matching of groundwater flow directions and hydraulic gradients under steady-state and transient conditions; simulation of aquifer pumping tests results; matching of documented pumping or natural discharge rates; and simulation of contaminant migration, plume formation, and concentrations. A quantitative analysis of the "goodness-of-fit" of the final calibration, in the form of appropriate graphs or tables presenting residual error values, must be included in documentation of the model.

Sensitivity testing of the resulting calibrated model is carried out by systematically varying each model input parameter over a range of values, either representing the uncertainty of the parameter estimated from field data or based on published or Argonne data for the parameter at analogous sites. A quantitative analysis of the effects of uncertainty in each parameter on the model calibration, in the form of appropriate graphs or tables presenting change in the calibration versus change in parameter values, must be included in documentation of the model.

\subsubsection{Model Application}

Mathematical groundwater flow and transport models might be developed for numerous reasons as part of the QuickSite ${ }^{\circledR}$ process, and the intended application of any given model might change during an investigation. The modeler and the project manager are to determine the suitability of each model for any given purpose. In all cases, a conservative approach should be used in the selection of appropriate models and key model parameters.

A conservative approach is particularly critical if simulation results are to be used in prediction of the expected performance of groundwater remediation scenarios or to provide input for the estimation of health and environmental risks. The results of simulations present an approximation to the net effects of actual remediation strategies and aquifer system behavior at a site. These results are subject to uncertainties, and therefore they should be considered a 
semiquantitative guide to expected system performance. Simulations of possible remedial actions should be based on technically feasible scenarios that are tailored to the specific conditions of the site and demonstrate the range of cleanup options available. A long-term estimate of conditions under a no-action alternative, taking into consideration both existing and potential groundwater discharge points, is to be included. Modeling of solute transport for the prediction of contaminant levels should include simulations of possible worst-case and most probable contaminant migration scenarios, in order to provide a conservative range of concentration estimates for use in subsequent risk assessment calculations.

An analysis of the results of any predictive simulations, including a full summary of all parameters (pumping rates, well locations, initial concentrations, etc.) used in the predictions, must be included in documentation of the model application.

\subsubsection{Documentation}

The exact format and content of the documentation provided for each modeling exercise will vary in a site-specific way, but the documentation must at minimum include the following:

- A statement of the technical objectives of the modeling exercise

- A summary of the key hydrogeologic factors pertaining to the site that form the basis of the conceptual model and serve as critical constraints imposed on the mathematical model

- A description of the basic features of the mathematical model, including dimensions and orientation of the modeled domain relative to the site and codes used

- A description of the calibration approach, calibration targets, and all assumptions used in calibration of the model

- A complete summary of all parameter values incorporated in the final model, with an evaluation of the resulting goodness of fit 
- A summary of the results of sensitivity testing of the calibrated model, with a discussion of the identified uncertainty levels

- An evaluation of the impact of model uncertainties, including critical assumptions, on any conclusions that might be drawn from simulations or predictions generated with the calibrated model 


\section{References}

Anderson, M., and W. Woessner, 1992, Applied Groundwater Modeling: Simulation of Flow and Advective Transport, Academic Press, Inc., New York.

ASTM, 1998, "Standard Practice for Expedited Site Characterization of Vadose Zone and Groundwater Contamination at Hazardous Waste Contaminated Sites," D6235 in Annual Book of ASTM Standards, American Society for Testing and Materials, West Conshohocken, Pennsylvania.

Bonazountas, M., and J. Wagner, 1984, SESOIL - A Seasonal Soil Compartment Model, Arthur J. Little, Inc., Cambridge, Massachusetts.

CDM, 1987, Data Quality Objectives for Remedial Response Actions: Development Process, prepared for Office of Emergency and Remedial Response and Office of Waste Programs Enforcement, Office of Solid Waste and Emergency Response, U.S. Environmental Protection Agency, EPA contract 68-01-6939, by CDM Federal Programs Corporation, Annandale, Virginia, March.

Chiang, W.H., and W. Kinzelbach, 1998, Processing Modflow - A Simulation System for Modeling Groundwater Flow and Pollution, Hamburg-Zurich, December.

EPA, 1987, "Superfund Program: Interim Guidance on Compliance with Other Applicable or Relevant and Appropriate Requirements," Federal Register 52(166):32496-32499, August 27.

EPA, 1988, CERCLA Compliance with Other Laws Manual: Interim Final, EPA/540/G-98/006, U.S. Environmental Protection Agency, August.

EPA, 1989a, CERCLA Compliance with Other Laws Manual: Part II. Clean Air Act and Other Environmental Statutes and State Regulations, EPA/540/G-89/009, U.S. Environmental Protection Agency, August.

EPA, 1989b, USEPA Contract Laboratory Program Statement of Work for Organic Analysis: Multi-Media, Multi-Concentration, U.S. Environmental Protection Agency SOW No. 2/88, Including Revisions 9/88 and 4/89. 
EPA, 1989c, USEPA Contract Laboratory Program Statement of Work for Inorganic Analysis: Multi-Media, Multi-Concentration, U.S. Environmental Protection Agency SOW No. 7/88, Including Revisions 2/89 and 6/89.

EPA, 1989d, Determining when Land Disposal Restrictions (LDRs) Are Applicable to CERCLA Response Actions, Superfund publication 9347.3-05FS, U.S. Environmental Protection Agency, Office of Solid Waste and Emergency Response, July (Appendix B in EPA 1991).

EPA, 1991, Management of Investigation-Derived Wastes During Site Inspections, OEER Directive 9345.3-02, EPA/540/G-91/009, U.S. Environmental Protection Agency, Office of Emergency and Remedial Response, May.

EPA, 1992, Guide to Management of Investigation-Derived Waste, Pub. 9345.3-03FS, U.S. Environmental Protection Agency, Office of Solid Waste and Emergency Response, April.

EPA, 1994, USEPA Contract Laboratory Program (CLP) National Functional Guidelines for Organic Data Review, EPA540/R-94/012, Office of Emergency and Remedial Response, U.S. Environmental Protection Agency, Washington, D.C., February.

EPA, 1998a, Superfund and EPCRA Hotline Training Module, Introduction to: Applicable or Relevant and Appropriate Requirements, U.S. Environmental Protection Agency, Office of Solid Waste and Emergency Response, February.

EPA, 1998b, Test Methods for Evaluating Solid Waste: Physical/Chemical Methods, EPA SW-846, 3rd edition, Draft Update IVA, U.S. Environmental Protection Agency, January.

Freeze, R.A., and J.A. Cherry, 1979, Groundwater, Prentice Hall, Englewood Cliffs, New Jersey.

Golden Software, 1995, Surfer ${ }^{\mathrm{TM}}$ for Windows: Version 6 User's Guide, Golden Software, Inc., Golden, Colorado.

Greenberg, A.E., et al. (editors), 1992, Standard Methods for the Examination of Water and Wastewater, 18th ed., American Public Health Association, 
Harbaugh, A., and M. McDonald, 1996, User's Documentation for MODFLOW-96: An Update to the U.S. Geological Survey Modular Finite-Difference Ground-Water Flow Model, Open-File Report 96-485, U.S. Geological Survey, Washington, D.C.

Harbaugh, A., E. Banta, M. Hill, and M. McDonald, 2000, MODFLOW-2000, the U.S. Geological Survey Modular Ground-Water Model - User Guide to Modularization Concepts and the Ground-Water Flow Process, Open File Report 00-92, U.S. Geological Survey, Washington, D.C.

Hill, M., 1992, MODFLOWP: A Computer Program for Estimating Parameters of a Transient, Three-Dimensional Groundwater Flow Model Using Nonlinear Regression, Open-File Report 91-484, U.S. Geological Survey, Washington, D.C.

Javandel, I., C. Doughty, and C. Tsang, 1987, “ODAST: A Computer Program for Evaluation of the Analytical Solution for One-Dimensional Contaminant Transport," pp. 129-132 in Groundwater Transport: Handbook of Mathematical Models, Water Research Monograph 10, American Geophysical Union, Washington, D.C.

Kawecki, M., 1993, "Recovery Analysis from Pumping Tests with Stepped Discharge," Ground Water 31(4):585-592.

Kelly, D., 1991, Collection and Interpretation of Pneumatic Slug Test Data in a Highly Permeable Aquifer, M.S. Thesis, University of Illinois, Urbana, Illinois.

Kruseman, G., and N. deRidder, 1991, Analysis and Evaluation of Pumping Test Data, International Institute for Land Reclamation and Improvement, The Netherlands.

McDonald, M., and A. Harbaugh, 1988, "A Modular Three-Dimensional Finite-Difference Groundwater Flow Model [MODFLOW]," Chapter A1 in Modeling Techniques, Techniques of Water Resources Investigations Book 6, U.S. Geological Survey, Washington, D.C.

National Ground Water Association, 1989, Handbook of Suggested Practices for the Design and Installation of Ground Water Monitoring Wells, Dublin, Ohio. 
Newell, C.J., R.K. McLeod, and J.R. Gonzales, 1996, BIOSCREEN: Natural Attenuation Decision Support System - User's Manual, EPA/600/R-96/087, U.S. Environmental Protection Agency, Cincinnati, Ohio.

Pollock, D., 1989, Documentation of Computer Programs to Compute and Display Pathlines Using Results from the U. S. Geological Survey Modular Three-Dimensional Finite-Difference Groundwater Flow Model [MODPATH], Open-File Report 89-381, U.S. Geological Survey, Washington, D.C.

Prosser, D., 1981, “A Method of Performing Response Tests on Highly Permeable Aquifers," Ground Water 19(6):588-592.

Schlenker, 1991, letter from R. Schlenker, Nebraska Department of Environmental Control, Lincoln, Nebraska, to H. Harrington, Ogallala Electronics, Ogallala, Nebraska, April 11.

Shafer, J., 1992, GWPATH: Groundwater Pathline and Travel Time Analysis, Version 4.0 User's Manual, J.M. Shafer, Columbia, South Carolina.

Waterloo, 1999, User's Manual for Visual MODFLOW, Waterloo Hydrogeologic, Inc., Waterloo, Ontario, Canada.

Yeh, G., 1981, AT123D: Analytical Transient One-, Two-, and Three-Dimensional Simulation of Waste Transport in the Aquifer System, Environmental Sciences Division Publication 1439, Oak Ridge National Laboratory, Oak Ridge, Tennessee.

Zheng, C., 1992, MT3D: A Modular, Three-Dimensional Transport Model for Simulation of Advection, Dispersion and Chemical Reactions of Contaminants in Groundwater Systems, Documentation and User's Guide V. 1.5, S.S. Papadopulos and Associates, Inc., Bethesda, Maryland.

Zheng, C., 1996, MT3D 96 User's Guide and Input Instructions, S.S. Papadopulos and Associates, Inc., Bethesda, Maryland.

Zheng, C., 1999, MT3D99: A Modular 3D Multispecies Transport Simulator User's Guide, S.S. Papadopulos and Associates, Inc., Bethesda, Maryland. 


\section{Appendix A:}

\section{Site Safety Review Form}




\section{Site Safety Review Form}

\section{Documentation of Changes in Site Health and Safety Plan}

Was the health and safety plan followed as presented?

Yes:

No:

Describe, in detail, any changes to the health and safety plan:

Reason for changes:

Followup, review, and evaluation prepared by:

Date:

Discipline:

Approved by:

Project Manager

Date:

Health and Safety Coordinator

Date: 


\section{Evaluation of Site Health and Safety Plan}

Was the health and safety plan adequate?

Yes:

No:

What changes would you recommend? 


\section{Appendix B:}

\section{Tailgate Safety Meeting Form}




\section{TAILGATE SAFETY MEETING}

Division

Date

Customer

Specific Location/Address

Type of Work

Chemicals Used
Facility

Time

Address

\section{SAFETY TOPICS PRESENTED}

Protective Clothing/Equipment

Chemical Hazards

Physical Hazards

Emergency Procedures

Hospital/Clinic

Hospital Address

Special Equipment

Other

\section{ATTENDEES}

Name Printed

Meeting conducted by:

Name Printed

Supervisor
Signature

Manager 


\section{Appendix C:}

\section{Material Safety Data Sheets}




\section{Contents}

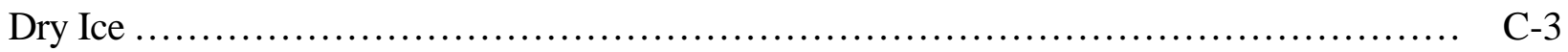

Carbon Tetrachloride........................................................................ C-9

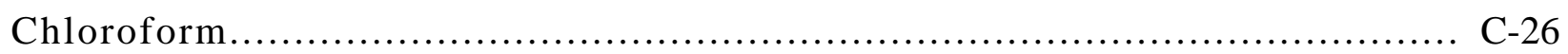

Hydrochloric Acid (10-33\%) ............................................................ C-47

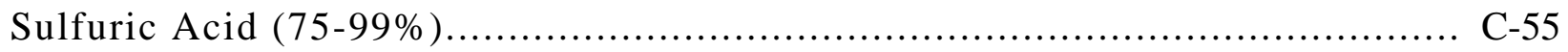




\title{
CARBON DIOXIDE SOLID (DRY ICE)
}

Product: 0000776

Revision date: 1999/02/15

\author{
Section 1: PRODUCT INFORMATION \\ Section 2: HAZARDOUS INGREDIENTS \\ Section 3: PHYSICAL DATA \\ Section 4: FIRE \& EXPLOSION DATA \\ Section 5: REACTIVITY DATA \\ Section 6: TOXICOLOGICAL PROPERTIES \\ Section 7: PREVENTATIVE MEASURES \\ Section 8: FIRST AID MEASURES \\ Section 9: ADDITIONAL INFORMATION
}

\section{Section 1: PRODUCT INFORMATION}

Chemical family: Oxides.

Supplier: Same as manufacturer.

Dry ice

Manufacturer: Praxair Products Inc.

1 City Centre Drive

Suite 1200

Mississauga, Ontario

Canada L5B 1M2

(905)803-1600.

Manufacturer emergency 800-363-0042. phone number:

TDG classification:

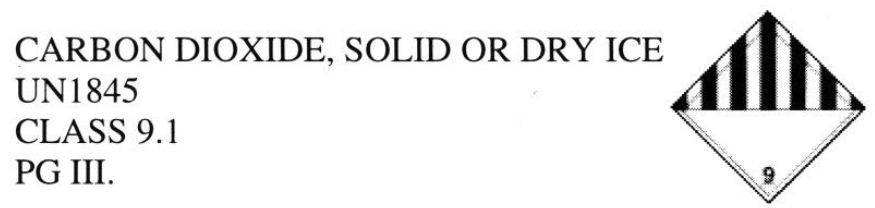

WHMIS classification:

E

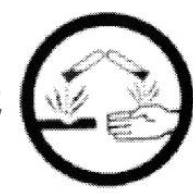

DSL status: Appears on DSL.

Supplier MSDS date: 1998/11/01 


\begin{tabular}{|l|l|l|l|l|l|}
\hline C.A.S. & Cuncentration of & Ingredient Name & TLV & LD50 & LC50 \\
\hline $124.38-9$ & 100 & CARBON DIOXIDE & 5000 PPM & NOT AVAILABLE & NOT AVAll.ABLE \\
\hline
\end{tabular}

\section{Section 3: PHYSICAL DATA}

Physical state: Solid

Appearance \& odor: Sublimes giving off carbon dioxide vapor which produces a sharp nasal sensation.

White solid in the form of snow.

Odor threshold (PPM): Odorless.

Vapour pressure (mm hg): (@ $20^{\circ} \mathrm{C}$ )

830 psig

Vapour density (air=1): $1.52\left(@ 21^{\circ} \mathrm{C}\right)$

Volatiles (\%)

By volume: 100

Evaporation rate (butyl acetate $=1$ ): High

Boiling point $\left({ }^{\circ} \mathrm{C}\right)$ : Sublimation point $=-78.5^{\circ} \mathrm{C}$

Freezing point $\left({ }^{\circ} \mathrm{C}\right)$ : Not applicable,

PH: Not applicable.

Specific gravity $20^{\circ} \mathrm{C}$ : Not applicable.

Solubility in water $(\%)$ : Slight.

Coefficient of waterbil dist.: Not applicable. 
Flammability: Not flammable.

Conditions of flammability: Not applicable.

Extinguishing Media:

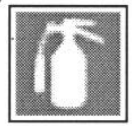

Use appropriate extinguishing media for surrounding fire.

Special procedures: Self-contained breathing apparatus required.

Firefighters should wear the usual protective gear.

Auto-ignition temperature: Not applicable.

Flash point $\left({ }^{\circ} \mathbf{C}\right)$, method: Not applicable.

Lower flammability

limit (\% vol):

Not applicable.

Upper flammability limit (\% vol): Not applicable.

Explosion Data

Sensitivity to static
discharge:

Sensitivity to mechanical
impact:

Hazardous combustion
products:

Explosive power: Not applicable.

\section{Section 5: REACTIVITY DATA}

Chemical stability: Stable under normal conditions.

Conditions of reactivity: In the presence of moisture, will form carbonic acid which may corrode some metals.

Hazardous polymerization: Will not occur.

Compatibility With Other

Substances

Incompatible substances: Alkali metals.

Chromium.

Hazardous decomposition

products: None 
MSDSDRY ICEP. 4 of 6

\section{Section 6: TOXICOLOGICAL PROPERTIES}

Route of entry: Skin contact, eye contact, inhalation and ingestion.

Eye Contact:

(O) Vapour may cause a stinging sensation.

Skin Contact:

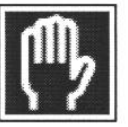

Can cause severe frostbite.

Inhalation:

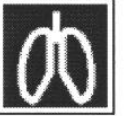

High vapor concentrations may cause drowsiness, slurred speech, nausea, headache or light-headedness.

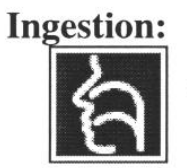

Can cause severe burns.

Effects of chronic exposure: None

LD50 of product, species \&
route:

LC50 of product, species \& Not available.

Exposure limit of material: See hazardous ingredients section.

Sensitization to product: None

Carcinogenic effects: None known.

Reproductive effects: None known.

Teratogenicity: None known.

Mutagenicity: None known.

Synergistic materials: None known. 


\section{Section 7: PREVENTATIVE MEASURES}

Precautionary Measures

Gloves/Type:

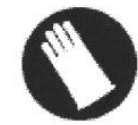

Insulated gloves.

Respiratory/Type: In case of oxygen deficient atmosphere.

Niosh approved.

\section{Eye/Type:}

Safety glasses with side shields (or goggles) and a face shield.

Footwear/Type: Safety boots per local regulations.

Clothing/Type: Wear adequate protective clothes.

Other/Type: Eye wash facility should be in close proximity.

Emergency shower should be in close proximity.

Ventilation requirements: Mechanical ventilation is satisfactory.

Leak/Spill: Evacuate all non-essential personnel.

Do not touch spilled material.

Stop leak without risk.

Wear appropriate protective equipment.

Stay upwind.

Allow to evaporate to atmosphere.

Waste disposal: In accordance with municipal, provincial and federal regulations.

Handling procedures and Maintain a good personal hygiene.

equipment: Use adequate ventilation.

Wear personal protective equipment appropriate to task.

Avoid all personal contact.

Storage requirements: Store in a well ventilated area.

Store away from incompatible materials.

Store in a cool and dry place.

Avoid storing container in a confined area.

Special shipping information: See transportation information. 


\section{Section 8: FIRST AID MEASURES}

MSDS DRTICE P, 6 of 6

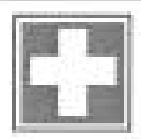

Skin contact: Treat for frostbite if necessary.

Obtain medical attention.

Eye contact: For frostbite, rinse with warm water for 15 minutes and obtain immediate medical attention.

Inhalation: Remove victim to fresh air. If not breathing qualified personnel should administer artificial respiration. Get medical attention.

Keep person warm and at rest.

If breathing is difficult, administer oxygen.

Ingestion: Obtain immediate medical attention.

Treat for possible frostbite.

Additional information: The above information is believed to be correct but does not purport to be all inclusive and shall be used only as a guide. This company shall not be held liable for any inaccuracies.

\section{Section 9: ADDITIONAL INFORMATION}

General note: This material safety data sheet was prepared from information obtained from various sources, including product suppliers and the canadian centre for occupational health and safety.

Issued by: Environment, health and safety.

Data prepared by: Conform-Action Data Systems

A division of 2843471 Canada inc:

1975 Hymus Blyd. suite 230

Dorval, QC H9P 1 J8

Tel: (514) 683-2060 Fax: (514) 683-1445

24 hr. 1-800-990-5093 support @ netmsds.com.

This Material Safety Data Sheet was generated by Conform-Plus Application Service. Visit us at www.netmsds.com. 


\section{MATERIAL SAFETY DATA SHEET ${ }^{\text {MTAMSD }} 19$

SECTION 1 CHEMICAL PRODUCT AND COMPANY IDENTIFICATION

MATHESON TRI-GAS, INC.

959 ROUTE 46 EAST

PARSIPPANY, NEW JERSEY USA 07054-0624 OR

530 WATSON STREET

WHITBY, ONTARIO, CANADA L1N 5R9
EMERGENCY CONTACT:

CHEMTREC 1-800-424-9300

INFORMATION CONTACT:

(USA) 973-257-1100

(WHITBY) 905-668-3570

(EDMONTON) 780-471-4036

\section{SUBSTANCE: CARBON TETRACHLORIDE}

TRADE NAMES/SYNONYMS:

MTG MSDS 19; TETRACHLOROMETHANE; PERCHLOROMETHANE; CARBON CHLORIDE; TETRACHLOROCARBON; METHANE TETRACHLORIDE; CARBON TET; FREON 10; HALON 104; BENZINOFORM; STCC 4940320; UN 1846; C-186; C-187; C-199; C-570; C-612; RCRA U211; MAT04310; RTECS FG4900000

CHEMICAL FAMILY: halogenated, aliphatic

CREATION DATE: Jan 241989

REVISION DATE: Mar 222001

SECTION 2 COMPOSITION, INFORMATION ON INGREDIENTS

COMPONENT: CARBON TETRACHLORIDE

CAS NUMBER: 56-23-5

EC NUMBER (EINECS): 200-262-8

EC INDEX NUMBER: 602-008-00-5

PERCENTAGE: 100.0

\section{SECTION 3 HAZARDS IDENTIFICATION}

NFPA RATINGS (SCALE 0-4): HEALTH=3 FIRE $=0$ REACTIVITY $=0$

EMERGENCY OVERVIEW:

COLOR: colorless

PHYSICAL FORM: liquid

ODOR: sweet odor

MAJOR HEALTH HAZARDS: central nervous system depression, suspect cancer hazard (in animals)

POTENTIAL HEALTH EFFECTS: 
INHALATION:

SHORT TERM EXPOSURE: irritation, digestive disorders, headache, symptoms of drunkenness, lung congestion, kidney damage, liver damage, effects on the brain, convulsions, coma

LONG TERM EXPOSURE: visual disturbances, reproductive effects, cancer

SKIN CONTACT:

SHORT TERM EXPOSURE: same as effects reported in short term inhalation, rash, symptoms of drunkenness, kidney damage, liver damage

LONG TERM EXPOSURE: same as effects reported in long term inhalation

EYE CONTACT:

SHORT TERM EXPOSURE: no information on significant adverse effects

LONG TERM EXPOSURE: no information is available

INGESTION:

SHORT TERM EXPOSURE: same as effects reported in short term inhalation, symptoms of drunkenness, lung congestion, kidney damage, liver damage

LONG TERM EXPOSURE: cancer

CARCINOGEN STATUS:

OSHA: No

NTP: Yes

IARC: Yes

\section{SECTION 4 FIRST AID MEASURES}

INHALATION: If adverse effects occur, remove to uncontaminated area. Give artificial respiration if not breathing. Get immediate medical attention.

SKIN CONTACT: Wash skin with soap and water for at least 15 minutes while removing contaminated clothing and shoes. Get medical attention, if needed. Thoroughly clean and dry contaminated clothing and shoes before reuse.

EYE CONTACT: Flush eyes with plenty of water for at least 15 minutes. Then get immediate medical attention.

INGESTION: Get medical attention immediately.

NOTE TO PHYSICIAN: For ingestion, consider gastric lavage. Avoid stimulants.

\section{SECTION 5 FIRE FIGHTING MEASURES}

FIRE AND EXPLOSION HAZARDS: Negligible fire hazard.

EXTINGUISHING MEDIA: regular dry chemical, regular foam, water

Large fires: Use regular foam or flood with fine water spray.

FIRE FIGHTING: Move container from fire area if it can be done without risk. Fight large fires from a protected location or safe distance. Stay away from the ends of tanks. Dike for later disposal. Do not scatter spilled material with high-pressure water streams. 
FLASH POINT: No data available.

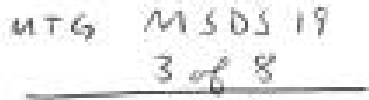

\title{
SECTION 6 ACCIDENTAL RELEASE MEASURES
}

\begin{abstract}
AIR RELEASE:
Reduce vapors with water spray. Stay upwind and keep out of low areas. Collect runoff for disposal as potential hazardous waste.
\end{abstract}

\section{SOIL RELEASE:}

Dig holding area such as lagoon, pond or pit for containment. Dike for later disposal. Absorb with sand or other non-combustible material. Collect with absorbent into suitable container.

\section{WATER RELEASE:}

Trap spilled material at bottom in deep water pockets, excavated holding areas or within sand bag barriers. Remove trapped material with suction boses. Absorb with activated carbon. Collect spilled material using mechanical equipment. Subject to California Safe Drinking Water and Toxic Enforcement Act of 1986 (Proposition 65). Keep out of water supplies and sewers.

\section{OCCUPATIONAL RELEASE:}

Do not touch spilled material. Stop leak if possible without personal risk. Reduce vapors with water spray. Small spills: Absorb with sand or other non-combustible material. Collect spilled material in appropriate container for disposal. Small dry spills: Move containers away from spill to a safe area. Large spills: Dike for later disposal. Keep unnecessary people away, isolate hazard area and deny entry. Ventilate closed spaces before entering. Notify Local Emergency Planning Committee and State Emergency Response Commission for release greater than or equal to RQ (U.S. SARA Section 304). If release occurs in the U.S. and is reportable under CERCLA Section 103, notify the National Response Center at (800)424-8802 (USA) or (202)426-2675 (USA).

\section{SECTION 7 HANDLING AND STORAGE}

STORAGE: Store and bandle in accordance with all current regulations and standards. Keep separated from incompatible substances. Protect from physical damage. Store in a cool, dry place. Store in a well-ventilated area. Avoid heat, flames, sparks and other sources of ignition.

\section{SECTION 8 EXPOSURE CONTROLS, PERSONAL PROTECTION}

\author{
EXPOSURE LIMITS: \\ CARBON TETRACHLORIDE: \\ 10 ppm OSHA TWA \\ $25 \mathrm{ppm}$ OSHA ceiling \\ 200 ppm OSHA peak 5 minute(s)/4 hour(s) \\ 2 ppm ( $12.6 \mathrm{mg} / \mathrm{m} 3$ ) OSHA TWA (vacuted by 58 FR 35338, June 30, 1993) \\ 5 ppm ACGIH TWA (skin) \\ 10 PPM ACGIH STEL \\ $2 \mathrm{ppm}$ ( $12.6 \mathrm{mg} / \mathrm{m} 3)$ NIOSH recommended STEL 60 minute(s)
}

VENTILATION: Provide local exhaust or process enclosure ventilation system. Ensure compliance with 
applicable exposure limits.

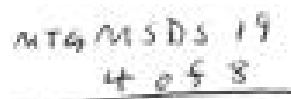

EYE PROTECTION: Wear splash resistant safety goggles with a faceshield. Provide an emergency eye wash fountain and quick drench shower in the immediate work area.

CLOTHING: Wear appropriate chemical resistant clothing.

GLOVES: Wear appropriate chemical resistant gloves.

RESPIRATOR: The following respirators and maximum use concentrations are drawn from NIOSH and/or OSHA.

At any detectable concentration -

Any self-contained breathing apparatus that has a full facepiece and is operated in a pressure-demand or other positive-pressure mode.

Any supplied-air respirator with full facepiece and operated in a pressure-demand or other positive-pressure mode in combination with a separate escape supply.

\section{Escape -}

Any air-purifying respirator with a full facepiece and an organic vapor canister.

Any appropriate escape-type, self-contained breathing apparatus.

For Unknown Concentrations or Immediately Dangerous to Life or Health -

Any supplied-air respirator with full facepiece and operated in a pressure-demand or other positive-pressure mode in combination with a separate escape supply.

Any self-contained breathing apparatus with a full facepiece.

\section{SECTION 9 PHYSICAL AND CHEMICAL PROPERTIES}

PHYSICAL STATE: liquid

COLOR: colorless

ODOR: sweet odor

MOLECULAR WEIGHT: 153.84

MOLECULAR FORMULA: C-CLA

BOILING POINT: $172 \mathrm{~F}$ (78 C)

FREEZING POINT: $-9 \mathrm{~F}(-23 \mathrm{C})$

VAPOR PRESSURE: $91.3 \mathrm{mmH}$ (i) $20 \mathrm{C}$

VAPOR DENSITY (air=1) $: 5.3$

SPECIFIC GRAVITY (water=1): 1.58

WATER SOLUBILITY: $0.08 \%$

PH: Not available

VOLATILITY: Not ayailable

ODOR THRESHOLD: $10-50 \mathrm{ppm}$

EVAPORATION RATE: 12.8 (butyl acetate $=1$ )

COEFFICIENT OF WATER/OIL DISTRIBUTION: Not available

SOLVENT SOLUBILITY:

Soluble: alcohol, ether, chloroform, benzene, carton disulfide, oils, naphtha

SECTION 10 STABILITY AND REACTIVITY

REACTIVITY: Stable at normal temperatures and pressure. 
CONDITIONS TO AVOID: Avoid heat, flames, sparks and other sources of ignition. Containers may
rupture or explode if exposed to heat.

INCOMPATIBILITIES: combustible materials, metal salts, peroxides, halogens, oxidizing materials, metals, bases, amines

HAZARDOUS DECOMPOSITION:

Thermal decomposition products: halogenated compounds, phosgene, oxides of carbon

POLYMERIZATION: Will not polymerize.

\section{SECTION II TOXICOLOGICAL INFORMATION}

\section{CARBON TETRACHLORIDE:}

\section{IRRITATION DATA:}

$4 \mathrm{mg}$ skin-rabbit mild; $500 \mathrm{mg} / 24$ hour(s) skin-rabbit mild: $2200 \mathrm{ug} / 30$ second(s) eyes-rabbit mild; 500 $\mathrm{mg} / 24$ hour(s) eyes-rabbit mild

TOXICITY DATA:

$8000 \mathrm{ppm} / 4$ hour(s) inhalation-rat LCS0; $>20 \mathrm{gm} / \mathrm{kg}$ skin-rabbit LD50; $2350 \mathrm{mg} / \mathrm{kg}$ oral-rat LDS0

CARCINOGEN STATUS: NTP: Anticipated Human Carcinogen; IARC: Animal Sufficient Evidence, Human Inadequate Evidence, Group 2B: ACGIH: A2 -Suspected Human Carcinogen

\section{ACUTE TOXICITY LEVEL:}

Moderately Toxic: ingestion

Slightly Toxic: inhalation, dermal absorption

TARGET ORGANS: central nervous system, liver, kidneys

MEDICAL CONDITIONS AGGRAVATED BY EXPOSURE; history of alcoholism, alcoholism

TUMORIGENIC DATA: Available.

MUTAGENIC DATA: Available.

REPRODUCTIVE EFFECTS DATA: Available.

ADDITIONAL DATA: May cross the placenta. May be excreted in breast milk. Alcohol may enhance the toxic effects. Stimulants such as epinephrine may induce ventricular fibrillation.

\section{SECTION 12 ECOLOGICAL INFORMATION}

\section{ECOTOXICITY DATA:}

FISH TOXICITY: 43100 ug/L 96 hour(s) LC50 (Mortality) Fathead minnow (Pimephales promelas)

INVERTEBRATE TOXICITY: $1500 \mathrm{ug} / \mathrm{L} 7$ hour(s) EC50 (Regeneration) Flatworm (Dugesia japonica) ALGAL TOXICITY $;>136000 \mathrm{ug} / \mathrm{L}$ NR hour(s) EC10 (Population Growth) Green algae (Haematococcus pluvialis)

OTHER TOXICITY: 900 ug/L 8 hour(s) EC50 (Teratogenesis) Leopard frog (Rana pipiens)

FATE AND TRANSPORT:

BIOCONCENTRATION: $30 \mathrm{ug} / \mathrm{L}$ 1-21 hour(s) BCF (Residue) Bluegill (Lepomis macrochirus) 52.3 ug/L

\section{ENVIRONMENTAL SUMMARY:}

Moderately toxic to aquatic life. 


\section{SECTION 13 DISPOSAL CONSIDERATIONS}

Dispose in accordance with all applicable regulations. Subject to disposal regulations: U.S. EPA 40 CFR 262. Hazardous Waste Number(s): U211. Hazardous Waste Number(s): D019. Dispose of in accordance with U.S. EPA 40 CFR 262 for concentrations at or above the Regulatory level. Regulatory level- 0.5 $\mathrm{mg} / \mathrm{L}$.

\section{SECTION 14 TRANSPORT INFORMATION}

U.S. DOT 49 CFR 172.101:

PROPER SHIPPING NAME: Carbon tetrachloride

ID NUMBER: UN 1846

HAZARD CLASS OR DIVISION: 6.1

PACKING GROUP: II

LABELING REQUIREMENTS: Poison

\section{SECTION 15 REGULATORY INFORMATION}

\section{U.S. REGULATIONS:}

CERCLA SECTIONS 102a/103 HAZARDOUS SUBSTANCES (40 CFR 302.4):

Carbon tetrachloride: 10 LBS RQ

SARA TITLE III SECTION 302 EXTREMELY HAZARDOUS SUBSTANCES (40 CFR 355.30): Not regulated.

SARA TITLE III SECTION 304 EXTREMELY HAZARDOUS SUBSTANCES (40 CFR 355.40): Not regulated.

SARA TITLE III SARA SECTIONS 311/312 HAZARDOUS CATEGORIES (40 CFR 370.21):

ACUTE: Yes

CHRONIC: Yes

FIRE: No

REACTIVE: No

SUDDEN RELEASE: No

SARA TITLE III SECTION 313 (40 CFR 372.65):

Carbon tetrachloride

OSHA PROCESS SAFETY (29CFR1910.119): Not regulated.

\section{STATE REGUIATIONS:}

California Proposition 65:

Known to the state of California to cause the following:

Carbon tetrachloride

Cancer (Oct 01, 1987) 


\section{CANADIAN REGULATIONS:} WHMIS CLASSIFICATION: D2

EUROPEAN REGULATIONS: EC CLASSIFICATION (ASSIGNED):

\begin{tabular}{|l|l|}
\hline $\mathrm{T}$ & Toxic \\
\hline $\mathrm{N}$ & Dangerous for the Environment \\
\hline & Carcinogen Category 3 \\
\hline
\end{tabular}

EC Classification may be inconsistent with independently-researched data.

\section{DANGER/HAZARD SYMBOL:}

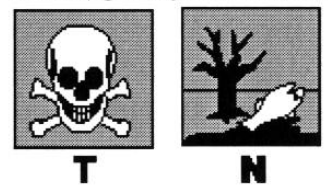

EC RISK AND SAFETY PHRASES:

\begin{tabular}{|c|c|}
\hline R 23/24/25 & Toxic by inhalation, in contact with skin and if swallowed. \\
\hline $\mathrm{R} 40$ & Possible risks of irreversible effects. \\
\hline $\mathrm{R} 48 / 23$ & Toxic: danger of serious damage to health by prolonged exposure through inhalation. \\
\hline $\mathrm{R} 52 / 53$ & $\begin{array}{l}\text { Harmful to aquatic organisms, may cause long-term adverse effects in the aquatic } \\
\text { environment. }\end{array}$ \\
\hline R 59 & Dangerous for the ozone layer. \\
\hline $\mathrm{S} 1 / 2$ & Keep locked-up and out of reach of children. \\
\hline S 23 & Do not breathe gas, fumes, vapour, or spray. \\
\hline S $36 / 37$ & Wear suitable protective clothing and gloves. \\
\hline S 45 & $\begin{array}{l}\text { In case of accident or if you feel unwell, seek medical advice immediately (show the } \\
\text { label where possible). }\end{array}$ \\
\hline S 59 & Refer to manufacturer/supplier for information on recovery/recycling. \\
\hline S 61 & Avoid release to the environment. Refer to special instructions/Safety data sheets. \\
\hline
\end{tabular}

CONCENTRATION LIMITS:

C $>=1 \%$ T R 23/24/25-40-48/23

$0.2 \%<=C<1 \%$ Xn R 20/21/22-48/20

NATIONAL INVENTORY STATUS:

U.S. INVENTORY (TSCA): Listed on inventory.

TSCA 12(b) EXPORT NOTIFICATION: Not listed.

CANADA INVENTORY (DSL): Not determined.

CANADA INVENTORY (NDSL): Not determined. 
SECTION 16 OTHER INFORMATION

\section{MSDS SUMMARY OF CHANGES}

SECTION 1 CHEMICAL PRODUCT AND COMPANY IDENTIFICATION

SECTION 3 HAZARDS IDENTIFICATION

SECTION 7 HANDLING AND STORAGE

SECTION 14 TRANSPORT INFORMATION

SECTION 15 REGULATORY INFORMATION

CCopyright 1984-2001 MDL Information Systems, Inc. All rights reserved.

MATHESON TRI-GAS, INC. MAKES NO EXPRESS OR IMPLIED WARRANTIES, GUARANTEES OR REPRESENTATIONS REGARDING THE PRODUCT OR THE INFORMATION HEREIN, INCLUDING BUT NOT LIMITED TO ANY IMPLIED WARRANTY OF MERCHANTABILITY OR FITNESS FOR USE. MATHESON TRI-GAS, INC. SHALL NOT BE LIABLE FOR ANY PERSONAL INJURY, PROPERTY OR OTHER DAMAGES OF ANY NATURE, WHETHER COMPENSATORY, CONSEQUENTIAL, EXEMPLARY, OR OTHERWISE, RESULTING FROM ANY PUBLICATION, USE OR RELIANCE UPON THE INFORMATION HEREIN. 


\section{OCCUPATIONAL SAFETY AND HEALTH GUIDELINE FOR CARBON TETRACHLORIDE}

\section{INTRODUCTION}

This guideline summarizes pertinent information about carbon tetrachloride for workers and employers as well as for physicians, industrial hygienists, and other occupational safety and health professionals who may need such information to conduct effective occupational safety and health programs. Recommendations may be superseded by new developments in these fields; readers are therefore advised to regard these recommendations as general guidelines and to determine periodically whether new information is available.

\section{SUBSTANCE IDENTIFICATION}

- Formula

$$
\mathrm{CCl}_{4}
$$

- Structure<smiles>ClC(Cl)(Cl)Cl</smiles>

\section{- Synonyms}

Tetrachloromethane; perchloromethane; methane tetrachloride; Nectorina; benzinoform; carbon chloride; Carbona; carbon tet
- Identifiers

1. CAS No.: 56-23-5

2. RTECS No.: FG4900000

3. DOT UN: 184655

4. DOT label: Poison

\section{- Appearance and odor}

Carbon tetrachloride is a noncombustible, colorless liquid with a sweet, aromatic, etherlike odor. The best estimate of the odor threshold for carbon tetrachloride is 250 parts per million (ppm) parts of air.

\section{CHEMICAL AND PHYSICAL PROPERTIES}

\section{- Physical data}

1. Molecular weight: 153.84

2. Boiling point $(760 \mathrm{~mm} \mathrm{Hg}): 76.7^{\circ} \mathrm{C}\left(170^{\circ} \mathrm{F}\right)$

3. Specific gravity (water $=1$ ): 1.59 at $20^{\circ} \mathrm{C}\left(68^{\circ} \mathrm{F}\right)$

4. Vapor density (air = 1 at boiling point of carbon tetrachloride): 5.3

5. Melting point: $-23^{\circ} \mathrm{C}\left(-9.4^{\circ} \mathrm{F}\right)$

6. Vapor pressure at $20^{\circ} \mathrm{C}\left(68^{\circ} \mathrm{F}\right): 91.3 \mathrm{~mm} \mathrm{Hg}$

U.S. DEPARTMENT OF HEALTH AND HUMAN SERVICES

Public Health Service

Centers for Disease Control and Prevention

National Institute for Occupational Safety and Health

Education and information Division

U.S. DEPARTMENT OF LABOR

Occupational Safety and Health Administration 
7. Solubility: Slightly soluble in water; miscible with alcohol, benzene, chloroform, ether, carbon disulfide, petroleum ether, and oils

\section{Evaporation rate: Data not available}

\section{Reactivity}

1. Conditions contributing to instability: None reported

2. Incompatibilities: Contact of carbon tetrachloride with fluorine gas, alkali metals, or aluminum may cause a violent reaction.

3. Hazardous decomposition products: Toxic gases (such as phosgene and hydrogen chloride) may be released in a fire involving carbon tetrachloride. When used to put out electrical fires, carbon tetrachloride may evolve phosgene gas.

4. Special precautions: None reported

\section{Flammability}

The National Fire Protection Association has assigned a flammability rating of $\mathbf{0}$ (no fire hazard) to carbon tetrachloride; this substance is not combustible.

\section{Flash point: Not applicable}

\section{Autoignition temperature: Not applicable}

3. Flammable limits in air: Not applicable

4. Extinguishant: Use an extinguishant that is appropriate for the materials involved in the surrounding fire.

Fires involving carbon tetrachloride should be fought upwind from the maximum distance possible. Isolate the hazard area and deny access to unnecessary personnel. Emergency personnel should stay out of low areas and ventilate closed spaces before entering. Containers of carbon tetrachloride may explode in the heat of the fire and should be moved from the fire area if it is possible to do so safely. If this is not possible, cool containers from the sides with water until well after the fire is out. Stay away from the ends of containers. Dikes should be used to contain fire-control water for later disposal. Fire fighters should wear a full set of protective clothing and self-contained breathing apparatus when fighting fires involving carbon tetrachloride. Chemical protective clothing that is specifically recommended for carbon tetrachloride may not provide thermal protection unless so stated by the clothing manufacturer. Structural Fire fighters' protective clothing is not effective against fires involving carbon tetrachloride.

\section{EXPOSURE LIMITS}

\section{- OSHA PEL}

The current Occupational Safety and Health Administration (OSHA) permissible exposure limit (PEL) for carbon tetrachloride is $10 \mathrm{ppm}$ as an $\mathbf{8 - h r}$ time-weighted average (TWA) concentration with a ceiling concentration of 25 ppm that may not be exceeded during an 8-hr workday except for a 5-min period every 4 hours; the acceptable maximum peak during this 5min period is $200 \mathrm{ppm}$ [29 CFR 1910.1000, Table Z-2].

\section{- NIOSH REL}

The National Institute for Occupational Safety and Health (NIOSH) designates carbon tetrachloride a potential occupational carcinogen and has established a recommended exposure limit (REL) for this substance of $2 \mathrm{ppm}\left(12.6 \mathrm{mg} / \mathrm{m}^{3}\right)$ as a 60 -min short-term exposure limit (STEL) [NIOSH 1992a]. The STEL is a 60-min TWA exposure that shall not be exceeded at any time during a workday.

\section{- ACGIH TLV}

The American Conference of Governmental Industrial Hygienists (ACGIH) has designated carbon tetrachloride an A2 substance (suspected human carcinogen) and has assigned carbon tetrachloride a threshold limit value (TLV) of $5 \mathrm{ppm}\left(31 \mathrm{mg} / \mathrm{m}^{3}\right.$ ) as a TWA for a normal 8-hr workday and a 40-hr workweek. The ACGIH has also assigned carbon tetrachloride a "Skin" notation, which indicates that the cutaneous route of exposure (including mucous membranes and eyes) contributes to overall exposure [ACGIH 1993].

\section{- Rationale for limits}

The NIOSH and ACGIH limits are based on the risk of cancer associated with exposure to carbon tetrachloride [ACGIH 1993; NIOSH 1992a]. 


\section{HEALTH HAZARD INFORMATION}

\section{- Routes of exposure}

Exposure to carbon tetrachloride can occur through inhalation of the vapor, eye or skin contact, absorption through the skin of the liquid, or ingestion.

\section{- Summary of toxicology}

1. Effects on Animals: In animals, carbon tetrachloride is an eye and skin irritant, a liver and kidney toxin, and a carcinogen. This chemical is a mild eye and skin irritant in rabbits [NIOSH 1992b]. Monkeys demonstrated little dermal absorption from ambient exposures. Likewise, rats dermally exposed to the liquid required large doses to induce lethality [Clayton and Clayton 1981]. The dermal $\mathrm{LD}_{50}$ in rats is $5,070 \mathrm{mg} / \mathrm{kg}$ [NIOSH 1992b]. The maximum exposures that caused no effects in male rats were: 3,000 ppm for $6 \mathrm{~min}, 800 \mathrm{ppm}$ for $30 \mathrm{~min}$, and $50 \mathrm{ppm}$ for $7 \mathrm{hr}$ [Clayton and Clayton 1981]. The highest airborne concentrations in which rats survived were $12,000 \mathrm{ppm}$ for $15 \mathrm{~min}$ and $3,000 \mathrm{ppm}$ for $8 \mathrm{hr}$ [Clayton and Clayton 1981]. The $\mathrm{LC}_{50}$ in rats and mice are $8,000 \mathrm{ppm}$ for $4 \mathrm{hr}$ and $9,526 \mathrm{ppm}$ for $8 \mathrm{hr}$, respectively [NIOSH 1992b]. The oral $\mathrm{LD}_{50}$ in rats is 2,350 mg/kg [NIOSH 1992b]. Rats, guinea pigs, rabbits, and monkeys were exposed to carbon tetrachloride vapors for $7 \mathrm{hr} /$ day, 5 days/week for up to 4 months. Rats, guinea pigs, and rabbits all showed histologic damage to the liver after exposures of $10 \mathrm{ppm}$ or higher but not after exposure to $5 \mathrm{ppm}$; monkeys exhibited histologic damage to the liver at concentrations of $100 \mathrm{ppm}$ or above but not at lower levels [Clayton and Clayton 1981]. Carbon tetrachloride was embryotoxic and fetotoxic but not teratogenic in rats exposed to 300 to $1,000 \mathrm{ppm}$ for $7 \mathrm{hr} /$ day on days 6 to 15 of gestation [IARC 1979; NIOSH 1992b]. This chemical also increased fetal mortality when pregnant mice were given a single $150 \mathrm{mg}$ dose [IARC 1979]. Carbon tetrachloride is weakly mutagenic in a wide variety of test systems [NIOSH 1992b]. This chemical produced liver tumors as well as cancers in mice, rats, and hamsters following administration by several routes, including inhalation and ingestion [ACGIH 1991; IARC 1979]. The International Agency for Research on Cancer (IARC) has determined that there is sufficient evidence of carbon tetrachloride's carcinogenicity in animals and that it is a Group 2B carcinogen (possibly carcinogenic in humans) [IARC 1987].
2. Effects on Humans: In humans, carbon tetrachloride is a mild eye and skin irritant, a central nervous system depressant, and a liver and kidney toxin. NIOSH, ACGIH, and other organizations classify carbon tetrachloride as a potential human carcinogen. The vapor of carbon tetrachloride is mildly irritating to the eyes [Grant 1986]; and has also caused visual disturbances (concentric restriction of color fields) [NLM 1991]. Prolonged or repeated contact of the liquid with the skin can cause pain, erythema, hyperemia, weal formation, tissue defatting and blistering [Grant 1986; Hathaway et al. 1991; NLM 1991]. The estimated no-observed-effect level for acute human exposure is $10 \mathrm{ppm}$ for $3 \mathrm{hr}$ [Hathaway et al. 1991]. A $\mathrm{TC}_{\mathrm{Lo}}$ (lowest concentration causing an effect) exposure of $20 \mathrm{ppm}$ (duration undefined) or $317 \mathrm{ppm}$ for $30 \mathrm{~min}$ has produced nausea and vomiting [NIOSH 1992b]. Acute symptoms can include abdominal cramps, nervousness, dyspnea, cyanosis, oliguria, proteinuria, hepatomegaly, and optic neuritis [NIOSH 1992b]. Polycythemia, anemia, and hemodilution also may follow acute exposure [Hathaway et al. 1991]. Mild acute poisoning can result in renal injury, and decreased renal blood flow and filtration, which may require up to 200 days for complete recovery. In severe acute poisoning, anuria and terminal uremia require active restoration of renal function, or death occurs [NLM 1991]. In humans, the majority of fatalities caused by inhalation of carbon tetrachloride have been the result of renal injury with secondary cardiac failure. Liver damage occurs more often from ingestion of the liquid than from inhalation of the vapor [Hathaway et al. 1991]. Persons consuming alcohol, those with poor nutritional status, and persons with pre-existing liver or kidney disease are more susceptible to poisoning by carbon tetrachloride [Gosselin et al. 1984]. Human fatalities caused by acute renal failure have resulted from exposure to carbon tetrachloride concentrations of $50,000 \mathrm{ppm}$ for $5 \mathrm{~min}$ [NLM 1991], 1,000 to $2,000 \mathrm{ppm}$ for $30 \mathrm{~min}$ to $1 \mathrm{hr}$ [Hathaway et al. 1991], or oral doses that exceed $1,500 \mathrm{mg} / \mathrm{kg}$ [NIOSH 1992b]. Although repeated exposure of workers to $10 \mathrm{ppm}$ did not induce signs or symptoms of toxicity, 25 to $30 \mathrm{ppm}$ caused nausea, vomiting, dizziness, drowsiness, and headache [NLM 1991]. Ten out of 17 workers exposed for an unspecified period to a 45- to 97-ppm concentration of carbon tetrachloride reported experiencing beadache and giddiness, and several of these workers also had symptoms of liver dysfunction [ACGIH 1991]. Workers exposed to carbon tetrachloride at unspeci- 
fied levels have experienced dizziness, vertigo, mental confusion, and incoordination, all signs and symptoens of central nervous system depression, and some have developed loss of visual acuity, convulsions, and eardiac arthythmias [Hathaway et al. 1991]. Carbon tetrachloride has been confirmed as a weak mutagen in a variety of assays [NIOSH $1992 \mathrm{~b}$ ]. In the preamble of the 1989 Air Consominanis; Final Rule. OSHA coocluded that an "occupational exposure to carbon tetrachloride at the 10-ppen PEL presents a significant risk of cancer to workers" [S4 Fed. Reg. 2681 (1989)]. IARC has concluded that there is insufficient buman data to directly classify carbon tetrachloride's carcinogenic risk to bumans [IARC 1987]

\section{- Signs and symptoms of exposure}

1. Acuse exposure: Carbon tetrachloride can induce mild irritation of the eyes and skin, with redness and inflammation, and central nervous system depression, with symptoms of malaise, headache, dizxiness, incoordination, confusion, stupor, coma, and convulsions; nausea, vomiting, abdominal pain, and diarrhea are also frequent. Acute exposures can lead to ventricular fibrillation (rapid, irregular heartbeat) and death from cartiac failure. Acute oral exposures berve primarily eaused liver damage, as evidenced by an enlarged and tender liver and jaundice, as well as acute nephritis, with a decrease in the volume of urinary output and the presence of blood, pus, or protein in the urine. Acute renal failure can result in coma and death.

2. Chronic exposure: Repeated contact of the skin with carbon tetrachloride may cause defatting of the skin and dermatitis, with redness and blister formation. Chroxic exposure has also been associated with nausea, vomiting dininess, drowsiness, headacbe, visual disturbances, and loss of visual acuity. The LARC classifies carbon tetmchloride as possibly carcinogeaic to humans based on sufficient animal data.

\section{- Emergency procedures}

\section{WARNING!}

Seek Immedlate medical attention for severely affected victims or for victims with signs and symptoms of toxicity or irritation!
Keep unconscious victims warm and on their sides to avoid choking if vomiting occurs. Initiate the following emergency procedures:

1. Eye exposure: Imitation may result from exposure to concentrated solutions, vapors, mists, or acrosols of carboa tetrachloride. Immediately and thoroughty flush eyes with large amounts of water, oceasionally tifting the upper and lower eyelids.

2. Skin exposure: Irritation may result. Immediately remove contaminated elothing and thoroughly wash contaminated skin with soap and water.

3. Inhalation exposure: Move the victim to fresh air inumediately.

If the victim is not breathing, clean any chemical contamination from the victim's lips and perform cardiopulmonary resuscitation (CPR); if breathing is difficult, give axygen.

4. Ingestian exposure: Take the following steps if carbon tetracbloride or any material containing it is ingested:

- Have the victim rinse the cootaminated mouth cavity several times with a fluid such as water.

-Have the victim drink a glass $(8 \mathrm{oz})$ of Auid sach as water.

- Indoce vomiting by touching the back of the throat with a finger until productive vomiting ceases. Do not give syrup of ipecac because of possible onset of respiratory depression and seizures.

-Do not force an unconscious or convulsing person to drink fluid or to vomit.

5. Rescue: Remove an incapacitated worker from further exposure and implement appropriate emergency procedures (e-g., those listed on the material safety data sheet required by OSHA's hazard communication standard [29 CFR 1910.1200]). All workers should be familiar with emergency procedures and the location and proper use of emergency equipment.

\section{EXPOSURE SOURCES AND CONTAOL METHODS}

The followiag operations may involve carbon tetrachlorido and result in worker exposures to this aubstances: 
-Manufacture of fluorocarbons for aerosols, refrigerants, and fire extinguishants (these uses of fluorocarbons have been largely phased out or banned)

-Use as a solvent in dry cleaning and in industry to dissolve resins, oils, fats, varnishes, and rubber waxes

-Use as an agricultural grain fumigant, pesticide, and anthelmintic and as an agent to extract oil from flowers and seeds

- Use in polymer technology as a reaction medium, catalyst, and chain transfer agent

-Use in organic synthesis for the chlorination of organic compounds and in the soap and perfume industries

-Use as a laboratory solvent

-Use in tin recovery and catalyst regeneration and as a cleaning agent for machinery and electrical equipment

The following methods are effective in controlling worker exposures to carbon tetrachloride, depending on the feasibility of implementation:

- Process enclosure

- Local exhaust ventilation

- General dilution ventilation

-Personal protective equipment

Good sources of information about control methods are as follows:

1. ACGIH [1992]. Industrial ventilation-a manual of recommended practice. 21st ed. Cincinnati, $\mathrm{OH}$ : American Conference of Governmental Industrial Hygienists.

2. Burton DJ [1986]. Industrial ventilation-a self study companion. Cincinnati, $\mathrm{OH}$ : American Conference of Governmental Industrial Hygienists.

3. Alden JL, Kane JM [1982]. Design of industrial ventilation systems. New York, NY: Industrial Press, Inc.

4. Wadden RA, Scheff PA [1987]. Engineering design for control of workplace hazards. New York, NY: McGraw-Hill.
5. Plog BA [1988]. Fundamentals of industrial hygiene. Chicago, IL: National Safety Council.

\section{MEDICAL MONITORING}

Workers who may be exposed to chemical hazards should be monitored in a systematic program of medical surveillance that is intended to prevent occupational injury and disease. The program should include education of employers and workers about work-related hazards, early detection of adverse health effects, and referral of workers for diagnosis and treatment. The occurrence of disease or other work-related adverse health effects should prompt immediate evaluation of primary preventive measures (e.g., industrial hygiene monitoring, engineering controls, and personal protective equipment). A medical monitoring program is intended to supplement, not replace, such measures. To place workers effectively and to detect and control work-related health effects, medical evaluations should be performed (1) before job placement, (2) periodically during the term of employment, and (3) at the time of job transfer or termination.

\section{- Preplacement medical evaluation}

Before a worker is placed in a job with a potential for exposure to carbon tetrachloride, a licensed health care professional should evaluate and document the worker's baseline bealth status with thorough medical, environmental, and occupational histories, a physical examination, and physiologic and laboratory tests appropriate for the anticipated occupational risks. These should concentrate on the function and integrity of the liver, kidneys, and nervous system.

A preplacement medical evaluation is recommended to detect and assess medical conditions that may be aggravated or may result in increased risk when a worker is exposed to carbon tetrachloride at or below the prescribed exposure limit. The licensed health care professional should consider the probable frequency, intensity, and duration of exposure as well as the nature and degree of any applicable medical condition. Such conditions (which should not be reganded as absolute contraindications to job placement) include a history of excessive alcohol intake and other findings consistent with diseases of the liver, kidney, or nervous system.

\section{- Periodic medical examinations and biological monitoring}

Occupational health interviews and physical examinations should be performed at regular intervals during the 
employment period, as mandated by any applicable Federal, State, or local standard. Where no standard exists and the hazard is minimal, evaluations should be conducted every 3 to 5 years or as frequently as recommended by an experienced occupational health physician. Additional examinations may be necessary if a worker develops symptoms attributable to carbon tetrachloride exposure. The interviews, examinations, and medical screening tests should focus on identifying the adverse effects of carbon tetrachloride on the liver, kidneys, or nervous system. Current health status should be compared with the baseline health status of the individnal worker or with expected values for a suitable reference population.

Biological monitoring involves sampling and analyzing body tissues or fluids to provide an index of exposure to a toxic substance or metabolite. Although carbon tetrachloride can be detected in the breath of exposed workers, data on the correlation between breath concentrations and airborne concentrations of carbon tetrachloride are not available. Therefore, no biological monitoring test acceptable for routine use has yet been developed for carbon tetrachloride.

\section{- Medical examinations recommended at the time of job transfer or termination}

The medical, environmental, and occupational history interviews, the physical examination, and selected physiologic or laboratory tests that were conducted at the time of placement should be repeated at the time of job transfer or termination. Any changes in the worker's health status should be compared with those expected for a suitable reference population. Because occupational exposure to carbon tetrachloride may cause diseases with prolonged latent periods, the need for medical monitoring may extend well beyond the termination of employment.

\section{WORKPLACE MONITORING AND MEASUREMENT}

A worker's exposure to airborne carbon tetrachloride is determined by using a charcoal tube (100/50-mg sections, $20 / 40$ mesh). Samples are collected at a recommended flow rate of $0.2 \mathrm{liter} / \mathrm{min}$ until a maximum air volume of 15 liters is collected. Analysis is conducted by gas chromatography using a flame ionization detector. The limit of detection for this procedure is $0.01 \mathrm{mg}$, and the method is described in NIOSH Method No. 1003 [NIOSH 1984].

\section{PERSONAL HYGIENE}

This substance can be absorbed through the skin in toxic amounts. Therefore, if carbon tetrachloride contacts the skin, workers should flush the affected areas immediately with plenty of water for $15 \mathrm{~min}$, and then wash with soap and water.

Clothing contaminated with carbon tetrachloride should be removed immediately, and provisions should be made for safely removing this chemical from these articles. Persons laundering the clothes should be informed of the hazardous properties of carbon tetrachloride, particularly its potential to cause severe central nervous system effects on acute exposure.

A worker who handles carbon tetrachloride should thoroughly wash hands, forearms, and face with soap and water before eating, using tobacco products, using toilet facilities, or applying cosmetics.

Workers should not eat, drink, use tobacco products, or apply cosmetics in areas where carbon tetrachloride is handled, processed, or stored.

\section{STORAGE}

Carbon tetrachloride should be stored in a cool, dry, wellventilated area in tightly sealed containers that are labeled in accordance with OSHA's hazard communication standard [29 CFR 1910.1200]. Containers of carbon tetrachloride should be protected from physical damage and direct sunlight and should be stored separately from aluminum, barium, dimethyl formamide, magnesium, potassium, sodium, triethylaluminum, calcium disilicide decaborane, ethylene, heat, sparks, and open flame. Because containers that formerly contained carbon tetrachloride may still hold product residues, they should be handled appropriately.

\section{SPILLS AND LEAKS}

In the event of a spill or leak involving carbon tetrachloride, persons not wearing protective equipment and clothing should be restricted from contaminated areas until cleanup is complete. The following steps should be undertaken following a spill or leak:

1. Do not touch the spilled material; stop the leak if it is possible to do so without risk.

2. Notify safety personnel. 
3. Ventilate the area of the spill or leak.

4. Use water spray to reduce vapors.

5. For small dry spills, use a clean shovel and gently place the material into a clean, dry container, creating as little dust as possible; cover and remove the container from the spill area.

6. For small liquid spills, absorb with sand or other noncombustible absorbent material and place into closed containers for later disposal.

7. For large liquid spills, build dikes far ahead of the spill to contain the carbon tetrachloride for later reclamation or disposal.

\section{SPECIAL REQUIREMENTS}

Environmental Protection Agency (EPA) requirements for emergency planning, reportable quantities of hazardous releases, community right-to-know, and hazardous waste management may change over time. Users are therefore advised to determine periodically whether new information is available.

\section{- Emergency planning requirements}

Carbon tetrachloride is not subject to EPA emergency planning requirements under the Superfund Amendments and Reauthorization Act (SARA) [42 USC 11022].

\section{- Reportable quantity requirements for hazardous releases}

A hazardous substance release is defined by EPA as any spilling, pumping, pouring, emitting, emptying, discharging, injecting, escaping, leaching, dumping, or disposing into the environment (including the abandonment or discarding of contaminated containers). In the event of a release that is above the reportable quantity for that chemical, employers are required by the Comprehensive Environmental Response, Compensation, and Liability Act (CERCLA) [40 CFR 355.40] to notify the proper Federal authorities.

The reportable quantity for carbon tetrachloride is $10 \mathrm{lb}$. If an amount equal to or greater than this quantity is released within a $24 \mathrm{hr}$ period in a manner that will expose persons outside the facility, employers are required to do the following:
-Notify the National Response Center immediately at (800) $424-8802$ or at (202) 426-2675 in Washington, D.C. [40 CFR 302.6].

-Notify the emergency response commission of the State likely to be affected by the release $[40$ CFR 355.40].

-Notify the community emergency coordinator of the local emergency planning committee (or relevant local emergency response personnel) of any area likely to be affected by the release [ 40 CFR 355.40 ].

\section{- Community right-to-know requirements}

Employers who own or operate facilities in SIC codes 20 to 39 , who employ 10 or more workers, and who manufacture $25,000 \mathrm{lb}$ or more or otherwise use 10,000 lb or more of carbon tetrachloride per calendar year are required by EPA [49 CFR Part 372.30] to submit a Toxic Chemical Release Inventory Form (Form R) to EPA reporting the amount of carbon tetrachloride emitted or released from their facility annually.

\section{- Hazardous waste management requirements}

EPA considers a waste to be hazardous if it exhibits any of the following characteristics: ignitability, corrosivity, reactivity, or toxicity as defined in 40 CFR 261.21261.24. Carbon tetrachloride is listed as a hazardous waste under the Resource Conservation and Recovery Act (RCRA) [40 CFR 355.40], and has been assigned EPA Hazardous Waste No. U211. This chemical is approved for land disposal as long as the concentration of carbon tetrachloride in the waste or treatment residual does not exceed $5.6 \mathrm{mg} / \mathrm{kg}$. Carbon tetrachloride also may be disposed of in an organometallic or organic lab pack that meets the requirements of 40 CFR 264.316 or 265.316 .

Providing detailed information about the removal and disposal of specific chemicals is beyond the scope of this guideline. The U.S. Department of Transportation, EPA, and State and local regulations should be followed to ensure that removal, transport, and disposal of this substance are conducted in accordance with existing regulations. To be certain that chemical waste disposal meets EPA regulatory requirements, employers should address any questions to the RCRA hotline at (800) 4249346 or at (202) $382-3000$ in Washington, D.C. In addition, relevant State and local authorities should be contacted for information about their requirements for waste removal and disposal. 


\section{RESPIRATORY PROTECTION}

\section{- Conditions for respirator use}

Good industrial hygiene practice requires that engineering controls be used where feasible to reduce workplace concentrations of hazardous materials to the prescribed exposure limit. However, some situations may require the use of respirators to control exposure. Respirators must be worn if the ambient concentration of carbon tetrachloride exceeds prescribed exposure limits. Respirators may be used (1) before engineering controls have been installed, (2) during work operations such as maintenance or repair activities that involve unknown exposures, (3) during operations that require entry into tanks or closed vessels, and (4) during emergencies. Workers should use only respirators that have been approved by NIOSH and the Mine Safety and Health Administration (MSHA).

- Respiratory protection program

Employers should institute a complete respiratory protection program that, at a minimum, complies with the requirements of OSHA's respiratory protection standard [29 CFR 1910.134]. Such a program must include respirator selection, an evaluation of the worker's ability to perform the work while wearing a respirator, the regular training of personnel, respirator fit testing, periodic workplace monitoring, and regular respirator maintenance, inspection, and cleaning. The implementation of an adequate respiratory protection program (including selection of the correct respirator) requires that a knowiedgeable person be in charge of the program and that the program be evaluated regularly. For additional information about the selection and use of respirators and about the medical screening of respirator users, consult the NIOSH Respirator Decision Logic [NIOSH 1987b] and the NIOSH Guide to Industrial Respiratory Protection [NIOSH 1987a].

\section{PERSONAL PROTECTIVE EQUIPMENT}

Protective clothing should be worn to prevent any skin contact with carbon tetrachloride. Chemical protective clothing should be selected on the basis of available performance data, manufacturers' recommendations, and evaluation of the clothing under actual conditions of use. The following materials have been recommended for use against permeation by carbon tetrachloride and may provide protection for periods greater than $8 \mathrm{hr}$. polyvinyl alcohol, Viton, Barricade(), and Responder. Materials that may withstand permeation for more than 4 but fewer than $8 \mathrm{hr}$ are Teflon and a polyethylene/ethylene vinyl laminate. Protective clothing made of butyl nubber, natural rubber, neoprene, nitrile rubber, polyethylene, or polyvinyl chloride are not recommended for protection against permeation by carbon tetrachloride.

If carbon tetrachloride is dissolved in water or an organic solvent, the permeation properties of both the solvent and the mixture must be considered when selecting personal protective equipment and clothing.

Safety glasses, goggles, or face shields should be worn during operations in which carbon tetrachloride might contact the eyes (e.g., through splashes of solution). Eyewash fountains and emergency showers should be available within the immediate work area whenever the potential exists for eye or skin contact with carbon tetrachloride. Contact lenses should not be worn if the potential exists for carbon tetrachloride exposure.

\section{REFERENCES CITED}

ACGIH [1991]. Documentation of the threshold limit values and biological exposure indices. 6th ed. Cincinnati, OH: American Conference of Governmental Industrial Hygienists.

ACGIH [1993]. 1993-1994 Threshold limit values for chemical substances and physical agents and biological exposure indices. Cincinnati, OH: American Conference of Governmental Industrial Hygienists.

Clayton G, Clayton F [1981]. Patty's industrial hygiene and toxicology. 3rd rev. ed. New York, NY: John Wiley \& Sons.

CFR. Code of Federal regulations. Washington, DC: U.S. Government Printing Office, Office of the Federal Register.

54 Fed. Reg. 2681 [1989]. Occupational Safety and Health Administration: air contaminants; final rule. (29 CFR 1910).

Gosselin RE, Smith RP, Hodge HC [1984]. Clinical toxicology of commercial products. 5th ed. Baltimore, MD: Williams \& Wilkins.

Grant WM [1986]. Toxicology of the eye. 3rd ed. Springfield, IL: Charles C. Thomas.

Hathaway GJ, Proctor NH, Hughes JP, and Fischman ML [1991]. Proctor and Hughes' chemical hazards of the 
workplace, 3rd ed. New York, NY: Van Nostrand Reinhold.

IARC [1979]. IARC monographs on the evaluation of carcinogenic risk of chemicals to humans: some halogenated bydrocarbons. Vol. 20. Lyon, France: World Health Organization, International Agency for Research on Cancet.

LARC [1987]. LARC monographs on the evaluation of carcinogenic risk of chemicals to humans. Suppl. 7. Lyon, France: World Health Organization, Interaational Agency for Research on Cancer.

NIOSH [1984]. Hydrocarbons, halogenated: Method No, 1003. In Eller PM, ed. NIOSH manual of analytical methods. 3rd ed. Cincinnati, OH: U.S. Department of Health and Human Services. Public Health Service. Centers for Disease Control, National Institate for Occupational Safety and Health.

NIOSH [1987a]. NIOSH guide to industrial respiratory protection. Cincinnati, OH: U.S. Department of Health and Human Services, Public Health Service, Centers for Disease Control, National Institute for Occupational Safety and Flealth, DHIHS (NIOSH) Publication No. 87-116.
NIOSH [1987b]. NIOSH respirator decision logic, Cincinnati, OH: U.S. Department of Health and Human Services. Public Health Service, Centers for Disease Control, National Institute for Occupational Safety and Health, DHHS (NIOSH) Publication No. 87-106.

NIOSH [1992a]. NIOSH recommendations for oceupational safety and health: compendium of policy documents and statements. Cincinasti, OH: U.S. Departinent of Health and Human Services, Public Health Service, Centers for Disease Control, National Institate for Occupational Safety and Health, DHHS (NIOSH) Publication No, 92-100.

NIOSH [1992b], Registry of toxic effects of chemical substances database: carbon tetrachloride. Cincinnati, OH: U.S. Department of Health and Human Services, Public Health Service, Centers for Disease Control, National Institute for Oecupational Safety and Health, Division of Standards Development and Techoology Transfer, Technical Information Branch.

NLM [1991]. The hazardous substances data bank: earbon tetrachloride. Bethesda, MD: National Library of Medicine. 


\section{MATERIAL SAFETY DATA SHEET}

$$
\text { MTG MSDS108 P. of } 8
$$

SECTION I CHEMICAL PRODUCT AND COMPANY IDENTIFICATION

MATHESON TRI-GAS, INC.

959 ROUTE 46 EAST

PARSIPPANY, NEW JERSEY USA 07054-0624 OR

530 WATSON STREET

WHITBY, ONTARIO, CANADA LIN 5R9
EMERGENCY CONTACT:

CHEMTREC 1-800-424-9300

INFORMATION CONTACT:

(USA) $973-257-1100$

(WHITBY) 905-668-3570

(EDMONTON) 780-471-4036

\section{SUBSTANCE: CHLOROFORM}

TRADE NAMES/SYNONYMS:

MTG MSDS 109; TRICHLOROMETHANE; METHANE TRICHLORIDE; R 20; FREON 20;

METHANE, TRICHLORO-; METHYL TRICHLORIDE; TRICHLOROFORM; R 20 (REFRIGERANT);

METHENYL TRICHLORIDE; RCRA U044; UN 1888; CHCl3; MAT04770; RTECS FS9100000

CHEMICAL FAMILY: halogenated, aliphatic

CREATION DATE: Jan 241989

REVISION DATE: Mar 222001

SECTION 2 COMPOSITION, INFORMATION ON INGREDIENTS

COMPONENT: CHLOROFORM

CAS NUMBER: $67-66-3$

EC NUMBER (EINECS): 200-663-8

PERCENTAGE: $>99$

COMPONENT: STABIL.IZERS

CAS NUMBER: Not assigned.

EC NUMBER: Not assigned.

PERCENTAGE: $<0.1$

\section{SECTION 3 HAZARDS IDENTIFICATION}

NFPA RATINGS (SCALE 0-4): HEALTH $=2$ FIRE $=0$ REACTIVITY $=0$

EMERGENCY OVERVIEW:

COLOR: colorless

PHYSICAL FORM: volatile liquid

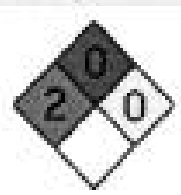

snon 
MAJOR HEALTH HAZARDS: respiratory tract irritation, skin irritation, eye irritation, liver damage, central nervous system depression, kidney damage, suspect cancer hazard (in animals)

POTENTIAL HEALTH EFFECTS:

INHALATION:

SHORT TERM EXPOSURE: irritation, nausea, vomiting, irregular heartbeat, headache, drowsiness, symptoms of drunkenness, fainting, disorientation, dilated pupils, kidney damage, liver damage, convulsions, coma

LONG TERM EXPOSURE: digestive disorders, tingling sensation, blurred vision, liver enlargement SKIN CONTACT:

SHORT TERM EXPOSURE: irritation

LONG TERM EXPOSURE: same as effects reported in short term exposure

EYE CONTACT:

SHORT TERM EXPOSURE: irritation, tearing

LONG TERM EXPOSURE: same as effects reported in short term exposure

INGESTION:

SHORT TERM EXPOSURE: nausea, vomiting, diarrhea, difficulty breathing, symptoms of drunkenness, dilated pupils, bluish skin color, kidney damage, liver damage

LONG TERM EXPOSURE: kidney damage, liver damage, cancer

CARCINOGEN STATUS:

OSHA: No

NTP: Yes

IARC: Yes

\section{SECTION 4 FIRST AID MEASURES}

INHALATION: If adverse effects occur, remove to uncontaminated area. Give artificial respiration if not breathing. Get immediate medical attention.

SKIN CONTACT: Wash skin with soap and water for at least 15 minutes while removing contaminated clothing and shoes. Get medical attention, if needed. Thoroughly clean and dry contaminated clothing and shoes before reuse.

EYE CONTACT: Flush eyes with plenty of water for at least 15 minutes. Then get immediate medical attention.

INGESTION: For ingestion, consider gastric lavage. Consider oxygen. Avoid epinephrine. Get medical attention immediately.

\section{SECTION 5 FIRE FIGHTING MEASURES}

FIRE AND EXPLOSION HAZARDS: Negligible fire hazard.

EXTINGUISHING MEDIA: regular dry chemical, regular foam, water

Large fires: Use regular foam or flood with fine water spray.

FIRE FIGHTING: Move container from fire area if it can be done without risk. Fight large fires from a 
MTG MSDS 1083 of 8 protected location or safe distance. Stay away from the ends of tanks. Dike for later disposal. Do not scatter spilled material with high-pressure water streams.

FLASH POINT: No data available.

\section{SECTION 6 ACCIDENTAL RELEASE MEASURES}

\section{SOIL RELEASE:}

Trap spilled material at bottom in deep water pockets, excavated holding areas or within sand bag barriers. Dike for later disposal. Absorb with sand or other non-combustible material. Collect with absorbent into suitable container.

\section{WATER RELEASE:}

Trap spilled material at bottom in deep water pockets, excavated holding areas or within sand bag barriers. Remove trapped material with suction hoses. Collect spilled material using mechanical equipment. Subject to California Safe Drinking Water and Toxic Enforcement Act of 1986 (Proposition 65). Keep out of water supplies and sewers.

\section{OCCUPATIONAL RELEASE:}

Do not touch spilled material. Stop leak if possible without personal risk. Reduce vapors with water spray. Small spills: Absorb with sand or other non-combustible material. Collect spilled material in appropriate container for disposal. Small dry spills: Move containers away from spill to a safe area. Large spills: Dike for later disposal. Keep unnecessary people away, isolate hazard area and deny entry. Ventilate closed spaces before entering. Notify Local Emergency Planning Committee and State Emergency Response Commission for release greater than or equal to RQ (U.S. SARA Section 304). If release occurs in the U.S. and is reportable under CERCLA Section 103, notify the National Response Center at (800)424-8802 (USA) or (202)426-2675 (USA).

\section{SECTION 7 HANDLING AND STORAGE}

STORAGE: Store and handle in accordance with all current regulations and standards. Notify State Emergency Response Commission for storage or use at amounts greater than or equal to the TPQ (U.S. EPA SARA Section 302). SARA Section 303 requires facilities storing a material with a TPQ to participate in local emergency response planning (U.S. EPA 40 CFR 355.30). Store in a cool, dry place. Store in a well-ventilated area. Keep separated from incompatible substances. Keep separated from incompatible substances.

\section{SECTION 8 EXPOSURE CONTROLS, PERSONAL PROTECTION}

\section{EXPOSURE LIMITS:}

\section{CHLOROFORM:}

$50 \mathrm{ppm}(240 \mathrm{mg} / \mathrm{m} 3)$ OSHA ceiling

2 ppm (9.78 mg/m3) OSHA TWA (vacated by 58 FR 35338, June 30, 1993)

$10 \mathrm{ppm}$ ACGIH TWA

$2 \mathrm{ppm}(9.78 \mathrm{mg} / \mathrm{m} 3)$ NIOSH recommended STEL 60 minute(s)

VENTILATION: Provide local exhaust or process enclosure ventilation system. Ensure compliance with 
applicable exposure limits.

MTSMSDS $109 \quad 4$ of 8

EYE PROTECTION: Wear splash resistant safety goggles. Provide an emergency eye wash fountain and quick drench shower in the immediate work area.

CLOTHING: Wear appropriate chemical resistant clothing.

GLOVES: Wear appropriate chemical resistant gloves.

RESPIRATOR: The following respirators and maximum use concentrations are drawn from NIOSH and/or OSHA.

At any detectable concentration -

Any self-contained breathing apparatus that has a full facepiece and is operated in a pressure-demand or other positive-pressure mode.

Any supplied-air respirator with full facepiece and operated in a pressure-demand or other positive-pressure mode in combination with a separate escape supply.

\section{Escape -}

Any air-purifying respirator with a full facepiece and an organic vapor canister.

Any appropriate escape-type, self-contained breathing apparatus.

For Unknown Concentrations or Immediately Dangerous to Life or Health -

Any supplied-air respirator with full facepiece and operated in a pressure-demand or other positive-pressure mode in combination with a separate escape supply.

Any self-contained breathing apparatus with a full facepiece.

\section{SECTION 9 PHYSICAL AND CHEMICAL PROPERTIES}

PHYSICAL STATE: liquid

APPEARANCE: clear

COLOR: colorless

PHYSICAL FORM: volatile liquid

ODOR: sweet odor and taste

MOLECULAR WEIGHT: 119.38

MOLECULAR FORMULA: $\mathrm{C}-\mathrm{H}-\mathrm{Cl} 3$

BOILING POINT: $144 \mathrm{~F}(62 \mathrm{C})$

FREEZING POINT: $-83 \mathrm{~F}(-64 \mathrm{C})$

VAPOR PRESSURE: $160 \mathrm{mmHg} @ 20 \mathrm{C}$

VAPOR DENSITY (air=1): 4.12

SPECIFIC GRAVITY (water=1): 1.4832

WATER SOLUBILITY: $0.82 \%$ @ $20 \mathrm{C}$

PH: Not available

VOLATILITY: $100 \%$

ODOR THRESHOLD: $200 \mathrm{ppm}$

EVAPORATION RATE: 11.6 (butyl acetate=1)

VISCOSITY: $56.3 \mathrm{cP} @ 20 \mathrm{C}$

COEFFICIENT OF WATER/OIL DISTRIBUTION: Not available

SOLVENT SOLUBILITY:

Soluble: alcohol, ether, acetone, benzene, ligroin, naphtha, petroleum ether, carbon tetrachloride, carbon disulfide, oils, organic solvents 


\section{SECTION 10 STABILITY AND REACTIVITY}

REACTIVITY: Stable at normal temperatures and pressure.

CONDITIONS TO AVOID: Avoid heat, flames, sparks and other sources of ignition. Containers may rupture or explode if exposed to heat.

INCOMPATIBILITIES: metals, combustible materials, oxidizing materials, halogens, bases

\section{HAZARDOUS DECOMPOSITION:}

Thermal decomposition products: oxides of chlorine, carbon, phosgene, chlorine, acid halides

POLYMERIZATION: Will not polymerize.

\section{SECTION 11 TOXICOLOGICAL INFORMATION}

\section{CHLOROFORM:}

\section{IRRITATION DATA:}

$10 \mathrm{mg} / 24$ hour(s) open skin-rabbit mild; $500 \mathrm{mg} / 24$ hour(s) skin-rabbit mild; $148 \mathrm{mg}$ eyes-rabbit; 20 $\mathrm{mg} / 24$ hour(s) eyes-rabbit moderate

\section{TOXICITY DATA:}

$47702 \mathrm{mg} / \mathrm{m} 3 / 4$ hour(s) inhalation-rat LC50; >20 gm/kg skin-rabbit LD50; $695 \mathrm{mg} / \mathrm{kg}$ oral-rat LD50

CARCINOGEN STATUS: NTP: Anticipated Human Carcinogen; IARC: Human Inadequate Evidence, Animal Sufficient Evidence, Group 2B; ACGIH: A3 -Animal Carcinogen

\section{LOCAL EFFECTS:}

Irritant: inhalation, skin, eye

ACUTE TOXICITY LEVEL:

Moderately Toxic: ingestion

Slightly Toxic: inhalation

TARGET ORGANS: central nervous system, liver, kidneys

MEDICAL CONDITIONS AGGRAVATED BY EXPOSURE: history of alcoholism, eye disorders, heart problems, kidney disorders, liver disorders, respiratory disorders, skin disorders and allergies

TUMORIGENIC DATA: Available.

MUTAGENIC DATA: Available.

REPRODUCTIVE EFFECTS DATA: Available.

ADDITIONAL DATA: May be excreted in breast milk. Alcohol may enhance the toxic effects.

Stimulants such as epinephrine may induce ventricular fibrillation.

\section{SECTION 12 ECOLOGICAL INFORMATION}

\section{ECOTOXICITY DATA:}

FISH TOXICITY: 66800 ug/L 96 hour(s) LC50 (Mortality) Rainbow trout,donaldson trout (Oncorhynchus mykiss)

INVERTEBRATE TOXICITY: 32000 ug/L 96 hour(s) NOEC (Mortality) Pink shrimp (america) (Penaeus duorarum)

ALGAL TOXICITY: >3200000 ug/L 48 hour(s) (Population Growth) Cryptomonad (Chilomonas paramecium) 
OTHER TOXICITY 270 ug 7 MTG MSOS 1096.08

FATE AND TRANSPORT:

BIOCONCENTRATION: $690 \mathrm{Ci} / \mathrm{mol} 6$ hour(s) BCF (Residue) Green algae (Selenastrum capricornutum) $13.9 \mathrm{Ci} / \mathrm{mol}$

\section{SECTION 13 DISPOSAL CONSIDERATIONS}

Dispose in accordance with all applicable regulations. Subject to disposal regulations: U.S. EPA 40 CFR 262. Hazardous Waste Number(s): U044. Hazardous Waste Number(s): D022. Dispose of in accordance with U.S. EPA 40 CFR 262 for concentrations at or above the Regulatory level. Regulatory level- 6.0 $\mathrm{mg} / \mathrm{L}$.

\section{SECTION I4 TRANSPORT INFORMATION}

U.S. DOT 49 CFR 172.101:

PROPER SHIPPING NAME: Chloroform

ID NUMBER: UN 1888

HAZARD CLASS OR DIVISION: 6.1

PACKING GROUP: III

LABELING REQUIREMENTS: Poison

\section{SECTION 15 REGULATORY INFORMATION}

\section{U.S. REGULATIONS:}

CERCLA SECTIONS 102a/103 HAZARDOUS SUBSTANCES (40 CFR 302.4):

Chloroform: 10 LBS RQ

SARA TITLE III SECTION 302 EXTREMELY HAZARDOUS SUBSTANCES (40 CFR 355.30): Chloroform: 10000 LBS TPQ

SARA TITLE III SECTION 304 EXTREMELY HAZARDOUS SUBSTANCES (40 CFR 355.40): Chloroform: 10 LBS RQ

SARA TITLE III SARA SECTIONS 311/312 HAZARDOUS CATEGORIES (40 CFR 370.21):

ACUTE: Yes

CHRONIC: Yes

FIRE: No

REACTIVE: No

SUDDEN RELEASE: No

SARA TITLE III SECTION 313 (40 CFR 372.65):

Chloroform

OSHA PROCESS SAFETY (29CFR1910.119): Not regulated.

\section{STATE REGULATIONS:}


California Proposition 65:

Known to the state of Califomia to cause the following:

MTG MSDS $1097 \% 8$

Chloroform

Cancer (Oct 01, 1987)

CANADLAN REGULATIONS:

WHMIS CLASSIFICATION: D2

EUROPEAN REGULATIONS:

EC CLASSIFICATION (ASSIGNED):

\begin{tabular}{|l|l|}
\hline $\mathrm{Xn}$ & Harmful \\
\hline $\mathrm{Xi}$ & Irritant \\
\hline & Carcinogen Cutegory 3 \\
\hline
\end{tabular}

EC Classification may be inconsistent with independently-researched data.

\section{DANGER/HAZARD SYMBOL:}

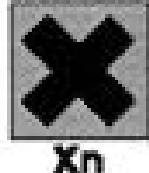

\section{EC RISK AND SAFETY PHRASES:}

\begin{tabular}{|l|l|}
\hline R 22 & Harmful if swallowed. \\
\hline R 38 & Irritating to skin. \\
\hline R 40 & Possible risks of irreversible effects. \\
\hline R $48 / 20 / 22$ & $\begin{array}{l}\text { Harmful: danger of serious damage to health by prolonged exposure through inhalation } \\
\text { and if swallowed. }\end{array}$ \\
\hline S 2 & Keep out of reach of children. \\
\hline S $36 / 37$ & Wear suitable protective clothing and gloves. \\
\hline
\end{tabular}

CONCENTRATION LIMITS:

$\mathrm{C}=20 \%$ Xn R 22-38-40-48/20/22

$5 \%<=\mathrm{C}<20 \%$ Xn R 22-40-48/20/22

$15<=\mathrm{C}<5 \%$ Xn R 40

NATIONAL INVENTORY STATUS:

U.S. INVENTORY (TSCA): Listed on inventory.

TSCA 12(b) EXPORT NOTIFICATION: Not listed.

CANADA INVENTORY (DSL): Not determined.

CANADA INVENTORY (NDSL): Not determined. 
SECTION 16 OTHER INFORMATION mTG usDS 1098 of 8

MSDS SUMMARY OF CHANGES

SECTION 1 CHEMICAL PRODUCT AND COMPANY IDENTIFICATION

SECTION 3 HAZARDS IDENTIFICATION

SECTION 7 HANDLING AND STORAGE

SECTION 11 TOXICOLOGICAL INFORMATION

SECTION 14 TRANSPORT INFORMATION

SECTION 15 REGULATORY INFORMATION

(C) Copyright 1984-2001 MDL Information Systems, Inc. All rights reserved.

MATHESON TRI-GAS, INC. MAKES NO EXPRESS OR IMPLIED WARRANTIES, GUARANTEES OR REPRESENTATIONS REGARDING THE PRODUCT OR THE INFORMATION HEREIN, INCLUDING BUT NOT LIMITED TO ANY IMPLIED WARRANTY OF MERCHANTABILITY OR FITNESS FOR USE. MATHESON TRI-GAS, INC. SHALL NOT BE LIABLE FOR ANY PERSONAL INJURY, PROPERTY OR OTHER DAMAGES OF ANY NATURE, WHETHER COMPENSATORY, CONSEQUENTIAL, EXEMPLARY, OR OTHERWISE, RESULTING FROM ANY PUBLICATION, USE OR RELIANCE UPON THE INFORMATION HEREIN. 


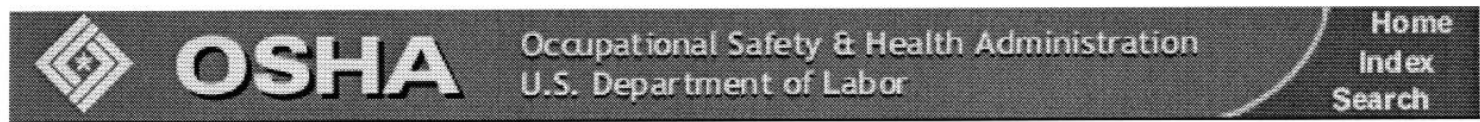

Technical Links > Health Guidelines > Chloroform

\begin{abstract}
Disclaimer: These guidelines were developed under contract using generally accepted secondary sources. The protocol used by the contractor for surveying these data sources was developed by the National Institute for Occupational Safety and Health (NIOSH), the Occupational Safety and Health Administration (OSHA), and the Department of Energy (DOE). The information contained in these guidelines is intended for reference purposes only. None of the agencies have conducted a comprehensive check of the information and data contained in these sources. It provides a summary of information about chemicals that workers may be exposed to in their workplaces. The secondary sources used for supplements 111 and $1 \mathrm{~V}$ were published before 1992 and 1993 , respectively, and for the remainder of the guidelines the secondary sources used were published before September 1996. This information may be superseded by new developments in the field of industrial hygiene. Therefore readers are advised to determine whether new information is available.
\end{abstract}

\title{
OCCUPATIONAL SAFETY AND HEALTH GUIDELINE FOR CHLOROFORM
}

\section{INTRODUCTION}

This guideline summarizes pertinent information about chloroform for workers and employers as well as for physicians, industrial hygienists, and other occupational safety and health professionals who may need such information to conduct effective occupational safety and health programs. Recommendations may be superseded by new developments in these fields; readers are therefore advised to regard these recommendations as general guidelines and to determine whether new information is available.

\section{SUBSTANCE IDENTIFICATION}

* Formula

$\mathrm{CHCl}(3)$

* Structure

(For Structure, see paper copy)

* Synonyms

Trichloromethane, trichloroform, freon 20, COBEHN Spray-Cleaner solvent, formyl trichloride, methane trichloride, methenyl trichloride, methyl trichloride

* Identifiers

1. CAS No.: 67-66-3

2. RTECS No.: FS9100000

3. DOT UN: 188855

4. DOT label: Poison

* Appearance and odor

Chloroform is a clear, colorless, and mobile liquid with a pleasant, sweet odor. Air odor threshold concentrations ranging from 85 to 307 parts per million (ppm) parts of air have been reported for chloroform. 


\section{CHEMICAL AND PHYSICAL PROPERTIES}

* Physical data

1. Molecular weight: 119.4

2. Boiling point (at $760 \mathrm{~mm} \mathrm{Hg}$ ): 62 degrees $C$ (143 degrees $F$ )

3. Specific gravity (water $=1$ ): 1.48 at 20 degrees C ( 68 degrees F)

4. Vapor density: 4.1

5. Melting point: -63.5 degrees $\mathrm{C}$ ( -82 degrees $\mathrm{F}$ )

6. Vapor pressure at 20 degrees C (68 degrees F): $160 \mathrm{~mm} \mathrm{Hg}$

7. Solubility: Slightly soluble in water; soluble in alcohol, ether, acetone, benzene, and ligroin.

8. Evaporation rate: Data not available.

\section{* Reactivity}

1. Conditions contributing to instability: Heat, air, and light.

2. Incompatibilities: Contact between chloroform and acetone, alkalis, and chemically active metals such as aluminum magnesium (in powder form), sodium, or potassium should be avoided. Chloroform is also incompatible with dinitrogen tetraoxide, fluorine, triisopropylphosphine, and solid potassium tert-butoxide.

3. Hazardous decomposition products: Toxic gases and vapors such as hydrogen chloride, chlorine, phosgene, and carbon monoxide may be released in a fire involving chloroform.

4. Special precautions: None reported.

* Flammability

The National Fire Protection Association has assigned a flammability rating of 0 (no fire hazard) to chloroform.

1. Flash point: Not applicable.

2. Autoignition temperature: Not applicable.

3. Flammable limits in air: Not applicable.

4. Extinguishant: Use an extinguishant that is suitable for the materials involved in the surrounding fire.

Fires involving chloroform should be fought upwind from the maximum distance possible. Keep unnecessary people away; isolate the hazard area and deny entry. Emergency personnel should stay out of low areas and ventilate closed spaces before entering. Containers of chloroform may explode in the heat of the fire and should be moved from the fire area if it is possible to do so safely. If this is not possible, cool fire exposed containers from the sides with water until well after the 
fire is out. Stay away from the ends of containers. Dike fire control water for later disposal; do not scatter this material. Firefighters should wear a full set of protective clothing and self-contained breathing apparatus when fighting fires involving chloroform.

\section{EXPOSURE LIMITS}

* OSHA PEL

The current Occupational Safety and Health Administration (OSHA) permissible exposure limit (PEL) for chloroform is $50 \mathrm{ppm}$ (240 milligrams per cubic meter $(\mathrm{mg} / \mathrm{m}(3)))$ as a ceiling limit. A worker's exposure to chloroform shall at no time exceed this ceiling level [29 CFR 1910.1000, Table Z-1].

* NIOSH REL

The National Institute for Occupational Safety and Health (NIOSH) has established a recommended exposure limit (REL) for chloroform of $2 \mathrm{ppm}(9.78 \mathrm{mg} / \mathrm{m}(3))$ as a 60-minute short-term exposure limit (STEL). NIOSH also considers chloroform a potential occupational carcinogen [NIOSH 1992].

\section{* ACGIH TLV}

The American Conference of Governmental Industrial Hygienists (ACGIH) has assigned chloroform a threshold limit value (TLV) of $10 \mathrm{ppm}(49 \mathrm{mg} / \mathrm{m}(3))$ as a TWA for a normal 8-hour workday and a 40-hour workweek. The ACGIH also considers chloroform a suspected human carcinogen (A2 substance) [ACGIH 1994, p. 16].

* Rationale for Limits

The NIOSH limit is based on the risk of central nervous system effects and potential for cancer; cancer of the liver and kidneys in animals [NIOSH 1992].

The ACGIH limit is based on the risk of cancer [ACGIH 1991, p. 290].

\section{HEALTH HAZARD INFORMATION}

* Routes of Exposure

Exposure to chloroform can occur through inhalation, ingestion, or contact with the skin or eyes [Sittig 1991].

\section{* Summary of toxicology}

1. Effects on Animals: Chloroform is a central nervous system depressant and carcinogen. Exposure of pregnant animals to chloroform increases the rate of fetal loss and malformation [Patnaik 1992]. The acute toxicity of chloroform is species-, strain-, sex-, and age-dependent. The oral $\mathrm{LD}(50)$ in young and older adult male Sprague-Dawley rats are 1,336 and $1,188 \mathrm{mg} / \mathrm{kg}$; in 14-day-old rats of the same species, the oral LD(50) is $445 \mathrm{mg} / \mathrm{kg}$ [Clayton and Clayton 1982]. The dermal LD(50) in rabbits is greater than $20 \mathrm{gm} / \mathrm{kg}$ [NIOSH 1995]. Males of many mouse strains are susceptible to kidney damage, but not the females. Liver damage was the cause of death in rats and mice after acute exposures [Clayton and Clayton 1982]. Two chronic studies of rats show that chloroform-induced kidney and liver damage begins to appear at the $50 \mathrm{ppm}$ exposure level and the severity of the exposure-related effects increases with dose [NLM 1995]. Chloroform was tested for carcinogenicity in three experiments 
in mice and one in rats. It produced liver cancer in mice, kidney tumors in male rats, and thyroid tumors in female rats [ACGIH 1991]. The International Agency for Research on Cancer (IARC) has concluded that chloroform is a carcinogen in experimental animals [IARC 1987]. Chloroform is both embryotoxic and teratogenic in experimental animals. Embryotoxic effects include decreased conception rate, fetal resorption, retarded fetal development, and small size [ACGIH 1991]. In another study, there was a significant incidence of cleft palate in the offspring of exposed pregnant mice [Clayton and Clayton 1982]. Chloroform crosses the placenta rapidly and enters the fetal circulation [NLM 1995]. Chloroform applied to rabbit skin caused redness and necrosis. Liquid chloroform instilled into rabbit eyes caused conjunctivitis and injury to the cornea [Clayton and Clayton 1982].

2. Effects on Humans: The toxicity of chloroform is well understood because of its long history of use as an anesthetic. Inhalation of $10,000 \mathrm{ppm}$ of chloroform vapor produces clinical anesthesia. Inhalation of higher doses causes cardiovascular depression, with death resulting from ventricular fibrillation. Delayed death is associated with liver necrosis [ACGIH 1991]. Chronic inhalation of chloroform may cause psychiatric and neurological symptoms, including depression, hallucinations, and moodiness [NLM 1995]. In studies with human volunteers, exposure to 4,100 ppm causes serious disorientation, and 1,000 ppm caused dizziness, nausea, and after effects of fatigue and headache. Exposures of 20 to 70 ppm for undefined lengths of time caused less extreme, but still evident, effects on the central nervous system [Hathaway et al. 1991]. Liver enlargement was demonstrated in 17 of 68 workers exposed to chloroform at concentrations of 10 to $200 \mathrm{ppm}$ for 1 to 4 years. Among other factors that increase the toxic effects of chloroform is ethanol [Hathaway et al. 1991]. As a result, alcoholics react more severely to exposure [Genium 1992]. Exposure to high concentrations of chloroform vapor causes redness and twitching of the eyes. Liquid chloroform splashed into the eye causes immediate burning, pain, and possible injury to the cornea. The eye returns to normal in 1 to 3 days [Grant 1986]. Application of chloroform to the skin causes burning, pain, redness, and vesiculation. Based on experimental animal studies, IARC has concluded that chloroform should be regarded as a cancer risk to humans. One study of people exposed to chloroform in their drinking water showed a correlation between chloroform concentration and rectal and bladder cancer [Hathaway et al. 1991].

* Signs and symptoms of exposure

1. Acute exposure: Inhalation of chloroform causes signs and symptoms of central nervous system depression. In the initial stages, there is a feeling of warmth of the face and body, then irritation of the mucous membranes, eyes, and skin, followed by excitation, loss of reflexes, sensation, and consciousness. The pupils dilate and have a reduced reaction to light. Prolonged inhalation causes paralysis, cardiac and respiratory failure, and death [Sax and Lewis 1989; Genium 1992]. Other symptoms may include digestive upset, mental dullness, and dizziness [Sittig 1991]. Chloroform vapors may irritate the eyes and skin. Chloroform liquid causes burning of the eye and transient corneal injury. Skin exposure results in burning and redness [NLM 1995]. Exposure of pregnant women to chloroform may result in fetal death or malformation based on animals studies [Clayton and Clayton 1982].

2. Chronic exposure: Chronic exposure to chloroform causes neurological and gastrointestinal signs and symptoms that resemble those of chronic alcoholism [Parmeggiani 1983]. These may include depression, liver enlargement, and gastrointestinal disorders [Sittig 1991]. Chronic skin exposure to chloroform may leave the skin red, dry, and cracking [Genium 1992].

\section{EMERGENCY MEDICAL PROCEDURES}


* Emergency medical procedures: [NIOSH to supply]

5. Rescue: Remove an incapacitated worker from further exposure and implement appropriate emergency procedures (e.g., those listed on the Material Safety Data Sheet required by OSHA's Hazard Communication Standard [29 CFR 1910.1200]). All workers should be familiar with emergency procedures, the location and proper use of emergency equipment, and methods of protecting themselves during rescue operations.

\section{EXPOSURE SOURCES AND CONTROL METHODS}

The following operations may involve chloroform and lead to worker exposures to this substance:

* The manufacture and transportation of chloroform

* Used in manufacture of fluorocarbons (especially chlorodifluoromethane) for refrigerants and aerosol propellants; used in fire extinguishers to lower the freezing temperature of carbon tetrachloride; used in manufacture of fluorocarbon resins, tribromomethane, plastics, and thermally stable polymers; used in the manufacture of artificial silk, floor polishes, dyes, and pesticides

* Used as an extractant solvent in manufacture of rubber, essential oils, sterols and alkaloids, guttapercha, resins, and in the recovery of fat from waste products

* Used in chemical analysis and assays; and in photographic processing

* Used as a general solvent of lacquers plastics, dyes, fats, greases, gums, oils, adhesives, and waxes, and in the rubber cleaning and dry cleaning industries

* Prior use as an anesthetic has been discontinued and uses in human drugs and cosmetics are now limited to use as a process solvent for final products that contain only residual amounts of chloroform

* Used as a fumigant for soil, a mildewicide for tobacco seedlings, a grain fumigant for various stored dry grains, and as an insecticide

Methods that are effective in controlling worker exposures to chloroform, depending on the feasibility of implementation, are as follows:

* Process enclosure

* Local exhaust ventilation

* General dilution ventilation

* Personal protective equipment

Workers responding to a release or potential release of a hazardous substance must be protected as required by paragraph (q) of OSHA's Hazardous Waste Operations and Emergency Response Standard [29 CFR 1910.120].

Good sources of information about control methods are as follows:

1. ACGIH [1992]. Industrial ventilation--a manual of recommended practice. 21st ed. Cincinnati, $\mathrm{OH}$ : American Conference of Governmental Industrial Hygienists.

2. Burton D] [1986]. Industrial ventilation--a self study companion. Cincinnati, $\mathrm{OH}$ : American Conference of Governmental Industrial Hygienists.

3. Alden JL, Kane JM [1982]. Design of industrial ventilation systems. New York, NY: 
Industrial Press, Inc.

4. Wadden RA, Scheff PA [1987]. Engineering design for control of workplace hazards. New York, NY: McGraw-Hill.

5. Plog BA [1988]. Fundamentals of industrial hygiene. Chicago, IL: National Safety Council.

\section{MEDICAL SURVEILLANCE}

OSHA is currently developing requirements for medical surveillance. When these requirements are promulgated, readers should refer to them for additional information and to determine whether employers whose employees are exposed to chloroform are required to implement medical surveillance procedures.

* Medical Screening

Workers who may be exposed to chemical hazards should be monitored in a systematic program of medical surveillance that is intended to prevent occupational injury and disease. The program should include education of employers and workers about work-related hazards, early detection of adverse health effects, and referral of workers for diagnosis and treatment. The occurrence of disease or other work-related adverse health effects should prompt immediate evaluation of primary preventive measures (e.g., industrial hygiene monitoring, engineering controls, and personal protective equipment). A medical surveillance program is intended to supplement, not replace, such measures. To detect and control work-related health effects, medical evaluations should be performed (1) before job placement, (2) periodically during the term of employment, and (3) at the time of job transfer or termination.

* Preplacement medical evaluation

Before a worker is placed in a job with a potential for exposure to chloroform, a licensed health care professional should evaluate and document the worker's baseline health status with thorough medical, environmental, and occupational histories, a physical examination, and physiologic and laboratory tests appropriate for the anticipated occupational risks. These should concentrate on the function and integrity of the skin, liver, kidneys, heart, and central nervous system.

A preplacement medical evaluation is recommended to assess medical conditions that may be aggravated or may result in increased risk when a worker is exposed to chloroform at or below the prescribed exposure limit. The health care professional should consider the probable frequency, intensity, and duration of exposure as well as the nature and degree of any applicable medical condition. Such conditions (which should not be regarded as absolute contraindications to job placement) include a history and other findings consistent with diseases of the skin, liver, kidneys, heart, or central nervous system.

* Periodic medical evaluations

Occupational health interviews and physical examinations should be performed at regular intervals during the employment period, as mandated by any applicable Federal, State, or local standard. Where no standard exists and the hazard is minimal, evaluations should be conducted every 3 to 5 years or as frequently as recommended by an experienced occupational health physician. Additional examinations may be necessary if a worker develops symptoms attributable to chloroform exposure. The interviews, examinations, and medical screening tests 
should focus on identifying the adverse effects of chloroform on the skin, liver, kidneys, heart, or central nervous system. Current health status should be compared with the baseline health status of the individual worker or with expected values for a suitable reference population.

* Termination medical evaluations

The medical, environmental, and occupational history interviews, the physical examination, and selected physiologic or laboratory tests that were conducted at the time of placement should be repeated at the time of job transfer or termination to determine the worker's medical status at the end of his or her employment. Any changes in the worker's health status should be compared with those expected for a suitable reference population. Because occupational exposure to chloroform may cause diseases with prolonged latent periods, the need for medical survelllance may extend well beyond the termination of employment.

* Biological monitoring

Biological monitoring involves sampling and analyzing body tissues or fluids to provide an index of exposure to a toxic substance or metabolite. The presence of chloroform in the blood and in expired air is an indication of exposure, but data are insufficient to correlate blood or breath levels with indices of exposure. Therefore, no biological monitoring test acceptable for routine use has yet been developed for chloroform.

\section{WORKPLACE MONITORING AND MEASUREMENT}

Determination of a worker's exposure to airborne chloroform is made using a charcoal tube (100/50 mg sections, $20 / 40$ mesh). Samples are collected at a maximum flow rate of 0.2 liter/minute (ceiling or TWA) until a maximum collection volume of 10 liters is reached (TWA) or for a minimum collection time of 15 minutes (ceiling). The sample is then treated with 99:1 carbon disulfide:dimethylformamide. Analysis is conducted by gas chromatography using a flame ionization detector (GC/FID). This method (OSHA 5) is described in the OSHA Computerized Information System [OSHA 1994] and is fully validated. NIOSH has published a similar method (Method No. 1003-for halogenated hydrocarbons) that can also be used to determine a worker's exposure to airborne chloroform [NIOSH 1994b].

\section{PERSONAL HYGIENE PROCEDURES}

If chloroform contacts the skin, workers should immediately wash the affected areas twice with soap and water and use cream or lotion to replace skin oils.

Clothing contaminated with chloroform should be removed immediately, and provisions should be made for the safe removal of the chemical from the clothing. Persons laundering the clothes should be informed of the hazardous properties of chloroform, particularly its potential for causing eye and skin irritation, and anesthesia when inhaled.

A worker who handles chloroform should thoroughly wash hands, forearms, and face with soap and water before eating, using tobacco products, using toilet facilities, applying cosmetics, or taking medication.

Workers should not eat, drink, use tobacco products, apply cosmetics, or take medication in areas where chloroform or a solution containing chloroform is handled,

processed, or stored. 


\section{STORAGE}

Chloroform should be stored in a cool, dry, well-ventilated area (less than 30 degrees C ( 86 degrees F)) in tightly sealed containers that are labeled in accordance with OSHA's Hazard Communication Standard [29 CFR 1910.1200]. Chloroform decomposes at ordinary temperatures in sunlight in the absence of air, and in the dark in the presence of air. Containers of chloroform should be protected from physical damage, heat sources, direct sunlight, and moisture, and should be stored separately from acetone, alkalis, and chemically active metals such as aluminum magnesium (in powder form), sodium, or potassium, dinitrogen tetraoxide, fluorine, triisopropylphosphine, and solid potassium tert-butoxide. Do not use rubber or plastic hose or pipe to transfer chloroform. Empty containers of chloroform should be handled appropriately.

\section{SPILLS AND LEAKS}

In the event of a spill or leak involving chloroform, persons not wearing protective equipment and fully-encapsulating, vapor-protective clothing should be restricted from contaminated areas until cleanup has been completed. The following steps should be undertaken following a spill or leak:

1. Notify safety personnel.

2. Remove all sources of heat and ignition.

3. Ventilate the area of the spill or leak.

4. Do not touch the spilled material; stop the leak if it is possible to do so without risk.

5. Water spray may be used to reduce vapors.

6. For small liquid spills, take up with sand or other noncombustible absorbent material and place into closed containers for later disposal.

7. For large liquid spills, build dikes far ahead of the spill to contain the chloroform for later reclamation or disposal.

\section{SPECIAL REQUIREMENTS}

U.S. Environmental Protection Agency (EPA) requirements for emergency planning, reportable quantities of hazardous releases, community right-to-know, and hazardous waste management may change over time. Users are therefore advised to determine periodically whether new information is available.

* Emergency planning requirements

Employers owning or operating a facility at which there are 10,000 pounds or more of chloroform must comply with EPA's emergency planning requirements [ 40 CFR Part 355.30].

* Reportable quantity requirements for hazardous releases

A hazardous substance release is defined by EPA as any spilling, leaking, pumping, pouring, emitting, emptying, discharging, injecting, escaping, leaching, dumping, or disposing into the environment (including the abandonment or discarding of contaminated containers) of hazardous substances. In the event of a release that is above the reportable quantity for that chemical, employers are required to notify the proper Federal, State, and local authorities [40 CFR 
$355.40]$.

The reportable quantity of chloroform is 10 pounds. If an amount equal to or greater than this quantity is released within a 24 -hour period in a manner that will expose persons outside the facility, employers are required to do the following:

- Notify the National Response Center immediately at (800) 424-8802 or at (202) 426-2675 in Washington, D.C. [40 CFR 302.6].

- Notify the emergency response commission of the State likely to be affected by the release [40 CFR 355.40].

- Notify the community emergency coordinator to the local emergency planning committee (or relevant local emergency response personnel) of any area likely to be affected by the release [ 40 CFR 355.40 ].

* Community right-to-know requirements

Employers who own or operate facilities in SIC codes 20 to 39 that employ 10 or more workers and that manufacture 25,000 pounds or more of chloroform per calendar year or otherwise use 10,000 pounds or more of chloroform per calendar year are required by EPA [40 CFR Part 372.30] to submit a Toxic Chemical Release Inventory form (Form R) to EPA reporting the amount of chloroform emitted or released from their facility annually.

* Hazardous waste management requirements

EPA considers a waste to be hazardous if it exhibits any of the following characteristics: ignitability, corrosivity, reactivity, or toxicity as defined in 40 CFR 261.21-261.24. Under the Resource Conservation and Recovery Act (RCRA) [40 USC 6901 et seq.], EPA has specifically listed many chemical wastes as hazardous. Chloroform is listed as a hazardous waste under RCRA and has been assigned EPA Hazardous Waste No. U044. It is approved for land disposal after treatment and only if the concentration of chloroform in the waste or treatment residual does not exceed $5.6 \mathrm{mg} / \mathrm{kg}$.

Providing detalled information about the removal and disposal of specific chemicals is beyond the scope of this guideline. The U.S. Department of Transportation, EPA, and State and local regulations should be followed to ensure that removal, transport, and disposal of this substance are conducted in accordance with existing regulations. To be certain that chemical waste disposal meets EPA regulatory requirements, employers should address any questions to the RCRA hotline at (703) 412-9810 (in the Washington, D.C. area) or toll-free at (800) 424-9346 (outside Washington, D.C.). In addition, relevant State and local authorities should be contacted for information on any requirements they may have for the waste removal and disposal of this substance.

\section{RESPIRATORY PROTECTION}

\section{* Conditions for respirator use}

Good industrial hygiene practice requires that engineering controls be used where feasible to reduce workplace concentrations of hazardous materials to the prescribed exposure limit. However, some situations may require the use of respirators to control exposure. Respirators must be worn if the ambient concentration of chloroform exceeds prescribed exposure limits. Respirators may 
be used (1) before engineering controls have been installed, (2) during work operations such as maintenance or repair activities that involve unknown exposures, (3) during operations that require entry into tanks or closed vessels, and (4) during emergencies. Workers should only use respirators that have been approved by NIOSH and the Mine Safety and Health Administration (MSHA).

* Respiratory protection program

Employers should institute a complete respiratory protection program that, at a minimum, complies with the requirements of OSHA's Respiratory Protection Standard [29 CFR 1910.134]. Such a program must include respirator selection, an evaluation of the worker's ability to perform the work while wearing a respirator, the regular training of personnel, respirator fit testing, periodic workplace monitoring, and regular respirator maintenance, inspection, and cleaning. The implementation of an adequate respiratory protection program (including selection of the correct respirator) requires that a knowledgeable person be in charge of the program and that the program be evaluated regularly. For additional information on the selection and use of respirators and on the medical screening of respirator users, consult the latest edition of the NIOSH Respirator Decision Logic [NIOSH 1987b] and the NIOSH Guide to Industrial Respiratory Protection [NIOSH 1987a].

\section{PERSONAL PROTECTIVE EQUIPMENT}

Workers should use appropriate personal protective clothing and equipment that must be carefully selected, used, and maintained to be effective in preventing skin contact with chloroform. The selection of the appropriate personal protective equipment (PPE) (e.g., gloves, sleeves, encapsulating suits) should be based on the extent of the worker's potential exposure to chloroform. The resistance of various materials to permeation by chloroform is shown below:

$\begin{array}{ll}\text { Material } & \text { Breakth } \\ \text { polyvinyl alcohol } & >8 \\ \text { fluoroelastomer } & >8 \\ 4 \mathrm{H}(\mathrm{PE} / \mathrm{EVAL}) & >8 \\ \text { barricade } & >8 \\ \text { responder } & >8 \\ \text { teflon } & >4 \\ \text { butyl rubber } & <1\left(^{*}\right) \\ \text { natural rubber } & <1\left(^{*}\right) \\ \text { polyethylene } & <1\left(^{*}\right) \\ \text { polyvinyl chloride } & <1\left(^{*}\right) \\ \text { saranex } & <1\left(^{*}\right) \\ \text { chemrel } & <1\left(^{*}\right)\end{array}$

(*) Not recommended, degradation may occur

To evaluate the use of these PPE materials with chloroform, users should consult the best available performance data and manufacturers' recommendations. Significant differences have been demonstrated in the chemical resistance of generically similar PPE materials (e.g., butyl) produced by different manufacturers. In addition, the 
chemical resistance of a mixture may be significantly different from that of any of its neat components.

Any chemical-resistant clothing that is used should be periodically evaluated to determine its effectiveness in preventing dermal contact. Safety showers and eye wash stations should be located close to operations that involve chloroform.

Splash-proof chemical safety goggles or face shields (20 to $30 \mathrm{~cm}$ long, minimum) should be worn during any operation in which a solvent, caustic, or other toxic substance may be splashed into the eyes.

In addition to the possible need for wearing protective outer apparel (e.g., aprons, encapsulating suits), workers should wear work uniforms, coveralls, or similar full-body coverings that are laundered each day. Employers should provide lockers or other closed areas to store work and street clothing separately. Employers should collect work clothing at the end of each work shift and provide for its laundering. Laundry personnel should be informed about the potential hazards of handling contaminated clothing and instructed about measures to minimize their health risk.

Protective clothing should be kept free of oil and grease and should be inspected and maintained regularly to preserve its effectiveness.

Protective clothing may interfere with the body's heat dissipation, especially during hot weather or during work in hot or poorly ventilated work environments.

\section{REFERENCES}

ACGIH [1991]. Documentation of the threshold limit values and biological exposure indices. 6th ed. Cincinnati, $\mathrm{OH}$ : American Conference of Governmental Industrial Hygienists.

ACGIH [1994]. 1994-1995 Threshold limit values for chemical substances and physical agents and biological exposure indices. Cincinnati, OH: American Conference of Governmental Industrial Hygienists.

Amoore JE, Hautala E [1983]. Odor as an aid to chemical safety: odor thresholds compared with threshold limit values and volatilities for 214 industrial chemicals in air and water dilution. J of App Tox 3(6):272-290.

Baselt RC [1988]. Biological monitoring methods for industrial chemicals. 2nd ed. Davis, CA: Biomedical Publications.

CFR. Code of Federal regulations. Washington, DC: U.S. Government Printing Office, Office of the Federal Register.

Clayton G, Clayton F [1981-1982]. Patty's industrial hygiene and toxicology. 3rd rev. ed. New York, NY: John Wiley \& Sons.

DOT [1993]. 1993 Emergency response guidebook, guide 55. Washington, DC: U.S. Department of Transportation, Office of Hazardous Materials Transportation, Research and Special Programs Administration.

Forsberg K, Mansdorf SZ [1993]. Quick selection guide to chemical protective clothing. New York, NY: Van Nostrand Reinhold.

Genium [1992]. Material safety data sheet No. 315. Schenectady, NY: Genium Publishing Corporation. 
Grant WM [1986]. Toxicology of the eye. 3rd ed, Springfield, IL: Charles C Thomas.

Grayson M [1985]. Kirk-Othmer concise encyclopedia of chemical technology. Abridged version, 3rd ed. New York, NY: John Wiley \& Sons.

Hathaway G], Proctor NH, Hughes JP, and Fischman ML [1991]. Proctor and Hughes' chemical hazards of the workplace. 3rd ed. New York, NY: Van Nostrand Reinhold.

IARC [1979]. IARC monographs on the evaluation of carcinogenic risk of chemicals to man. Volume 20. Lyon, France: World Health Organization, International Agency for Research on Cancer.

IARC [1987]. IARC monographs on the evaluation of carcinogenic risk of chemicals to man. Supplement 7. Lyon, France: World Health Organization, International Agency for Research on Cancer. Lewis RJ, ed. [1993]. Hawley's condensed chemical dictionary. 12 th ed. New York, NY: Van Nostrand Reinhold Company.

Mickelsen RL, Hall RC [1987]. A breakthrough time comparison of nitrile and neoprene glove materials produced by different glove manufacturers. Am Ind Hyg Assoc J 48(11): 941-947.

Mickelsen RL, Hall RC, Chern RT, Myers JR [1991]. Evaluation of a simple weight-loss method for determining the permeation of organic liquids through rubber films. Am Ind Hyg Assoc J 52(10): 445-447.

NFPA [1986]. Fire protection guide on hazardous materials. 9th ed. Quincy, MA: National Fire Protection Association.

NIOSH [1987a]. NIOSH guide to industrial respiratory protection. Cincinnati, OH: U.S. Department of Health and Human Services, Public Health Service, Centers for Disease Control, National Institute for Occupational Safety and Health, DHHS (NIOSH) Publication No. 87-116.

NIOSH [1987b], NIOSH respirator decision logic. Cincinnati, OH: U.S. Department of Health and Human Services, Public Health Service, Centers for Disease Control, National Institute for Occupational Safety and Health, DHHS (NIOSH) Publication No, 87-108.

NIOSH [1992]. Recommendations for occupational safety and health: Compendium of policy documents and statements. Cincinnati, OH: U.S. Department of Health and Human Services, Public Health Service, Centers for Disease Control, National Institute for Occupational Safety and Health, DHHS (NIOSH) Publication No. 92-100.

NIOSH [1994a]. NIOSH pocket guide to chemical hazards. Cincinnati, OH: U.S. Department of Health and Human Services, Public Health Service, Centers for Disease Control, National Institute for Occupational Safety and Health, DHHS (NIOSH) Publication No. 94-116.

NIOSH [1994b]. NIOSH manual of analytical methods. 4th ed. Cincinnati, OH: U.S. Department of Health and Human Services, Public Heaith Service, Centers for Disease Control, National Institute for Occupational Safety and Health, DHHS (NIOSH) Publication No. 94-113.

NIOSH [1995]. Registry of toxic effects of chemical substances: Chloroform. Cincinnati, $\mathrm{OH}:$ U.S. Department of Health and Human Services, Public Health Service, Centers for Disease Control, National Institute for Occupational Safety and Health. Division of Standards Development and Technology Transfer, Technical Information Branch. 
NJDH [1985]. Hazardous substance fact sheet: Chloroform. Trenton, NJ: New Jersey Department of Health.

NLM [1995]. Hazardous substances data bank: Chloroform. Bethesda, MD: National Library of Medicine.

OSHA [1994]. Computerized information system. Washington, DC: U.S. Department of Labor, Occupational Safety and Health Administration.

Parmeggiani L [1983]. Encyclopedia of occupational health and safety. 3rd rev. ed. Geneva, Switzerland: International Labour Organisation.

Patnaik P [1992]. A comprehensive guide to the hazardous properties of chemical substances. New York, NY: Van Nostrand Reinhold.

Rumack. Poisindex.

Sax NI, Lewis RJ [1989]. Dangerous properties of industrial materials. 7th ed. New York, NY: Van Nostrand Reinhold Company.

Sittig M [1991]. Handbook of toxic and hazardous chemicals. 3rd ed. Park Ridge, NJ: Noyes Publications.

USC. United States code. Washington. DC: U.S. Government Printing Office.

Windholz M, ed. [1983]. Merck Index 10th ed. Rahway, NJ: Merck \& Company. 


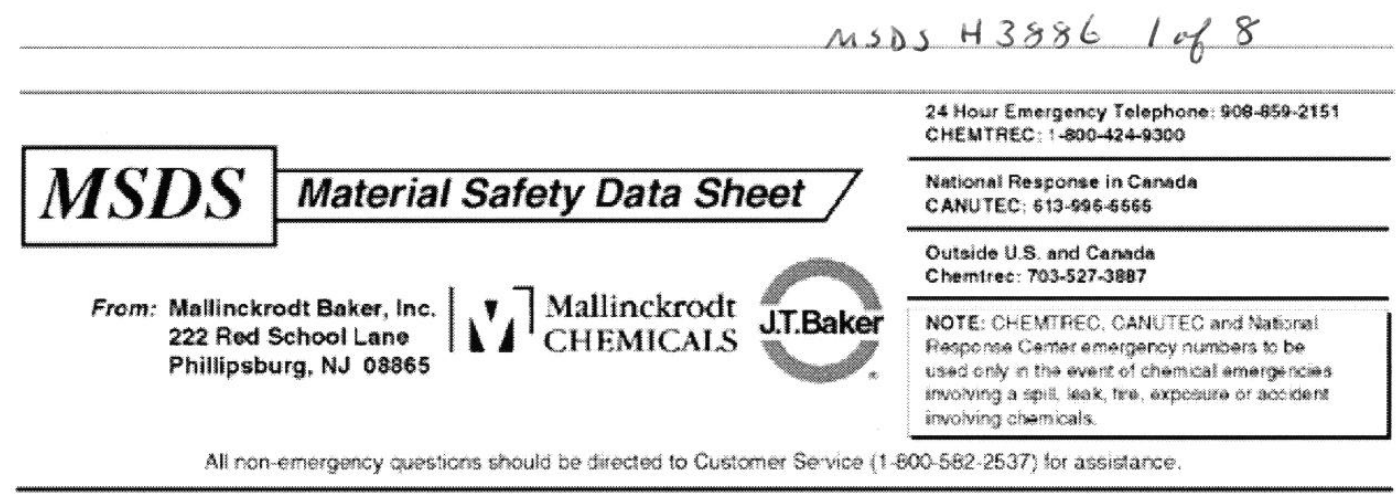

\section{HYDROCHLORIC ACID (10\%-33\%)}

MSDS Number: H3886 --- Effective Date: 11/17/99

\section{Product Identification}

Synonyms: This MSDS applies to the concentrated standard used to make laboratory solutions and any solution that contains more than $10 \%$ but less than 33\% Hydrochloric acid. For diluted product, see MSDS for Hydrochloric Acid (less than 10\%). For saturated solution

CAS No.: 7647-01-0

Molecular Weight: 36.46

Chemical Formula: $\mathrm{HCl}$ in $\mathrm{H} 2 \mathrm{O}$

Product Codes:

J.T. Baker: 0323, 0327, 4654, 4657, 4658, 5618, 5619

Mallinckrodt: 2608, 2609, 2625, H151, H168, V024, V035, V328

\section{Composition/Information on Ingredients}

\begin{tabular}{|c|c|c|c|}
\hline Ingredient & CAS No & Percent & Hazardous \\
\hline - - - - - - - - - - - - - - - - - - - - - - - - - - - - - - - - - & ----------- & ------- & --------- \\
\hline Hydrogen Chloride & 7647-01-0 & $10-33 \%$ & Yes \\
\hline & $7732-18-5$ & $67-90 \%$ & No \\
\hline
\end{tabular}

\section{Hazards Identification}

Emergency Overview

POISON! DANGER! CORROSIVE. LIQUID AND MIST CAUSE SEVERE BURNS 
TO ALL BODY TISSUE. MAY BE FATAL IF SWALLOWED OR INHALED.

J.T. Baker SAF-T-DATA ${ }^{(t m)}$ Ratings (Provided here for your convenience)

Health Rating: 3 - Severe (Poison)

Flammability Rating: 0 - None

Reactivity Rating: 2 - Moderate

Contact Rating: 3 - Severe (Corrosive)

Lab Protective Equip: GOGGLES \& SHIELD; LAB COAT \& APRON; VENT HOOD; PROPER GLOVES

Storage Color Code: White (Corrosive)

\section{Potential Health Effects}

\section{Inhalation:}

Corrosive! Inhalation of vapors can cause coughing, choking, inflammation of the nose, throat, and upper respiratory tract, and in severe cases, pulmonary edema, circulatory failure, and death.

Ingestion:

Corrosive! Swallowing hydrochloric acid can cause immediate pain and burns of the mouth. throat, esophagus and gastrointestinal tract. May cause nausea, vomiting, and diarrhea, and in severe cases, death.

\section{Skin Contact:}

Corrosive! Can cause redness, pain, and severe skin burns, Concentrated solutions cause deep ulcers and discolor skin.

\section{Eye Contact:}

Corrosive! Vapors are irritating and may cause damage to the eyes. Contact may cause severe burns and permanent eye damage.

Chronic Exposure:

Long-term exposure to concentrated vapors may cause erosion of teeth. Long term exposures seldom occur due to the corrosive properties of the acid.

Aggravation of Pre-existing Conditions:

Persons with pre-existing skin disorders or eye disease may be more susceptible to the effects of this substance.

\section{First Aid Measures}

\section{Inhalation:}

Remove to fresh air. If not breathing, give artificial respiration. If breathing is difficult, give oxygen. Get medical attention immediately.

Ingestion:

DO NOT INDUCE VOMITING! Give large quantities of water or milk if available. Never give anything by mouth to an unconscious person. Get medical attention immediately.

Skin Contact:

In case of contact, immediately flush skin with plenty of water for at least 15 minutes while 
removing contaminated clothing and shoes. Wash clothing before reuse. Thoroughly clean shoes before reuse. Get medical attention immediately.

Eye Contact:

Immediately flush eyes with plenty of water for at least 15 minutes, lifting lower and upper eyelids occasionally. Get medical attention immediately.

\section{Fire Fighting Measures}

Fire:

Not considered to be a fire hazard. May react with metals or heat to release flammable hydrogen gas.

Explosion:

Not considered to be an explosion hazard.

Fire Extinguishing Media:

Water or water spray. Neutralize with soda ash or slaked lime.

Special Information:

In the event of a fire, wear full protective clothing and NIOSH-approved self-contained breathing apparatus with full facepiece operated in the pressure demand or other positive pressure mode. Structural firefighter's protective clothing is ineffective for fires involving hydrochloric acid. Stay away from ends of tanks. Cool tanks with water spray until well after fire is out.

\section{Accidental Release Measures}

Ventilate area of leak or spill. Wear appropriate personal protective equipment as specified in Section 8. Isolate hazard area. Keep unnecessary and unprotected personnel from entering. Contain and recover liquid when possible. Neutralize with alkaline material (soda ash, lime), then absorb with an inert material (e. g., vermiculite, dry sand, earth), and place in a chemical waste container. Do not use combustible materials, such as saw dust. Do not flush to sewer! US Regulations (CERCLA) require reporting spills and releases to soil, water and air in excess of reportable quantities. The toll free number for the US Coast Guard National Response Center is $(800) 424-8802$.

J. T. Baker NEUTRASORB(R) or TEAM(R) 'Low Nat' acid neutralizers are recommended for spills of this product.

\section{Handling and Storage}

Store in a cool, dry, ventilated storage area with acid resistant floors and good drainage. Protect from physical damage. Keep out of direct sunlight and away from heat, water, and incompatible materials. Do not wash out container and use it for other purposes. When diluting, the acid should always be added slowly to water and in small amounts. Never use hot water and never add water to the acid. Water added to acid can cause uncontrolled boiling and 
splashing. When opening metal containers, use non-sparking tools because of the possibility of hydrogen gas being present. Containers of this material may be hazardous when empty since they retain product residues (vapors, liquid); observe all warnings and precautions listed for the product.

\title{
8. Exposure Controls/Personal Protection
}

\author{
Airborne Exposure Limits: \\ For Hydrochloric acid: \\ - OSHA Permissible Exposure Limit (PEL): \\ 5 ppm (Ceiling) \\ - ACGIH Threshold Limit Value (TLV): \\ 5 ppm (STEL/Ceiling)
}

\section{Ventilation System:}

A system of local and/or general exhaust is recommended to keep employee exposures below the Airborne Exposure Limits. Local exhaust ventilation is generally preferred because it can control the emissions of the contaminant at its source, preventing dispersion of it into the general work area. Please refer to the ACGIH document, Industrial Ventilation, A Manual of Recommended Practices, most recent edition, for details.

Personal Respirators (NIOSH Approved):

If the exposure limit is exceeded, a full facepiece respirator with an acid gas cartridge may be worn up to 50 times the exposure limit or the maximum use concentration specified by the appropriate regulatory agency or respirator supplier, whichever is lowest. For emergencies or instances where the exposure levels are not known, use a full-facepiece positive-pressure, air-supplied respirator. WARNING: Air purifying respirators do not protect workers in oxygen-deficient atmospheres.

\section{Skin Protection:}

Rubber or neoprene gloves and additional protection including impervious boots, apron, or coveralls, as needed in areas of unusual exposure to prevent skin contact.

Eye Protection:

Use chemical safety goggles and/or a full face shield where splashing is possible. Maintain eye wash fountain and quick-drench facilities in work area.

\section{Physical and Chemical Properties}

\author{
Appearance: \\ Clear, colorless liquid. \\ Odor: \\ Pungent odor. \\ Solubility: \\ Infinitely soluble. \\ Density: \\ $1.05 @ 15 \mathrm{C}(59 \mathrm{~F})$
}


pH:

For HCL solutions: $0.1(1.0 \mathrm{~N}), 1.1(0.1 \mathrm{~N}), 2.02(0.01 \mathrm{~N})$

$\%$ Volatiles by volume @ 21C (70F):

100

Boiling Point:

101 - 103C (214 - 217F)

Melting Point:

No information found.

Vapor Density (Air=1):

No information found.

Vapor Pressure (mm Hg):

No information found.

Evaporation Rate (BuAc=1):

No information found.

\section{Stability and Reactivity}

Stability:

Stable under ordinary conditions of use and storage.

Hazardous Decomposition Products:

When heated to decomposition, emits toxic hydrogen chloride fumes and will react with water or steam to produce heat and toxic and corrosive fumes. Thermal oxidative decomposition produces toxic chlorine fumes and explosive hydrogen gas.

Hazardous Polymerization:

Will not occur.

Incompatibilities:

A strong mineral acid, concentrated hydrochloric acid is highly reactive with strong bases, metals, metal oxides, hydroxides, amines, carbonates and other alkaline materials.

Incompatible with materials such as cyanides, sulfides, sulfites, and formaldehyde.

Conditions to Avoid:

Heat, direct sunlight.

\section{Toxicological Information}

Hydrochloric acid: Inhalation rat LC50: 3124 ppm/1H; Oral rabbit LD50: 900 mg/kg. Investigated as a tumorigen, mutagen, reproductive effector.

\begin{tabular}{|c|c|c|c|}
\hline & $---\mathrm{NTP}$ & Carcinogen--- & \\
\hline Ingredient & Known & Anticipated & IARC Category \\
\hline Hydrogen Chloride (7647-01-0) & No & $\begin{array}{c}\text { No } \\
\text { No }\end{array}$ & 3 \\
\hline Water $(7732-18-5)$ & No & No & None \\
\hline
\end{tabular}




\section{Ecological Information}

Environmental Fate:

When released into the soil, this material is not expected to biodegrade. When released into the soil, this material may leach into groundwater.

Environmental Toxicity:

This material is expected to be toxic to aquatic life.

\section{Disposal Considerations}

Whatever cannot be saved for recovery or recycling should be handled as hazardous waste and sent to a RCRA approved waste facility. Processing, use or contamination of this product may change the waste management options. State and local disposal regulations may differ from federal disposal regulations. Dispose of container and unused contents in accordance with federal, state and local requirements.

\section{Transport Information}

Domestic (Land, D.O.T.)

Proper Shipping Name: HYDROCHLORIC ACID

Hazard Class: 8

UN/NA: UN1789

Packing Group: II

Information reported for product/size: $200 \mathrm{~L}$

International (Water, I.M.O.)

Proper Shipping Name: HYDROCHLORIC ACID

Hazard Class: 8

UN/NA: UN1789

Packing Group: II

Information reported for product/size: $200 \mathrm{~L}$

\section{Regulatory Information}

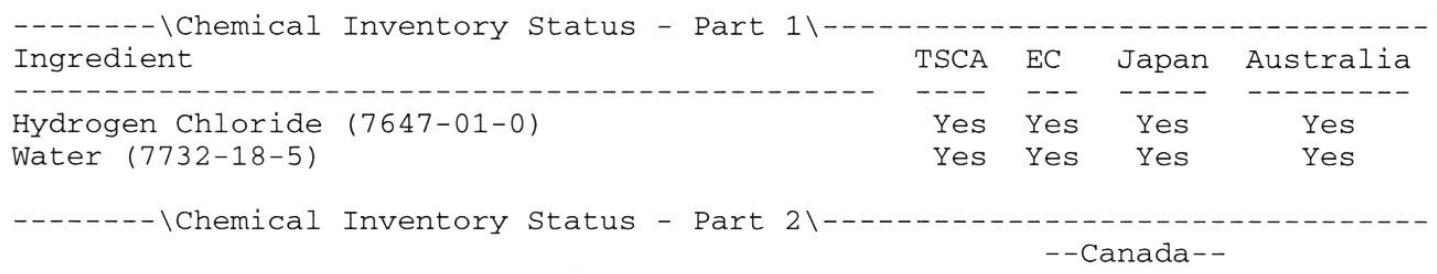




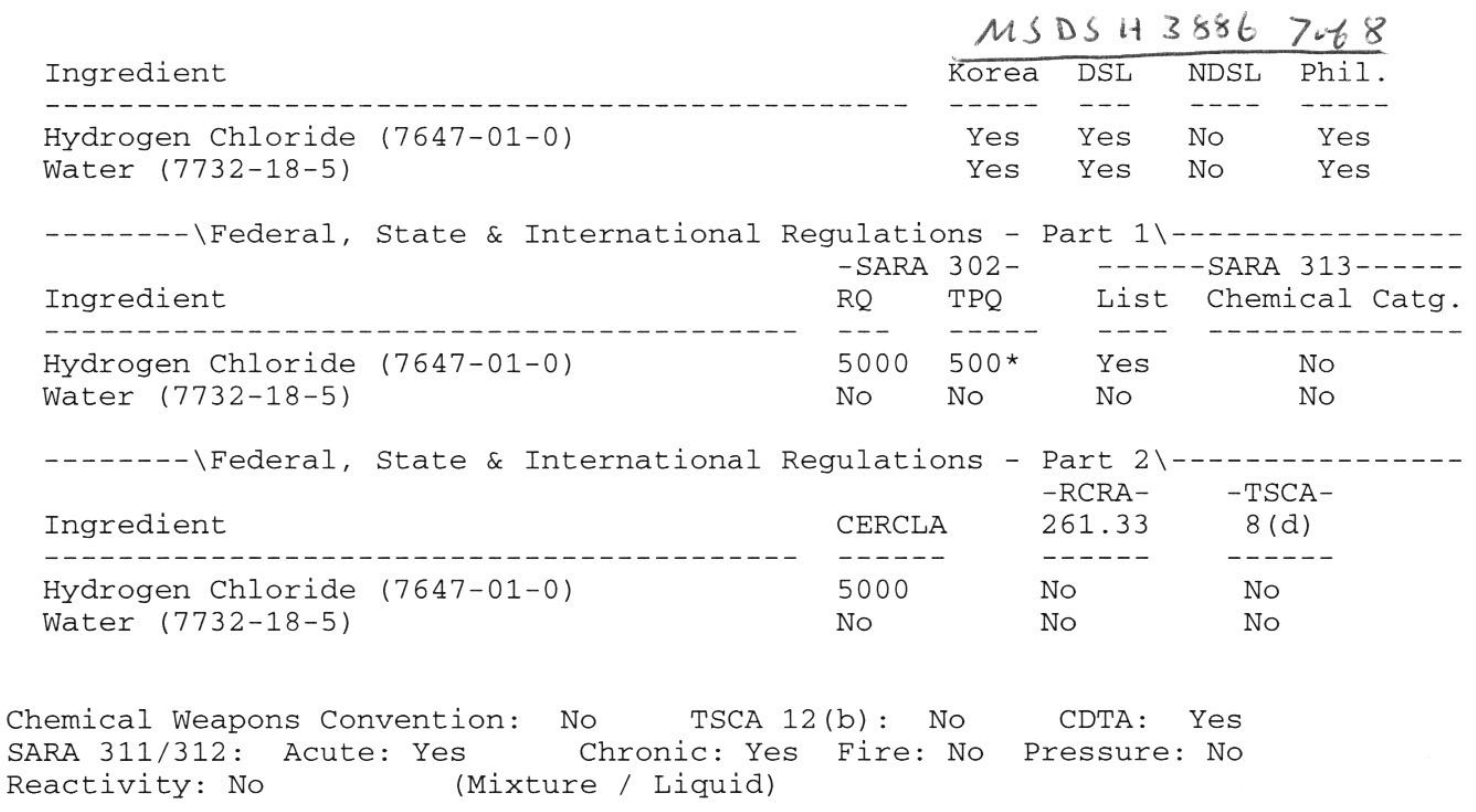

Australian Hazchem Code: 2R

Poison Schedule: No information found. WHMIS:

This MSDS has been prepared according to the hazard criteria of the Controlled Products Regulations (CPR) and the MSDS contains all of the information required by the CPR.

\section{Other Information}

NFPA Ratings: Health: 3 Flammability: 0 Reactivity: 0

Label Hazard Warning:

POISON! DANGER! CORROSIVE. LIQUID AND MIST CAUSE SEVERE BURNS TO

ALL BODY TISSUE. MAY BE FATAL IF SWALLOWED OR INHALED.

Label Precautions:

Do not get in eyes, on skin, or on clothing.

Avoid breathing vapor or mist.

Keep container closed.

Use with adequate ventilation.

Wash thoroughly after handling.

Label First Aid:

If swallowed, DO NOT INDUCE VOMITING. Give large quantities of water. Never give anything by mouth to an unconscious person. If inhaled, remove to fresh air. If not breathing, give artificial respiration. If breathing is difficult, give oxygen. In case of contact, immediately flush eyes or skin with plenty of water for at least 15 minutes. Remove contaminated clothing and shoes. Wash clothing before reuse. In all cases call a physician.

Product Use:

Laboratory Reagent.

Revision Information:

No changes. 
Disclaimer:

MSDS H 38868068

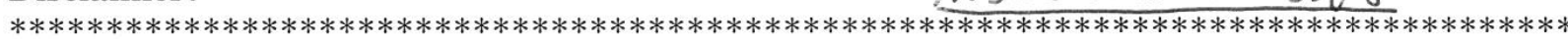

Mallinckrodt Baker, Inc. provides the information contained herein in good faith but makes no representation as to its comprehensiveness or accuracy. This document is intended only as a guide to the appropriate precautionary handling of the material by a properly trained person using this product. Individuals receiving the information must exercise their independent judgment in determining its appropriateness for a particular purpose. MALLINCKRODT BAKER, INC. MAKES NO REPRESENTATIONS OR WARRANTIES, EITHER EXPRESS OR IMPLIED, INCLUDING WITHOUT LIMITATION ANY WARRANTIES OF MERCHANTABILITY, FITNESS FOR A PARTICULAR PURPOSE WITH RESPECT TO THE INFORMATION SET FORTH HEREIN OR THE PRODUCT TO WHICH THE INFORMATION REFERS. ACCORDINGLY, MALLINCKRODT BAKER, INC. WILL NOT BE RESPONSIBLE FOR DAMAGES RESULTING FROM USE OF OR RELIANCE UPON THIS INFORMATION.

******************************************************************************************

Prepared by: Strategic Services Division

Phone Number: (314) 539-1600 (U.S.A.) 
Material Safety Data Sheet

Revision Issued: 3/23/2000
Supercedes: 6/17/99

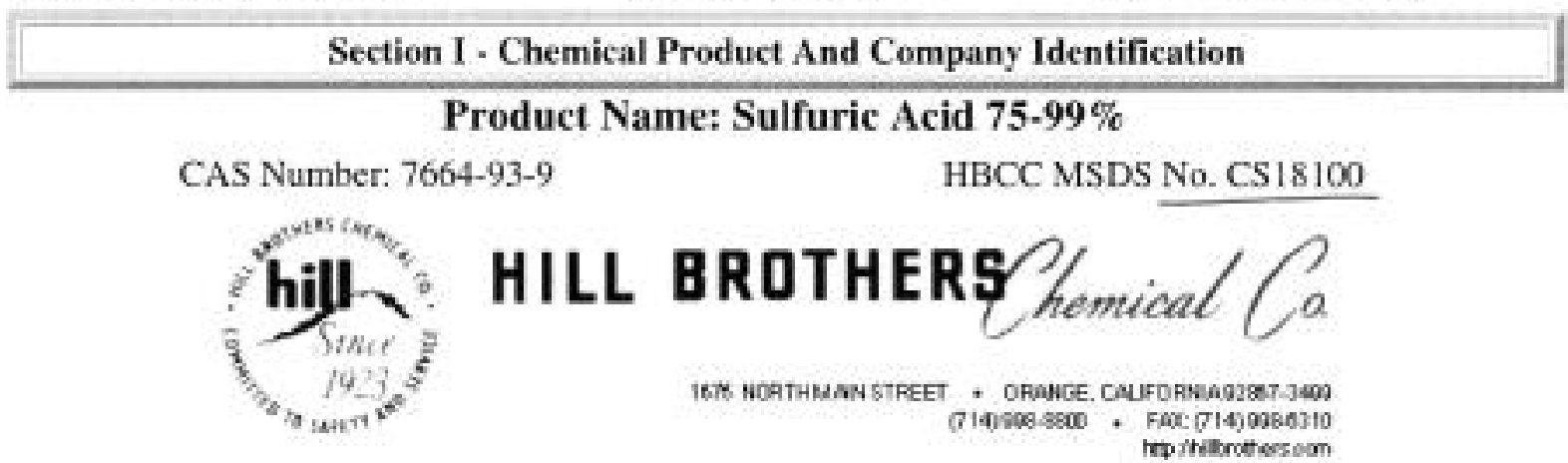

1675 No. Main Street, Orange, California 92867

Telephone No: 714-998-8800 I Outside Calif: $800-821-7234$ । Chemtrec: $800-424-9300$

\begin{tabular}{|l|l|l|l|l|l|}
\hline \multicolumn{7}{|c|}{ Section II - Composition/Information On Ingredients } \\
\hline Chemical Name & CAS Number & 5 & ACGIH TLV & OSHA PEL & STEL \\
\hline Sulfuric Acid $\left(\mathrm{H}_{2} \mathrm{SO}_{4}\right)$ & $7664-93-9$ & $75-99$ & $1 \mathrm{mg} / \mathrm{m}^{3}$ & $1 \mathrm{mg} / \mathrm{m}^{3}$ & $3 \mathrm{mg} / \mathrm{m}^{3}$ \\
\hline Sulfur Dioxide & $7446-09-5$ & $<2$ & $2 \mathrm{ppm}$ & $5 \mathrm{ppm}$ & $5 \mathrm{ppm}$ \\
\hline \hline
\end{tabular}

Routes of Exposure: Sulfuric acid can affect the body if it is inhaled or if it comes in contact with the eyes or skin. It can also aftect the body if it is swallowed.

Points of Attack: Sulfuric acid attacks the respiratory system, eyes, skin, teeth, and lungs.

Summary of Acute Health Hazards: Concentrated sulfuric acid will effectively remove the elements of water from many organic materials with which it comes in contact. It is even more rapidly injurious to mucous membranes and exceedingly dingerous to the eyes.

Ingestion: Causes serious bums of the mouth or perforation of the esophagus or stomach. May be fatal if swallowed.

Inhalation: Corrosive and highly toxic. May be harmful or fatal if inhaled. May cause severe irritation and burns of the nose, throat and respiratory tract.

Skin: Splashes on the skin will cause severe skin burns. Burning and charring of the skin are a result of the great affinity for, and strong exothermic reaction with, water. Direct contact can be severely irritating to the skin and may result in redness, swelling, burns and severe skin damage.

Eyes: Direct contact with the liquid or exposure to vapors or mists may cause stinging, tearing, redness, swelling, corneal damage and irreversible eye damage. Splashes in the eyes will cause severe burns.

Contact lenses should not be worn when working with this chemical.

Effects of Overexposure: May cause severe irritation and burns of the mouth, nose, throat, respiratory and digestive tract, coughing, nausea, vomiting, abdominal pain, chest pain, pneumonitis (inflammation of the fluid in the lungs), pulmonary edema (accumulation of the fluid in the lungs), and perforation of the stomach. Overexposure to acid mists has been reported to cause erosion to tooth enamel.

Medical Conditions Generally Aggravated by Exposure: Persons with pre-existing skin disorders and/or respiratory disorders (e.2. Asthma-like conditions) may be more susceptible to the effects of this 
material, and may be aggravated by exposure to this material.

Note to Physicians: Sulfuric acid is reported to cause pulmonary function impairment. Periodic surveillance is indicated. Sulfuric acid may cause acute lung damage. Surveillance of the lungs is indicated. Ingestion may cause gastroesophageal perforation. Perforation may occur within 72 hours, but along with abscess formation, can occur weeks later. Long term complications may include esophageal, gastric or pyloric strictures or stenosis.

\section{Section IV - First Aid Measures}

Ingestion: If liquid sulfuric acid or solutions containing sulfuric acid have been swallowed and the person is conscious, give him one glass of water ( $1 / 2$ glass of water to children under 5$)$, immediately to dilute the sulfuric acid. Do NOT induce vomiting. Do not attempt to make the exposed person vomit. Do not leave victim unattended. GET MEDICAL ATTENTION IMMEDIATELY.

Inhalation: If a person breathes in large amounts of sulfuric acid, move the exposed person to fresh air at once. If breathing has stopped, perform artificial respiration. If breathing is difficult, give oxygen. Keep the affected person warm and at rest. GET MEDICAL ATTENTION AS SOON AS POSSIBLE.

Skin: If liquid sulfuric acid or solutions containing sulfuric acid get on the skin, immediately flush the contaminated skin with water for at least 15 minutes. If skin surface is damaged, apply a clean dressing. If liquid sulfuric acid or solutions containing sulfuric acid penetrate through the clothing, immediately remove the clothing, shoes and constrictive jewelry under a safety shower and continue to wash the skin for at least 15 minutes. GET MEDICAL ATTENTION IMMEDIATELY.

Eyes: If liquid sulfuric acid or solutions containing sulfuric acid get into the eyes, flush eyes immediately with a directed stream of water for at least 30 minutes while forcibly holding eyelids apart to ensure complete irrigation of all eye and lid tissue. GET MEDICAL ATTENTION IMMEDIATELY. Contact lenses should not be worn when working with this chemical.

Section V - Fire Fighting Measures

$\begin{array}{ll}\text { Flash Point: Non-flammable } & \text { Autoignition Temperature: N/A } \\ \text { Lower Explosive Limit: N/A } & \text { Upper Explosive Limit: N/A }\end{array}$

Unusual Fire and Explosion Hazards: Not flammable but highly reactive and capable of igniting finely divided combustible materials on contact. Reacts violently with water and organic materials with evolution of heat. If involved in fire, may release hazardous oxides of sulfur. Vapors are heavier than air and may accumulate in low areas. Containers exposed to extreme heat may ruputure due to pressure buildup. Contact with common metals may generate hydrogen, which can form flammable mixture with air.

Extinguishing Media: Fires involving small amount of combustibles may be smothered with suitable dry chemical, soda ash, lime, sand or $\mathrm{CO} 2$. Use water on combustibles burning in vicinity of this material but use care as water applied directly to this acid results in evolution of heat and causes splattering.

Special Firefighting Procedures: Causes severe, deep burns to tissue; very corrosive effect. Sulfuric Acid is extremely slippery. Emergency responders in the danger area should wear bunker gear and self contained breathing apparatus for fires beyond the incipient stage (29CFR 1910.156). In addition, wear other appropriate protective equipment as conditions warrant (see Section 8). Water reactive. Contact with water may generate heat. Isolate damage area, keep unauthorized personnel out. If tank, railcar, or tank truck is involved in a fire, isolate for $1 / 2$ mile in all directions. Consider initial evacuation for $1 / 2$ mile in all directions. Stop spill/release if it can be done with minimal risk. Move undamaged containers from danger area if it can be done with minimal risk. Fires involving small amounts of combustibles may be smothered with suitable dry chemicals. Use water on combustibles burning but avoid using water directly on acid as it results in evolution of heat and causes splattering.

\section{Section VI - Accidental Release Measures}


MSDSCS18100 3.3065

If sulfuric acid is spilled or leaked, ventilate area. Wear appropriate protective equipment including respiratory protection as conditions warrant (see Section 8). Collect spilled or leaked material in the most convenient and safe manner for reclamation or for disposal in a secured sanitary landfill. Sulfuric acid should be absorbed in vermiculite, dry sand, earth, or a similar material. It may also be diluted and neutralized. Add slowly to solution of soda ash and slaked lime with stirring. Use Caution around spill area, Sulfuric Acid is extremely slippery. Stay upwind and away from spill release.

\section{Section VII - Handling and Storage}

Protect against physical damage and water. Keep containers closed. Sulfuric Acid is extremely slippery. Do not enter confined spaces such as tanks or pits without following proper entry procedures such as ASTM D-4276. To prevent ignition of hydrogen gas generated in metal containers (from metal contact) smoking, open flames and sparks must not be permitted in storage areas. This product has a great affinity for water, abstracting it from the air and also from many organic substances; hence it will char wood, etc.. When diluting, the acid should be added to the diluent. Separate from carbides, chlorates, fulminates, nitrates, picrates, powdered metals, and combustible materials. Keep away from strong oxidizing agents including oxygen and chlorine.

Other Precautions: Persons not wearing protective equipment and clothing should be restricted from areas of spills or leaks until cleanup has been completed.

\section{Section VIII - Exposure Controls/Personal Protection}

Respiratory Protection: Good industrial hygiene practices recommend that engineering controls be used to reduce environmental concentrations to the permissible exposure level. However, there are some exceptions where respirators may be used to control exposure. Respirators may be used when engineering and work practice controls are not technically feasible, when such controls are in the process of being installed, or when they fail and need to be supplemented. If the use of respirators is necessary, a NIOSH/MSHA approved air purifying respirator with $\mathrm{N} 95$ filter may be used under conditions where airborne concentrations are expected to exceed exposure limits (see Section II). Protection provided by air purifying respirators is limited (see manufactureres respirator selection guide). Use a positive pressure air supplied respirator if there is potential for an uncontrolled release, exposure levels are not known, or any other circumstances where air purifying respirators may not provide adequate protection. A respiratory protection program that meets OSHA'a 29 CFR 1910.134 and ANSI Z88.2 requirements must be followed whenever workplace conditions warrant a respirator's use.

Ventilation: General mechanical ventilation may be sufficient to keep sulfuric acid vapor concentrations within specified time-weighted TLV range. If general ventilation proves inadequate to maintain safe vapor concentrations, supplemental local exhaust may be required.

Protective Clothing: Employees should be provided with and required to use impervious clothing, gloves, face shields (eight-inch minimum), and other appropriate protective clothing necessary to prevent any possibility of skin contact with liquid sulfuric acid or solutions containing more than $1 \%$ sulfuric acid by weight.

Eye Protection: Employees should be provided with and required to use splash-proof safety goggles where there is any possibility of liquid sulfuric acid or solutions containing sulfuric acid contacting the eyes. Contact lenses should not be worn when working with this chemical.

Other Protective Clothing or Equipment: Rubber apron, rubber boots, eyewash stations and safety showers must be available in the immediate work area for emergency use.

Work/Hygienic Practices: Avoid contact with the skin and avoid breathing vapors. Do not eat, drink, or smoke in work area. Wash hands before eating, drinking, or using restroom. 
Physical State: Liquid

Melting Point/Range: $3^{\circ} \mathrm{C} ; 37^{\circ} \mathrm{F}$
MSDSCS18100 4 of 5

pH: 1.0

Boiling Point/Range: $260^{\circ} \mathrm{F} ; 315^{\circ} \mathrm{C}$

Appearance/Color/Odor: Colorless to dark brown; odorless unless hot, then choking

Solubility in Water: $100 \%$

Specific Gravity(Water=1): 1.6-1.84

Vapor Density(Air=1): 3.4

Evaporation Rate (N-Butyl Acetate=1): $<1$
Vapor Pressure(mmHg): 1 @ $145.8^{\circ} \mathrm{F}$

Molecular Weight: 98

\% Volatiles: Negligible

Weight/Gallon: 15.2 Lbs.

How to detect this compound : Sampling and analyses may be performed by collection of sulfuric acid on a cellulose membrane filter, followed by extraction with distilled water and isopropyl alcohol, treatment with perchloric acid, and titration with barium perchlorate. Also, detector tubes certified by NIOSH under 42 CFR Part 84 or other direct-reading devices calibrated to measure sulfuric acid may be used.

\section{Section X - Stability and Reactivity}

Stability: Stable Hazardous Polymerization: Will not occur

Conditions to Avoid: Temperatures above $150^{\circ} \mathrm{F}$

Materials to Avoid: Contact of acid with organic materials (such as chlorates, carbides, fulminates, and picrates), alkaline materials and water may cause fires and explosions. Contact of acid with metals may form toxic sulfur dioxide fumes and flammable hydrogen gas. Contact with hypochlorites (e.g., chlorine bleach), sulfides, or cyanides will produce toxic gases.

Hazardous Decomposition Products: Toxic gases and vapors (such as sulfuric acid fume, sulfur dioxide, and carbon monoxide) may be released when sulfuric acid decomposes. Decomposes to water and sulfur trioxide above $644^{\circ} \mathrm{F}$.

\section{Section XI - Toxicological Information}

(Sulfuric acid) mist severely irritates the eyes, respiratory tract, and skin. Concentrated sulfuric acid destroys tissue due to its severe dehydrating action, whereas the dilute form acts as a mild irritant due to acid properties. The LC50 of mist of 1-micron particle size for an 8 hour exposure was $50 \mathrm{mg} / \mathrm{m}^{3}$ for adult guinea pigs and $18 \mathrm{mg} / \mathrm{m}^{3}$ for young animals. Continuous exposure of guinea pigs to $2 \mathrm{mg} / \mathrm{m}^{3}$ for 5 days caused pulmonary edema and thickening of the alveolar walls; exposure of guinea pigs to $2 \mathrm{mg} / \mathrm{m}^{3}$ for 1 hour caused an increase in pulmonary airway resistance from reflex bronchoconstriction. A worker sprayed in the face with liquid fuming sulfuric acid suffered skin burns of the face and body, as well as pulmonary edema from inhalation. Sequelae were pulmonary fibrosis, residual bronchitis, and pulmonary emphysema; in addition, necrosis of the skin resulted in marked scarring. In human subjects, concentrations of about 5 $\mathrm{mg} / \mathrm{m}^{3}$ were objectionable, usually causing cough, an increase in respiratory rate, and impairment of ventilatory capacity. Workers exposed to concentrations of 12.6 to $35 \mathrm{mg} / \mathrm{m}^{3}$ had a markedly higher incidence of erosion and discoloration of teeth than was noted in unexposed individuals. Splashed in the eye, the concentrated acid causes extremely severe damage, often leading to blindness, whereas dilute acid produces more transient effects from which recovery may be complete. Repeated exposure of workers to the mist causes chronic conjunctivitis, tracheobronchitis, stomatitis, and dermatitis, as well as dental erosion. While ingestion of the liquid is unlikely in ordinary industrial use, the highly corrosive nature of the substance may be expected to produce serious mucous membrane burns of the mouth and esophagus.

Section XII - Ecological Information


MSDSCS18100 5of

\section{Section XIII - Disposal Considerations}

Sulfuric acid may be placed in sealed containers or absorbed in vermiculite, dry sand, earth, or a similar material and disposed of in a secured sanitary landfill. It may also be diluted and neutralized. Check with your Federal, State, and Local authorities as neutralized sulfuric acid may be allowed to be flushed down the drain. Empty conatiners must be handled with care due to material residue.

\section{Section XIV - Transport Information}

DOT Proper Shipping Name: RQ Sulfuric Acid

DOT Hazard Class/ I.D. No.: 8, UN1830, II

\section{Section XV - Regulatory Information}

Reportable Quantity: 1,000 Pounds (454 Kilograms) (66.71 Gal.)

NFPA Rating: Health - 3; Fire - 0; Reactivity - 2

$0=$ Insignificant $1=$ Slight $2=$ Moderate $3=$ High $4=$ Extreme

Carcinogenicity Lists: Yes NTP: No IARC Monograph: No OSHA Regulated: Yes

Section 313 Supplier Notification: This product contains the following toxic chemcial(s) subject to the reporting requirements of SARA TITLE III Section 313 of the Emergency Planning and Community Right-To Know Act of 1986 and of 40 CFR 372:

CAS \#

7664-93-9
Chemical Name

Sulfuric Acid
\% By Weight

75-99

\section{Section XVI - Other Information}

Synonyms/Common Names: H2SO4; Oil of Vitriol; Spirit of Sulfur; Hydrogen Sulfate; Oleum

Chemical Family/Type: Inorganic Acid

Sections changed since last revision: I, II, IX, XV

IMPORTANT! Read this MSDS before use or disposal of this product. Pass along the information to employees and any other persons who could be exposed to the product to be sure that they are aware of the information before use or other exposure. This MSDS has been prepared according to the OSHA Hazard Communication Standard [29 CFR 1910.1200]. The MSDS information is based on sources believed to be reliable. However, since data, safety standards, and government regulations are subject to change and the conditions of handling and use, or misuse are beyond our control, Hill Brothers Chemical Company makes no warranty, either expressed or implied, with respect to the completeness or continuing accuracy of the information contained herein and disclaims all liability for reliance thereon. Also, additional information may be necessary or helpful for specific conditions and circumstances of use. It is the user's responsibility to determine the suitability of this product and to evaluate risks prior to use, and then to exercise appropriate precautions for protection of employees and others. 


\section{Appendix D:}

Sample and Document Management Procedures 


\section{Contents}

D.1 Sample Documentation and Control ....................................... D-3

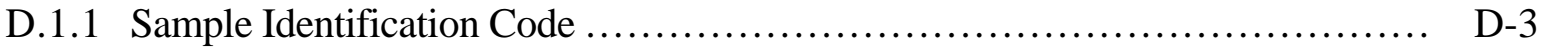

D.1.2 Project Logbook..................................................... D-4

D.1.3 Sampling Logbook ........................................................ D

D.1.4 Sample Label ...................................................... D-12

D.1.5 Chain-of-Custody Record............................................ D-13

D.1.6 Water Level Measurement Logbook................................... D-16

D.2 Document Control.......................................................... D-17

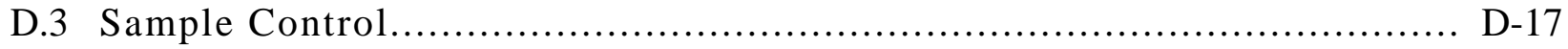

D.3.1 Sample Identity — Sample Label ................................... D-17

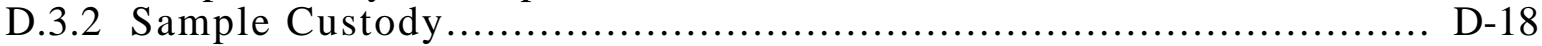

D.3.3 Disposal of Samples or Other Physical Evidence .......................... D-19

\section{Figures}

D.1 Table of contents for general field logbook................................... D-6

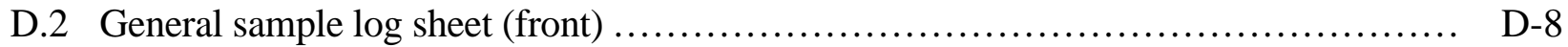

D.3 Monitoring well ground water sample log sheet................................. D-9

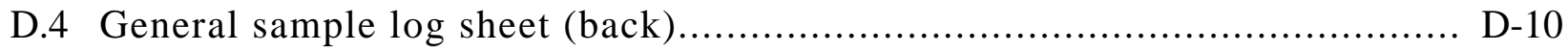

D.5 Preprinted sample bottle label............................................. D-12

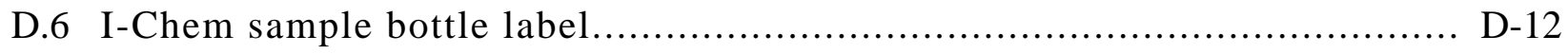

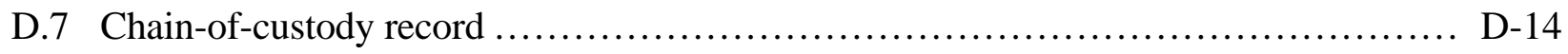

D.8 Custody seal................................................................. D-19

\section{Table}

D.1 Documents used by the sampling and analysis team............................. D-18 


\section{Appendix D:}

\section{Sample and Document Management Procedures}

This appendix provides a framework and specific guidance for maintaining control of samples and documentation. These procedures are needed to (1) establish the authenticity of the information generated and (2) facilitate interpretation of sampling and analysis results.

Complete field logbooks, sample labels, and chain-of-custody forms by using waterproof ink. If weather conditions prohibit the use of ink, use a pencil and note the reason for its use in the logbook. If an error is made on any field document, make a correction by drawing a single line through the error and entering the correct information. Initial and date all corrections. If a field document is damaged, lost, or destroyed, record the serial number of the document and its position. Do not discard field documents that are voided; they must be maintained in the files for accountability.

\section{D.1 Sample Documentation and Control}

\section{D.1.1 Sample Identification Code}

Assign each sample collected for analysis a unique five-digit number selected from a continuous number series, plus encoded information, to create an alphanumeric identifier or sample ID. The encoded information is to identify the work site and sample matrix. Additional information normally specifies the sample location designation (for environmental samples) or the sample type (for QC samples).

The general system is as follows:

Sample ID:

A

B

$-\mathrm{C}-$

D

\section{AABBB-C-DDDDD}

Site name (two letters)

Additional information (letters, numbers, or both; variable number of characters)

Sample medium (one letter)

Unique serial number (five digits) 
Though the serial number alone distinguishes the sample uniquely, the additional information facilitates sample handling and data processing and provides a safeguard against transcriptional errors. In practice, a block of numbers from a continuous series is assigned to a site in advance of field work. A number from this series is assigned to each sample at the time of sampling.

Examples are as follows:

Sample ID: $\quad$ CRSB01-S-10445

CR Craig, Nebraska

SB01 Soil boring number 01, a formally named and mapped location

-S- Soil

10445 Unique number assigned from continuous series

Sample ID: $\quad$ CRQCTB-W-10446

CR Craig, Nebraska

QC Quality control sample

TB Trip blank

-W- Water

10446 Unique number assigned from continuous series

\section{D.1.2 Project Logbook}

The project logbook is used to record general information, events, and activities of the sampling staff and related information that becomes available to the project manager at the site.

The project manager is to complete the project logbook and place it in the project file after QA review.

\section{D.1.3 Sampling Logbook}

The sampling logbook is used (1) to record the activities of a sampling team (for later reconstruction of the sampling event) and (2) to record location, quantitative information, and measurements for each physical sample collected. 
The sampling logbook's cover will clearly display the title, "Sampling Logbook," in addition to the

- Logbook number (two-digit numeric),

- Name of the sampling organization, and

- Name of the site.

Each sampling logbook will be bound, with consecutively numbered pages. It will contain the following forms:

- Sampling Logbook Table of Content

- General Sample Log Sheet(s)

- Monitoring Well Ground Water Sampling Log Sheet(s)

\section{D.1.3.1 Sampling Logbook Table of Contents}

The Sampling Logbook Table of Contents form (Figure D.1) will contain the following information:

- Sampling Location. A map and written description of the location of sample collection is to be included in the site-specific sampling plan.

- Date Sampled. Indicate the date $(\mathrm{dd} / \mathrm{mmm} / \mathrm{yy})$ of sample collection (e.g., 08/SEP/01). Record the day and year with two numerical digits each. For the first nine days of the month, use the digits 01 through 09. Follow this procedure whenever a date is recorded.

- Sample ID Number(s). Indicate the identification number(s) of the physical sample(s) collected. 


\section{Sampling Logbook}

Table of Contents

\begin{tabular}{|c|c|c|c|}
\hline Sampling Location & Date Sampled & Sample ID Number & $\begin{array}{l}\text { Page No. } \\
\text { Sample } \\
\text { Log Sheet }\end{array}$ \\
\hline & & & \\
\hline & & & \\
\hline & & & \\
\hline & & & \\
\hline & & & \\
\hline & & & \\
\hline & & & \\
\hline & & & \\
\hline & & & \\
\hline & & & \\
\hline & & & \\
\hline & & & \\
\hline & & & \\
\hline & & & \\
\hline & & & \\
\hline & & & \\
\hline & & & \\
\hline & & & \\
\hline & & & \\
\hline & & & \\
\hline & & & \\
\hline & & & \\
\hline & & & \\
\hline & & & \\
\hline & & & \\
\hline & & & \\
\hline & & & \\
\hline & & & \\
\hline & & & \\
\hline & & & \\
\hline
\end{tabular}

FIGURE D.1 Table of contents for general field logbook. 
- Sample Log Sheet (Page No.). Give the page number within the sampling logbook where quantitative information and measurements are recorded for the given location or sample number(s).

\section{D.1.3.2 General Sample Log Sheet}

Use the General Sample Log Sheet (Figure D.2) to record information for samples collected in a variety of environments. Use the Monitoring Well Ground Water Sample Log Sheet (Figure D.3) to record information for samples collected from monitoring wells. Both forms use a common second page (Figure D.4).

- Sample ID (root). The unique sample ID (Section D.1.1).

- Collection Date. The date (dd/mmm/yy) of sample collection (e.g., 08/SEP/01).

- Site. The name of the former CCC/USDA facility.

- Collection Time. The time, based on a 24-hr clock (e.g., 0900, 1450), when the sample material was obtained.

- Sampling Location. The location of the sampled area (specified by code, description, or both).

- Sampling Point. The exact point where the sample was collected, as indicated by code, description, and/or coordinates (e.g., N10/E45).

- Sample Depth (below surface). The depth below the ground surface level where the sample was collected. If a code is assigned, also indicate the actual depth and the appropriate units.

- Sample Medium. Circle the description that most appropriately describes the sample material. 


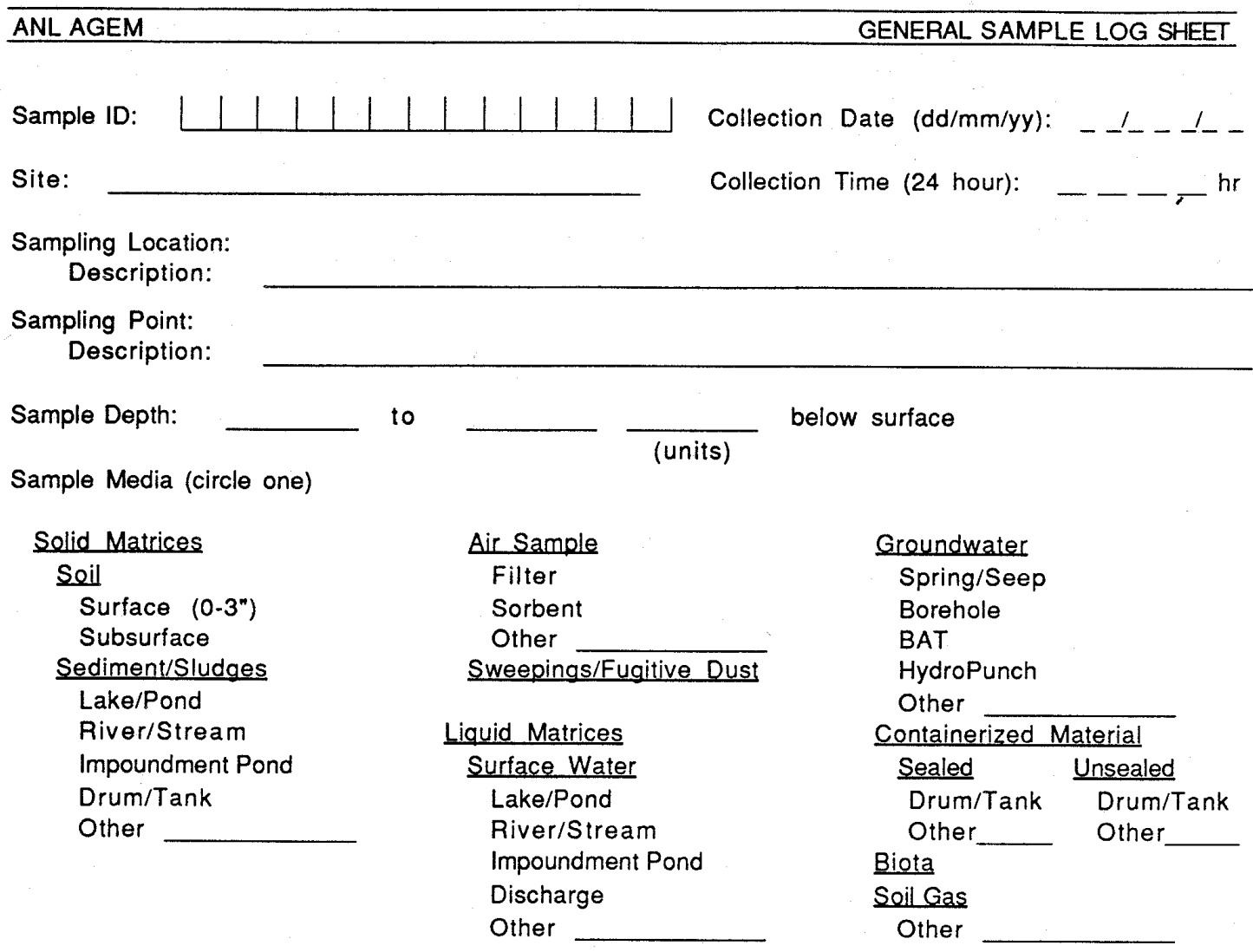

Field Observations:

Field Measurements:

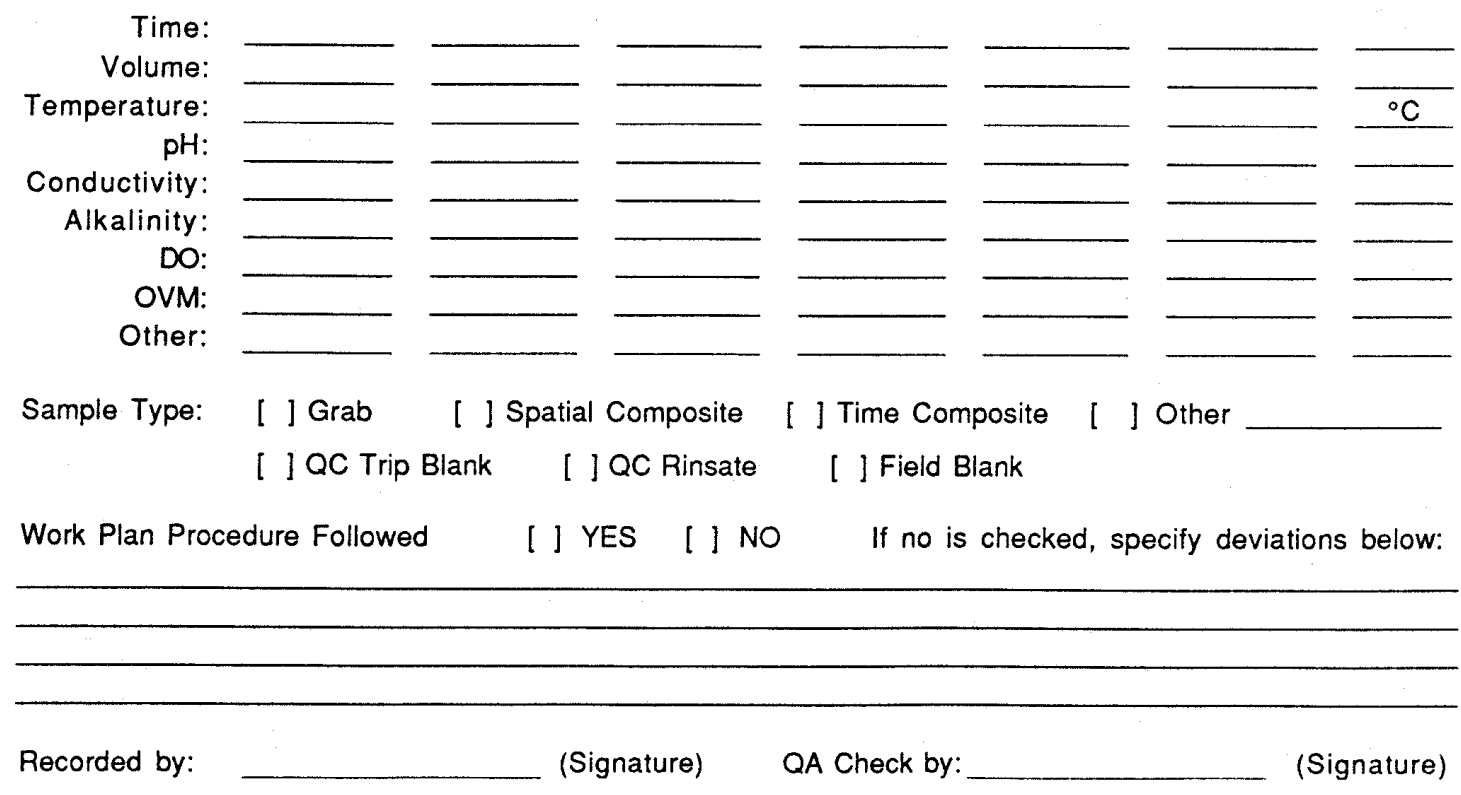

FIGURE D.2 General sample log sheet (front). 
Sample ID:

Purging Date (dd/mm/yy): _ L _ _

Site:

Well ID Number or Description:

Well Coordinates or Location:

Depth of Screen Section (from top of inner casing): $\mathrm{ft}$ to $f t$ Type of Inner Casing:

Depth to water from top of inner casing: Depth of well from top of inner casing: Depth of water in well: Water volume for $2^{n}$ well:

Water volume for $4^{\text {" well: }}$

Purge Method: [ ] Bailer

Purge Rate/Time:

Sample Method: [ ] Bailer

[ ] Bladder Pump

[ ] Redi-Flo Pump

\begin{tabular}{ll}
$f t$ & $\left(h_{1}\right)$ \\
\hline$f t$ & $\left(h_{2}\right)$ \\
$f t$. & $\left(h_{2}-h_{1}\right)$ \\
\hline gal. & (depth of water $\times 0.167)$ \\
gal. & (depth of water $\times 0.65$ )
\end{tabular}

[ $]$ Other (specify)

Total Purge Volume:

[ ] Other (specify)

[ ] Depth

Field Observations:

Field Measurements:

units

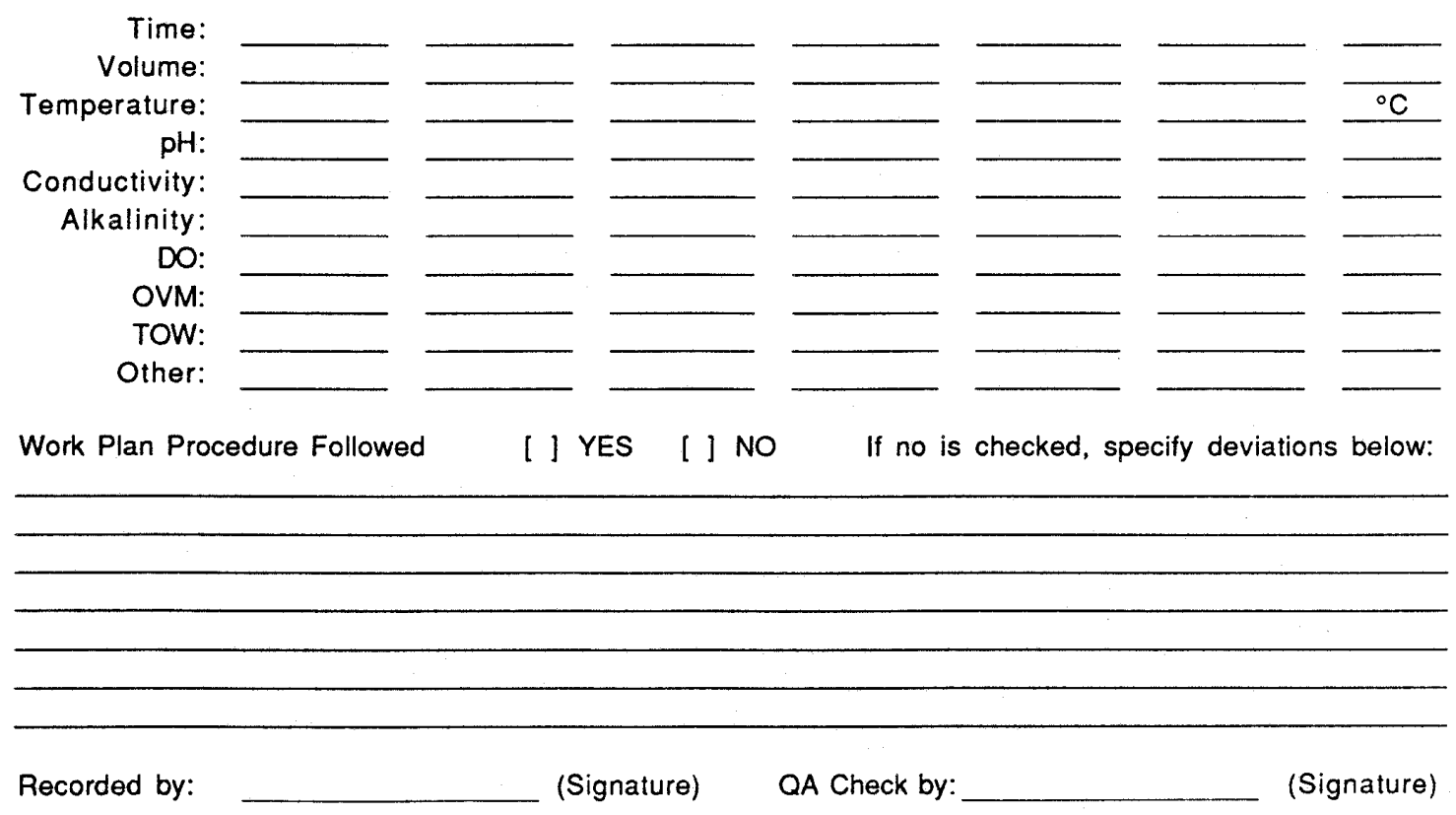

FIGURE D.3 Monitoring well ground water sample log sheet. 
Sample ID:

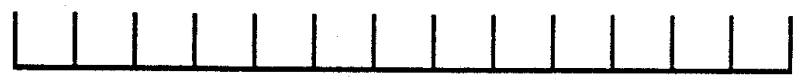

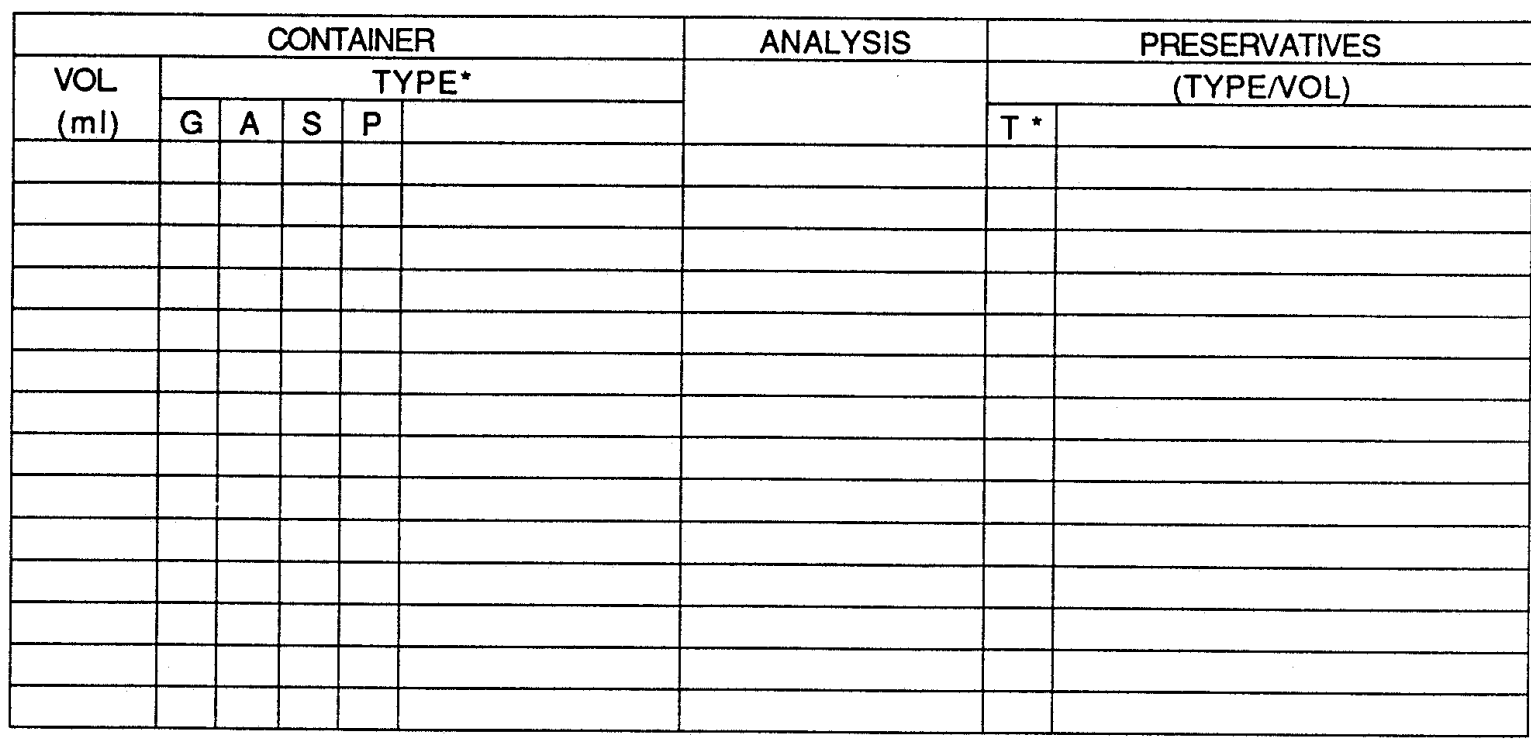

* Check if appropriate: $G=$ glass, $A=$ amber, $S=$ with septum, $P=$ polyethylene, $T=$ temp. of $4^{\circ} \mathrm{C}$ SKETCH OF SOURCE LOCATION AND SAMPLING POINTS/NOTES:

Recorded by: (Signature) QA Check by; (Signature)

FIGURE D.4 General sample log sheet (back). 
- Field Observations. Record visual or other observations relevant to the sampling area, the waste source, or the sample itself. Examples are

- Soil - color, texture, moisture, cohesiveness, odor;

- Sediment - exposed or lying under water, texture, color, cohesiveness, viscosity;

- Water - turbidity, water level, flow, flow rate;

- Drum - container type, size, shape, markings, volume of contents, viscosity;

- Sampling site — terrain, topography, landforms.

- Field Measurements. Record results of quantitative measurements made of the sampling area or the sample (e.g., $\mathrm{pH}$, conductivity).

- Sample Type. Indicate the type of sample collected.

- Work Plan Procedure Followed. Confirm that the sampling procedures specified in Section 6 of this Master Work Plan and in the site-specific work plan were followed. Record deviations in the space provided and on additional sheets as required.

- Recorded by (signature). Sign to verify recording of the entries on the form.

- QA Check by (signature). Sign to verify performance of the QA check on the completed form.

- Sample Number. Indicate the identification number assigned to the physical sample (Section D.1.1).

- Container Volume. Record the total volume of the sample container in which the sample was placed (e.g., $250 \mathrm{~mL}$ ). 
- Container Type. Indicate the type of container, as coded in the footnote on the form.

- Analysis. Indicate the analysis that will be performed by the analytical chemistry laboratory (as specified in Section 6.1).

- Preservatives (type/vol). Record the type and volume of preservative(s) added (if applicable) and the conditions under which the sample was kept.

\section{D.1.3.3 Documentation Process}

The sampling logbook is to be completed by the sampling team, with a QA check by the project manager or designee.

\section{D.1.4 Sample Label}

The purpose of the sample label (Figure D.5) is to maintain sample identity. Use selfadhesive labels preprinted with the site identifier and the series of unique five-digit numbers that are incorporated into sample IDs as described in Section D.1.1. Add other portions of the sample identification code as required to identify the sample. If more sample aliquots are collected for analysis than preprinted labels are available, use standard sample labels from I-Chem Research (Figure D.6).
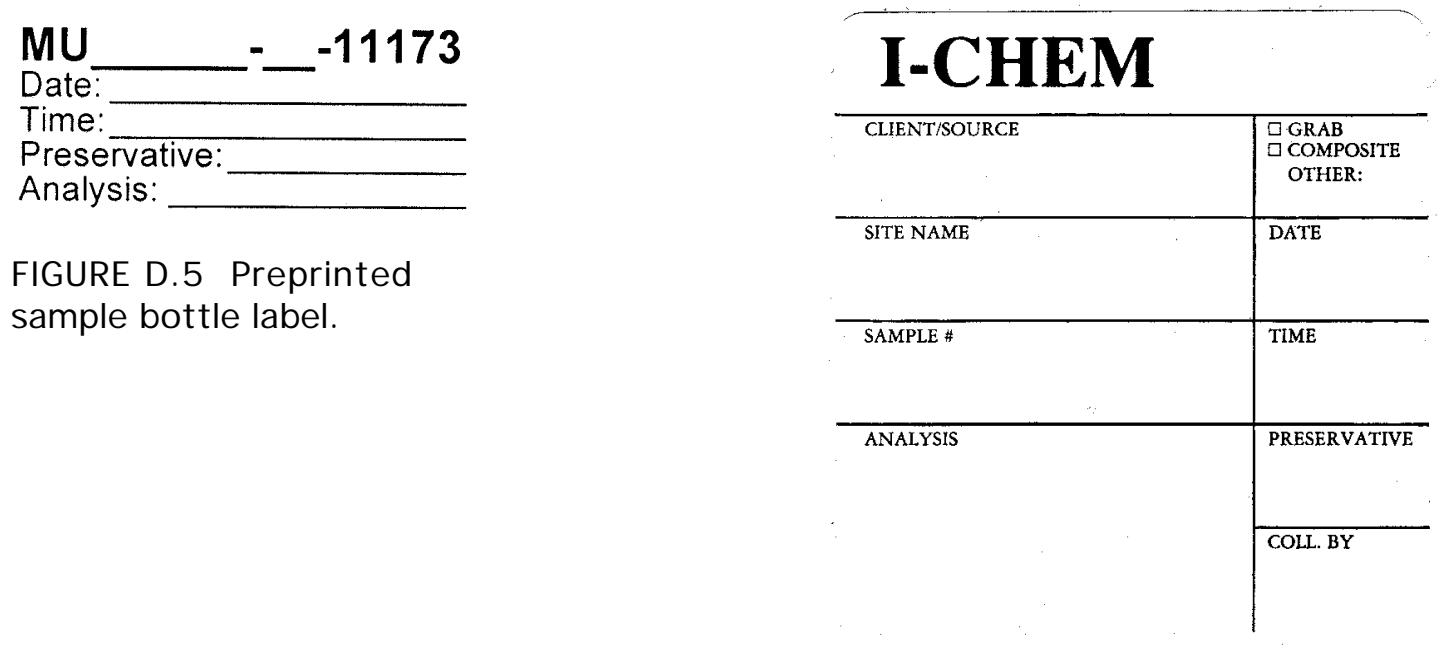

FIGURE D.6 I-Chem sample bottle label. 
The sample label is to be completed by the person collecting the sample. After a QA check by the project manager or designee, enter the label information into the laboratory data management system during sample log-in. Discard the bottle and sample, as authorized, after analysis.

\section{D.1.5 Chain-of-Custody Record}

\section{D.1.5.1 Purpose and Description}

Use the Chain-of-Custody Record (Figure D.7) to document transfer in the possession and custody of samples. The record attests that, from sample collection to laboratory analysis, the sample was constantly under custody.

The serialized Chain-of-Custody Record forms contain the following information:

- Matrix. The medium (soil/sediment or groundwater) sampled.

- Receiving Lab. The name of the laboratory to which the sample is being sent.

- Shipping Container No. The identifying number of physical description of the container in which the sample is to be shipped.

- Shipping Info. Carrier airbill number or other pertinent shipping detail.

- ANL Field Contact (name and temporary phone). The name and telephone number of an individual who can provide information about the sample(s).

- Project/Site. The name of the former CCC/USDA facility where the sampling was conducted. 


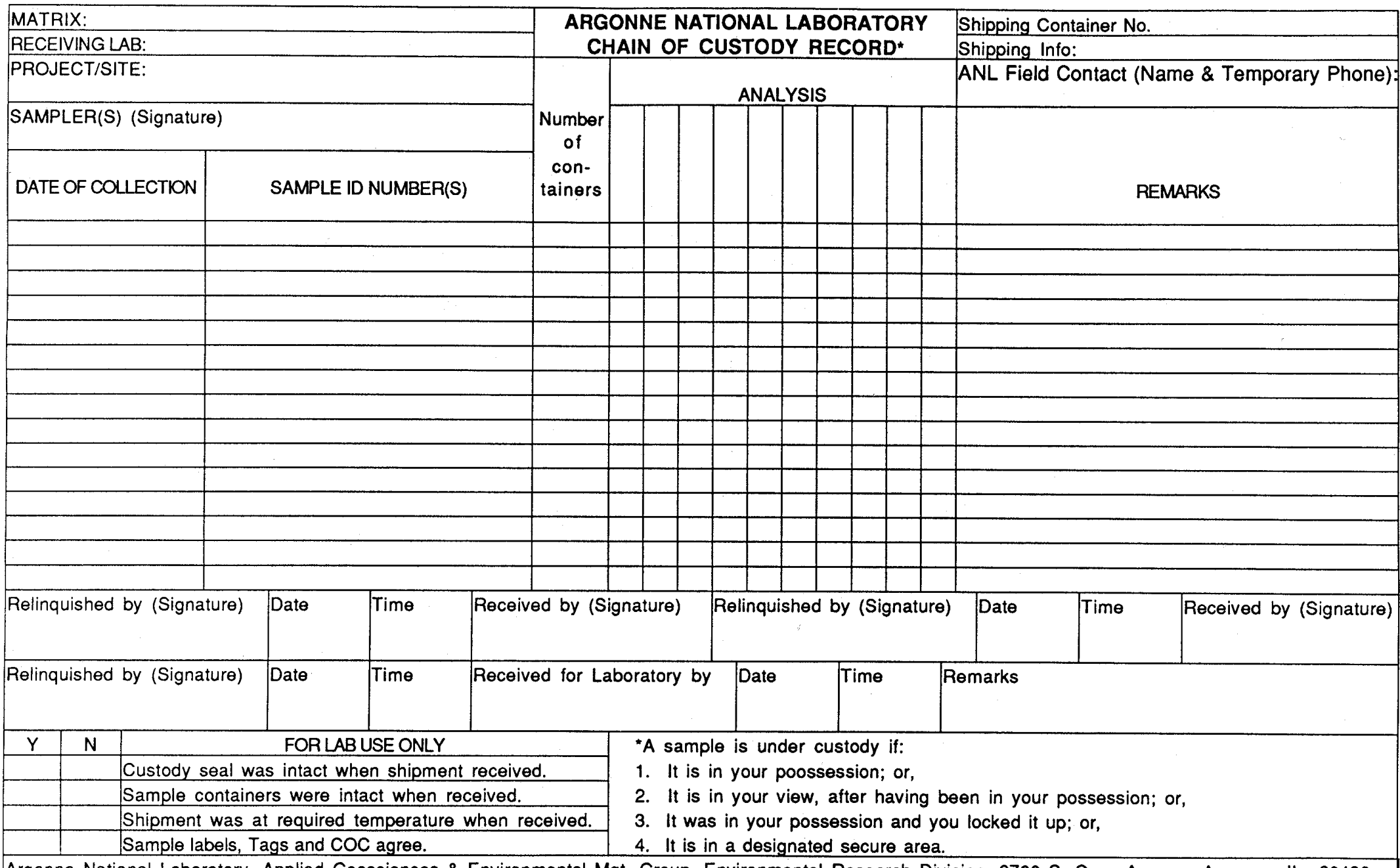

Argonne National Laboratory, Applied Geosciences \& Environmental Mgt. Group, Environmental Research Division, 9700 S. Cass Avenue, Argonne, IL 60439 ER-160 (10-92)

FIGURE D.7 Chain-of-custody record. 
- Sampler(s) (signature). The signature(s) of individual(s) who physically collected the sample.

- Date of Collection. The date $(\mathrm{dd} / \mathrm{mmm} / \mathrm{yy})$ of sample collection (e.g., 08/SEP/01).

- Sample ID Number(s). The identification number(s) of the physical sample(s).

- Number of Containers. The total number of containers used for each respective sample.

- Analysis. The analysis to be performed on the sample.

- Remarks. Comments about the individual sample(s) (e.g., "Sample container was broken and discarded.”).

- Relinquished by/Received by, Date, Time. The names of the individual who relinquished possession and custody of the sample(s) and the individual who accepted the possession and custody of the sample(s), together with the date and time of transfer. The first person to relinquish the sample(s) must be one of the individuals who collected the sample(s).

- Remarks. Comments about all of the samples inventoried on the Chain-ofCustody Record (e.g., "High-priority sample. Please analyze first and fax preliminary results to project manager.”).

- For Lab Use Only. Verification by the analytical laboratory sample custodian that the custody seal and sample containers were intact when they were received; that the shipment was at the required temperature; and that the sample labels, tags, and Chain-of-Custody Record agree.

\section{D.1.5.2 Documentation Process}

The Chain-of-Custody Record is to be initiated by the sampler, reviewed and signed during any change in custody, and QA reviewed and signed by the project manager or designee. A copy 
of the record is to be held in the temporary field file until the original is received at the primary analytical chemistry laboratory. The original record is to be shipped in the container with the samples to the primary laboratory, in a prominently labeled plastic pouch. There the record is to be QA reviewed and signed. The record must be included in the project file.

The Chain-of-Custody Record is the critical link between the sampling activities conducted in the field, the laboratory analyses requested, and the resulting analytical data reported by the laboratory. The Project QA/QC Coordinator is to perform a cross-check of the samples documented in the sampling logbook, reported to the laboratory on the Chain-of-Custody Record, and included in the computer file of samples and analyses to verify the completeness and accuracy of the recorded information. The Chain-of-Custody Record provides the basis for (1) subsequent discussion with the analytical laboratory, if necessary, regarding the status of samples and analyses; (2) documenting receipt of data from the laboratory; and (3) storage and retrieval of the numerous analytical data packages associated with the project.

\section{D.1.6 Water Level Measurement Logbook}

Water levels measured during drilling and construction are not considered part of the water level database and are to be recorded separately from water level data collected after well completion. Measure precompletion water levels relative to the ground surface level. Record the results in the drilling log, the sampling logbook, or both if relevant. Once the well has been completed, measure water levels relative to an accurately surveyed reference point. Water levels measured after establishment of the reference point become part of the water level database for a site. Initially record the water levels measured during the sampling of completed, developed wells in the sampling logbook, and then transcribe the data to the water level logbook when appropriate.

For long-term water level monitoring programs, use the water level logbook to record water level measurements referenced to the surveyed point. The water level logbook is to be bound, with consecutively numbered pages. The cover is to clearly display the title, "Water Level Logbook," in addition to the name of the site and logbook number. The water level logbook is to be completed by the measurement team and included in the project archive.

Procedures to ensure consistency in water level measurements and minimization of random measurement error are in Appendix F, Section F.2. 


\section{D.2 Document Control}

The goal of document control, adopted from the National Enforcement Investigations Center (NEIC) Document Control Program, is to ensure that all project documents used by the sampling and analysis team are accounted for when a project is completed. Table D.1 lists the principal documents used by the sampling and analysis team.

Document control includes the use of serialized documents, a document inventory procedure, and a document filing system, as follows:

- Sample labels and Chain-of-Custody Records have preprinted serial numbers. All issued numbers must be appropriately accounted for.

- The project manager or designee is to inventory all project documents.

- A project file for each site from which samples are collected is to be maintained by the project manager. At a minimum, the project file must contain all of the original documents specified in Table D.1. The project file is to contain no personal observations or irrelevant information. When the project objectives have been met, the project file is reviewed. Thereafter, it becomes a permanent evidentiary file. After a document has been deposited in the evidentiary file, it may be checked out only through the project manager.

\section{D.3 Sample Control}

According to the NEIC, a sample is physical evidence collected from a facility or the environment. Consequently, the gathered evidence must be authentic. Maintaining the authenticity of evidence is referred to as sample control. The authenticity of evidence depends on its identity and integrity.

\section{D.3.1 Sample Identity - Sample Label}

Sampling team members are to label evidence so that it can easily be identified and distinguished from similar evidence, from collection to analysis. 
TABLE D.1 Documents used by the sampling and analysis team.

\section{Document}

Sampling and Analysis Plan

Project Logbook

Field Logbooks

Sample Labels

Chain-of-Custody Forms

Shipping Forms

Analytical Logbooks, Laboratory Data Books, Calculations, Bench Cards, Graphs, etc.

Correspondence

Report Notes, Calculations, etc.

Litigation Documents

Miscellaneous Photos, Maps, Drawings, etc.

Software Programs

Sampling and Analysis Report

\section{D.3.2 Sample Custody}

To establish the integrity of the samples, it might be necessary to demonstrate to a court that the samples were maintained under custody from the time of collection in the field to the time of analysis at the analytical chemistry laboratory.

The NEIC considers a sample under a person's custody when

1. It is in his possession; or

2. It is in his view, after being in his possession; or

3. It was in his possession and he locked it up; or

4. It is in a designated secure area. 


\section{D.3.2.1 Chain-of-Custody Record}

The Chain-of-Custody Record (Figure D.7) lists all transfers in the possession of samples. This piece of documentary evidence attests that the sample was under custody constantly between sample collection and laboratory analysis.

\section{D.3.2.2 Custody Seals}

When they are shipped from the field to the analytical chemistry laboratory, samples pass through the hands of postal clerks, couriers, and others who are unidentified. However, the samples are effectively in a secure area. The NEIC procedure requires that a custody seal (Figure D.8) be affixed to the shipping container in such a way that the integrity of the samples can be demonstrated if the shipping container is properly secured and it arrives at the analytical chemistry laboratory with the custody seals intact and with adequate documentation. Therefore, signatures from intermediary handlers are not required. The custody seal is to be signed and dated by the individual who prepares the container for shipping at the field site.

\section{D.3.3 Disposal of Samples or Other Physical Evidence}

Before any sample or other physical evidence is discarded, the project manager must be contacted in writing, and specific permission must be received in writing.

\section{CUSTODY SEAL}

DATE

SIGNATURE

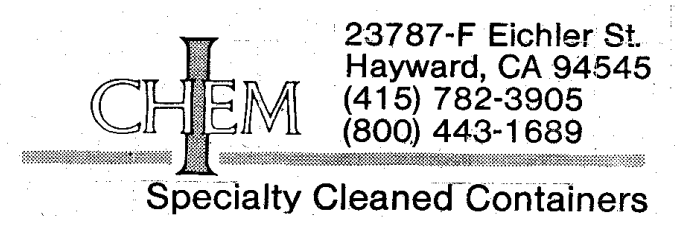

FIGURE D.8 Custody seal. 


\section{Appendix E:}

\section{Standard Operating Procedures}




\section{Contents}

E.1 Procedure for Measuring Water Levels in Wells........................... E-3

E.2 Procedures for Use of Water Level Recorder Software ......................... E-12

E.3 Modifications to Analytical Methods for Volatile Organic Compounds............... E-12

E.4 Procedure for Operating the Betsy Seisgun ................................. E-19 


\section{Appendix E:}

\section{Standard Operating Procedures}

\section{E.1 Procedure for Measuring Water Levels in Wells}

The accurate and precise determination of groundwater gradients and temporal variations in groundwater levels requires the monitoring of groundwater levels with a standardized approach; properly maintained equipment; and careful, thorough record keeping. Here we describe the methods to be used for monitoring groundwater levels in monitoring wells and for archiving water level data in the central groundwater level database. Procedures for using water level recorder software are in Section E.2.

Water levels measured during drilling are not considered to be part of the water level database and should be recorded separately from water level data collected after well construction. During drilling, water levels are normally taken relative to ground surface and recorded in the drilling log, the water sampling logbook (if relevant), or both. Once the well has been developed and surface construction completed, water levels can be measured relative to an accurately surveyed reference point. Water levels measured after establishment of the reference point are considered part of the water level database for a site. Use the procedures outlined here to ensure consistency of measurements and minimize random measurement error.

Water levels measured after establishment of the reference point are to be recorded in a dedicated water level logbook or bound (not loose-leaf) field notebook clearly marked with the name of the investigation site. The water level logbook is to be included in the project archive.

\section{E.1.1 Establishing a Water Level Monitoring Point}

Use the following procedure to establish a water level monitoring point:

1. Establish and identify a measurement reference point. The preferred point is the top of the well casing. Make a permanent mark at the reference point, preferably a physical mark such as a saw or knife cut, in addition to an arrow drawn with a marker pen. 
2. Clearly mark the well identification number or the name of the measurement location near the measurement reference point.

3. Record well identification details in the water level logbook. Note the measuring reference point position precisely.

4. Measure and record the depth to the groundwater in the well as described in Section E.1.2.

5. Measure and record the depth of the well by using a weighted tape. Lower the tape into the well until the tape goes slack. Record the depth of the well below ground surface, and confirm that the well is clear across the screen interval by comparing the measured depth with the well construction log.

\section{E.1.2 Water Level Measurement by Hand}

Use a graduated electronic water sensor measuring tape (water level meter) to measure water levels by hand. Check the depth interval markings on the tape periodically by using an accurate measuring device. The frequency needed for this check depends on the amount of use and whether the cable is believed for any reason to have been stretched. At a minimum, check the calibration at the beginning of a new project or sampling program. The steps for the hand measurement of water levels are as follows:

1. Check for proper operation of the water level meter by immersing the sensor tip in water. Clean and dry the sensor tip before lowering it into a borehole.

2. Measure the water level by slowly lowering the cable until the sensor indicates contact with water.

3. Fine-tune the measurement by raising and lowering the cable in gradually smaller increments until the most precise reading is obtained.

4. Read the depth to the water from the water level meter at the measurement reference point, and record the value in the logbook. Include the date and time 
of the reading, and note the prevailing weather conditions. Use military time (the 24-hr clock) for time entries.

5. Compare the water level with any previous data from that site. If the water level measurement is inconsistent with previous values, take a second reading for confirmation while the water level measuring device is still in place.

6. Before moving to the next well, decontaminate the portion of the tape and sensor that was immersed. Spray the cable and sensor with deionized water, and dry the tip with a disposable paper towel.

\section{E.1.3 Automatically Recorded Water Levels}

Accurate measurement of water levels - either with pressure transducers and automatic data loggers or with self-contained downhole pressure recording devices - demands organized, thorough, detailed record keeping. Each water level recording system requires a specific set of protocols to ensure good system operation. For details on operating individual water level recording systems, refer to the manufacturers' instructions and manuals. All systems should be installed with the general procedures described below.

\section{E.1.3.1 Test Setup}

The instructions below are applicable to the use of either conventional pressure transducers (which require a separate data logging unit at the surface) or self-contained downhole recording devices that are equipped with a vented cable for passive sensor correction for changes in atmospheric pressure. For simplicity, the term "pressure sensor" will be used to indicate either type of device.

Set up the water level recording system for a test and begin the test as follows:

1. Measure and record the water level and the depth of the well by using the procedures in Section E.1.2. 
2. Select a depth of installation for the pressure sensor. This depth must be within the specified pressure operating range and must allow for the maximum anticipated water level variation in the borehole. Do not immerse the pressure sensor beyond its operating depth. Doing so could cause permanent damage. The operating range of such devices is normally specified by the manufacturer as pressure in pounds per square inch (psi). Multiply the value in psi by 2.30667 to convert the value to a water level range.

3. Place a mark on the pressure sensor cable at the selected installation depth. If the pressure sensor cable is already marked at 5- or 10-ft intervals, select one of these marks as the pressure sensor installation depth.

4. Lower the pressure sensor into the borehole to the required installation depth. Attach the pressure sensor securely to the well. In attaching the pressure sensor, avoid sharp edges that might kink or tear the cable. Do not bend the cable in curves of radius less than $1 \mathrm{in}$. Doing so could obstruct the vent tube in the cable. Protect the wellhead and data recorder against disturbance or damage due to severe weather, vandalism, curious residents, and traffic.

5. Connect the transducer (if applicable) to the data recorder.

6. Enter the required setup parameters, pressure sensor calibration information, and details of the desired monitoring schedule. The setup and calibration input data required will vary for different pressure sensor and data recorder systems (as specified by individual equipment manuals); however, all tests should be programmed by using the following guidelines:

- Set data recorders to log water level measurements as depth to water from the established physical reference point (usually the top of the casing).

- If a recorder reference level (an arbitrary value relative to which all pressure measurements are reported) is required, set this level at the handmeasured water level determined in step 9 below. For recorders that allow a delayed test start (programmed test start), select the option to set the reference level immediately (when the hand water level measurement is made), not at the start of data recording. 
- Check the date and time setting of each data recorder internal clock, and adjust to local time. If multiple recorders are being installed, synchronize all internal clocks; this is often accomplished most simply by synchronizing each recorder to the internal clock of the portable computer being used to program the data recorders.

- A 4-hr measurement interval, with measurements at 0000, 0400, 0800, 1200, 1600, and $2000 \mathrm{hr}$, is the standard for long-term water level monitoring (one week or longer). Shorter intervals (1-10 min) may be required, however, to provide detailed data on the effects of well pumping.

- Record and double-check the identity of the pressure sensor measuring each borehole, and the recorder channel to which each sensor is connected if a multichannel data recorder is being used.

- If permitted by the operating programs, assign each pressure sensor and recorder a unique name to appear in the water level data file. Assigned device names should include (if possible) the instrument serial number, the investigation site name, and the designation of the well being monitored.

7. Check the pressure sensor response by raising the sensor in the water column a known amount (the more the better) and taking a new pressure reading. (Most pressure sensing devices can be interrogated for a reading without starting to record a test.) The indicated water level change should agree with the change in pressure sensor height to within $1 \%$ or $0.1 \mathrm{ft}$ per $10 \mathrm{ft}$ of water level change. Depending on the results, do the following:

- If the error exceeds $1 \%$, check all calibration settings. If the error is confirmed, check the response again by raising the pressure sensor a known distance. Allow extra time for water levels to reequilibrate to the change in depth of the sensor.

- If the calibration is accurate, return the pressure sensor to its original position. 
- If the response test continues to indicate equipment problems, replace the pressure sensor, and arrange for repair of the faulty equipment.

Note that this test is valid only for boreholes that are approximately vertical. If a pressure sensor is to be used in a borehole that deviates significantly from vertical, test the sensor in an alternate, vertical borehole before installation in the deviated hole.

8. After completion of the response test and return of the pressure sensor to its original position, allow water levels to reequilibrate fully before moving to the next step.

9. Hand measure and record the water level again as accurately and precisely as possible.

10. Set the recording device's reference water level reading to the water level just measured by hand.

11. Activate the test to begin recording data per the required measurement schedule.

12. Confirm that the test has started and that data are being collected successfully by the recorder.

13. Ensure that all cable etc. connectors and weatherproof caps are properly in place. Close and secure the well cover and any additional enclosure if an external data recorder is used. These actions prepare the system to run unattended.

14. Record all test setup information in the logbook, including pressure sensor and recorder model and serial numbers, sensor installation depth, and measurement interval for each test. 


\section{E.1.3.2 Data Downloading}

Download data as follows:

1. Upon return to the site, check for signs of damage or disturbance of the well or recording device since the previous visit. In particular, verify that the pressure sensor is still set at its original reference position.

2. Take a current pressure sensor reading by interrogating the sensor directly.

3. Take a hand water level reading (Section E.1.2) as soon as possible after the pressure sensor reading. Record the result in the logbook. Note: Take the pressure sensor reading before the hand water level measurement to ensure that the sensor reading is not affected by immersion of the water level meter.

4. Compare the change in water levels (since the previous readings) shown in the logbook for both the pressure sensor and the hand measurements. When the automatic water level recorders are functioning properly, the pressure sensor and hand readings should agree to within $0.05 \mathrm{ft}$. If the difference is greater, check both the pressure sensor and hand measurements again. If the difference is confirmed, check the calibration of the pressure sensor as in step 7 of Section E.1.3.1. If the calibration is still accurate, return the pressure sensor to its original position for continued data recording or the start of a new test. Aside from the pressure sensor, possible sources of calibration error in the recorded water level data are

- Battery failure,

- Severe temperature changes (verifiable by checking weather records),

- Severe electrical interference from nearby external sources (for example, lightning strikes),

- Previous inaccurate hand water level measurements (corrected by accurate readings in the future), and 
- An inaccurate hand water level meter (documented by checking the calibration of the meter against a reliable measure).

5. Download the data for the current test before stopping the test (if necessary). For some recording devices, a name derived from the programmed test information is automatically assigned to the downloaded file. If this is not the case for a particular recording device, the file will have to be named manually. To name downloaded data files, create an eight-character code representing the

- Site name (two letters),

- Well identification (two numbers), and

- Date of download (two letters for the month and two numbers for the date).

Add a three-letter suffix to the eight-character code to name files (.BIN for binary files or .DAT for ASCII files). An example file name would be BR01MR20.DAT for the March 20 download from SB01 at Bruno.

For file systems that allow more than eight characters, a longer, more descriptive file name may be used as long as it reflects the site name, well identification, and date of download in a clear format. An acceptable example is BRUNO_SB01_3-20-01.DAT.

6. When the download is complete, convert the data file (if necessary) into a format (e.g., EXCEL spreadsheet) suitable for quick scanning of the data. Scan the data to verify that the full data record is in the file and that the equipment appears to be functioning properly.

7. Stop or continue the current test as required. For some recorders, starting a new test will reduce the size of the file to be downloaded the next time. It might also increase the available recorder memory. Some recording systems permit the internal storage of data sets from multiple tests in nonvolatile memory. In other systems, all preexisting data in memory must be deleted 
before a new test can be programmed. Never delete any files from the recording device until downloaded data have been checked and backed up on floppy disk.

8. If data collection is to be continued, ensure that all cable etc. connectors and weatherproof caps are properly in place. Close and secure the well cover and any additional enclosure if an external data recorder is used. These actions prepare the system to run unattended.

9. At the end of the day, make a floppy disk backup copy of all downloaded files.

\section{E.1.4 Archiving of Groundwater Level Data}

\section{E.1.4.1 Hand-Measured Water Levels}

All original water level logbooks or field notebooks containing water level data are to be included in the project archive. Transcribed copies or photocopies of these documents may not be placed in the permanent records as a substitute for the original documents. Photocopies of original documents containing water level data may be entered into the permanent records, however, if they are particularly relevant to a specific site investigation and this is the only form in which these data can be obtained. (An example is copies of historic water level measurements recorded by a municipal official as part of the documentation maintained for a public water supply system.)

\section{E.1.4.2 Automatically Recorded Water Levels}

All downloaded data files obtained from automatic water level recording equipment are to be archived in the central database. All files must be clearly identified by using the naming protocols described in Section E.1.3.2. For data downloaded in binary format, a copy of the original binary file plus a version of the same file in readable format (text, Excel, or similar) should be retained. The choice of electronic storage medium is at the discretion of the project manager. 


\section{E.2 Procedures for Use of Water Level Recorder Software}

The range of water level sensing and recording devices that are currently available precludes definition of a standard software operating procedure for use in QuickSite ${ }^{\circledR}$ investigations. For most such devices, interrogation of the pressure sensor and programming or downloading of the data recorder is accomplished by using device-specific software installed on a portable computer. The portable computer is connected to the recorder in the field by using an interface cable. For other systems, programming is accomplished by using a keypad that is integral to the recording unit itself. All software programs necessary for the operation of water level recorders are to be used in accord with the manufacturer's instructions and with the procedures specified in Section E.1.3. All personnel required to use these programs and equipment are to be trained to an appropriate level of proficiency.

Both the portable computer software and operating firmware installed in the data recorders are to be maintained at the most recent revision level for each specific device type.

\section{E.3 Modifications to Analytical Methods for Volatile Organic Compounds}

\section{E.3.1 Headspace Analysis of Vegetation Samples}

\section{E.3.1.1 Overview}

The AGEM Laboratory has developed a headspace method for the analysis of VOCs in vegetation samples. The analysis of each sample takes approximately $50 \mathrm{~min}$. The total analytical capacity for the laboratory is approximately 20 samples per day. The headspace sampler allows the equilibration of multiple samples to begin during the analysis of previous samples. The typical detection limit for carbon tetrachloride is $50 \mathrm{ppt}(50 \mathrm{pg} / \mathrm{g}$ or $0.05 \mu \mathrm{g} / \mathrm{kg})$. The typical detection limit for chloroform is approximately $750 \mathrm{ppt}(750 \mathrm{pg} / \mathrm{g}$ or $0.75 \mu \mathrm{g} / \mathrm{kg})$, because the presence of chloroform in the methanol solvent prevents accurate standard preparation below this level. The system is calibrated for the following VOCs:

- Carbon tetrachloride

- Chloroform

- Tetrachloroethene (PCE)

- 1,2-Dichloropropane 
- Dichloroethenes (DCEs)

- Methylene chloride

- 1,1,1-Trichloroethane

The addition of a flame ionization detector to the gas chromatograph (GC) system in the near future will allow for the analysis of BTEX (benzene, toluene, ethylbenzene, xylene) compounds, as well as improved high-level detection of chlorinated species.

\section{E.3.1.2 Procedure}

Prepare samples in 20-mL headspace vials. Seal approximately 1-3 g of vegetation sample (preserved at $-70^{\circ} \mathrm{C}$ ) in each vial. Weigh the vial before and after adding the vegetation to determine the weight of the vegetation sample to $0.01 \mathrm{~g}$ accuracy.

Prepare standards by injecting known quantities of dilute standards containing carbon tetrachloride, tetrachloroethene, and chloroform into a headspace vial. Calibrate the GC system on the basis of the mass of the VOC present in the vial.

The GC parameters for vegetation analysis are as follows:

- Sampler

- Oven temperature

- Equilibration hold time

- Vial pressurization time

- Loop fill time

- Loop equilibrium time

- Sample injection time

- Oven stabilization time

- Agitation

- Oven step

- Equilibration step increase
Headspace

$90^{\circ} \mathrm{C}$

$120 \mathrm{~min}$

$0.20 \mathrm{~min}$

$0.20 \mathrm{~min}$

$0.05 \mathrm{~min}$

$1.00 \mathrm{~min}$

$1.00 \mathrm{~min}$

$\mathrm{HIGH}$

NO

NO

\section{E.3.1.3 Quality Control/Quality Assurance}

A calibration curve (minimum of six points), laboratory blanks, and a sample duplicate are analyzed with each set of samples. Overall reproducibility is $5-15 \%$. 


\section{E.3.2 Headspace Analysis of Soil Samples}

\section{E.3.2.1 Overview}

The AGEM laboratory has developed a low-level headspace method for the analysis of VOCs in soil samples. The analysis of each sample takes approximately $70 \mathrm{~min}$. The total analytical capacity for the laboratory is approximately 36 samples per day. The headspace sampler allows the equilibration of multiple samples to be started during the analysis of previous samples. The typical detection limit for carbon tetrachloride is $50 \mathrm{ppt}(50 \mathrm{pg} / \mathrm{g}$ or $0.05 \mu \mathrm{g} / \mathrm{kg}$ ). The typical detection limit for chloroform is approximately $750 \mathrm{ppt}(750 \mathrm{pg} / \mathrm{g}$ or $0.75 \mu \mathrm{g} / \mathrm{kg}$ ), because the presence of chloroform in the methanol solvent prevents accurate standard preparation below this level. The system is calibrated for the following VOCs:

- Carbon tetrachloride

- Chloroform

- Tetrachloroethene (PCE)

- 1,2-Dichloropropane

- Dichloroethenes (DCEs)

- Methylene chloride

- 1,1,1-Trichloroethane

The addition of a flame ionization detector to the GC system in the near future will allow for the analysis of BTEX compounds, as well as improved high-level detection of chlorinated species.

\section{E.3.2.2 Procedure}

Prepare samples in 20-mL headspace vials. Seal approximately 1-3 g of soil sample (preserved at $-70^{\circ} \mathrm{C}$ ) in the vial. Weigh the vial before and after adding the soil to determine the weight of the soil sample to $0.01 \mathrm{~g}$ accuracy.

Prepare standards by injecting known quantities of dilute standards containing carbon tetrachloride, tetrachloroethene, and chloroform into a headspace vial. Calibrate the GC system on the basis of the mass of the VOC present in the vial. 
The GC parameters for the soil analysis are as follows:

- Sampler

- Oven temperature

- Equilibration hold time

- Vial pressurization time

- Loop fill time

- Loop equilibrium time

- Sample injection time

- Oven stabilization time

- Agitation

- Oven step

- Equilibration step increase
Headspace

$90^{\circ} \mathrm{C}^{*}$

$60 \mathrm{~min}$

$0.30 \mathrm{~min}$

$0.40 \mathrm{~min}$

$0.10 \mathrm{~min}$

$1.00 \mathrm{~min}$

$1.00 \mathrm{~min}$

$\mathrm{HIGH}$

$\mathrm{NO}$

NO

*The high temperature ensures complete evaporation of VOC species in the soil matrix.

\section{E.3.2.3 Quality Control/Quality Assurance}

A calibration curve (minimum of six points), laboratory blanks, field blanks, and a sample duplicate are analyzed with each set of samples. Overall reproducibility is 5-15\%.

\section{E.3.3 Purge-and-Trap Determination of Water Samples}

\section{E.3.3.1 Overview}

The AGEM Laboratory has developed a purge-and trap method for the determination of VOCs in well water and drinking water samples. This method is a modification of EPA Method 524.2 for the determination of VOCs in drinking water. In this method, the VOCs are extracted (purged) from the sample matrix by bubbling an inert gas through the sample. The purge components are trapped in a specific sorbent tube. Subsequently, the sorbent tube is heated and backflushed with an inert gas to desorb the components into the gas chromatograph-mass spectrometer (GC-MS) system.

The compounds eluting from the GC column are identified both by retention time and by comparison with reference library spectra. The concentration of each compound is calculated through comparison of the MS response for the quantitation ion to corresponding calibration 
curves or results for internal standards. The analysis of each sample takes approximately $40 \mathrm{~min}$ (including purging and separation/detection time). The total analytical capacity for the laboratory is approximately 14 samples per day. Instrumental detection limits are $0.04 \mu \mathrm{g} / \mathrm{L}$ for carbon tetrachloride and $0.02 \mu \mathrm{g} / \mathrm{L}$ for chloroform. Method detection limits are estimated at $1 \mu \mathrm{g} / \mathrm{L}$ for both components. The system is presently calibrated for the following 23 compounds:

benzene
bromochloroethane
bromodichloromethane
4-bromofluorobenzene
carbon tetrachloride
chlorobenzene
chloroform
dibromochloromethane
dibromomethane
1,2-dichlorobenzene-d4
1,1-dichloroethane
1,2-dichloroethane

\section{E.3.3.2 Procedure}

To calibrate the instrument, prepare standard samples with concentrations ranging from $0.5 \mu \mathrm{g} / \mathrm{L}$ to $150 \mu \mathrm{g} / \mathrm{L}$. Analyze these samples, and prepare a calibration plot. Perform calibration checks regularly. Place $10-\mathrm{mL}$ samples (instead of the 5-mL samples recommended by the method) into purge tubes. Add $10 \mu \mathrm{L}$ each of fluorobenzene (internal standard), 1,2-dichlorobenzene (surrogate), and bromofluorobenzene (surrogate) to each sample, and place the sample in the autosampler. Analysis parameters are as follows:

- Trap

- Desorb temperature

- Purge time

- Desorb temperature

- Desorb time

- Line temperature

- Column

- Carrier flow

- Oven profile

- Detector

\author{
1,2-dichloropropane \\ cis-1,3-dichloropropene \\ trans-1,3-dichloropropene \\ fluorobenzene \\ methylene chloride \\ tetrachloroethane \\ 1,1,2,2-tetrachloroethane \\ toluene \\ 1,1,1-trichloroethane \\ 1,1,2-trichloroethane \\ trichloroethene
}




\section{E.3.3.3 Quality Control/Quality Assurance}

Laboratory blanks, calibration curves (minimum of eight points), duplicate samples, calibration checks (RSD [relative standard deviation] $< \pm 20 \%$ ), instrument calibration (autotune and 4-bromofluorobenzene [BFB] tune), and surrogate spike recoveries (RSD $< \pm 20 \%$ ) are checked/performed for each data set.

\section{E.3.3.4 Modifications of Methodology}

The modifications of Method 524.2 are as follows:

- Sample size is $10 \mathrm{~mL}$ instead of the $5 \mathrm{~mL}$ recommended by the method.

- A Tenax-silica gel-charcoal trap is used in conjunction with a dry ice cryogenic interface.

- $\quad$ The dry ice cryogenic trap is at $-20^{\circ} \mathrm{C}$.

- The desorption temperature is increased from $180^{\circ} \mathrm{C}$ to $225^{\circ} \mathrm{C}$.

- A Supelco DB-624 capillary column is used, $30 \mathrm{~m}$ long and $0.25 \mathrm{~mm}$ in diameter.

\section{E.3.4 Purge-and-Trap Determination of Soil Samples with Methanol Extraction}

\section{E.3.4.1 Overview}

The AGEM Laboratory has developed a purge-and-trap method with methanol extraction for the determination of low levels of VOCs in soil samples. The methanol extraction procedure resembles the one described in EPA Method 5035 (December 1996; EPA 1998b) for determination for high levels of VOCs (> $200 \mu \mathrm{g} / \mathrm{kg}$ ). The method has been modified to increase the volume of methanol introduced into the sample cell up to $8 \mathrm{~mL}$ and minimize detection limits. Volumes of methanol under $5 \mathrm{~mL}$ are optimal for the analysis and detection of carbon 
tetrachloride in soil samples. For methanol:water ratios of 1:10, the methanol method detection limits for carbon tetrachloride are $10 \mu \mathrm{g} / \mathrm{kg}$.

In this method, the VOCs are extracted (purged) from the sample matrix by bubbling an inert gas through the sample. The purge components are trapped in a specific sorbent tube. Subsequently, the sorbent tube is heated and backflushed with an inert gas to desorb the components into the GC-MS system. Parameters are the same as those used for the water analysis (Section E.3.3.2). The compounds eluting from the GC column are identified both by retention time and by comparison with reference library spectra. The concentration of each compound is calculated by comparison of the MS response for the quantitation ion to corresponding calibration curves or results for internal standards. The analysis of each sample takes approximately $40 \mathrm{~min}$ (including purge and separation/detection time). The total analytical capacity for the laboratory is approximately 14 samples per day. The system is presently calibrated for the following 23 compounds:

benzene

bromochloroethane

bromodichloromethane

4-bromofluorobenzene

carbon tetrachloride

chlorobenzene

chloroform

dibromochloromethane

dibromomethane

1,2-dichlorobenzene-d4

1,1-dichloroethane

1,2-dichloroethane 1,2-dichloropropane

cis-1,3-dichloropropene

trans-1,3-dichloropropene

fluorobenzene

methylene chloride

tetrachloroethane

1,1,2,2-tetrachloroethane

toluene

1,1,1-trichloroethane

1,1,2-trichloroethane

trichloroethene

\section{E.3.4.2 Procedure}

Prepare samples by placing approximately 10-15 g of soil in a VOC analysis vial. Add an approximately equal volume $(10 \mathrm{~mL})$ of pure methanol. Shake the vial, and allow the contents to equilibrate for about $24 \mathrm{hr}$.

To calibrate the instrument, prepare standard samples with concentrations ranging from $0.5 \mu \mathrm{g} / \mathrm{L}$ to $150 \mu \mathrm{g} / \mathrm{L}$. Analyze the standard samples, and prepare a calibration plot. Perform calibration checks regularly. Place $10-\mathrm{mL}$ samples $(9 \mathrm{~mL}$ of water and $1 \mathrm{~mL}$ of methanol extract 
after equilibration) into purge tubes. Add $10 \mu \mathrm{L}$ of internal standard, and placed the sample in the autosampler. Analysis parameters are as follows:

- Trap

- Desorb temperature

- Purge time

- Desorb temperature

- Desorb time

- Line temperature

- Column

- Carrier flow

- Oven profile

- Detector
Tenax-silica gel-charcoal

$-20^{\circ} \mathrm{C}$ (dry ice cryogenic trap)

$11 \mathrm{~min}$

$225^{\circ} \mathrm{C}$

$4 \mathrm{~min}$

$100^{\circ} \mathrm{C}$

$0.31-\mathrm{mm} \times 30-\mathrm{m}$ DB-624

$1 \mathrm{~mL} / \mathrm{min}(\mathrm{He})$

$35^{\circ} \mathrm{C}(6 \mathrm{~min})$ to $200^{\circ} \mathrm{C}(2.5 \mathrm{~min})$ at $10^{\circ} \mathrm{C} / \mathrm{min}$

Mass spectrometer

\section{E.3.4.3 Quality Control/Quality Assurance}

Laboratory blanks, calibration curves (minimum of eight points), duplicate samples, calibration checks (RSD $< \pm 20 \%$ ), instrument calibration (autotune and BFB tune), and surrogate spike recoveries $(\mathrm{RSD}< \pm 20 \%)$ are checked/performed for each data set.

\section{E.4 Procedure for Operating the Betsy Seisgun}

The Betsy Seisgun (BSG) is a device used to introduce acoustic waves into the subsurface in conjunction with seismic refraction and reflection geophysical surveys. The BSG should be used only in conjunction with such surveys; no other use of the device is covered by this procedure.

The BSG produces acoustic waves in the subsurface by means of the explosive force of a downwardly fired shotgun shell detonated with the BSG packed into a prepared auger hole. Detonation occurs when the firing pin is struck by a hammer to which a trigger switch is attached. When the hammer hits, it simultaneously depresses the firing pin and closes the trigger switch, sending a time-zero pulse to the recording system. 


\section{E.4.1 Personnel}

All personnel, whether performing or assisting in the operation of the BSG, should read and be familiar with the handbook describing in detail the operation and maintenance of the BSG. Personnel should use the BSG only in the performance of seismic refraction or reflection surveys (surface or borehole). Operation of the BSG is to be under the direction of a qualified geophysicist in conjunction with performance of the seismic survey.

\section{E.4.2 Protective Clothing}

Personnel operating or assisting in the operation of the BSG should wear clothing that allows for freedom of movement and is adapted to the climatic conditions at the survey site. Clothing should fit so that it does not catch on equipment or hinder the movement of the operator or assistant.

Personnel operating the equipment should wear modified Level D personal protective equipment (Sections 3.3.9.2 and 3.3.9.3), plus hearing protection as indicated in Section 3.3.4.2.

\section{E.4.3 Explosive Source}

The explosive source for the BSG is an 8-gauge shotgun shell. Argonne personnel will use only shells prepared by the manufacturer specifically for the BSG, which do not contain shot material.

All BSG shells will be stored and maintained in accordance with the manufacturer's recommendations, as follows:

1. Store in a cool, dry location.

2. Keep away from open flame.

3. Avoid dropping and severe impacts.

4. Do not use if wet or misfired. 


\section{E.4.4 Betsy Seisgun}

The BSG is to be operated in strict compliance with the manufacturer's instructions. The BSG is a safe instrument when the manufacturer's directions for operation are followed.

Operate the BSG as follows:

1. Wear the appropriate protective equipment (Section E.4.2).

2. Keep the trigger safety engaged at all times, except just before the shell is detonated.

3. Load and discharge the shell away from the seismograph operator and other personnel not associated with the shooting crew.

4. Pack the BSG into the auger hole by using water or sand and water, so that the force of the detonation goes downward. If water alone is not sufficient, pour and tamp sand and water into the annular space around the BSG.

5. Construct auger holes 1.5-3 in. in diameter and at least $2 \mathrm{ft}$ deep but no more than $3 \mathrm{ft}$ deep.

6. Use a splatter shield or similar device over the auger hole to minimize blowback. Tamping water and sand around the BSG will also minimize blowback.

7. Auger holes are mandatory even in areas where hard rock lies at the ground surface. Packing the holes with sand and water will provide the proper safety margin. If holes cannot be drilled, the BSG may not be used.

\section{E.4.5 Removal of Unspent Shells}

One hazardous facet in the operation of the BSG is the removal of unspent shells from the barrel of the gun. An unspent shell is one that has failed to detonate. No more than two attempts 
should be made to detonate a shell. If the second attempt fails, the shell should be treated as an undetonated shell and handled as follows:

1. Immediately engage the safety of the BSG.

2. Remove the BSG from the auger hole, and point it away from surrounding personnel and the operator.

3. Unscrew the barrel of the BSG, and push the shell out of the barrel with the wooden rod supplied by the manufacturer.

4. Upon removal of the shell, carefully pry open the forward end of the shell sleeve with a small pen knife, and remove the powder.

5. Mix the powder with soil. Then spread the mixture over the ground in a wide area.

6. Dispose of the empty shell casing in normal trash. 


\section{Appendix F:}

Forms and Diagrams for Drilling Operations in Kansas 


\section{Figures}

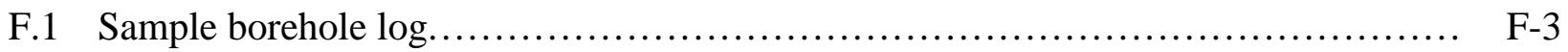

F.2 Details of stick-up well construction........................................... F-4

F.3 Morrison Bros. Co. Model 418XA limited-access manhole......................... F-5

F.4 Details of flush-mount well construction.................................... F-6

F.5 Field record of well construction ............................................. F-7

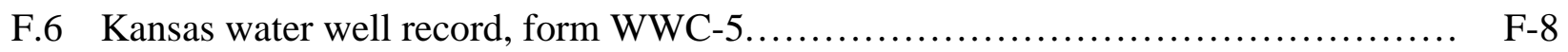

F.7 Kansas specifications for flush-mount piezometer installation..................... F-9

F.8 Morrison Bros. Co. Model 678XA pipe plug .................................... F-10

F.9 Kansas specifications for stick-up piezometer installation....................... F-11

F.10 Kansas water well plugging record, form WWC-5P.......................... F-12 


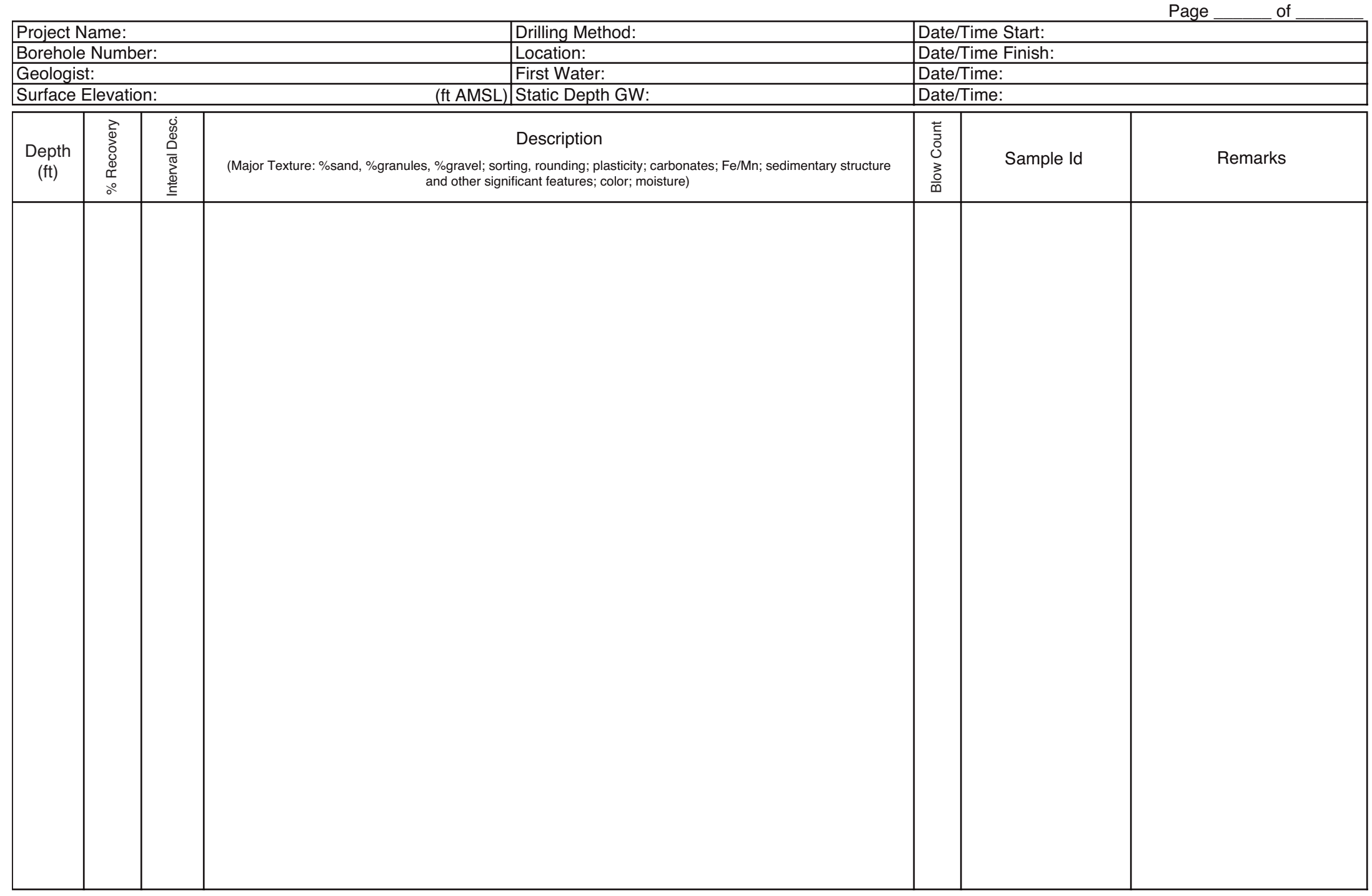

FIGURE F.1 Sample borehole log. 


\section{Stick-up Well construction}

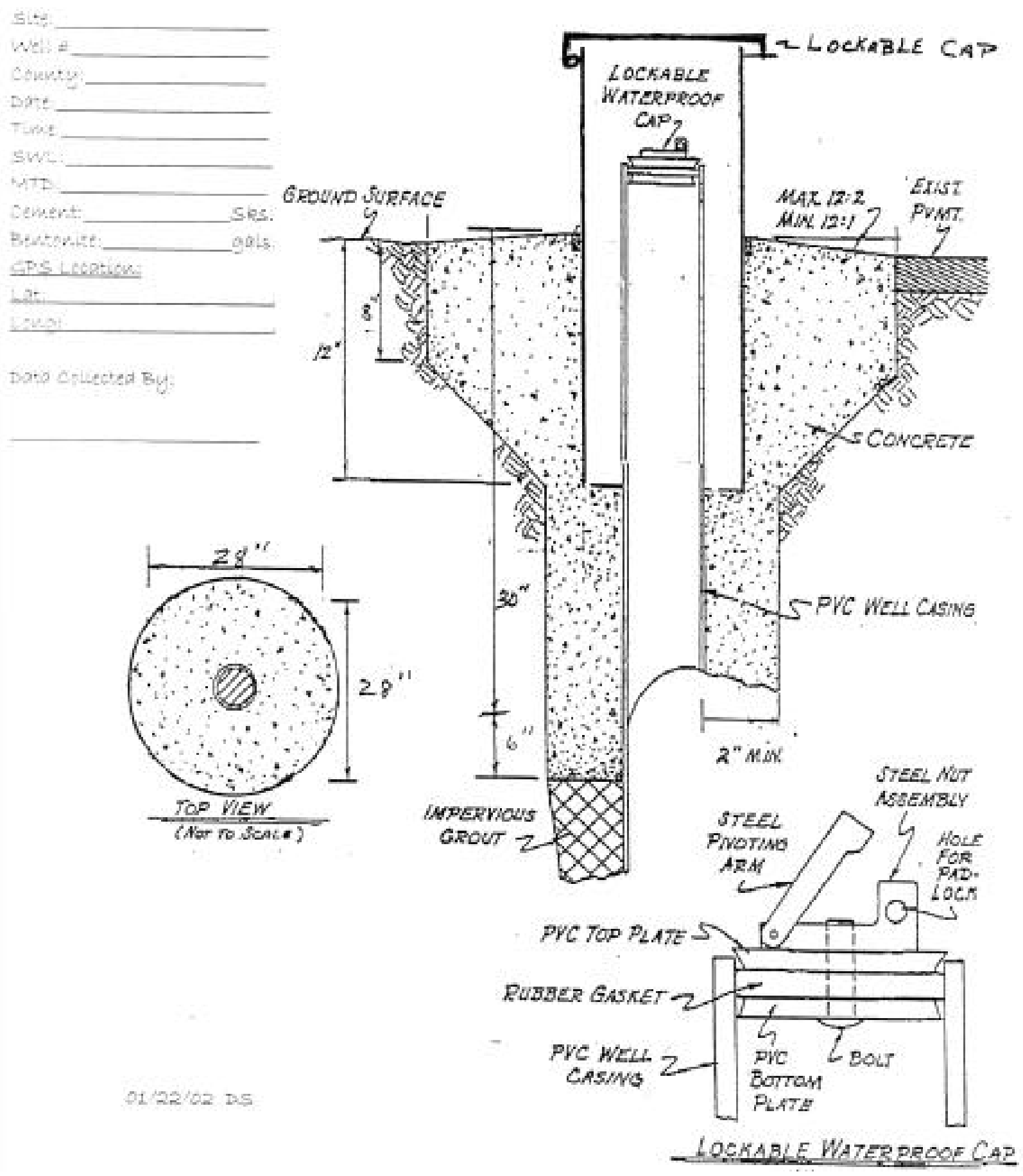

FIGURE F.2 Details of stick-up well construction. 

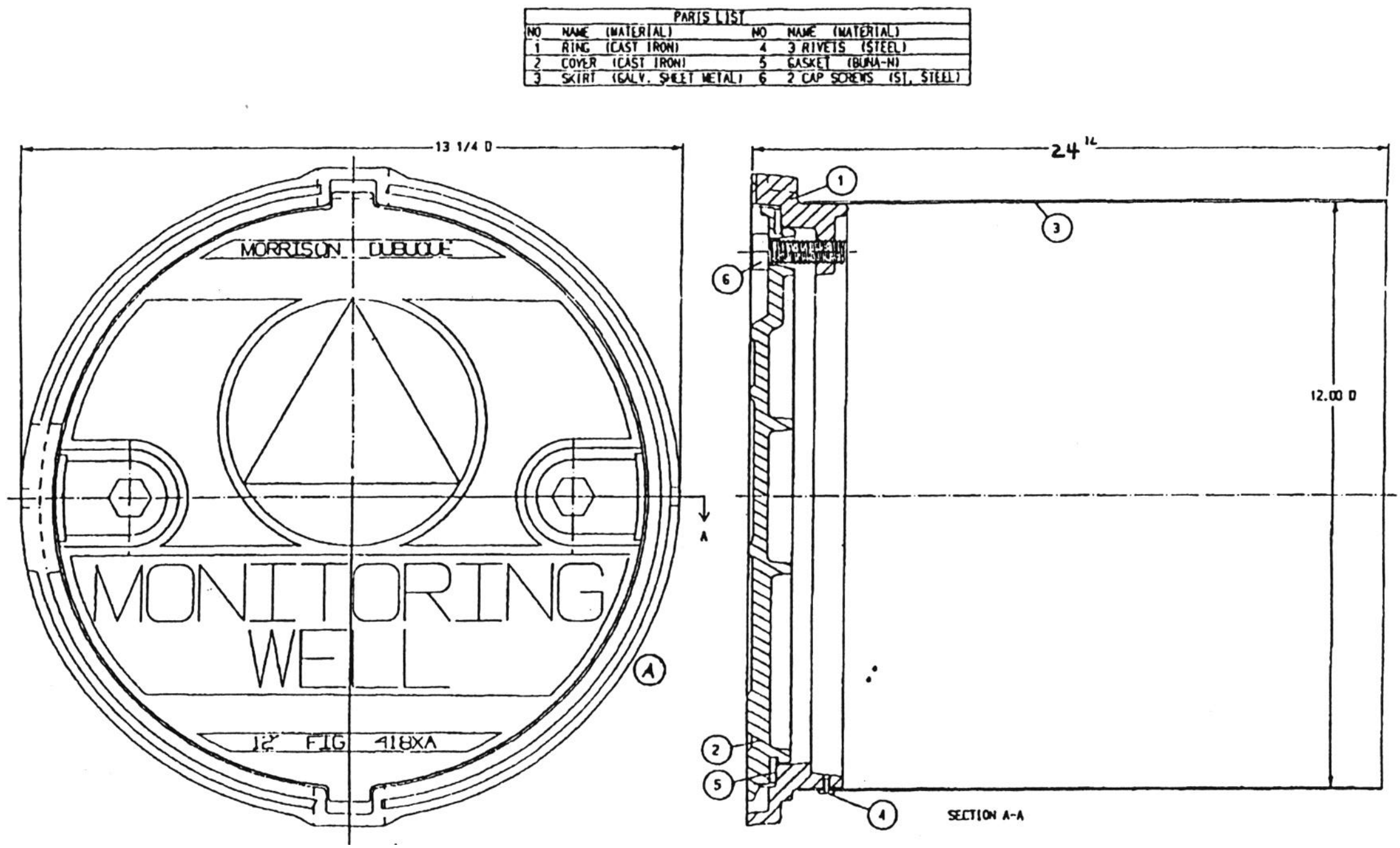

FIGURE F.3 Morrison Bros. Co. Model 418XA limited-access manhole (not to scale). 


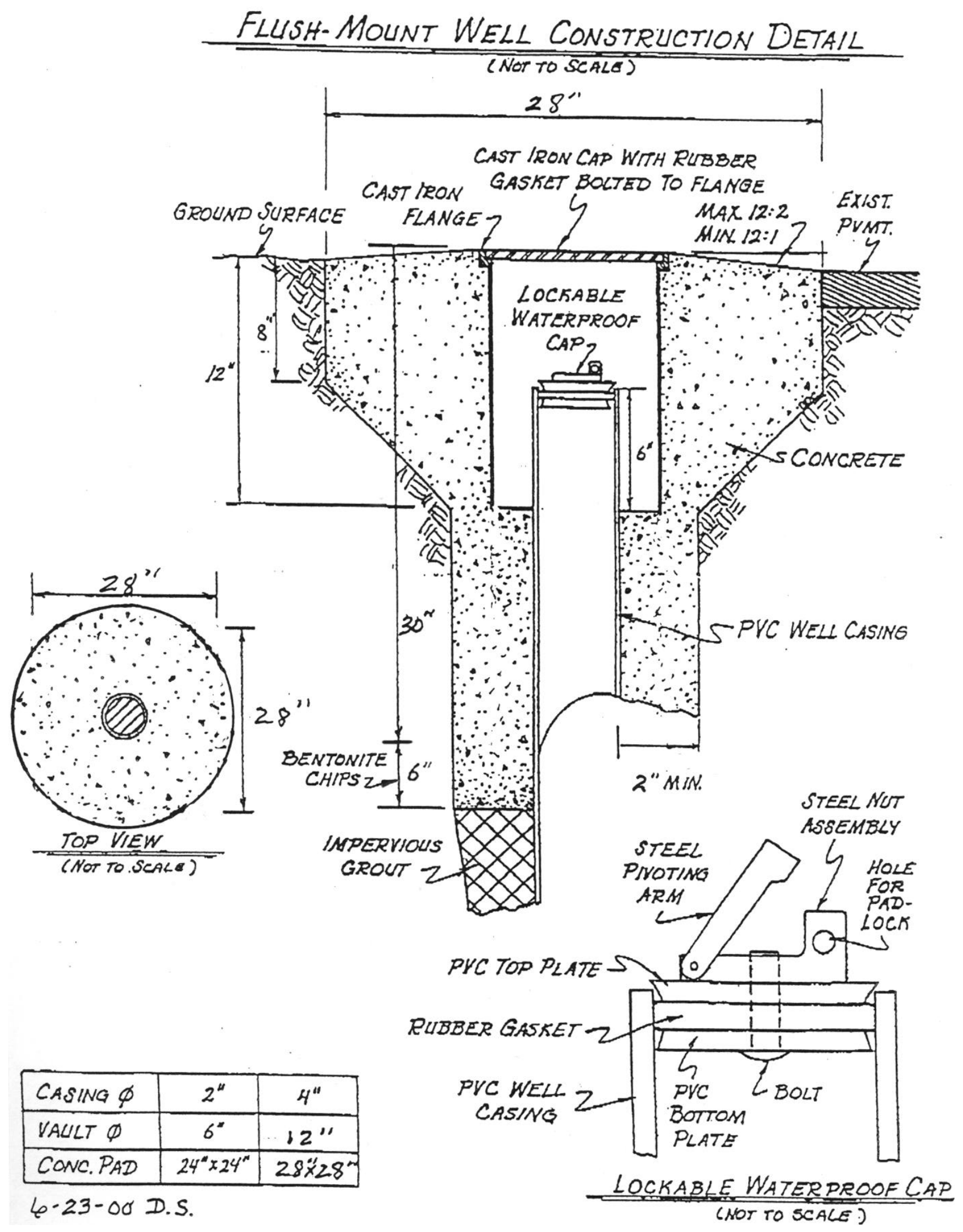

FIGURE F.4 Details of flush-mount well construction. 


\section{Field Record}

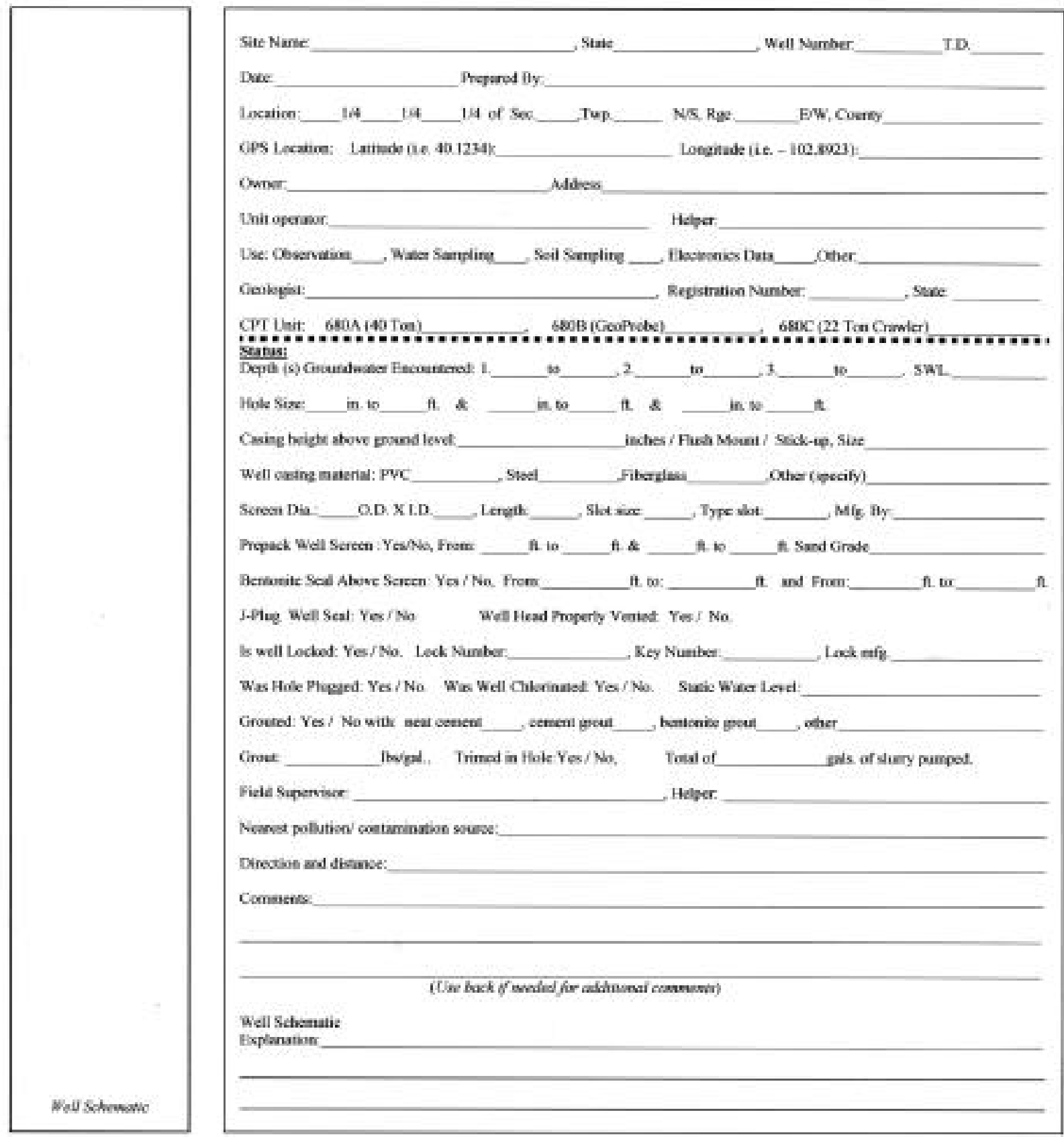

Rememher; Your actions today help insure clean and safe water for generations to comellt!

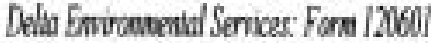

FIGURE F.5 Field record of well construction. 


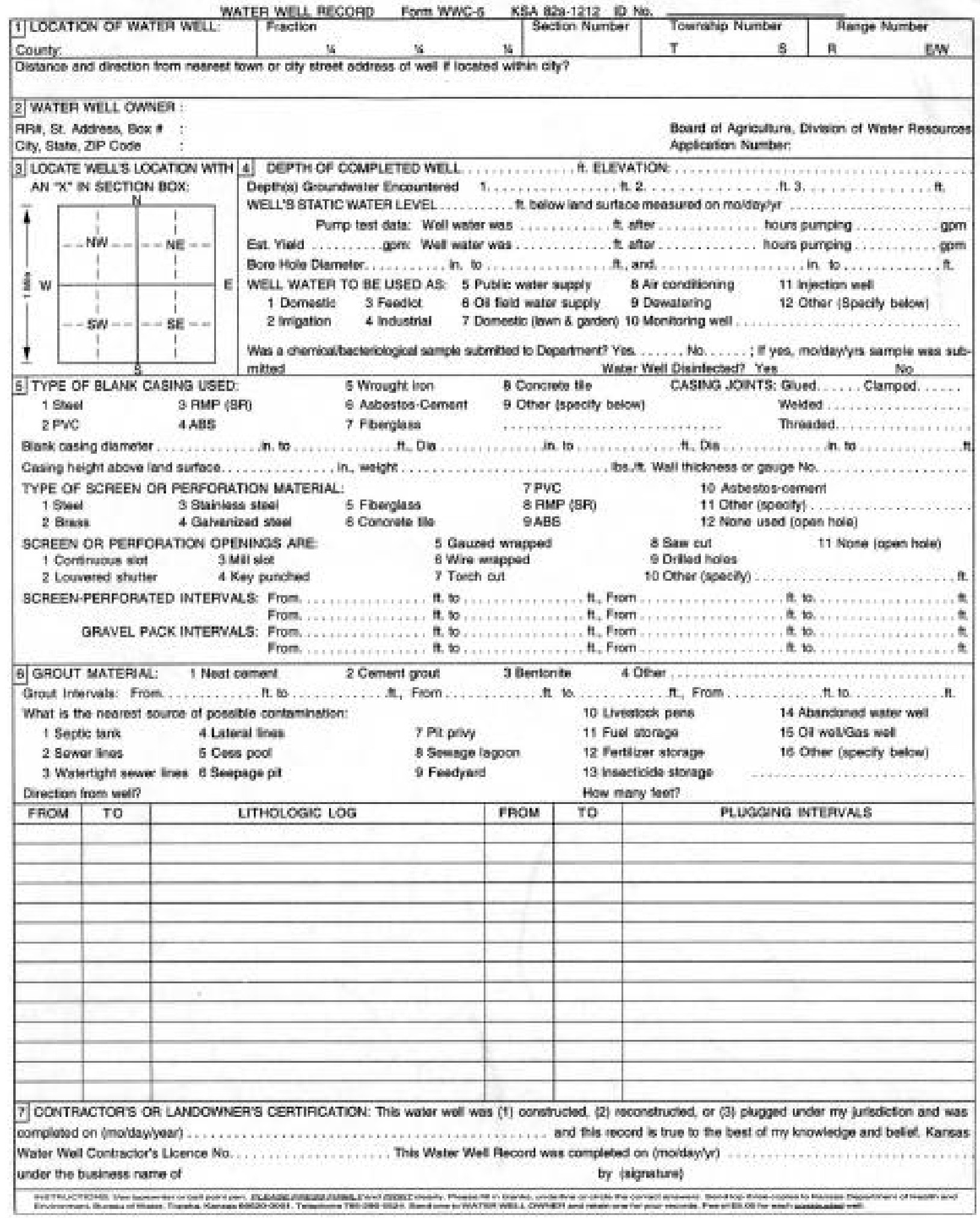

FIGURE F.6 Kansas water well record, form WWC-5. 


\section{Piezometer Installation: Flush Mount}

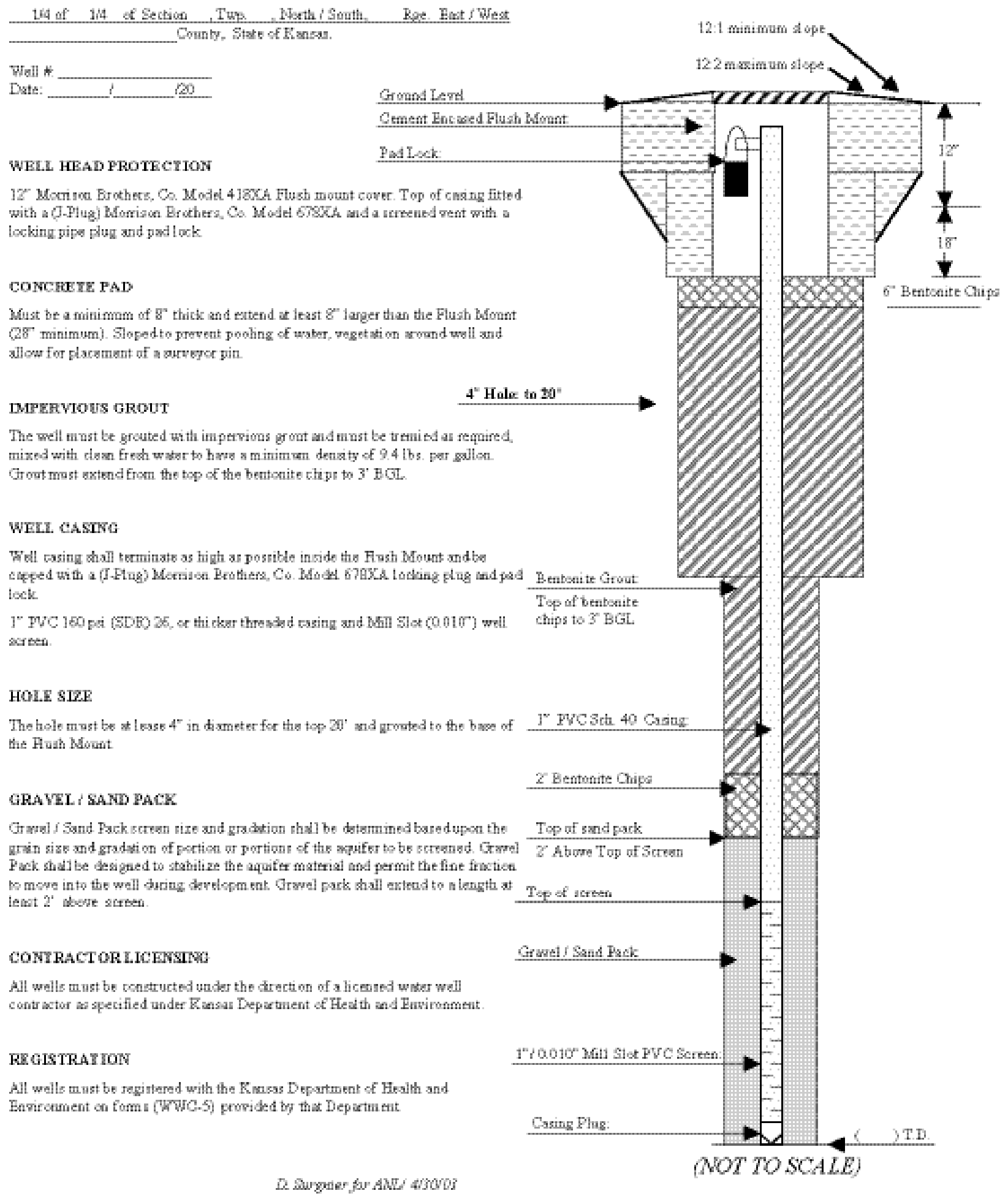

FIGURE F.7 Kansas specifications for flush-mount piezometer installation. 


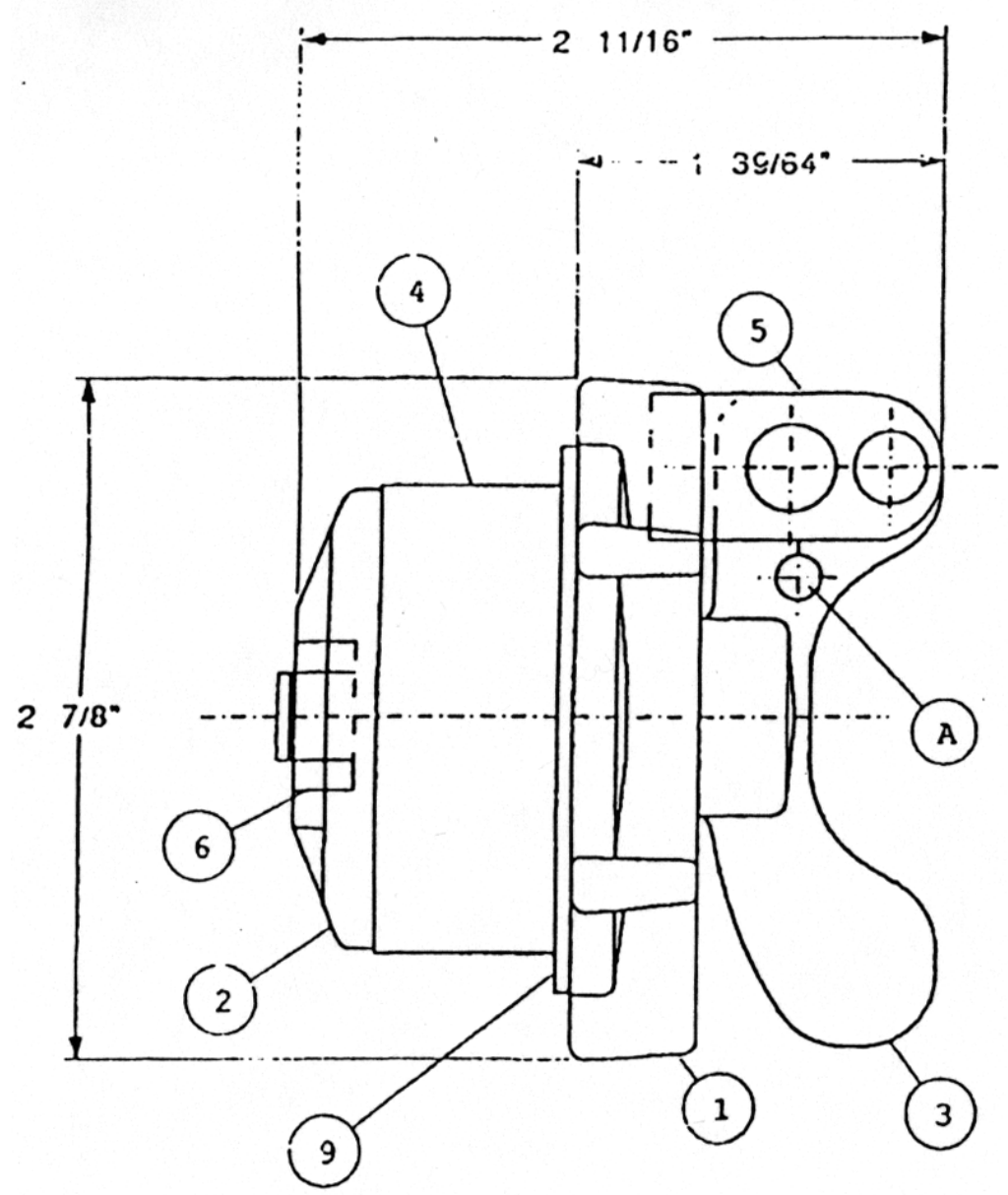

\begin{tabular}{|cll|}
\hline \multicolumn{3}{|c|}{ PARTS LIST } \\
\hline PART NO. & DESCRIPTION & MATERIAL \\
\hline 1 & TOP PLATE & PLASTIC \\
\hline 2 & BOTTOM PLATE & PLASTIC \\
\hline 3 & BOLT & BRASS \\
\hline 4 & SEAL & BUNA-N \\
\hline 5 & LOCK TEVER & STAINIESS TFOL \\
\hline 5 & NUT & BRASS \\
\hline 7 & RTVET & BRASS \\
\hline 9 & TOP SEAL & BUNA-N \\
\hline
\end{tabular}

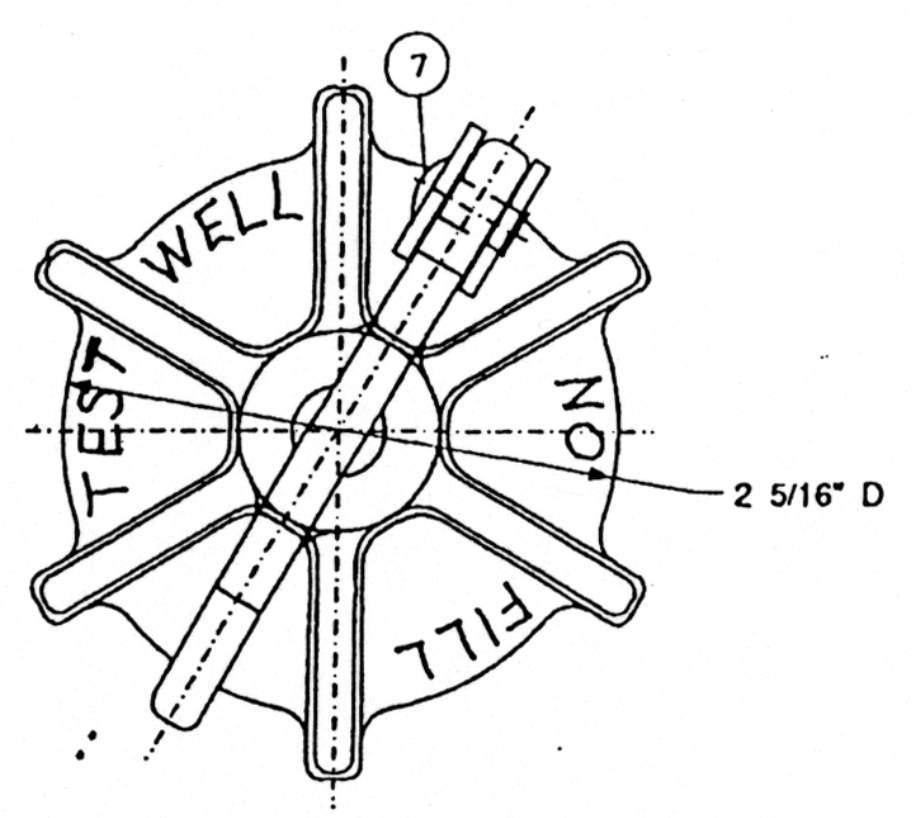

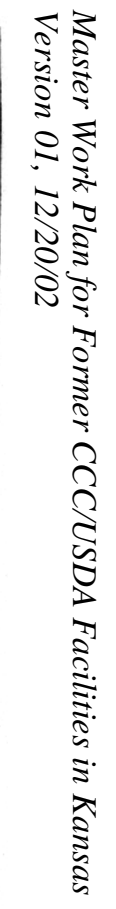

FIGURE F.8 Morrison Bros. Co. Model 678XA pipe plug (not to scale). 


\section{Piezometer Installation: Stickup}

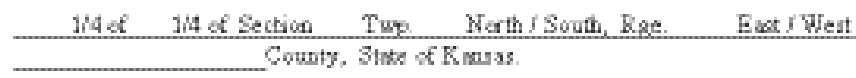

Wet *

Dast $\ldots-\gamma$

\section{WELL HEAD PROTECTION}

8-12 PWC / Sbet Casing of PVC extonding 3' AGL with slocking cap Top of caning

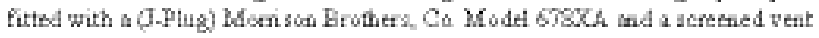
with a locking pipe plug and pad lock.

\section{CONCRETE PAD}

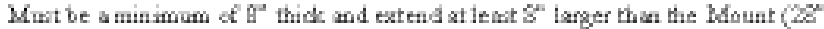
minimum Xloped to perent pooling of water, vegetah on acound well and allow for placement of a morveyor pir

\section{MPERVIOUS GROUT}

\section{Holes to 20}

The well most be grouted with impervicus grout and must be tremied as requed by: (High Soliat Bentenite $\lambda$ mixed with ciem fresh water to have a minimem deusity of 94 lbs. per gallow. Grout must entend from the top of the bentenite chife to 3 ' $\mathrm{B}$ GL.

\section{WEL.L CASING}

Well casing stall tecminate as high as poscible insid the Mount ma carped with a Pentorite Gront (J-A1ug) Mocrison Brothers, Co. Nodel 678Xd locking plug and pad lock

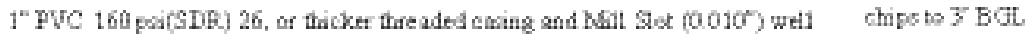
streen.

\section{HOLESIZE}

The bole most be of suffici ent aize to allow Grout co all sides of the casing form the auface to 20 below ground level.

\section{GRAYEL / SAND PACK}

Growel i Sand Pack screen size and gradation shall be determined baed opon the grain nize and gradation of portion or poctions of the nquifer to be streened. Oravel Prak shall be decigned to stabilize the nuifer materid and pecmit the fine fraction to move into the well dering devel opment. Gravel pack shall extend to a least 2 above the screen apertures

\section{CONTRACTOR LICERERTG}

All wells murt be constructed on der the dection of a licensed water well contrator $\&$ specified under Xmas Depatment of Health and Fnvircoment

\section{REGISTRATION}

All wells must be registered with the Finsas Department of Health and Euvironment on forms (CxwC-5) provided by tha Depatment.

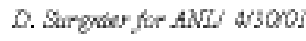

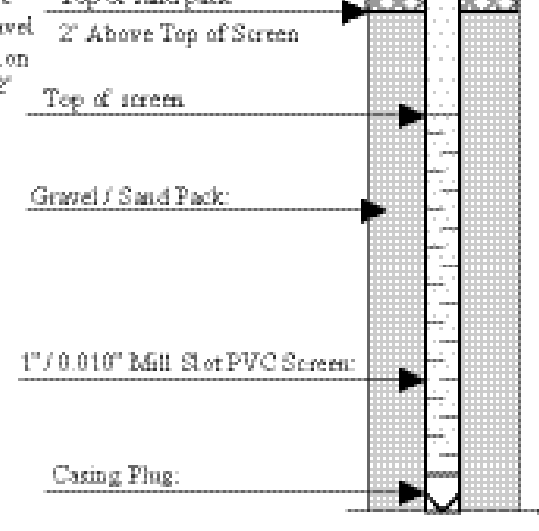

(NOT TO SCALE)

2 Ahove Tog of Screen

Tse of acreen

Grwel/ SandPack: Tep of bentenite

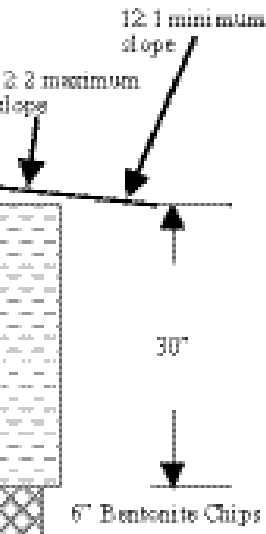

1" PVC Sch 40 Caning

2 Bentomibe Chips

Top of and pack

FIGURE F.9 Kansas specifications for stick-up piezometer installation. 
WATER WELL PLUGGING RECORD Form WWC-5P KSA 82a-1212 ID NO.

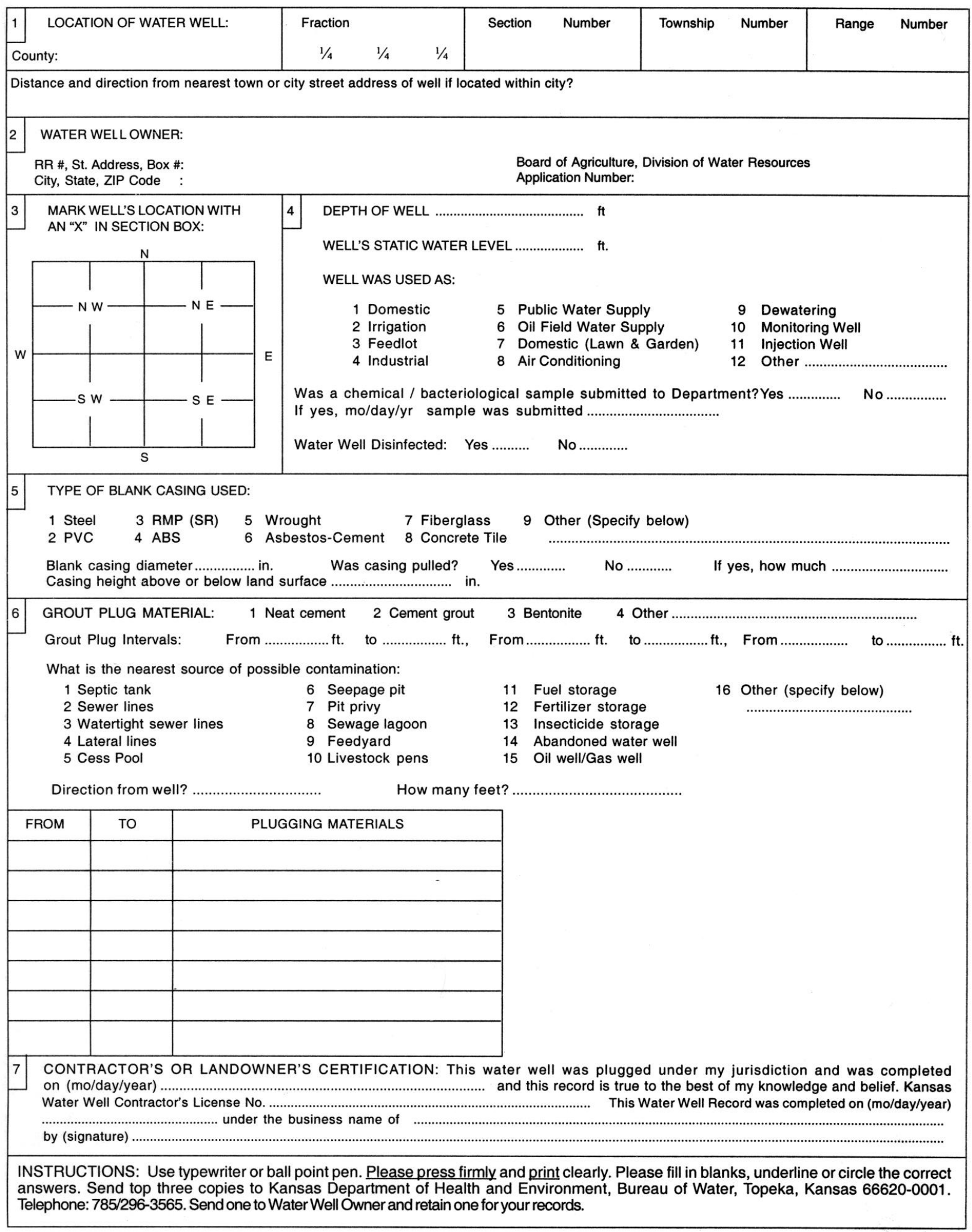

FIGURE F.10 Kansas water well plugging record, form WWC-5P. 